\title{
Design of DC Light Bulb for the DC House Project
}

\author{
A Thesis \\ Presented to \\ The Faculty of California Polytechnic State University,
}

San Luis Obispo

\author{
In Partial Fulfillment \\ of the Requirements for the Degree of \\ Master of Science in Electrical Engineering
}

By

Kent Liang

June 2012 
(C) 2012

Kent Liang

\section{ALL RIGHTS RESERVED}




\section{Committee Membership}

Title: Design of DC Light Bulb for the DC House Project

Author: $\quad$ Kent Liang

Date Submitted: June 2012

Committee Chair: Dr. Taufik, Professor

Committee Member: Dr. Xiao-Hua Yu, Professor

Committee Member: Dr. James G. Harris, Professor Emeritus 


\section{Abstract}

Title: $\quad$ Design of DC Light Bulb for the DC House Project

Author: $\quad$ Kent Liang

This thesis focuses on the design and implementation of an economical and energy efficient DC Light Bulb for the DC House Project. For the DC lighting system, emphasis is on the DC-DC LED driver, dimmer circuit, LED lighting array, and physical packing design. In this paper, a DC Light Bulb is designed, simulated, and tested to operate at a wide input voltage ranging from 24 VDC to 72 VDC, to be fully dimmable using pulse-width modulation technique, and to produce lumination intensities equivalent to a standard $100 \mathrm{~W}$ A19 incandescent light bulb at one-tenth the total power consumption. The DC Light Bulb's physical design also takes advantage of the same physical dimensions of a standard A19 incandescent light bulb using an E26 Edison screw base. Results from computer simulations and hardware tests demonstrated the feasibility of the proposed DC Light Bulb in terms of overall efficiency, line regulation, load regulation, power consumption, total lumens, luminous efficacy, and thermal profile. 


\section{Acknowledgements}

I would like to thank my parents for giving me the opportunity and continued support as I pursue both a Bachelor's Degree in Electrical Engineering and a Master's Degree in Electrical Engineering. I would like to acknowledge my advisor Dr. Taufik for his exceptional teaching style, friendliness, patience, support, and overall as a great mentor. I would also like to thank my friends, fellow classmates, and professors for their encouragement, inspiration, and entertainment through my college education. 


\section{Table of Contents}

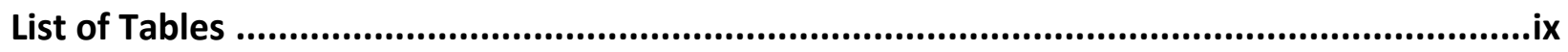

List of Figures

Chapter 1: Introduction ................................................................................................ 1

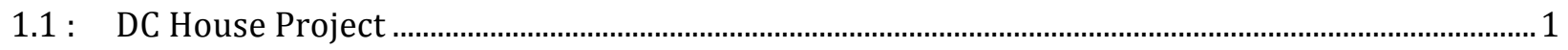

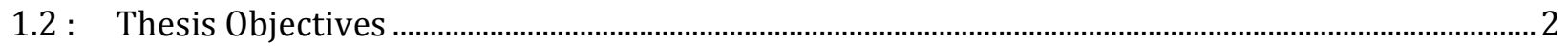

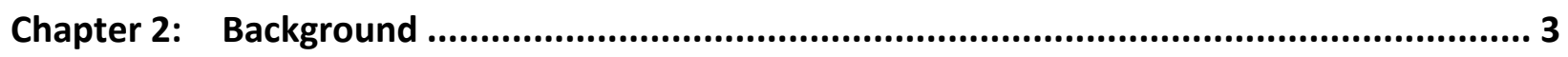

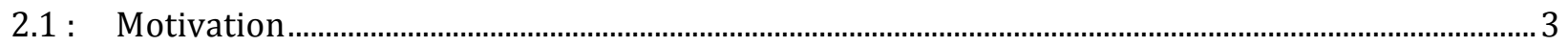

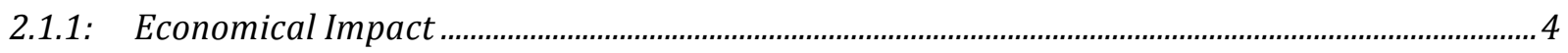

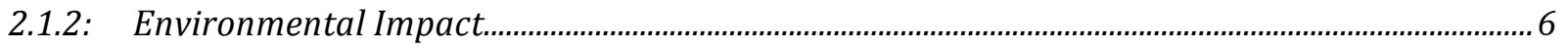

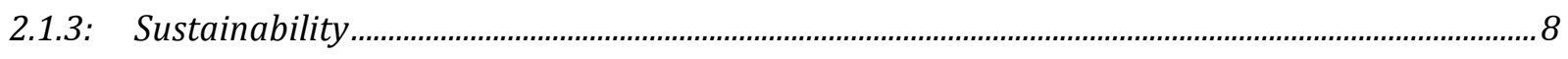

2.1.4: Ethical Impact....................................................................................................................................9

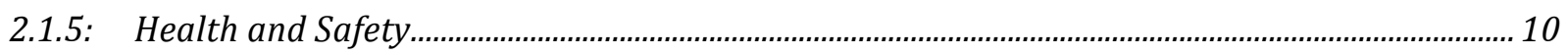

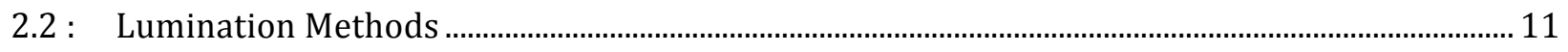

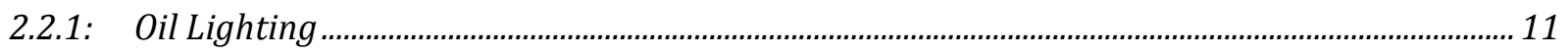

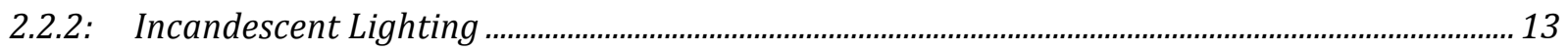

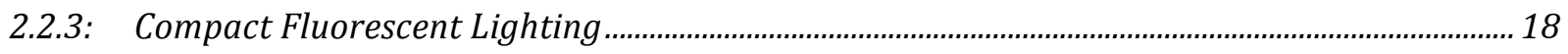

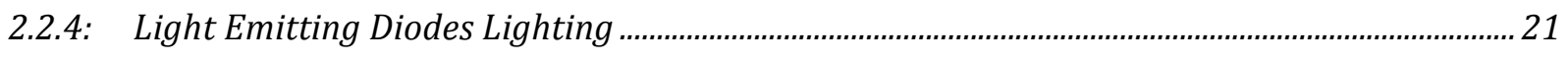

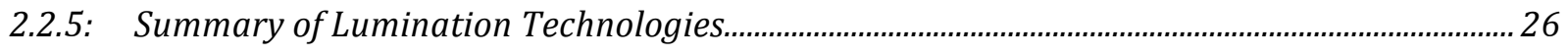

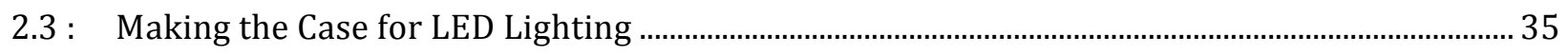

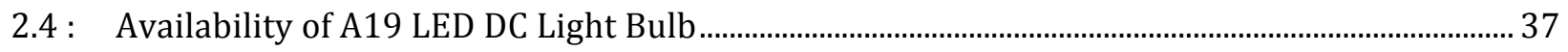

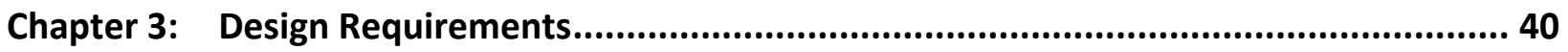




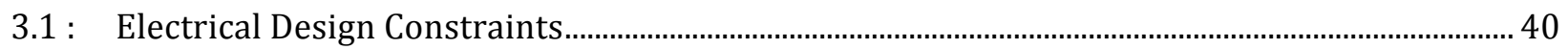

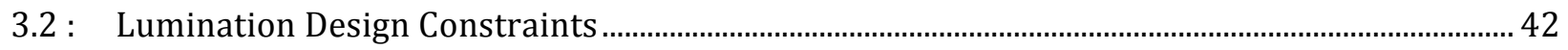

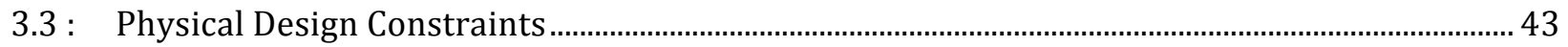

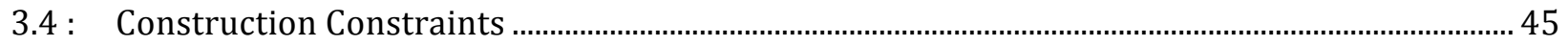

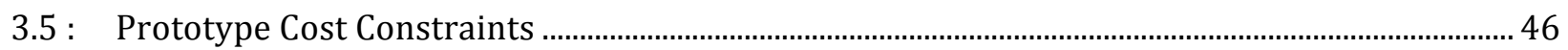

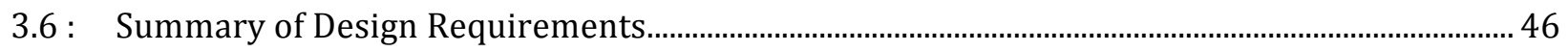

Chapter 4: Design Simulations and Components Selection ........................................... 48

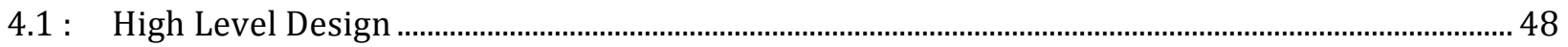

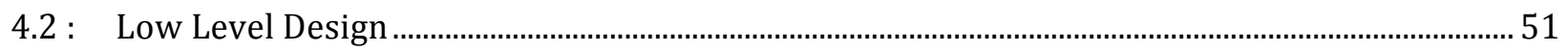

4.2.1: Dimmer Circuit

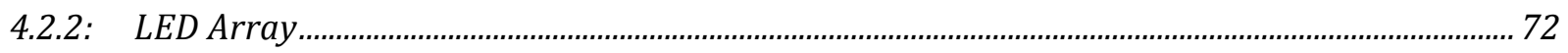

4.2.3: LED Driver

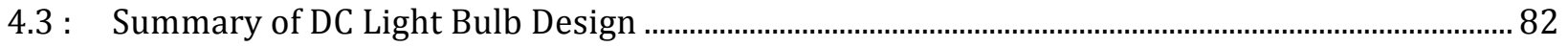

Chapter 5: Hardware Design and Results ................................................................... 85

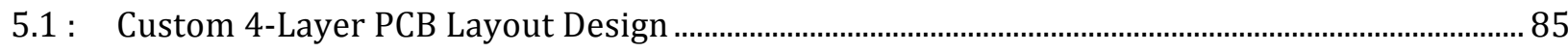

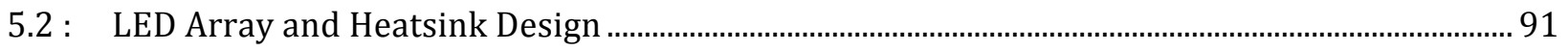

5.3 : Efficiency and Line Regulation Testing ……................................................................................... 92

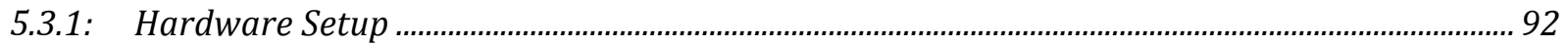

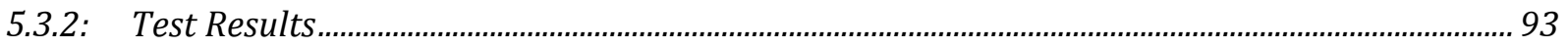

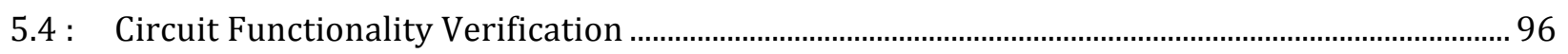

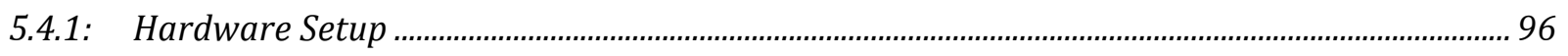

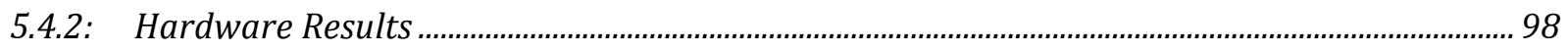

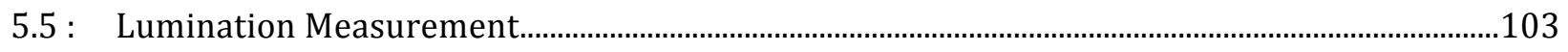

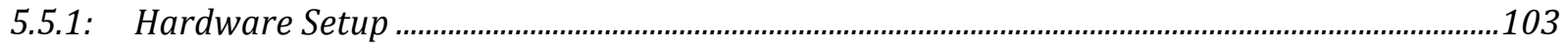




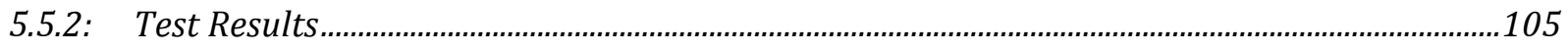

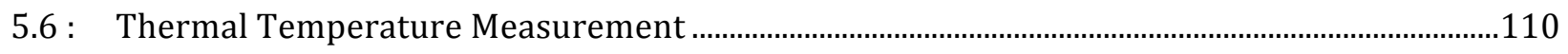

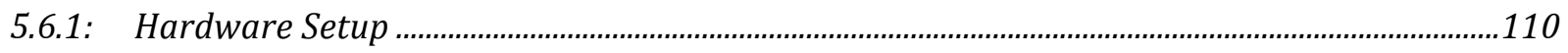

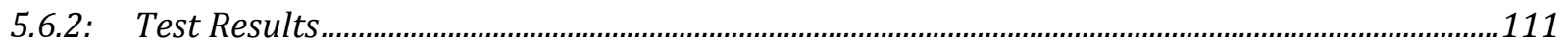

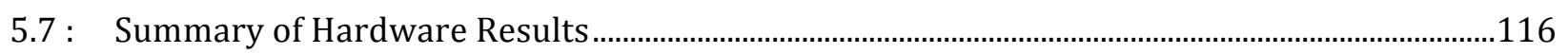

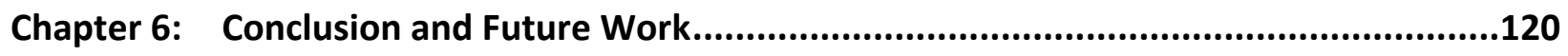

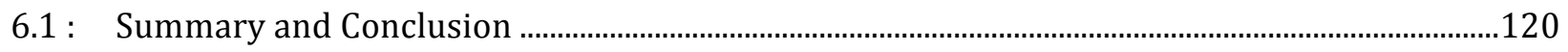

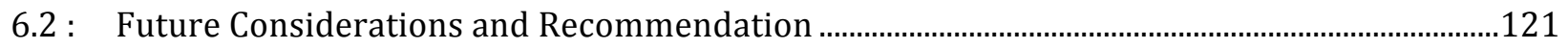

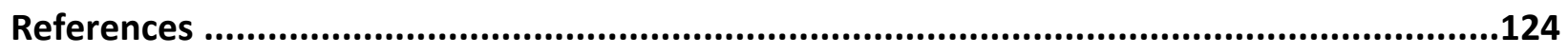

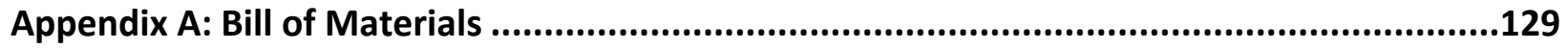




\section{List of Tables}

TABLE 2-1: COMPARISON SUMMARY OF OIL, INCANDESCENT, CFL, AND LED LIGHTING TECHNOLOGIES ...................................... 34

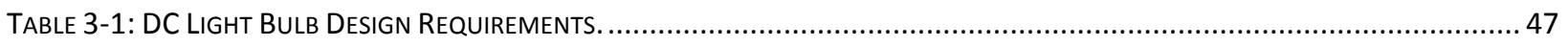

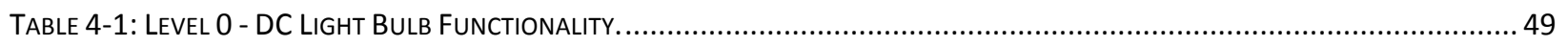

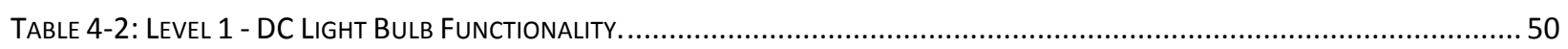

TAble 4-3: Dimmer Slide Potentiometer V(MOD) Voltage Divider Network.......................................................... 56

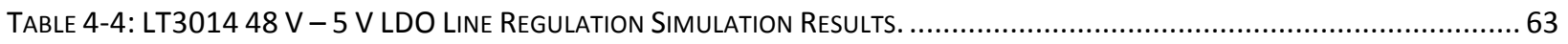

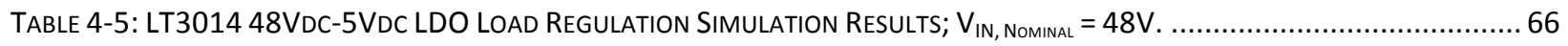

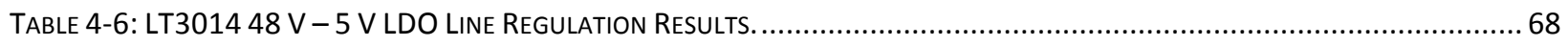

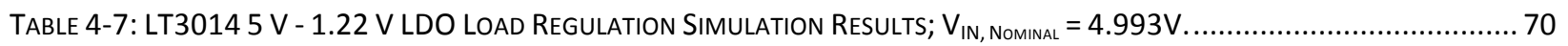

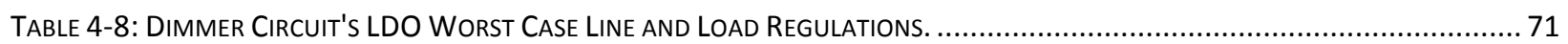

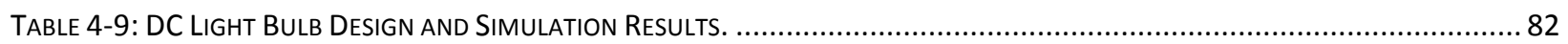

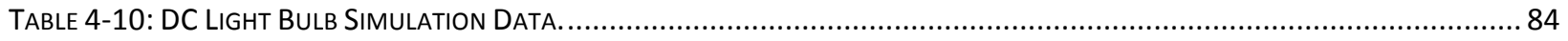

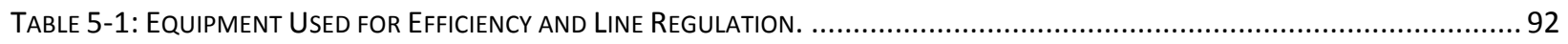

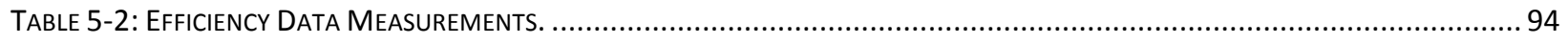

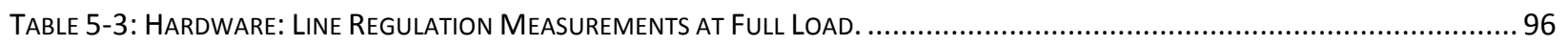

TABLE 5-4: EQUIPMENT USED FOR HARdWARE CIRCUIT FunCtIONALITY VERIFICATION...................................................... 97

TABLE 5-5: INDUCTOR CURRENT, I(L1) CONVERSION FOR FIGURE 5-14 (A) AND (B). .......................................................... 102

TABLE 5-6: LED CURRENT, I(LED) CONVERSION For FIGURE 5-15 (A) AND (B) .............................................................. 103

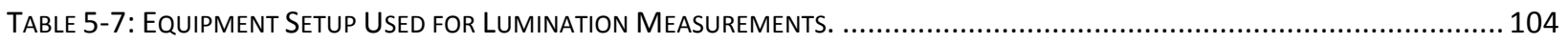

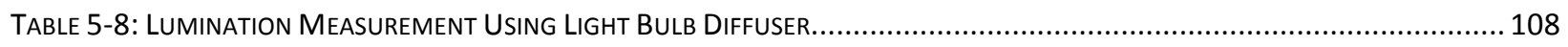

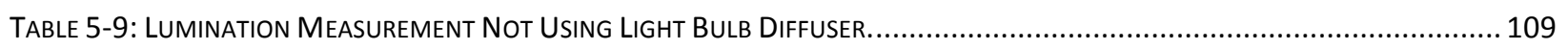

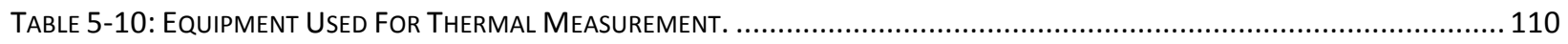




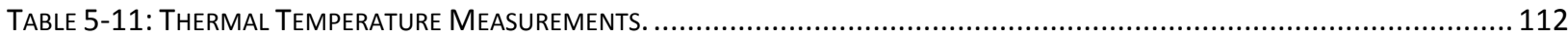

TABle 5-12: DC Light Bulb Simulation Vs. HaRdWARE Summary. 


\section{List of Figures}

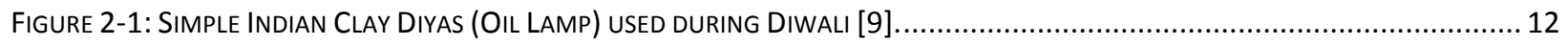

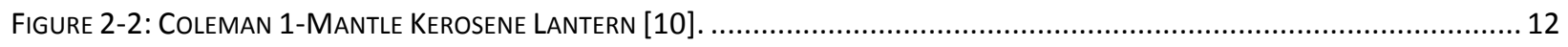

FIGURE 2-3: StANDARD INCANDESCENT LIGHT BULB CONSTRUCTION [15] ................................................................. 14

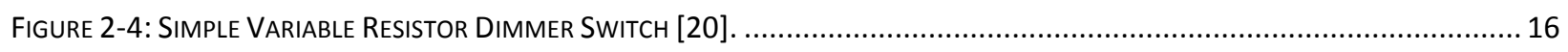

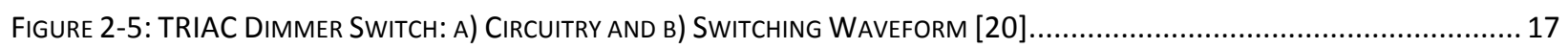

FIGURE 2-6: VARIOUS CFL SIZES AND SHAPES, INCLUDING (A) TWIN-TUBE INTEGRAL, (B AND C) TRIPLE-TUBE INTEGRAL,

(D) INTEGRAL MODEL WITH CASING THAT REDUCES GLARE, (E) MODULAR CIRCLINE AND BALLAST, AND

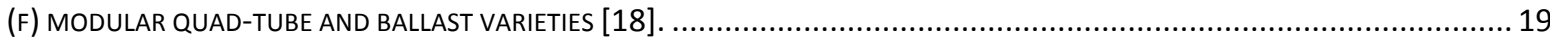

FIGURE 2-7: PN JUNCTION OF A LED UNDERGOING ELECTROLUMINESCENCE [26] ........................................................ 21

Figure 2-8: PHosphor BASEd White LED: EfFECTS OF YAG PHosPhor CoATING ON A BLUE LED [26]. ................................. 23

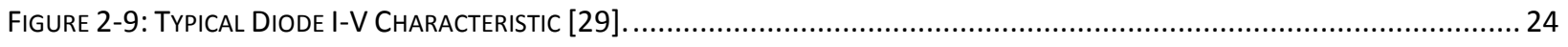

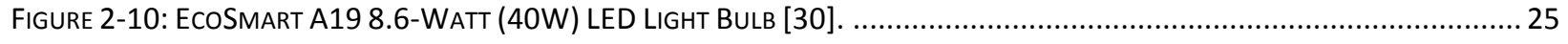

Figure 2-11: Two Flashlights With Relatively The Same Amount of LUX Some Distances Away [34]......................... 27

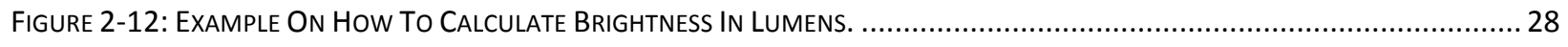

FIGURE 2-13: GE-60W A19 INCANDESCENT LIGHT BULB: BRIGHTNESS OF 780 LUMENS [35] .............................................. 29

Figure 2-14: Selecting an Energy-Efficient CFL Bulb BaSed on Lumens Rather Than Watts [36]................................ 30

FIGURE 2-15: ProjeCted LUMINOUS EfFICACY Of SOLID-STATE LIGHTING [36] ............................................................... 31

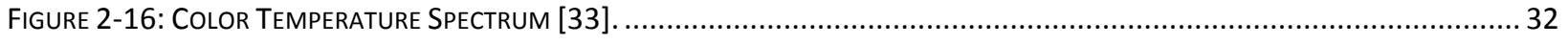

Figure 2-17: U.S. Site Electricity Savings in 2010 From Led Market Penetration [40] ............................................... 35

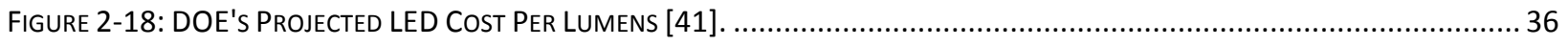

Figure 2-19: Recommended Roof Space Requirement Per PV Power Rating And EfFiciency [43] ................................. 38

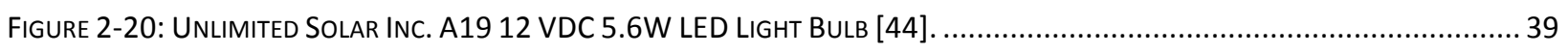


Figure 3-1: StANdARd A19 Light Bulb ANd E26 SCREW BASE Dimensions.

Figure 3-2: Custom Slide Dimmer Enclosure, a) SWitch Box, B) SWitch Box With Wall Plate.

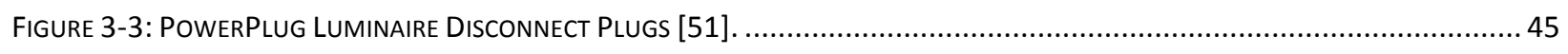

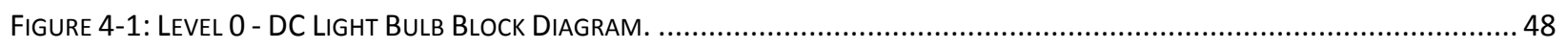

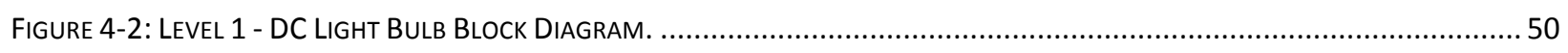

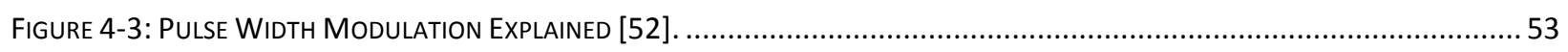

Figure 4-4: LTC6992-1 TimerBlox: Voltage-Controlled PulSe Width Modulator. ..................................................54

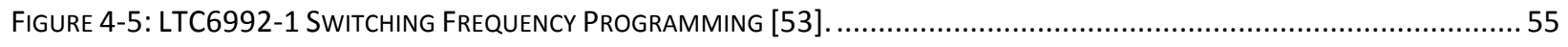

FIGURE 4-6: LTC6992-1 PWM AT (A) D = 0\%, (B) D = 28\%, (C) D = 50\%, AND (D) D = 100\%................................... 57

FIGURE 4-7: LTC6992-1 POWER CONSUMPTION AT FULL LOAD, D = 100\% ......................................................... 59

Figure 4-8: LT3014: LOW DROPOUt MiCROPOWER LINEAR REgULATOR, (A) 48 V - 5 V LDO AND (B) 5 V - 1.22 V LDO............ 60

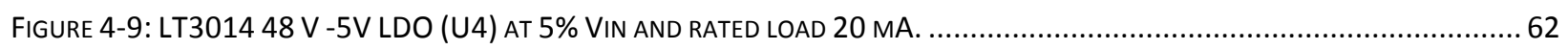

FIGURE 4-10: LT3014 $48 \mathrm{~V}-5 \mathrm{~V}$ LDO AT $\mathrm{V}_{\text {IN, Low INPUT }}=45.6 \mathrm{~V}$ (5\% $\left.\mathrm{V}_{\text {IN, NominaL }}\right)$ AND RATED LOAD 20 MA..............................63

FIGURE 4-11: LT3014 $48 \mathrm{~V}-5 \mathrm{~V}$ LDO, $\mathrm{R}_{\text {LOAD }}=4 \mathrm{~K} \Omega, 2 \mathrm{~K} \Omega, 1.33 \mathrm{~K} \Omega, 1 \mathrm{~K} \Omega, 800 \Omega, 666.67 \Omega, 571.43 \Omega, 500 \Omega$, $444.44 \Omega$, AND $250 \Omega$. 64

FIGURE 4-12: LT3014 48VDC-5VDC LDO SIMULATION WAVEFORM AT VIN, NoMINAL $=48 \mathrm{~V}$, I LOAD VARYING FROM $10 \%$ TO $100 \%$ OF $I_{\text {RATED }}=20$ MA. 65

FIGURE 4-13: LT3014 5VDC-1.22VDC LDO (U3) AT 5\% VIN AND RATED LOAD 20MA. 67

FIGURE 4-14: LT3014 5 V - 1.22 V LDO AT $\mathrm{V}_{\text {IN, Low INPUT }}=4.993 \mathrm{~V}\left(5 \% \mathrm{~V}_{\text {IN, NominaL }}\right)$ AND RATED LOAD 20 MA. 68

FigURE 4-15: LT3014 5 V - 1.22 V LDO SCHEMATIC DiAgRAM, $R_{\text {LOAD }}=610 \Omega, 305 \Omega, 203.33 \Omega, 152.5 \Omega$, $101.67 \Omega, 87.143 \Omega, 76.25 \Omega, 67.778 \Omega$, AND $61 \Omega$. 69

FIGURE 4-16: LT3014 5 V - 1.22 V LDO SIMULATION WAVEFORM AT V IN, NOMINAL $=4.993 \mathrm{~V}$, I LOAD VARYING FROM $10 \%$ TO $100 \%$ OF $\mathrm{I}_{\text {RATED }}=20 \mathrm{MA}$. 69

Figure 4-17: Complete Dimmer Circuit Design, (A) 48 V - 5 V LDO, (B) 5 V - 1.22 V LDO, (C) PWM CONTROLLER. 71 
Figure 4-18: DC Light Bulb Enclosure Dimensions, (A) Light Diffuser, (B) Aluminum Heatsink,

(C) INNER SLeEVE for Electronics, (D) E26 SCREW BASE...

Figure 4-19: 25 MM MCPCB for 4 CREE XPG LEDs IN SeRIES, (A) Physical Design, (B) SChematic Design. 74

Figure 4-20: CREE XPG LED's ForWARd CURRENT VS. Voltage CHARACTERISTICS [58]............................................ 75

FIGURE 4-21:CREE XPG COOL White (5000K) ForWARd CURRENT VS. AMBIENT TEMPERATURe [58] ................................... 75

Figure 4-22: LED Driver SChematic In BuCK Mode Operating AT 1 A FulL LoAd..................................................... 76

FIGURE 4-23: V(PWM_5V) VS. V(PWMOUT) FOR (A) D = 0\%, (B) $D=28.086 \%,(C) D=50.07 \%,(D) D=93.176 \% \ldots \ldots \ldots \ldots . .77$

FIGURE 4-24: V(PWMOUT) VS. V(M1 GATE) FOR (A) D = 0\%, (B) D = 28.086\%, (C) D = 50.07\%, (D) $D=93.176 \% \ldots \ldots \ldots \ldots .78$

FIGURE 4-25: V(PWMOUT) VS. V(M2 GATE) FOR (A) D = 0\%, (B) $D=28.086 \%$, (C) $D=50.07 \%,(D) D=93.176 \% \ldots \ldots \ldots \ldots .79$

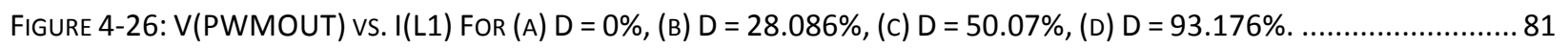

FIGURE 4-27: V(PWMOUT) VS. I(LED) FOR (A) D = 0\%, (B) D = 28.086\%, (C) D = 50.07\%, (D) D = 93.176\%................... 81

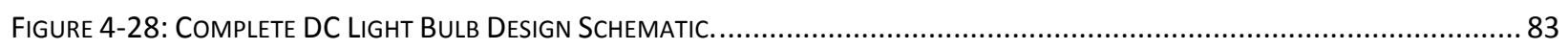

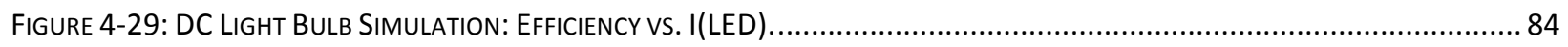

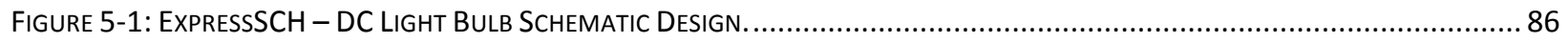

Figure 5-2: ExpressPCB - 4-Layer PCB layout Design, (A) Top Signal Plane, (B) InNer Ground Plane,

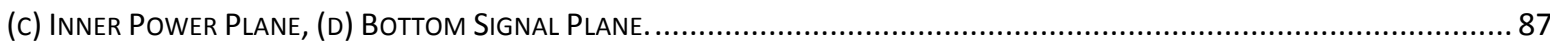

Figure 5-3: DC Light Bulb Custom 4-Layer PCB layout After Manufacturing, (A) Top Layer, (B) Bottom Layer. ............. 88

Figure 5-4: DC light Bulb Custom 4-Layer PCV After Being Cut to Size, (A) Top Layer, (B) Bottom Layer. ..................... 89

Figure 5-5: Custom PCB Fitted into InNer SleEVe, (A) Top VieW, (B) Bottom VieW, (C) Side VieW.................................89

Figure 5-6: Custom PCB Populated With Components And Ready For Testing,

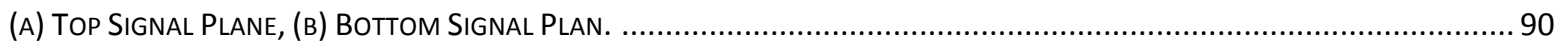

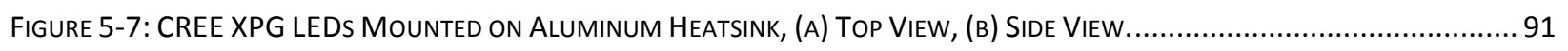

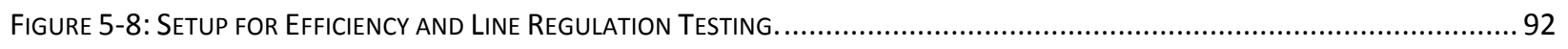

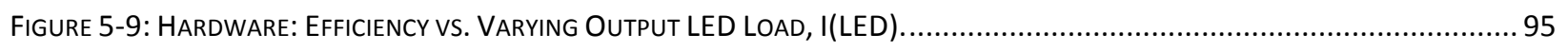


Figure 5-10: Setup for Circuit Functionality Verification, (a) Oscilloscope and Current Probe Amplifier

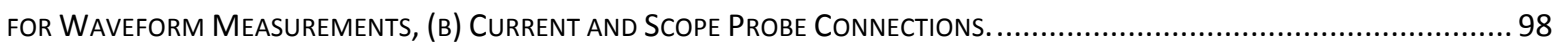

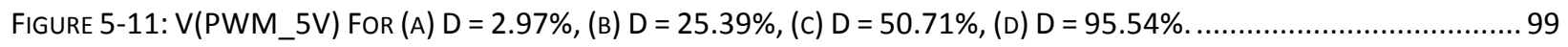

FIGURE 5-12: [CH1] V(PWMOUT) VS. [CH2] V(M1_GATE) FOR (A) D = 49.24\%, (B) D = 95.53\%............................... 100

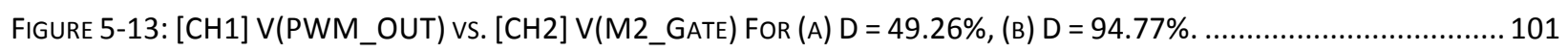

FIGURE 5-14: [CH1] V(PWM_OUT) VS. [CH3] I(L1) FOR (A) D = 49.99\%, (B) D = 5.52\%..................................... 102

FIGURE 5-15: [CH1] V(PWM_OUT) VS. [CH3] I(LED) FOR (A) D = 50.02\%, (B) D = 94.71\%.................................... 103

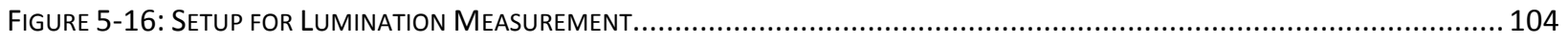

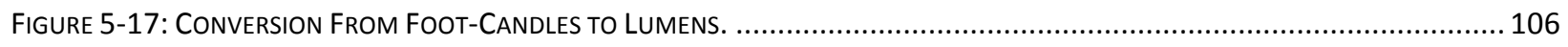

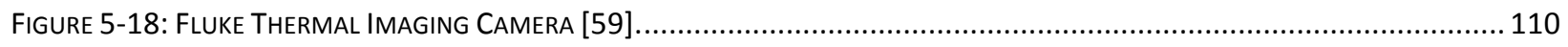

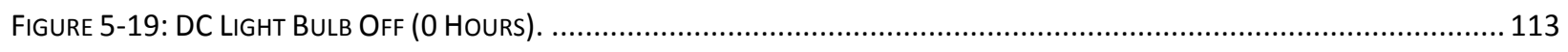

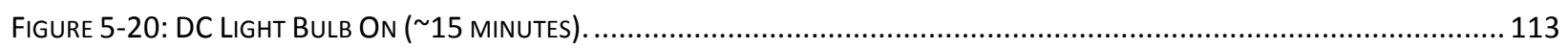

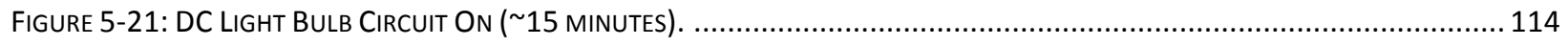

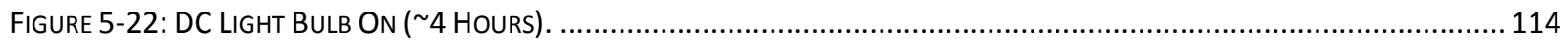

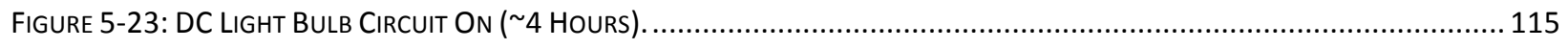

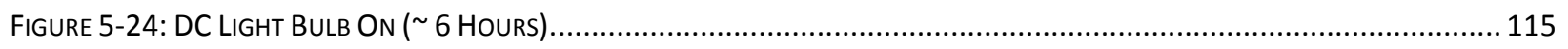

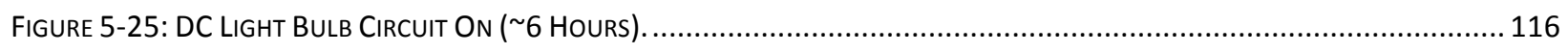

Figure 5-26: Custom DC Light BulB 4-LAyER PCB - Fully Populated, Top (LEFT) ANd Bottom (RIGHT) LAYER.................. 118

Figure 5-27: Fully Populated PCB Fitted Into Light BulB's InNer SleeVe, Bottom (Left) ANd Top (RIGHT) VieW.............. 118

Figure 5-28: A19 DC LIGHT BULB (LEFT) WITH DiMmer Box (RIGHT) - FULLY ASSEMBLED....................................... 119

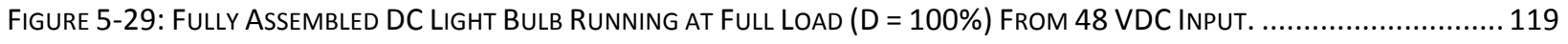




\section{Chapter 1: Introduction}

\section{1 : DC House Project}

The DC House Project is an on-going student based project that consists of various senior projects and Master's thesis. The DC House Project's main goal is to provide a source of direct current electrical power to individuals in the form of a housing unit. As the project progresses, these housing units would expand to form a grid of DC powered neighborhoods. The DC House incorporates various forms of renewable energy conversions, such as photovoltaic power generation, hydropower generation, wind power generation, and human power generation. Through the DC power generated, household applications such as a fan, a lighting system, a stove, a TV, a laptop, and a refrigerator can be powered directly. The uniqueness of having a DC powered ready-home just makes sense for geographical locations where the utility grid is inaccessible.

Phase 1 of the DC House Projects established the foundation of a DC powered ready home. During this phase (AY 2010 - 2011), the DC House's distribution system design and load flow analysis were modeled [45]. Photovoltaic, wind power, hydroelectric, bicycle power generation systems were also modeled and tested through prototype systems [48]. Conversion systems from generation to household application connectivity, such as multipleinput DC-DC converter and a variable voltage DC wall outlet were also demonstrated through prototype models [48]. 
The on-going Phase 2 of the DC House Project (AY 2011 - 2012) focuses on integration of household applications, improvements from generation to household connectivity conversions, and alternative forms of low cost power generation. Home applications include a

DC light bulb design and a cell phone charging station. Connectivity conversion systems include improving the variable voltage DC wall outlet and improving the multi-input DC-DC converter design. Feasibility of low cost small-scale power generation applications includes a low speed car alternator and a human powered seesaw. During this phase, the modeling and construction planning of the DC House are also evaluated.

Phase 3 of the DC House Project (AY 2012 - 2013) will focus on field-testing of the DC House's generation systems, household applications, and conversion systems. A working DC House model will then be presented to the public.

\section{2: Thesis Objectives}

For this thesis, a strong focus is in the design, implementation, and testing of an economical and energy efficient DC Light Bulb for the DC House Project. For this DC lighting system, emphasis is on the DC-DC module design, LED lighting array circuit, PWM dimmer feature, and physical packaging design that takes advantage of the traditional A19 60W incandescent light bulb dimension using a standard E26 Edison screw base. 


\section{Chapter 2: Background}

\section{1 : Motivation}

Sparsely human populated areas such as small villages in developing countries or remote locations away from urban cities often do not have access to electricity, due to inaccessibility to an electrical grid tied AC power source. For example, in 2009, 1.3 billion people or about $20 \%$ of the entire world's population were without electricity. This equates to roughly 587 million people in Africa, 675 million people in developing Asia, and 55 million people in Eastern Europe/Eurasia that had no access to electricity [1]. The capital required to built the electrical infrastructure (such as distribution substations, transmission lines, service transformers, etc.) and the recurring operational costs, which includes equipment repairs and replacements, are often hard to justify financially for low populated areas. According to Edison Electric Institute (EEI), from 2004-2008, United States invested \$4.6 M/GW/year, New Zealand invested $\$ 22.0 \mathrm{M} / \mathrm{GW} /$ year, and The Netherlands invested $\$ 12.0 \mathrm{M} / \mathrm{GW} /$ year in high voltage $(>230 \mathrm{kV})$ transmission normalized by year [2]. The cost of distribution transmission (<230kV) would be considerably more costly compared to high voltage transmission, due to increased in resistive losses $\left(I^{2} R\right)$ through the transmission conductors (related by Ohm's Law, V=IR, and power loss through a conductor, $P=I^{2} R$; when voltage decrease, current increases by the square term, $\left.I^{2}\right)$. The power grid's high infrastructure cost creates an opportunity for engineers to use new technologies to meet the electricity needs in rural areas by using alternative means that 
are less expensive, such as the renewable energy generation methods presented in the DC House Project.

Through the successful completion of the DC House Project, it would provide selfsustaining DC power through various forms of renewable energy conversions, such as photovoltaic, hydropower, wind, and human power generation. The DC power generated could then be used to provide basic living necessities such as room lighting after sunset, cooking using an electric stove, and refrigeration of perishable foods. For this thesis, a focus will be on developing a DC lighting system, "DC Light Bulb," that would accommodate the lumination requirements for the DC House Project. The DC Light Bulb's economical impact, environmental impact, sustainability, and ethical impact are analyzed in the following sections.

\subsection{1: Economical Impact}

Economical impact can be defined by the measure of workforce, education, and health care development. The DC Light Bulb plays an integral role in influencing economical growth through human capital, financial capital, and natural capital.

In terms of human capital, the DC lighting system influences economical growth through an increase in employment productivity and educational literacy. More available lumination means an individual can work longer hours or work during the night when natural sunlight is not available. For example, lighting would allow a seamstress or tailor to fit his/her customer 
with the perfect suit or dress, without having to worry about the time of day. For example, lighting would also allow adult education and literacy classes during the evenings [3] or more time for students to read, write, and learn math, science, and other topics. Thus, the DC Light Bulb would influence human productivity that creates economic value.

In terms of financial capital, the DC Light Bulb provides lumination that creates a more productive labor force and thus a larger revenue stream. For example, lighting in a clothing assembly line allows employees to work different shifts around the clock means more products to market and more return in net profit. The more money allows entrepreneurs or businesses to buy the necessary manufacturing equipment needed to make their products or provide services to their surrounding community, thus creating economical growth.

In terms of natural capital, the growth in employment, educational literacy, businesses, and economical wealth allows individuals, entrepreneurs, business owners and their employees the opportunity to take part in keeping the natural environment sustainable. For example, services such as recycling consumer products and packaging materials is a way the economy can balance the resources they use to improve their quality of life while disposing what they don't need back into the environment in a sustainable way. 


\subsection{2: Environmental Impact}

Environmental impacts associated with the use of the DC Light Bulb include the manufacturing, shipping, use, and disposable of the system. During the manufacturing stage, toxic chemicals are used to fabricate the semiconductors components. Toxic chemicals such as acetone used in polishing the silicon wafers cause nose, throat, eye irritation, and possible coma. Benzene used as photo-electrochemical etching causes damage in bone marrow, anemia, excessive bleeding, and immune system effects to name a few hazards [4]. These toxic chemicals must be eventually disposed back into the environment in one form or another. During the transportation stage, the DC lighting system must travel many thousands and thousands of miles through cargo trucks, trains, boats, and airplanes before reaching the developing countries that would eventually use the DC lighting system. During the time it took to get the product from point $A$ to point $B$ it has caused the release of an enormous amount of carbon dioxide into the atmosphere and thus contributing to global climate change [5]. During the use of the DC lighting system, it can potentially be hazardous if using low-intensity red LEDs, for it leaches $\mathrm{Pb}$ at levels exceeding regulatory limits [6]. However, for this particular project white/natural color LEDs were used and thus this hazard is avoided. Lastly, the disposable of the lighting system after it exceeds the end of its life expectancy may end up in electronicwaste landfills. It is estimated that only about $15-20 \%$ of e-waste is recycled, and the rest of these electronics go directly into landfills and incinerators in the United States [7]. Given this staggering estimation, it can be easily assumed that developing countries most likely do not 
have the necessary facilities to recycle electronic waste. Thus, the environmental impact is very high in this stage of the lighting system's life cycle.

The DC Light Bulb is a subsystem incorporated into the DC House Project. This lighting system uses the DC power generated through natural resources provided by the sun that powers the photovoltaic solar panels, natural wind that powers the wind turbines, flow of stream water that spins the generator, and human powered see-saw that charges the battery.

The DC lighting system in conjunction with the DC House will improve the environment dramatically. For example using self-sustaining dc power, removes the need of high power AC transmission lines and towers that blocks the line of sight for homeowners. Also, a DC powered system eliminates the need of harmful underground AC transmission lines that are often made from lead based materials. The use of natural resources to power a person's home saves the consumer money, while leaving a smaller footprint on the environment. Overall, the use of a self-sustaining DC powered house improves the overall land usage through a smaller required footprint to supply electricity to the home.

The DC lighting system has minimal impact on species in the environment. The majority of the DC lighting fixture will be integrated into the DC house. External DC lighting will be housed in weatherproof lighting fixtures. However, studies have shown that light pollution can threaten wildlife by disrupting biological rhythms and cause blindness to birds during their biannual migrations [8]. As a result, turning down the brightness to a soft yellow color at night would reduce interfering with wild animals at night. In other words, reducing the lighting 
intensity at night would reduce birds from being disoriented from the bright light, thus leading to fewer crashes into night-lit towers [8].

\subsection{3: Sustainability}

The DC Light Bulb is designed to be maintenance free. However, issues may arise with insufficient input power supplied to the LED driver and LED lighting array. Inadequate input power may be caused by lack of supply voltage due to dirty solar panels that degrades its overall sun radiation to dc power conversion. Inadequate input power may also be caused by a calm day with not enough constant wind to spin the wind turbine, thus generating insufficient power to drive the DC lighting system. Similarly, lack of water generated input power and or human generated input power can also cause the lighting system to not operate. Another issue may be caused by not keeping the lighting system clean from debris, thus causing insufficient ventilation to maintain normal operation. Since light intensity is related to heat dissipation, without adequate ventilation to release the accumulated heat, the lighting system may eventually overheat and malfunction.

The DC Light Bulb takes advantage of renewable resources through the use of solar, wind, water, and human generated electricity. Since the sun, wind, and water are highly sustainable, using renewable technology to take advantage of such resources is highly appropriate. 


\subsection{4: Ethical Impact}

Ethical implications related to the design, manufacture, use, of the DC Light Bulb can occur. It is often that the project being developed has been attempted by someone else. It would be unethical to use the other inventor's design schematic as the student's without authorization. A better approach is to study and analysis his/her design and incorporates the technology, pros, and cons of the design as an aid to developing the student's design. Credit should always be cited when an idea or invention is borrowed. In addition, one should gather more research from various designs and academic books to formulate a more defined and academically develop design. The purpose of the design project is to evaluate the student's ability to incorporate a design using the skills developed through the rigorous academic engineering program and ability then to incorporate desirable system functionalities learned through justifiable and creditable research of other scholarly designs, while giving credit where it is deserved.

Ethical implications during the operational phase of the DC lighting system can impact its overall use. The desired case is to use the DC lighting system as a way to extend lighting past sunset. With additional lighting, children can further educate themselves through reading and writing. Parents can catch up or get a heads start on the next day's worth of work, such as preparing food, repairing garments, cleaning, and or preparing his or her business functions, such as auditing accounts, and much more that was once impossible without lighting to see what he or she was doing. However, additional lighting created by the DC lighting system can also influence the demand for longer work hours throughout the day and more irregular work 
schedules brought on by profit hungry business owners and entrepreneurs. For business owners, more lighting means more products to market and thus an increases revenue stream. An unethical implication that often occurs in such businesses is the demand of increase in productivity while maintaining the same level of pay to its employees. In developing countries, where money is scarce, large corporations and business often dominate both politically and economically on the living standards of its employees. Thus the use of additional lighting can quickly play a negative implication on the standard of living in low-income families. For example, where families were once supportive of one another and shared lengthy bonding activities, can quickly turn into family separations. The adults are slaved away at work and the children are left misguided throughout the day, thus the possibility of a life of drugs and crime.

\subsection{5: Health and Safety}

Health and safety concerns associated with the design and use of the DC Light Blub may

occur. Since the lighting system is powered by electricity and the light generates heat, the concern of getting electrocuted and burned may be an issue if not handled with proper care. To reduce the chances of electrical shock, the installation of the lighting system must follow the NEC 2010 design, installation, and safety standards. To reduce the chance of getting a burn, the lighting fixture should be mounted at a distance where it is appropriately away from the reach of children and adults. If such distances cannot be achieved, appropriate lighting protection 
wire guards should be installed around the light fixture to minimize change of getting burnt and damage to the lighting array.

\section{2: Lumination Methods}

The four most common methods of lumination are oil lighting, incandescent lighting, compact fluorescent lighting (CFL), and light-emitting diode (LED) lighting. In the following sections, advantages and disadvantages of each lumination method will be evaluated based on efficiency, brightness output, operating lifetime, and dimming capability.

\subsection{1: Oil Lighting}

Oil lighting is the most common source of lumination in rural areas such as small villages in developing countries and in remote locations away from urban cities. Oil based lighting is simply a clay pot filled with some form of oil that is dipped with wick and provides an open flame lumination for a period of time. The size and shape of oil lamps varied by culture, religion, and era. Figure 2-1 illustrates a traditional Indian Diyas (oil lamp) used during Diwali ceremonies [9]. Figure 2-2 illustrates a modern kerosene lantern used for camping [10]. The simplicity of oil lamps allow them to run off of different forms of fuels such as olive, fish, and nut based oils used by ancient Mediterranean cultures; castor oil used by Egyptians cultures; peanut, carrot, and nettle oils used by African cultures; and ghee (a form of butter) oil used by 
Indian cultures. The lighting filament or wick were also simple to obtain, often made from linen, tow, or, dried plants such as flax, papyrus, or rush [11].

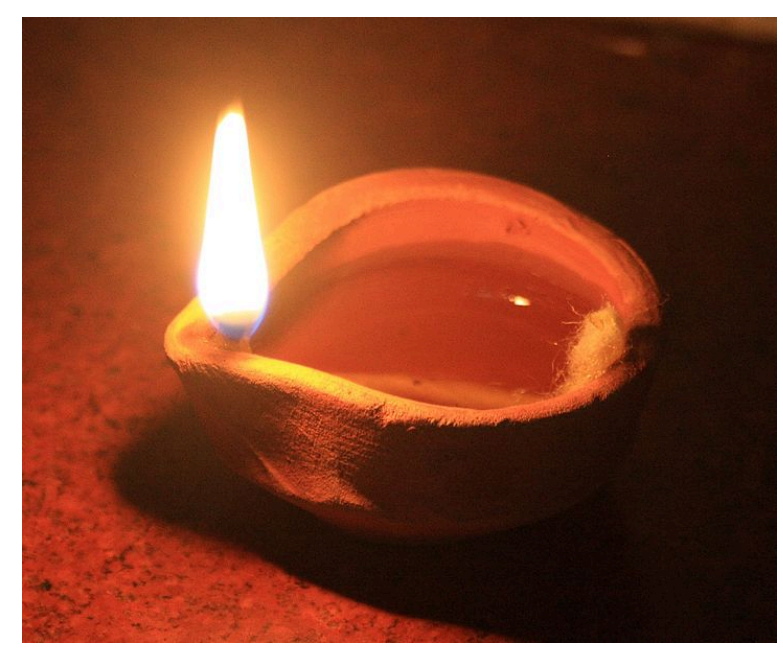

Figure 2-1: Simple Indian Clay Diyas (Oil Lamp) used during Diwali [9].

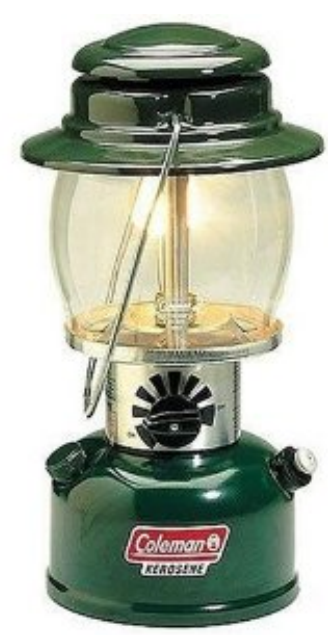

Figure 2-2: Coleman 1-Mantle Kerosene Lantern [10].

Before the availability of electricity, oil lamps were the simplest form of illumination. It was easy to construct out of clay, stone, or some form of metal. The fuel source and lighting wick were also easily obtained through nature. However, it is inefficient and can often be a fire 
hazard if left unattended. Candles (paraffin wax based oils) produce a luminous efficacy of about 0.16 to 0.30 lumens per watt or about one hundred times less than an incandescent light bulb $[12,13]$. On average the flame temperature is around $1000^{\circ} \mathrm{C}[13]$. Candles produce a color temperature of $1000 \mathrm{~K}-1700 \mathrm{~K}$ and a color rendering index of $100[13,32]$. Dimming the brightness on an oil lamp is relatively hard. The wick thickness only determined the lifetime of lumination (smaller diameter wicks allow longer lifetime) but has no direct control on how bright it would burn. As technology progresses and availability of electricity in urban cities increases, the introduction of incandescent light bulbs became the common form of illumination.

\subsection{2: Incandescent Lighting}

The introduction of incandescent lighting has been around since the mid 1800's. Thomas Edison filed his first patent, "Improvement In Electric Lights," in October of 1878 that described the design of a practical incandescent lamp using a carbon filament [14]. An incandescent light bulb produces lumination by supplying an electric current source through a wire filament until it reaches a high enough temperature that causes it to glow. This translates to about $10 \%$ useable light efficiency or $90 \%$ in wasted heat energy [15]. The wire filament is often made from carbon or tungsten and is preserved from oxidation using a glass enclosure

filled with some form of inert gas (such as argon or nitrogen), halogen gas, or pure vacuum. Figure 2-3 illustrates a standard A19 120VAC 60W incandescent light bulb. 


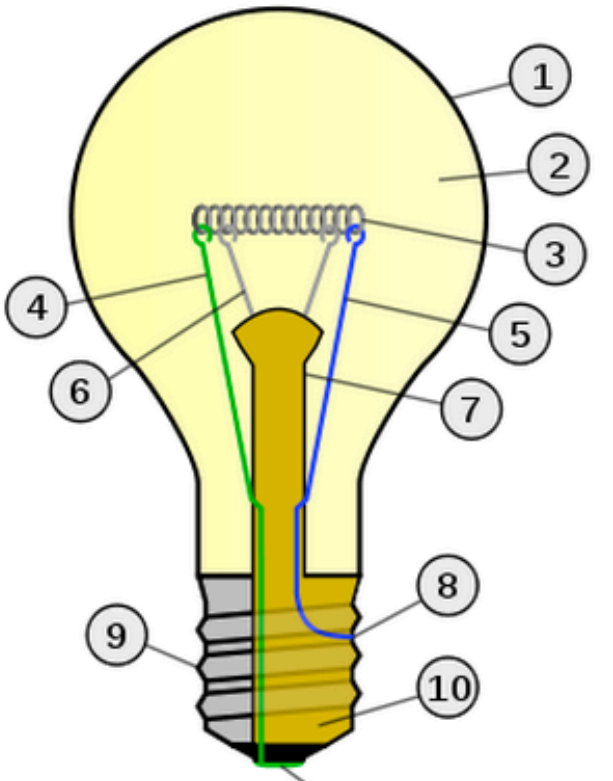

(11)
1. Outline of Glass bulb

2. Low pressure inert gas (argon, nitrogen, krypton, xenon)

3. Tungsten filament

4. Contact wire (goes out of stem)

5. Contact wire (goes into stem)

6. Support wires (one end embedded in stem; conduct no current)

7. Stem (glass mount)

8. Contact wire (goes out of stem)

9. Cap (sleeve)

10. Insulation (vitrite)

11. Electrical contact

Figure 2-3: Standard Incandescent Light Bulb Construction [15].

Incandescent light bulb comes in various dimensions, such as the standard "A" (or A19), reflector shape (Rxx), candle shape (Bxx), parabolic aluminized reflector (PARxx), and multifaceted reflector shape (MRxx) to name a few [15]. In United States " $x x^{\prime \prime}$ designates the

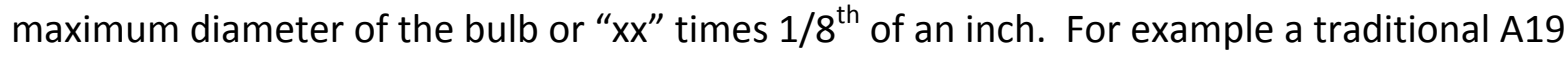
bulb would have a maximum diameter of 19 times $1 / 8^{\text {th }}$ of an inch or a 2.375 inch diameter. In United States, the screw base's (Ezz) diameter is defined by "zz" times 0.03937 inch, where "zz" is in millimeters. A standard E26 Edison screw base would have a diameter of 26 times 0.03937 inch/mm or 1.024 inches. According to the U.S. Department of Energy (DOE), incandescent lamps are categorized into three types, standard " $A$ " bulb, energy-saving incandescent (or halogen), and reflector bulb [16]. 
Incandescent lamp have higher efficacy (Lumens per Watt) compared to an oil lamp, however overall it is considered having a poor illumination output. A standard " $A$ " bulb produces an efficacy of 10-17 Lm/W, an energy-saving (halogen) produces 12-22 Lm/W, and a reflector type incandescent bulb produces $12-19 \mathrm{Lm} / \mathrm{W}$. A standard "A" bulb have a typical operating lifetime of 750-2500 hours, halogen bulb have a typical lifetime of 2000-4000 hours, and a reflector type incandescent bulb have a typical lifetime of 2000-3000 hours. Overall, all three types of incandescent bulb produces a good color rendition index (CPI), where the color temperature range from warm (2700K) to neutral (3200K) color temperatures. Incandescent light bulbs are relatively inexpensive to buy, often costing less than $\$ 1.00$ per bulb, but due to its shorter operating lifespan (for example, standard "A" bulbs have a lifetime of 750-2500 hours), it would cost more to operate over a longer period of time. According to a study done by Xcel Energy, it would cost $\$ 5.25 /$ year to operate an incandescent light bulb, where a compact fluorescent light (CFL) bulb would cost $\$ 1.61 /$ year; assuming $\$ 0.07 / \mathrm{kWh}$ and an initial bulb cost of $\$ 1.00$ for incandescent and $\$ 6.00$ for CFL [17]. The study also translates that an incandescent light bulb must be replaced every 9 months (assuming it has a lifetime of 750 hours), where a CFL would require replacing every 10 years (assuming it has a lifetime of 10,000 hours). In other words, the incandescent light bulb must be replaced thirteen times in ten years. Incandescent light bulbs are slowly transitioning out due to more efficient lumination technologies, but they are still commonly used for mood lighting

Incandescent light bulbs are also dimmable via a dimmer knob or sliding lever to control the illumination output. Early dimmer switches consist of a variable resistor that allows the 
user to rotate a contact arm (or knob) to adjust the amount of resistance, thus the amount of current that is allowed to flow into the light bulb filament. Figure 2-4 illustrates a simple variable resistor dimmer circuit. The lower the resistance, the more current is allowed to flow. Despite this simple dimmer switch design, a lot of energy is wasted in the form of heat through the variable resistor.

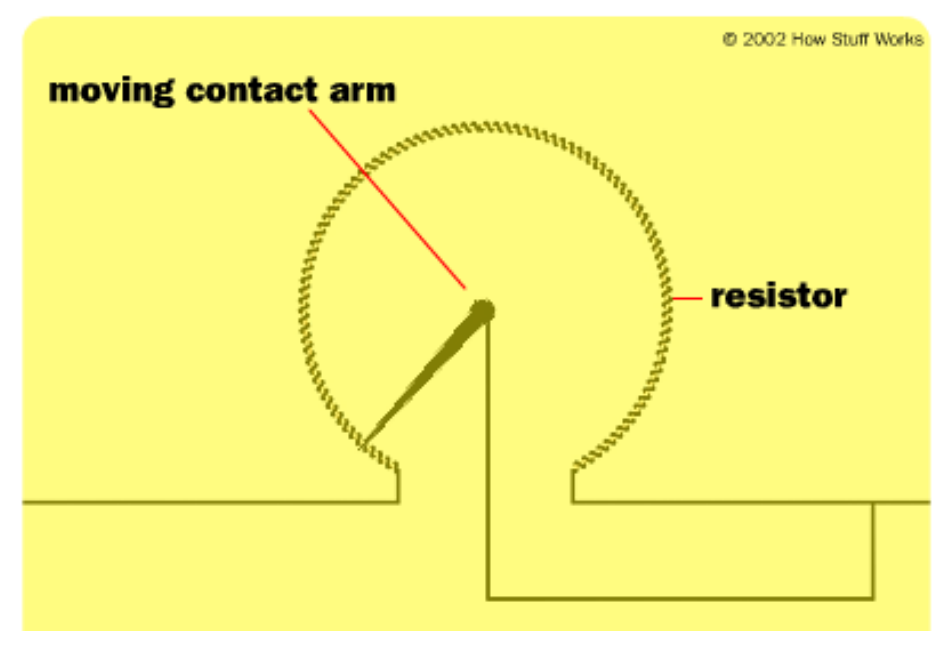

Figure 2-4: Simple Variable Resistor Dimmer Switch [20].

The most common type of incandescent dimmer switch is the triode alternating current (TRIAC) switch. Figure 2-5 illustrates a typical TRIAC dimmer switch circuitry and switching waveform. Depending on the dimmer's knob or slider position, the variable resistor's resistances is either increased or decreased. With a high resistive path, it takes longer for current to flow and to charge the firing capacitor, thus a longer time to build enough gate voltage to turn-on the TRIAC switch. Essentially, a TRIAC switch is a bidirectional voltagecontrolled switch that alters the input AC source voltage on and off repeatedly over every switching period. The constant on and off reduces power loss through the resistive element 
(thus improving overall efficiency), but creates a buzzing sound due to abrupt voltage switching. The continuous on and off of the AC voltage switching causes steep change in current per time through the inductive light bulb filament and causes the magnetic field to also change abruptly. As a result, vibration and buzzing is created through the light bulb filament. Higher quality incandescent dimmers include a LC filter (choke inductor and interference capacitor) that temporarily stores and supplies extra current at a delayed interval to smooth out the sharp change in voltage levels, thus reducing the buzzing effect [20]. Despite the possible buzzing in lower-end incandescent dimmers, incandescent light bulbs are great in mood lighting applications. In the next section, the more efficient CFL bulb will be reviewed and its dimming capabilities will also be evaluated.
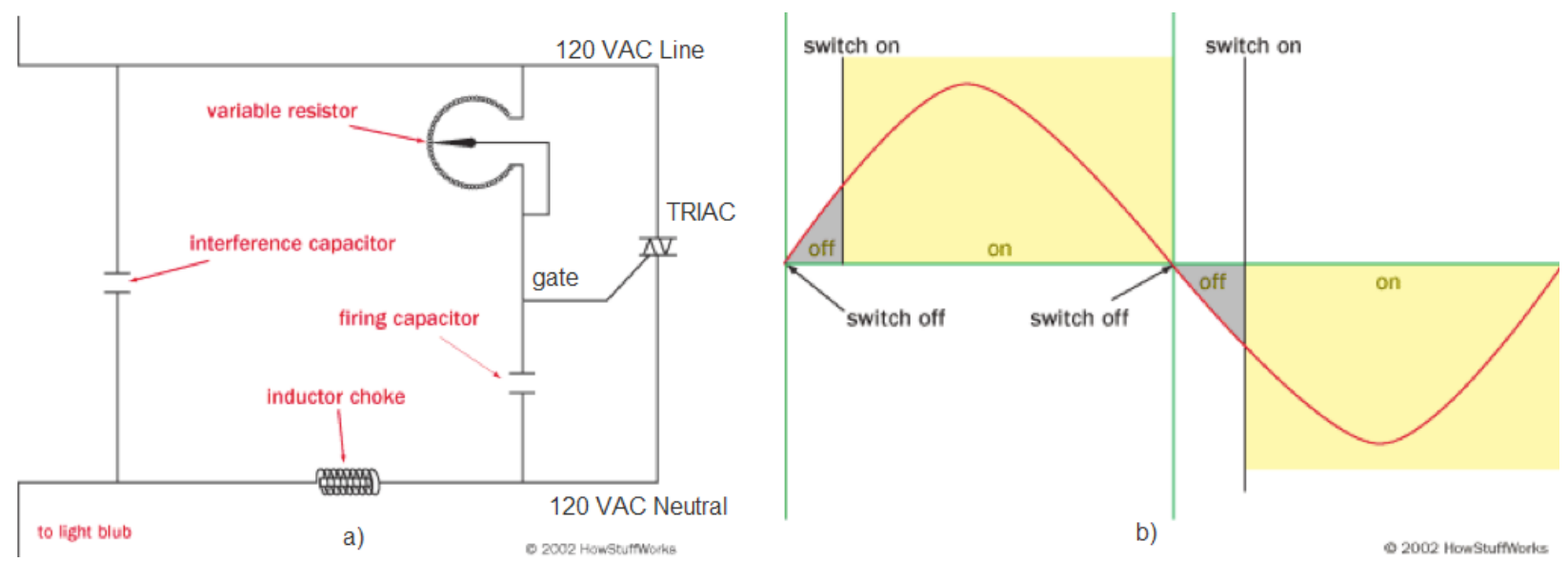

Figure 2-5: TRIAC Dimmer Switch: a) Circuitry and b) Switching Waveform [20]. 


\subsection{3: Compact Fluorescent Lighting}

Compact fluorescent light (CFL) bulb is a more energy efficient alternative to incandescent light bulbs. According to U.S. Department of Energy, CFL have an efficacy of 50$70 \mathrm{Lm} / \mathrm{W}$ and an operating lifetime of 10,000 hours [16]. Despite CFL having a good color rendition index, it somewhat suffers when it comes to light dimming. CFL is a type of gasdischarge lamp that uses constant current to energize mercury and inert gases within its burner (gas-filled tube section of the lighting enclosure) [18]. The exited mercury atoms are then converted into ultraviolet light that interacts with the white fluorescent coating and phosphors mixture in the lamp tube to produces visible light. Fluorescent lamps are characterized as a negative differential resistant device [19]. If current were allowed to flow freely through the device, its resistance would decrease as its voltage increased. Eventually the device would fail due to over-voltage. To prevent high voltage, magnetic or electric ballast is used to regulate the amount of current through the fluorescent lamp. Ballast used in early fluorescent tube lighting was often bulky and costly. Through advancement in lighting technology, engineers were able to integrate the electronic ballast into the base of the lamp housing, thus reducing the cost. Despite the 3-10 times greater initial cost in CFL compared to incandescent lighting, it uses 3-4 times less wattage and last 6-15 times longer compared to the latter [18]. CFL comes in many different shapes and sizes and often complement dimensions are available for incandescent light bulbs, such as the standard "A" (or A19) bulb. Figure 2-4 illustrates the various available CFL bulb sizes and shapes. 


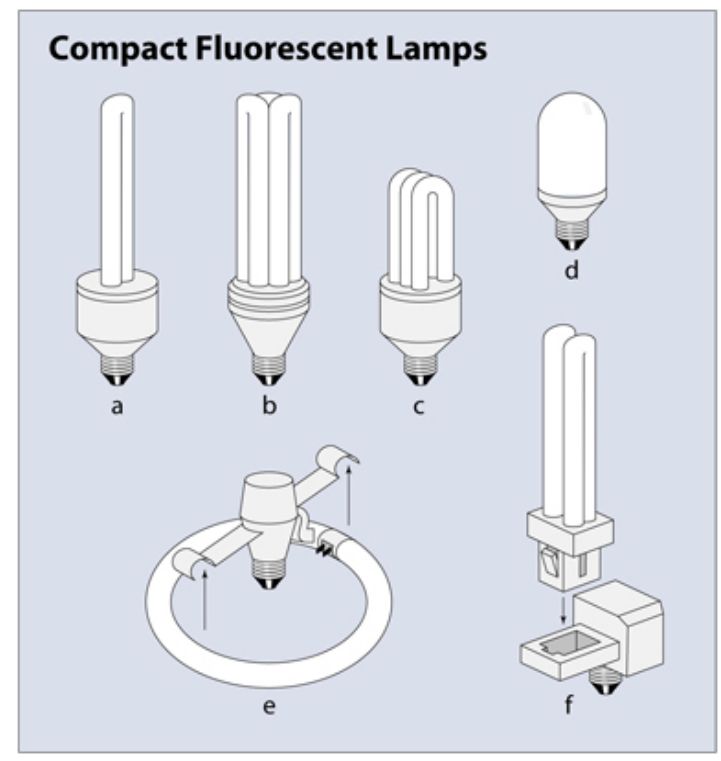

Figure 2-6: Various CFL sizes and shapes, including (a) twin-tube integral, (b and c) triple-tube integral, (d) integral model with casing that reduces glare, (e) modular circline and ballast, and (f) modular quad-tube and ballast varieties [18].

CFL bulbs are also somewhat dimmable, depending on the CFL's ballast type, internal lighting circuitry, and the dimmer circuitry. Traditionally, incandescent light bulbs can dim lower than CFL bulbs. Typical CFL bulbs can only dim down to between $10 \%-30 \%$ of its measured light output [21]. Some common CFL dimming issues are caused by light dropping out, light not turning on, and light turning off unexpectedly (or flickering). Light drop out occurs when the dimmer knob or slider position does not correspond to the light intensity. For example, when the dimmer's slider is fully down, but the light is still partially lit or when the slider is mid-way to full up, but the brightness remains at the same light intensity. Lights not coming back on can occur after the dimmer was set to a low light setting and then turned off. The lower dimming level may not provide sufficient voltage to turn CFL back on. Thus the 
dimmer knob or slider must be set to full brightness before turning back on. Lastly, the flickering of CFL lumination can occur when there are source voltage fluctuations, such as the high in-rush current required during air-conditioning or refrigerator start-ups, or simply caused by poorly regulated line voltage from the utility. As a result, at lower dimmer levels, flicker can become more noticeable.

CFL bulbs are great in terms of having a high efficacy to power usages ratio, long lifetime, and justifiable higher cost when compared to incandescent bulbs and oil lamps, but it is more harmful to the environment after its end of use due to small traces of mercury averaging $4 \mathrm{mg}$ in each bulb [22]. Mercury vapor that escapes into the air when a CFL breaks is also harmful to humans and then environment. The EPA suggests that each year 103 metric tons of mercury is released into the air each year, where half of these emissions come from coal power plants [23]. Mercury vapor is the main cause of water and biological contamination in fish. A CFL bulb requires mercury inside its bulb to generate lumination. Assuming a CFL bulb breaks, it is estimated that $11 \%$ of its mercury vapor escapes into the air or water. The EPA suggests that if all 272 million CFLs sold in 2009 were disposed in a landfill; it would generate 0.12 metric tons or $0.12 \%$ of the total mercury emission in the United States [22]. For this particular reason, a more environmental friendly lumination solution is required. 


\subsection{4: Light Emitting Diodes Lighting}

Light Emitting Diode (LED) lighting is one of the newest forms of lumination methods used today. LED lighting is attractive due to its high efficacy ranging from 27 to $200+$ lumens per watt, long lifetime ranging from 25,000 to 50,000 hours, and relatively low operating power consumption ranging from a few $\mathrm{mW}$ to $20 \mathrm{~W}$ for typical home applications [24]. However, the relatively high cost (\$10 to $\$ 150)$ influences slower adoption into homes and businesses.

LEDs are often a category under solid-stage lighting (SSL), which describes a type of semiconductor used to convert electricity into light [25]. The characteristic of a LED is similar to a diode, when it is forward biased electrons from the anode terminal are allowed to recombine with electron holes at the cathode terminal. LED undergoes electroluminescence when the electron meets a hole; it releases photon light energy as it drops into a lower energy band [26]. The electroluminescence process is illustrated in Figure 2-7.

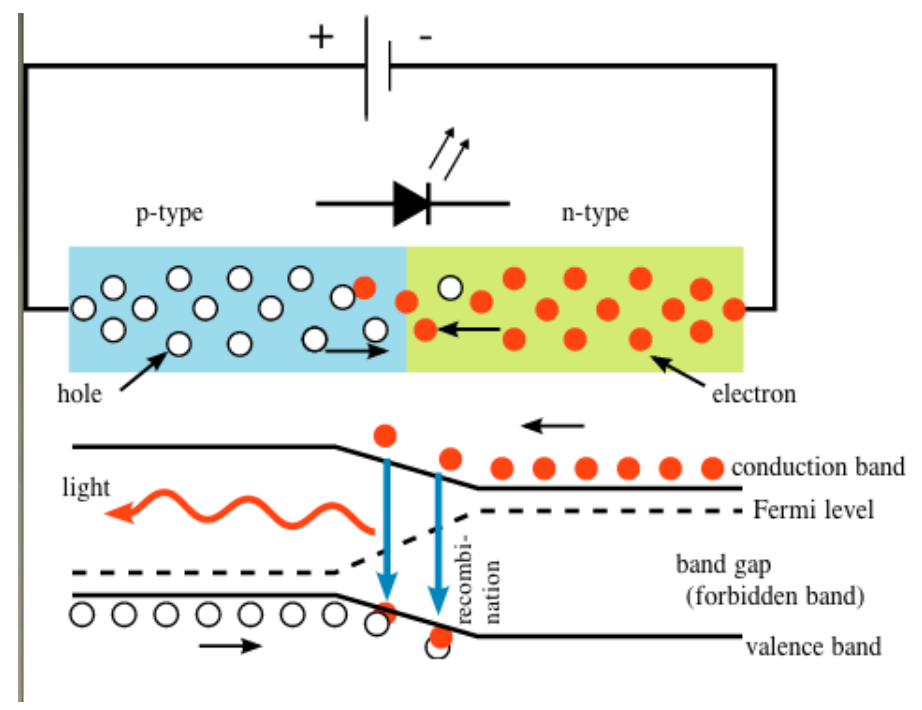

Figure 2-7: PN Junction of a LED Undergoing Electroluminescence [26]. 
The two most common methods used to achieve white LED light are the phosphor method and the RGB method. A popular phosphor-based white LED method involves coating a indium gallium nitride (InGaN) blue LED with a yttrium aluminum garnet (YAG) yellow phosphor to shift the shorter blue wavelength to a longer wavelength, thus creating a perceived white light seen by our eyes [26, 27]. Figure 2-8 illustrates the effect of YAG phosphor coating on a blue LED. The phosphor method is often favored over the RGB method when manufacturing high power white LEDs due to its simplicity, repeatable color rendering index, and lower cost. The RGB method involves mixing three primary colors: red, green, and blue LEDs to create a multi-color white LED. This method often requires a color sensing circuit to control the shade of each color's intensity. The RGB method may be favored in situations where the ambient temperature is outside the recommended LED operating conditions, or in situations where accurate color rendition is required. LEDs experience gradual lumen depreciation after about 35,000 to 50,000 hours of operation due to primary heat generated at the LED's junction [28]. Using a RGB white light module to correct the change in lumen imbalance between each color may extend its useful service life. 


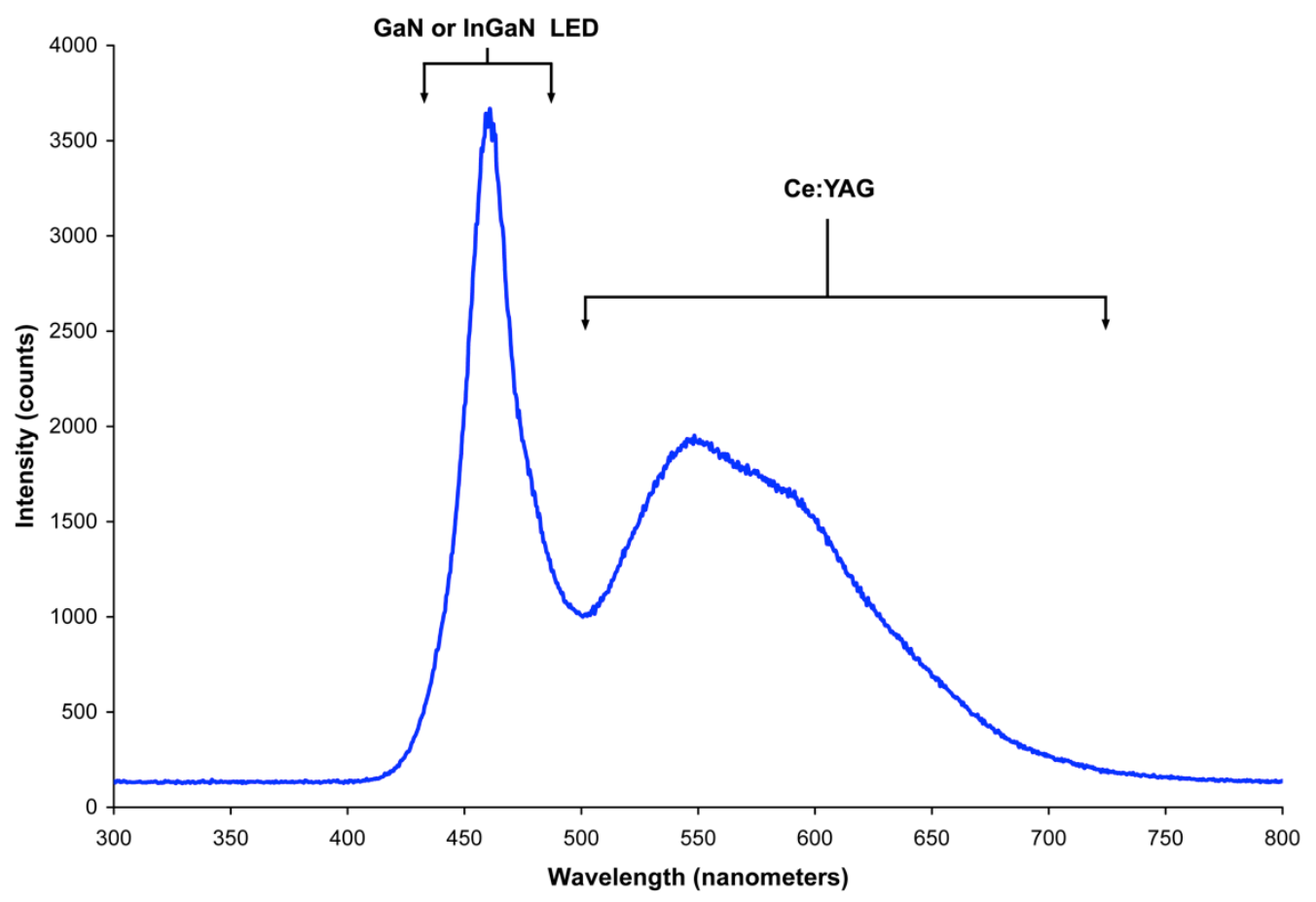

Figure 2-8: Phosphor Based White LED: Effects of YAG Phosphor Coating on a Blue LED [26].

As mentioned earlier, LEDs share similar current versus voltage operating characteristics (I-V curve) as a diode. Figure 2-9 illustrates a typical I-V diagram for a diode. For a diode or LED, a very small change in voltage can cause an exponential change in current. The brightness of a LED is directly dependent on the amount of current during the forward conduction mode. The high cost in LED lighting is partially the result of requiring a constant-current circuitry to power the LED and to prevent the LED from exceeding the maximum current rating. 


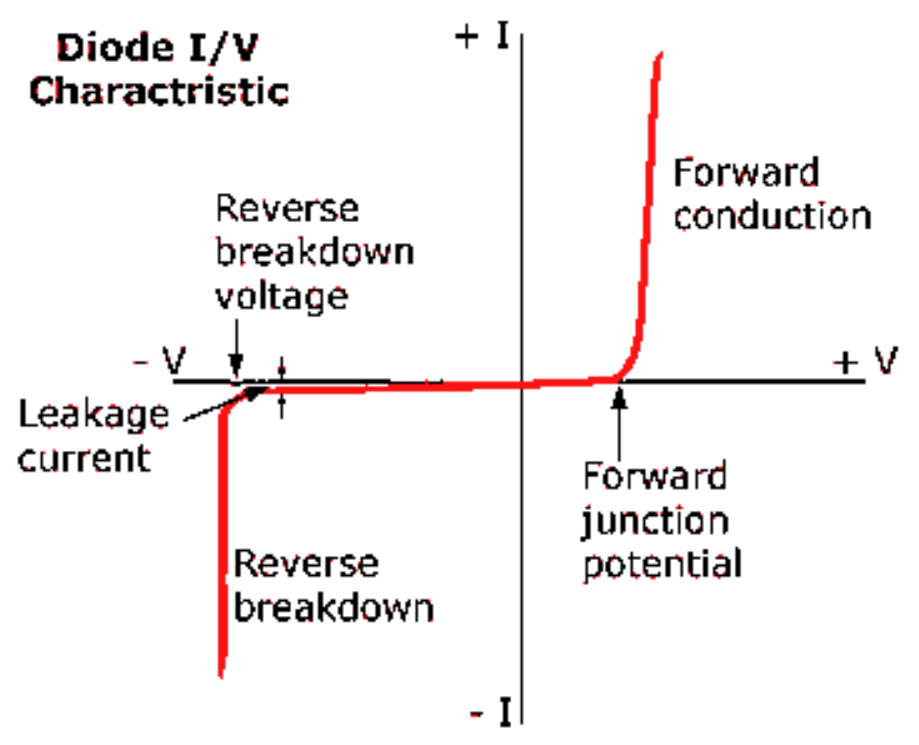

Figure 2-9: Typical Diode I-V Characteristic [29].

LEDs vary in shape, size, and lumens/watt output. U.S. Department of Energy suggests that in 2010, typical off the shelf 120VAC LED bulbs had efficacies of $64 \mathrm{Lm} / \mathrm{W}$ for LED A19 (warm white) lamp, $93 \mathrm{Lm} / \mathrm{W}$ for LED warm white package, and $130 \mathrm{Lm} / \mathrm{W}$ for LED cool white package [27]. In the same study, typical incandescent bulb had efficacy of $15 \mathrm{Lm} / \mathrm{W}$, halogen had $20 \mathrm{Lm} / \mathrm{W}$, and CFL had $63 \mathrm{Lm} / \mathrm{W}$. Figure 2-10 illustrates a reasonably priced EcoSmart 120VAC 8.6W (40W) A19 LED light bulb costing \$9.97 [30]. The EcoSmart light bulb produces 430 lumens or an efficacy of $50 \mathrm{Lm} / \mathrm{W}$. Despite the higher cost, LED light easily out perform incandescent and CFL bulbs in terms of lumination output and efficacy. 


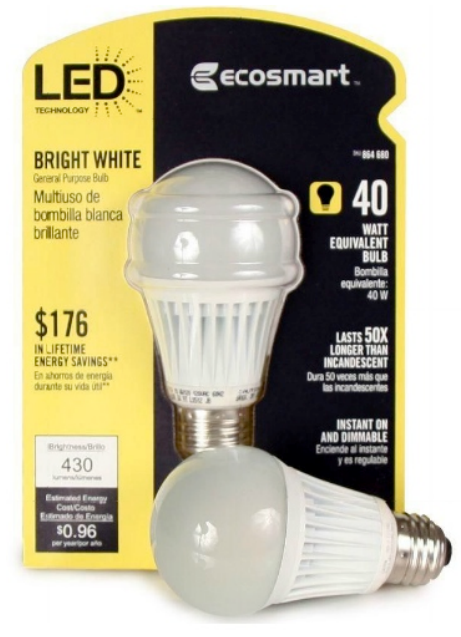

Figure 2-10: EcoSmart A19 8.6-Watt (40W) LED Light Bulb [30].

Some off-the-shelf LED bulbs are dimmable, depending on the light bulb's internal circuitry and type of dimmer used. Often times, LED bulbs are not compatible with line-voltage incandescent dimmers, such as the TRIAC dimmer presented in Figure 2-5. Due to insufficient power to operate at lower dimming settings or due to line-voltage fluctuation causing steep current spikes, can damage the LED light bulb and incandescent dimmer circuitry [31]. Some manufacturers modified their LED light bulbs to accommodate incandescent dimmers and provide a list of compatible dimmers on their website. More expensive dimmers designed specifically for LED light bulbs are also available. Two common types of LED dimmers use lowvoltage controls such as a variable resistor or a $0-10 \mathrm{VDC}$ controller to control the amount of current flowing through the LEDs. As suggested from the LED I-V curve in Figure 2-9, the LED brightness is dependent on the amount of current that flows through it. Analog dimming can vary the LED's current but have poor resolution. Voltage-controlled pulse width modulation (PWM) dimming offers more dimming resolution, thus leading to less flickering of the lights at 
lower shade settings. PWM dimming uses a variable resistor to adjust the amount of voltage (0-10VDC) sent to its electronic circuitry to pulsate the on and off time, thus varying the amount of current seen through the LED during each switching period (usually at a frequency two times greater than the line frequency).

\subsection{5: Summary of Lumination Technologies}

Oil, incandescent, CFL, and LED lighting methods will be summarized and compared based on efficacy, lifetime, color rendition index, color temperature, estimated cost, and dimmer capability. In conjunction to these comparisons, to better understand the various methods consumers and lighting manufactures evaluate the brightness of a product, such as a light bulb or a flashlight, a review of foot-candles, luminous flux per unit area (LUX), lumens, luminous efficacy, color rendition index, and color temperature will also be explained.

Foot-candles or LUX is a measure of the throw of the light, or a measure of how well it projects light at a particular spot some distances away [34]. Foot-candle or LUX is not a measurement of the lights overall brightness. Equation 2-1 describes the mathematical relationship between foot-candles and LUX.

$$
1 \text { foot }- \text { candle }=10.76391 L U X=10.76391 \frac{\mathrm{Lm}}{(\mathrm{m})^{2}}
$$

Figure 2-11 illustrates an example of two different flashlights with relatively the same amount of LUX (200 LUX versus 210 LUX) at the center spot some distances away. The top 
flashlight has a better overall brightness (lumens per area; $\mathrm{Lm} / \mathrm{m}^{2}$ ) compared the bottom flashlight with a narrower beam. Consumers often use a light meter to measure the amount of light (in foot-candles or LUX) produced from a given illumination source. However, lighting manufacturers often describe their product's brightness in terms of lumens.

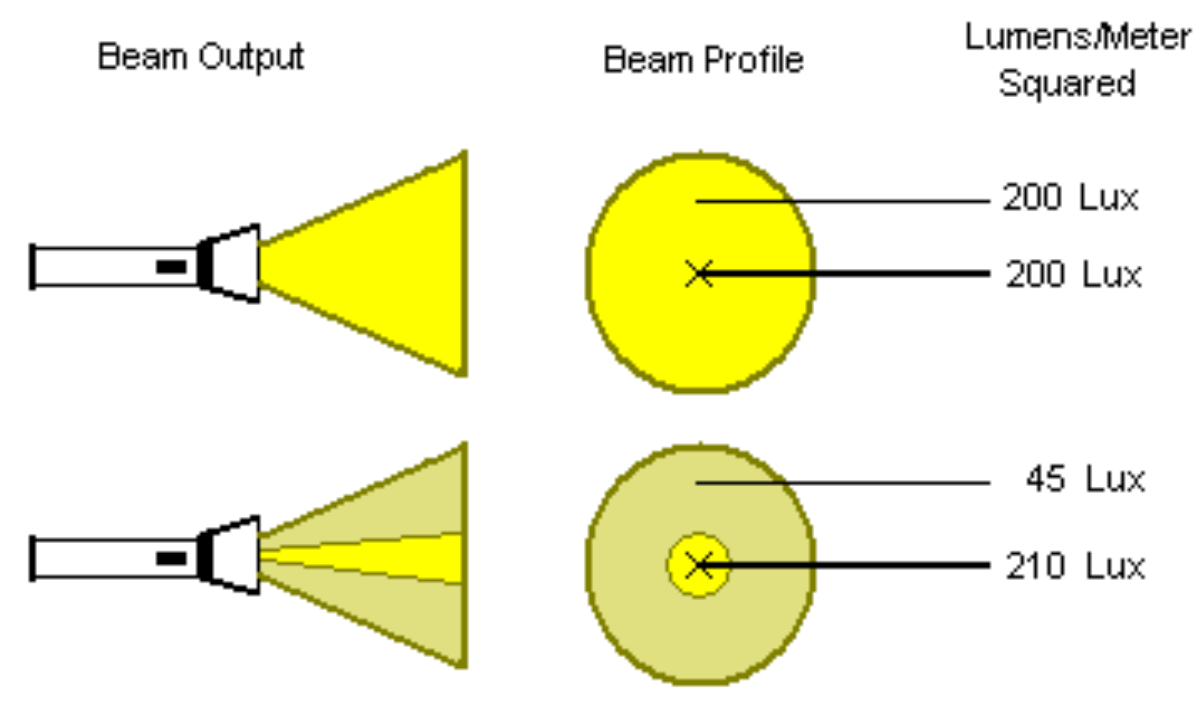

Figure 2-11: Two Flashlights With Relatively The Same Amount of LUX Some Distances Away [34].

Lumen is a measurement of the overall brightness per given area outputted by the light bulb or flashlight. When accounting for the overall brightness, the total surface area must be measured and calculated.

For example, if a room's dimension were 8 feet wide by 8 feet long by 8 feet high, then it would have a total surface area of $35.675 \mathrm{~m}^{2}$ (Equation 2-2). A consumer reads 1.95 footcandles from a light meter that is placed directly under the ceiling light bulb 8 feet away. Neglecting the height of the light bulb and the light bulb's base, this particular light bulb is then 
calculated to produce 748.8 lumens (Equation 2-3). Figure 2-12 illustrates this example and Figure 2-13 suggests that a standard A19 60W incandescent light bulb produces 780 lumens.

$$
\begin{aligned}
& A_{\text {room }}=6 *(8 f t . * 8 f t .)=384 \mathrm{ft}^{2} *\left(0.3048 \frac{\mathrm{m}}{\mathrm{ft} .}\right)^{2}=35.675 \mathrm{~m}^{2} \\
& \text { Room Lumens }=1.95 \text { foot }- \text { candle } * \frac{10.76391 \frac{\mathrm{Lm}}{\mathrm{m}^{2}}}{1 \text { foot-candle }} * 35.675 \mathrm{~m}^{2}=748.8 \mathrm{Lm}
\end{aligned}
$$

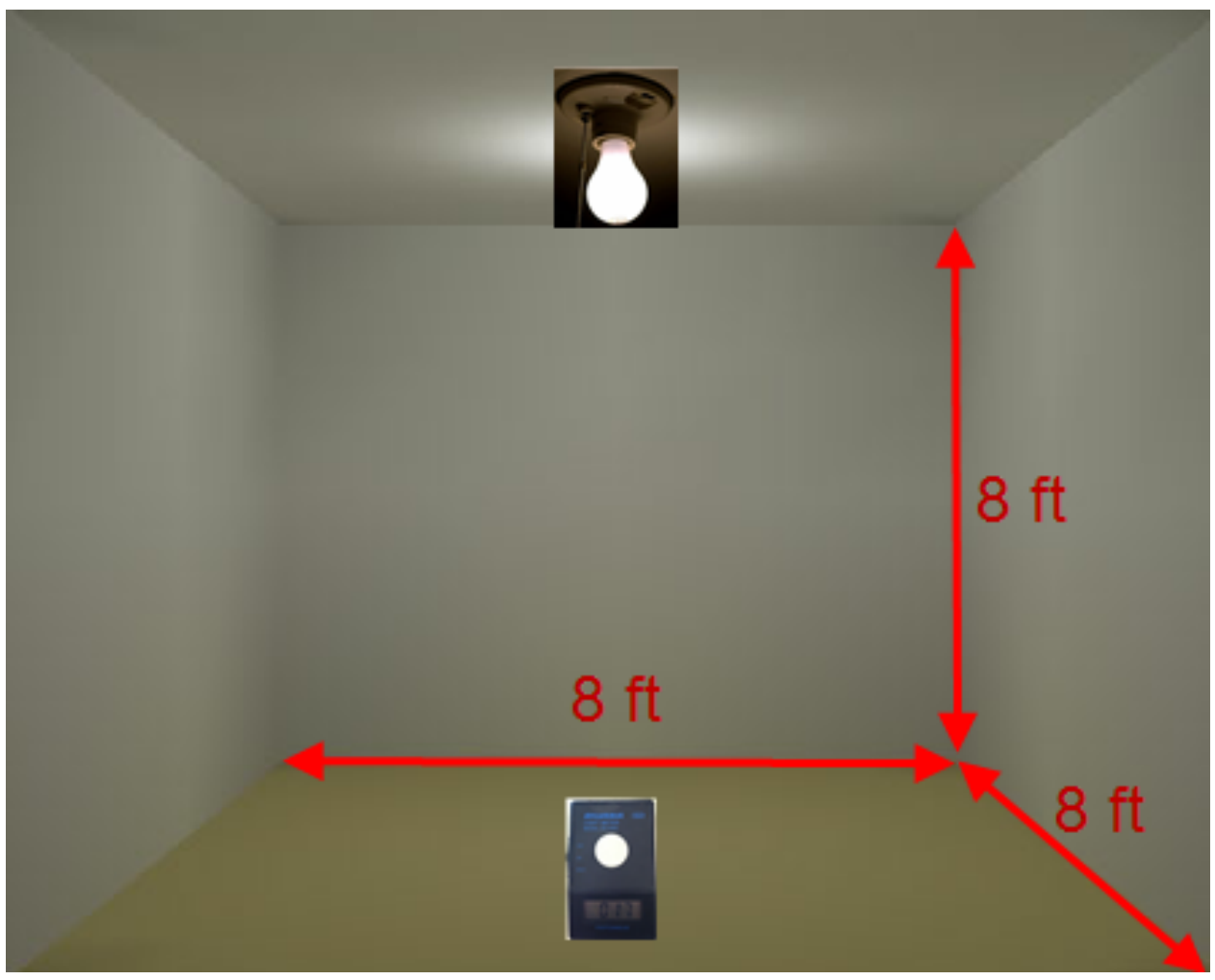

Figure 2-12: Example On How To Calculate Brightness In Lumens. 


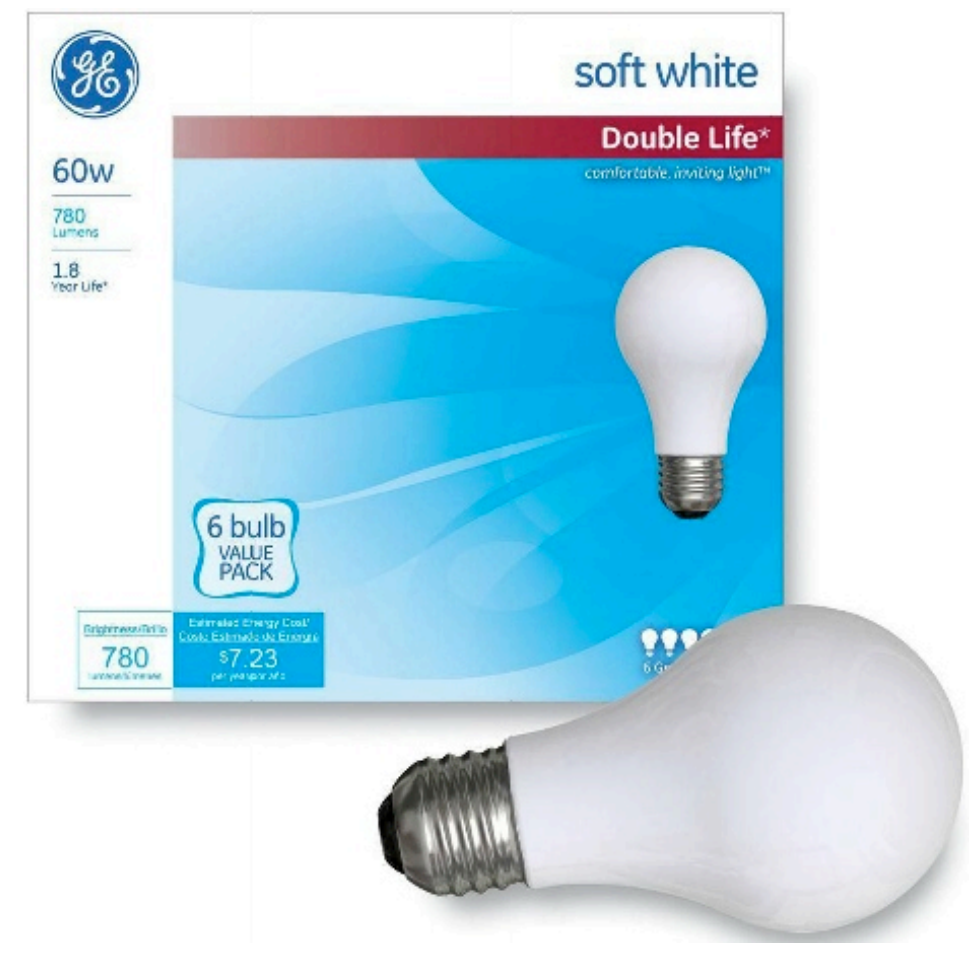

Figure 2-13: GE-60W A19 Incandescent Light Bulb: Brightness of 780 Lumens [35].

It is generally a pretty confusing process when trying to determine the amount of lighting required in a given room. A customer must consider variables such as room size, desired brightness, color temperature, and power consumption when trying to determine the right light bulb for his/her application. As the example presented previously, knowing footcandles or LUX does not directly determine the overall brightness (lumens) in the particular room dimensions. Designing for specific room brightness would require a few trial-and-error iterations. According to U.S Department of Energy, it is generally a rule-of-thumb to select a light bulb's brightness based on its rated lumens rather than on its power usage. Figure 2-14, suggests the typical amount of lumens that a standard CFL bulb would produce when compared to a traditional incandescent light bulb's wattage rating. 


\section{LUMENS: THE NEW WAY TO SHOP FOR LIGHT}

\section{Choose Your Next Light Bulb for the Brightness You Want.}

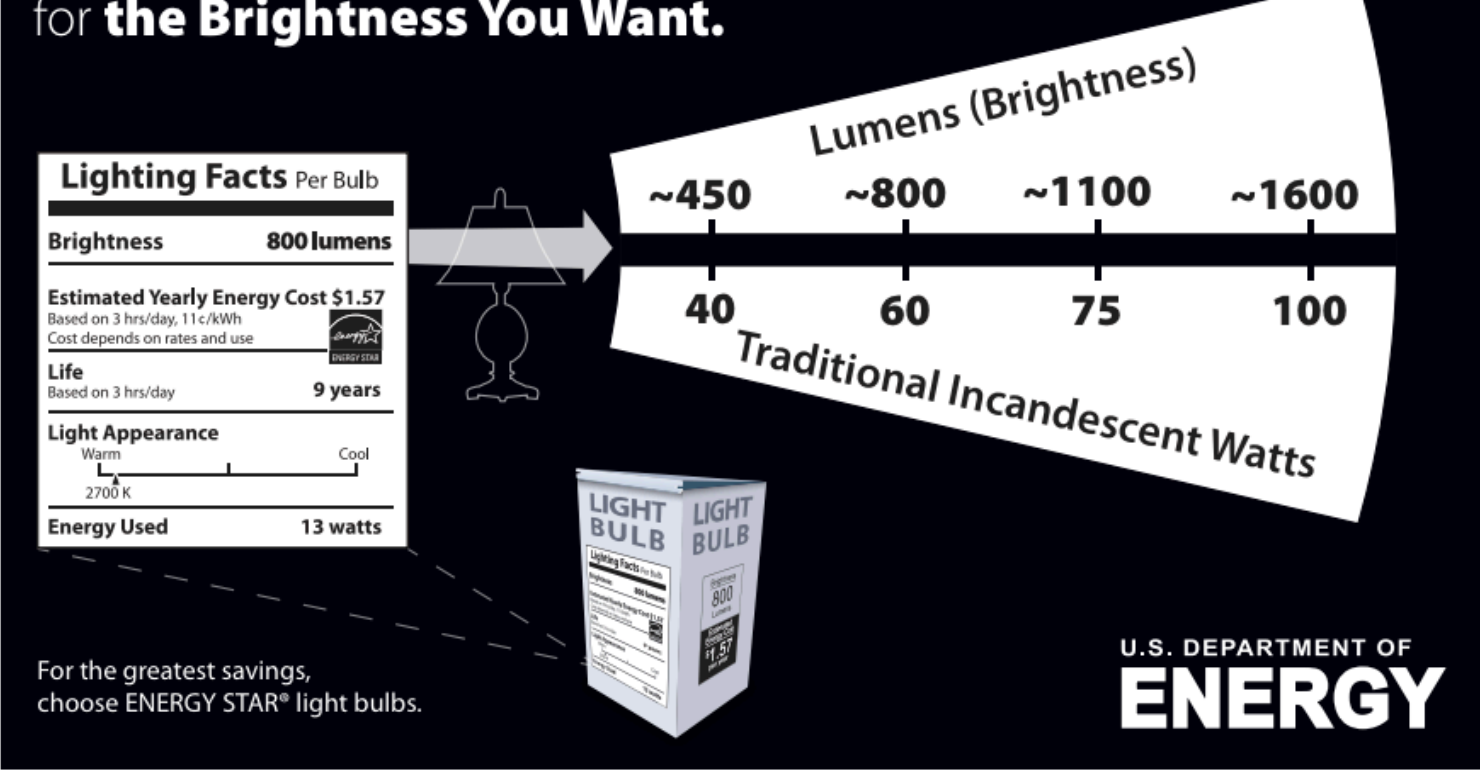

Figure 2-14: Selecting an Energy-Efficient CFL Bulb Based on Lumens Rather Than Watts [36].

Lighting manufactures have made LED based light bulbs to closely follow the same lumens profile of CFL bulbs. The brightness selection process shown in Figure 2-14 is somewhat still valid when using LED based light bulbs. However, with the constant advancements in LED technology, selecting the brightness of a LED light bulb, or a LED flashlight, or any high power LED application should not be based solely on the amount of lumens it can produce but also its luminous efficacy.

Luminous efficacy is a measure of how well a light source can produce light per given source power (lumens/watt). Figure 2-15 illustrates the projected trend of LED's efficacy proposed by U.S. Department of Energy. 


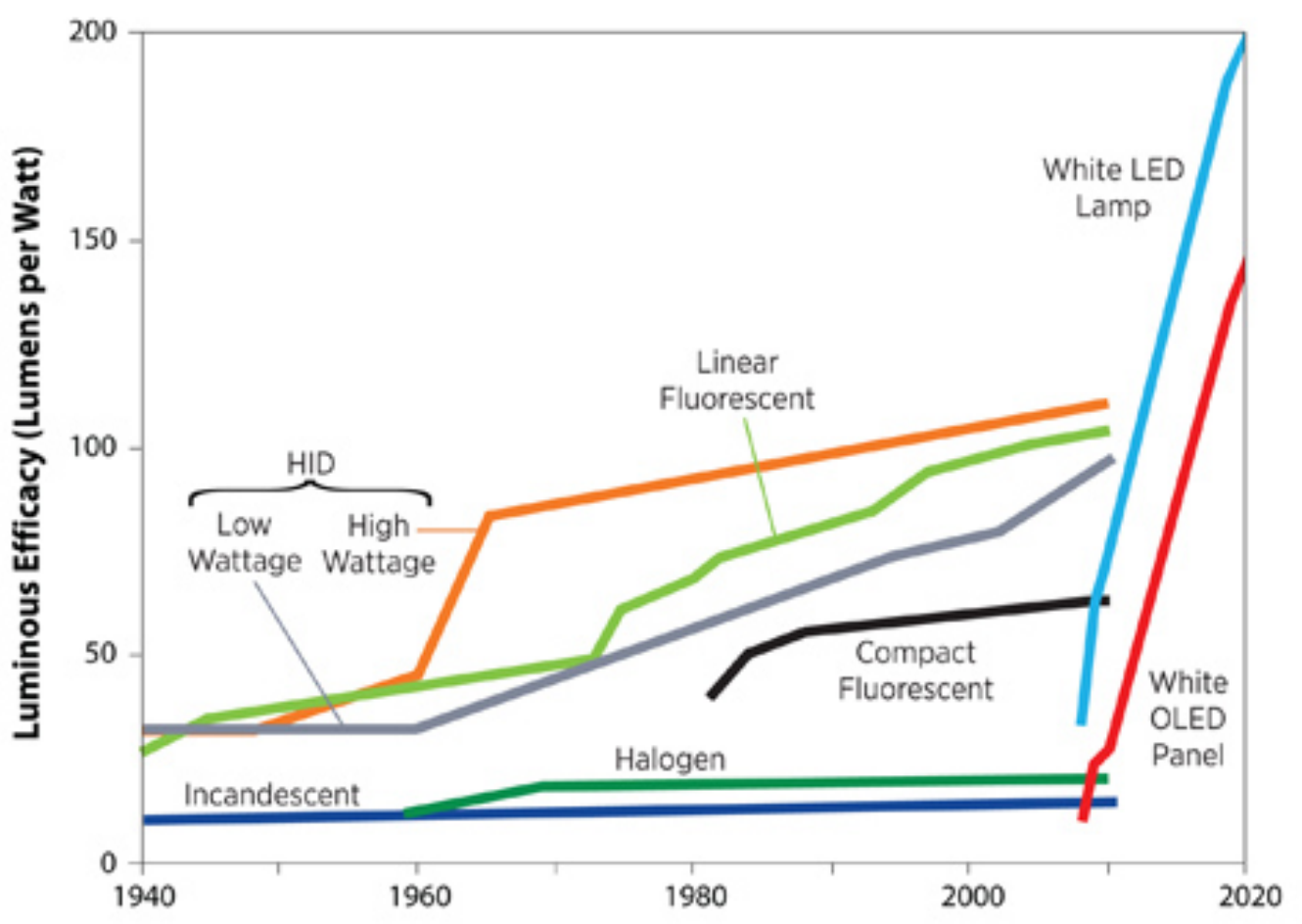

While traditional lighting technologies are relatively mature and offer

less potential for improvement, SSL is still at a comparatively early stage

and continues to achieve dramatic advances in efficacy.

Source: DOE SSL R\&D Multi-Year Program Plan

Figure 2-15: Projected Luminous Efficacy of Solid-State Lighting [36].

As Figure 2-15 suggests, LED's brightness to power requirement ratio will improve almost linearly by the year 2020. This means LEDs will continue to get brighter and brighter at lower supply power requirements.

Next, color rendition index (CRI) and the color temperature scale are explained. CRI is the measure of how well an artificial light source is able to render the colors of skin tones, objects, and materials, when compared to a reference illuminant [37]. According to ENERGY STAR compliances, CRI is scaled with reference to an incandescent light source (or a candle 
flame) [38]. CRI is scaled from 0 to 100 . A score of $100 \mathrm{CRI}$ would produce the most accurate incandescent (yellowish hue) color replication. Typically, warm to cool white fluorescent light bulbs such as CFLs produces fair to good color rendering with a CRI score of 50-70. Due to the various inorganic semiconductor materials and phosphors tinting methods in altering the color wavelength in LEDs, they have a slightly better CRI scores ranging from $70-90$.

\begin{tabular}{|c|c|c|}
\hline $\begin{array}{l}\text { Degrees } \\
\text { Kelvin }\end{array}$ & $\begin{array}{l}\text { Type of } \\
\text { Light Source }\end{array}$ & $\begin{array}{l}\text { Indoor ( } 3200 k) \text { Outdoor }(5500 k) \\
\text { Color Balance Color Balance }\end{array}$ \\
\hline 1700-1800K & Match Flame & \\
\hline 1850-1930K & Candle Flame & \\
\hline $2000-3000 \mathrm{~K}$ & Sun: At Sunrise or Sunset & \\
\hline $2500-2900 \mathrm{~K}$ & Household Tungsten Bulbs & \\
\hline $3000 \mathrm{~K}$ & Tungsten lamp 500W-1k & \\
\hline $3200-3500 \mathrm{~K}$ & Quartz Lights & \\
\hline $3200-7500 \mathrm{~K}$ & Fluorescent Lights & \\
\hline $3275 \mathrm{~K}$ & Tungsten Lamp 2k & \\
\hline $3380 \mathrm{~K}$ & Tungsten Lamp 5k, 10k & \\
\hline $5000-5400 \mathrm{~K}$ & Sun: Direct at Noon & \\
\hline $5500-6500 \mathrm{~K}$ & Daylight (Sun + Sky) & \\
\hline $5500-6500 \mathrm{~K}$ & Sun: through clouds/haze & \\
\hline $6000-7500 \mathrm{~K}$ & Sky: Overcast & \\
\hline $6500 \mathrm{~K}$ & RGB Monitor (White Pt.) & \\
\hline $7000-8000 \mathrm{~K}$ & Outdoor Shade Areas & \\
\hline $8000-10000 \mathrm{~K}$ & Sky: Partly Cloudy & \\
\hline
\end{tabular}

Figure 2-16: Color Temperature Spectrum [33].

Lastly, the color temperature scale is a measure of the hue when compared to an ideal blackbody radiator. Color temperature is often expressed in terms of absolute temperature or kelvins (K). Depending on the referencing lighting source such as the brightness of a standard incandescent light bulb indoors or the brightness of a candle's flame outdoors, the color temperature will change slightly. For example, a CFL may be rated as having a cool white color 
of $3200 \mathrm{~K}$ but it appears to be more yellow in color. As suggested earlier, selecting the desired brightness is often a tricky process that requires multiple trial and error attempts.

A summary comparing typical luminous efficacy, lifetime, CRI, color temperature, cost, and dimming compatibility for oil, incandescent, CFL, and LED is presented in Table 2-1. Lighting by oil lamps and candles offer the best color reproduction but suffers on luminous efficacy (brightness output) and no dimmability. Lighting by incandescent light bulbs have been around the longest, thus its relative cheap price. It has great CRI and good light controllability via a TRIAC dimmer, but its operating lifetime is very poor, often requiring replacements after $750-2500$ hours or about every three months. Lighting by florescent lamps, such as CFL is ENERGY STAR's recommended lighting method today. It offers much higher luminous efficacy between $50-70 \mathrm{Lm} / \mathrm{W}$ and almost five times longer runtime $(10,000$ hours $)$ when compared to incandescent light bulbs. However, its CRI score $(65-88)$ is fair and estimated cost $(\$ 6.50)$ per bulb is around 20 times more than an equivalent incandescent light bulb $(\$ 0.35)$. CFL's dimmer capability causes flickering when using lower quality dimmers compatible with incandescent lamps. Lastly, LED lamps offer the best luminous efficacy, great CRI, and extremely long runtime $(25,000-50,000$ or about 5.7 years $)$, but relatively expensive ranging from $\$ 10-\$ 150$. 
Table 2-1: Comparison Summary of Oil, Incandescent, CFL, and LED Lighting Technologies

\begin{tabular}{|c|c|c|c|c|c|c|c|}
\hline $\begin{array}{l}\text { Lighting } \\
\text { Type }\end{array}$ & $\begin{array}{l}\text { Lighting } \\
\text { Size }\end{array}$ & $\begin{array}{c}\text { Luminous } \\
\text { Efficacy } \\
\text { (Lumens/Watt) }\end{array}$ & $\begin{array}{r}\text { Lifetime } \\
\text { (hours) }\end{array}$ & $\begin{array}{l}\text { Color } \\
\text { Rendition } \\
\text { Index } \\
\text { (CRI) }\end{array}$ & $\begin{array}{c}\text { Color } \\
\text { Temperature } \\
\text { (K) } \\
\end{array}$ & $\begin{array}{c}\text { Est. Cost } \\
\text { per Bulb } \\
\text { (\$) }\end{array}$ & $\begin{array}{c}\text { Dimmer } \\
\text { Capability }\end{array}$ \\
\hline \multirow[t]{2}{*}{ Oil Lamp } & Oil & 0.16 & $\begin{array}{c}0-6 \\
\text { (varies) }\end{array}$ & $\begin{array}{c}100 \\
\text { (excellent) }\end{array}$ & $\begin{array}{c}1000-1700 \\
\text { (yellow) }\end{array}$ & $\begin{array}{c}\$ 4.99- \\
\$ 300 \\
\text { (basic to } \\
\text { decorative } \\
\text { style) }\end{array}$ & No \\
\hline & Candle & 0.3 & $\begin{array}{c}0-6 \\
\text { (varies) }\end{array}$ & $\begin{array}{c}100 \\
\text { (excellent) }\end{array}$ & $\begin{array}{c}1000-1700 \\
\text { (yellow) }\end{array}$ & $\begin{array}{c}\$ 1.00- \\
\$ 60.00 \\
\text { (basic to } \\
\text { scented) }\end{array}$ & No \\
\hline \multirow[t]{3}{*}{ Incandescent } & A19 & $10-17$ & $\begin{array}{l}750- \\
2500\end{array}$ & $\begin{array}{c}98-100 \\
\text { (excellent) }\end{array}$ & $\begin{array}{c}(2700-2800 \\
(\text { warm) }\end{array}$ & $\$ 0.35$ & Yes \\
\hline & Halogen & $10-22$ & $\begin{array}{l}1000- \\
4000\end{array}$ & $\begin{array}{c}98-100 \\
\text { (excellent) }\end{array}$ & $\begin{array}{c}2900-3200 \\
\text { (warm to } \\
\text { neutral) }\end{array}$ & $\begin{array}{l}\$ 0.65- \\
\$ 2.00\end{array}$ & Yes \\
\hline & Reflector & $12-19$ & $\begin{array}{c}2000- \\
3000\end{array}$ & $\begin{array}{c}98-100 \\
\text { (excellent) }\end{array}$ & 2800 (warm) & $\begin{array}{l}\$ 1.00- \\
\$ 45.00\end{array}$ & Yes \\
\hline CFL & A19 & $50-70$ & 10000 & $\begin{array}{c}65-88 \text { (fair } \\
\text { to good) }\end{array}$ & $\begin{array}{c}2700-6500 \\
\text { (warm to } \\
\text { cool) }\end{array}$ & $\begin{array}{c}\$ 5.00- \\
\$ 8.00\end{array}$ & $\begin{array}{l}\text { Yes (may } \\
\text { flicker) }\end{array}$ \\
\hline \multirow[t]{3}{*}{ LED } & A19 & 64 & $\begin{array}{c}25000- \\
50000\end{array}$ & $\begin{array}{l}80-85 \\
\text { (good) }\end{array}$ & $\begin{array}{c}3000 \\
\text { (neutral) }\end{array}$ & $\begin{array}{l}\$ 10.00- \\
\$ 150.00\end{array}$ & $\begin{array}{c}\text { Yes } \\
\text { (PWM) }\end{array}$ \\
\hline & $\begin{array}{l}\text { Warm } \\
\text { White } \\
\text { Package }\end{array}$ & $27-54$ & $\begin{array}{c}25000- \\
50000\end{array}$ & $\begin{array}{c}70-90 \text { (fair } \\
\text { to good) }\end{array}$ & $\begin{array}{c}3300 \\
\text { (neutral) }\end{array}$ & $\begin{array}{l}\$ 10.00- \\
\$ 150.00\end{array}$ & $\begin{array}{c}\text { Yes } \\
\text { (PWM) }\end{array}$ \\
\hline & $\begin{array}{c}\text { Cool } \\
\text { White } \\
\text { Package }\end{array}$ & $60-92$ & $\begin{array}{c}25000- \\
50000\end{array}$ & $\begin{array}{c}\text { 70-90 (fair } \\
\text { to good) }\end{array}$ & 5000 (cool) & $\begin{array}{l}\$ 10.00- \\
\$ 150.00\end{array}$ & $\begin{array}{c}\text { Yes } \\
\text { (PWM) }\end{array}$ \\
\hline
\end{tabular}




\section{3 : Making the Case for LED Lighting}

LED lighting technology is the latest trend in lumination applications. As Figure 2-15 suggests White LED lamp is expected to reach $200 \mathrm{Lm} / \mathrm{W}$ by the year 2020. As of April 2012, Cree sets the best R\&D LED performance record with 254 Lm/W [39]. The U.S. Department of Energy suggests,

"It is estimated that switching to LED lighting over the next two decades could save the country \$250 billion in energy costs over that period, reduce the electricity consumption for lighting by nearly one half, and avoid 1,800 million metric tons of carbon emission. DOE is not alone in recognizing the importance of that kind of savings; Congress recognizes it too, which is why the Energy Policy Act of 2005 mandates DOE to accelerate SSL (solid-state lighting) technology" [36].

In an independent study presented to the U.S. Department of Energy, it is suggested that in 2010, LED lighting applications alone influenced 3.9 TWh/year in electricity savings, also shown in Figure 2-17 [40].

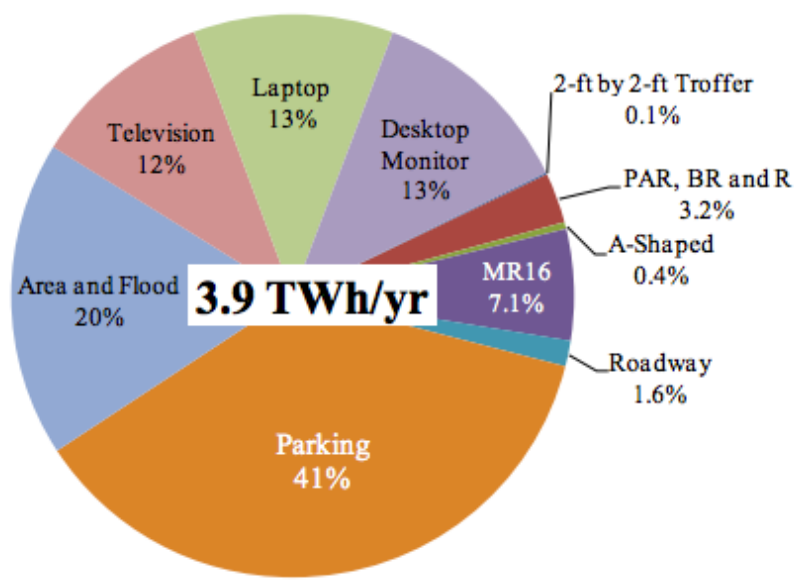

Figure 2-17: U.S. Site Electricity Savings in 2010 From LED Market Penetration [40]. 
Despite the current market's high cost in LED lamps, the expected cost per lumens would fall by a factor of 10 every decade and the amount of lumens per watt would increase by a factor of 20, also shown in Figure 2-18 [41].

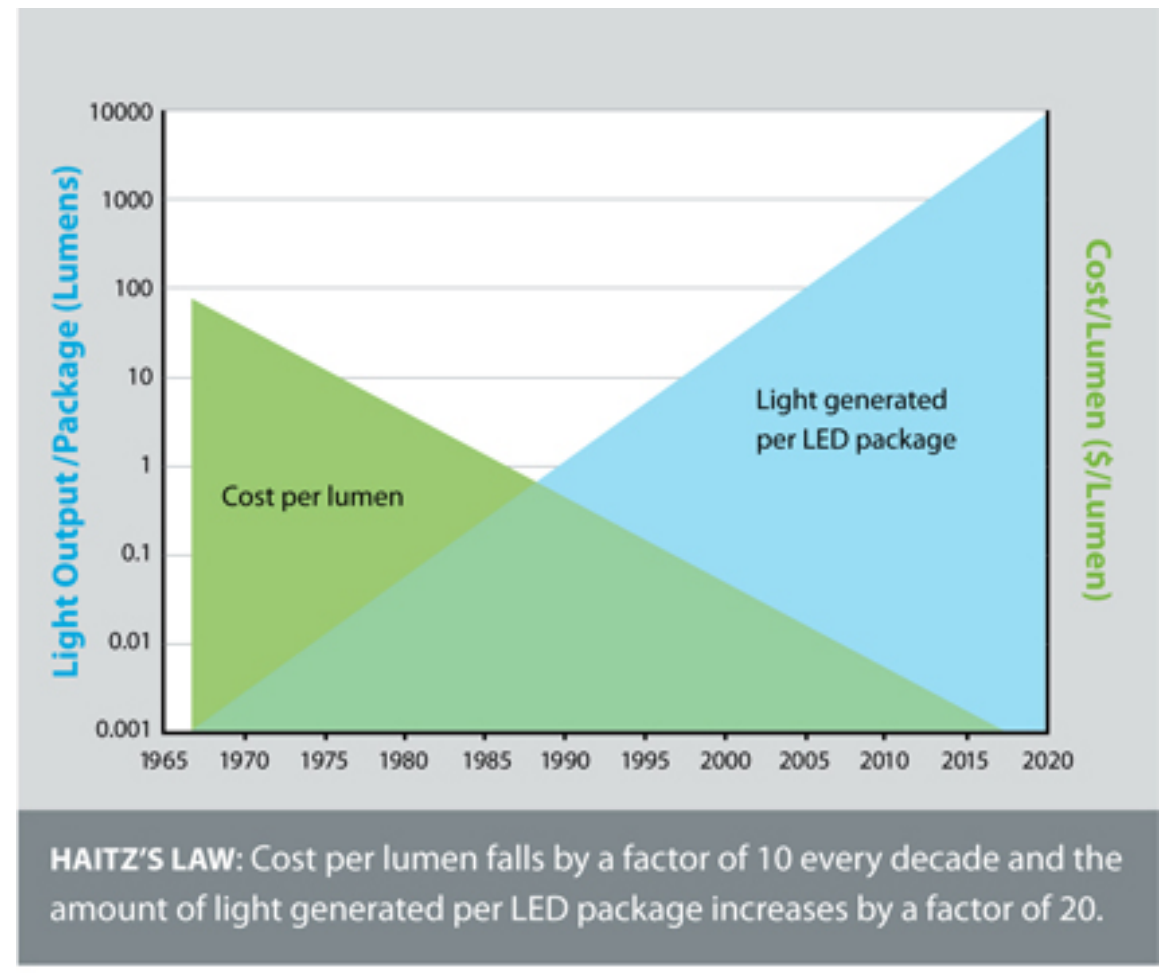

Source: DOE SSL Multiyear Program Plan

Figure 2-18: DOE's Projected LED Cost Per Lumens [41].

The huge potential energy savings from solid-state LED lighting is very apparent and its price point per bulb would eventually decrease. As suggested earlier, DOE estimates that \$250 billion dollars could be saved in the next two decades if LED lighting is fully integrated into the U.S. economy. This also triggered congress to pass the Energy Policy Act in 2005 in an attempt to speed up the advancements in LED technology. The independent study presented to the DOE suggests that if LED lighting was full saturated into the U.S. market a saving of 263 
TWh/year could have been seen [40]. The staggering cost savings and luminous efficacy performance of LED technology will only improve over time.

\section{4 : $\quad$ Availability of A19 LED DC Light Bulb}

In this section, a look at the availability of standard " $A$ " (A19) direct current LED light bulbs will be reviewed. Since the DC House Project operates off of purely DC generated power, it would be appropriate to design a lighting system that does not involve inverting (DC - AC) and then selecting a $\mathrm{AC}$ rated light bulb, where its internal electronics would rectify the $\mathrm{AC}$ to high frequency $D C$ to power the LED array. Eliminating the $D C-A C$ and $A C-D C$ electronics would save on overall DC Light Bulb design time, prototype cost, PCB space requirement, number of components required, and overall packaging size.

Since majority of U.S. lighting market is tailored toward populated urban cities where consumers have access to the AC electrical grid, the availability of equivalent DC lighting systems are scarce due to low demand and implementation. The trend of AC system lighting technologies have evolved from incandescent to CFL to LED lighting, while maintaining the U.S. standard A19 bulb size with a medium base (E26 - U.S. standard Edison screw base). This practice is not true for DC systems. The major market for DC systems is in the auto industry, where the car's battery runs off of 12 VDC. Standard car light bulb sizes are incompatible with the traditional AC base A19 light bulb size. The slow adoption in renewable energy methods such as photovoltaic (PV) power generation creates a small demand for DC lighting systems. 
Typical solar panels have a rated efficiency around $11-15 \%$ [42]. Figure 2-19 suggests that a 500W PV system with solar panel efficiency of $12 \%$ would require $50 \mathrm{ft}^{2}$ of roof area, or a roof space of 7 feet by 7 feet [43].

\begin{tabular}{|c|c|c|c|c|c|c|c|}
\hline \multicolumn{8}{|c|}{ Roof Area Needed in Square Feet (shown in Bold Type) } \\
\hline $\begin{array}{c}\text { PV Module } \\
\text { Efficiency (\%) }\end{array}$ & \multicolumn{7}{|c|}{ PV Capacity Rating (Watts) } \\
\hline & 100 & 250 & 500 & 1,000 & 2,000 & 4,000 & 10,000 \\
\hline 4 & 30 & 75 & 150 & 300 & 600 & $\mathbf{1 , 2 0 0}$ & 3,000 \\
\hline 8 & 15 & 38 & 75 & 150 & 300 & 600 & $\mathbf{1 , 5 0 0}$ \\
\hline 12 & 10 & 25 & $\mathbf{5 0}$ & 100 & 200 & 400 & $\mathbf{1 , 0 0 0}$ \\
\hline 16 & 8 & 20 & 40 & 80 & 160 & 320 & 800 \\
\hline
\end{tabular}

Figure 2-19: Recommended Roof Space Requirement Per PV Power Rating and Efficiency [43].

Typically, PV systems have a voltage bus of 12 VDC and have optional battery storage systems that operate at 12 VDC or 24 VDC. For this particular reason, the lighting industry is slowly introducing 12 VDC light bulbs using the traditional A19 bulb dimension. For example, Unlimited Solar Inc. offers a non-dimmable A19 12 VDC 5.6W LED light bulb that outputs a cool white (5000K) color at 400 lumens, also shown in Figure 2-20 [44]. 


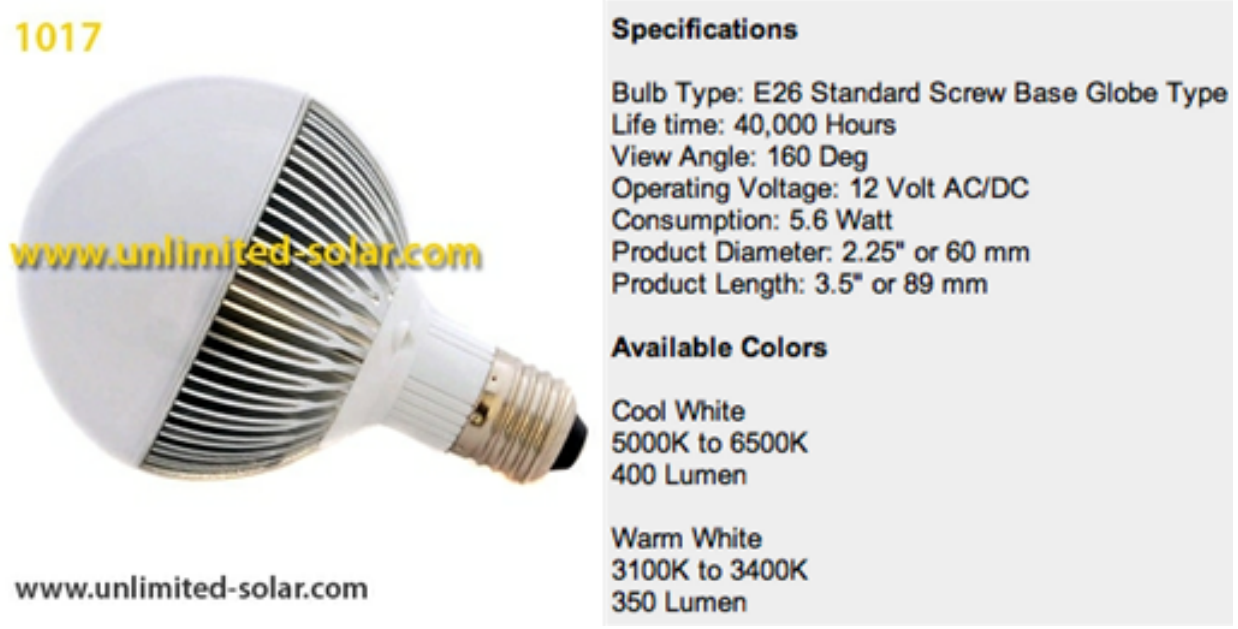

Figure 2-20: Unlimited Solar Inc. A19 12 VDC 5.6W LED Light Bulb [44].

The limited availability of DC ready light bulbs in the standard A19 size offers opportunity for research and development in creating a new DC Light Bulb design. It would be beneficial to design a universal light bulb that accepts a wider input DC voltage range, offers higher efficacy (Lm/W), greater brightness coverage (lumens), dimming ability, low power consumption, relatively low cost, and most importantly retains the standard A19 light bulb size using a medium base. In the next chapter, a DC Light Bulb design will be presented. 


\section{Chapter 3: Design Requirements}

In the following sections, a DC Light Bulb's design requirements for the DC House project will be presented. As mentioned in the previous chapter, due to limited market selection A19 DC light bulbs creates opportunities for research and development in designing more energy efficient and brighter lumination systems, while attempting to retain the traditional A19 incandescent light bulbs form factor. The new DC Light Bulb should attempt to accommodate a wide input voltage range, while remaining energy efficient. Some common bus voltages generated from renewable generation techniques are 12 VDC, 24 VDC, 48 VDC, and 72 VDC. The lighting system design should also be dimmable and be relatively inexpensive. The proposed DC Light Bulb will be designed based on electrical, lumination, size, and construction constraints.

\section{1 : Electrical Design Constraints}

The DC House Project is designed to be a self-sustaining DC powered ready-home that can meet the electrical needs to power the home's lighting system and appliances such as a fan, a radio, a small electric stove, and a mini refrigerator. Previous DC load flow studies indicate that the DC House operates best at 48 VDC when the home is supplied with roughly 500W from renewable generation sources such as photovoltaic power, hydropower, wind power, and 
human power generation [45] [49]. At the bare minimum the DC Light Bulb should be able to operate at 48 VDC.

Target performance specifications for the DC Light Bulb includes efficiencies greater than $80 \%$, line regulation less than $5 \%$ when there is $\pm 15 \%$ fluctuations from the source voltage, and low power consumption. The desired $80 \%$ efficiency is within reason, when compared to typical DC - DC converters that achieves efficiencies between $78-92 \%$ [46]. Line regulation is a measure of a power converter's ability to maintain the specified output voltage even when the input source voltage fluctuates. As illustrated earlier in Figure 2-9 (I - V curve of a diode or LED) the current can exponentially increase when a small forward voltage is applied. If a DC - DC converter is unable to maintain line regulation and it is driving a LED array at its output, immediate LED failure will occur. The overall lighting system load on any given branch should not exceed the maximum indoor luminaire rating of $21 \mathrm{~W}$ or the maximum outdoor luminaire rating of $30 \mathrm{~W}$ as suggested from previous DC load flow analysis for the DC House [45]. For example, if the DC Light Bulb's total power consumption is $10 \mathrm{~W}$, then only two DC Light Bulbs can be placed in series for indoor lighting. This also means that three DC Light Bulb can be placed in series for outdoor luminaire. In the next section, the lumination design goals will be addressed. 


\section{2: Lumination Design Constraints}

From the staggering advancements in solid-stage lighting technology, in particular white LED's efficacy (Lm/W) ratios (as suggested in Figure 2-15), the DC Light Bulb design should take advantage of this to develop a lighting system that maintains low power consumption [36]. Figure 2-15 suggests that in 2010, about 75 lumens/watt was obtained. This luminous efficacy is used as a baseline in designing the DC Light Bulb's LED array. To gauge the desired total lumination, the suggested rule-of-thumb sizing process comparing total lumens versus power rating of a reference incandescent light bulb presented in Figure 2-14 should be used. Figure 214 suggests a $60 \mathrm{~W}$ incandescent light bulb produces about 800 lumens. Since the total amount of light (lumens) that fills a room is also dependent on the total surface area of the room, the ability to adjust the brightness level can alleviate some of the guesswork in determining the appropriate lighting intensity required for task such as cooking (high brightness), reading (moderate brightness), or watching a movie (low brightness). Therefore, the DC Light Bulb design should incorporate a slide dimmer that allows the user to adjust the brightness level needed for any particular task.

In an independent study evaluating 33 office workers ability to perform routine office task such as reading documents placed horizontally on the desk, inputting data viewed on a computer screen, or taking notes while on the phone were evaluated under different lighting conditions. It was found that the workers performed best when there was sufficient lighting to make their surrounding environment appear clear and crisp. The result of the study, suggests that acuity slowly decays with age and recommends color temperatures ranging from 5000K- 
5900K to produce optimum clarity, productivity, and comfort throughout a normal work day [46]. Therefore, the DC Light Bulb should output a cool white color temperature between 5000K - 5900K. In the next section, physical design of the DC Light Bulb will be defined.

\section{3 : Physical Design Constraints}

As technology progressed from incandescent to CFL and to LED light bulbs for AC powered systems, the trend in keeping the standard " $A$ " (or A19) size remained consistent. The traditional A19 size has been around since Thomas Edison filed his patent on a practical incandescent lamp in 1878 [14]. With over one hundred years in consistency using the A19 light bulb size and United State's standard E26 screw base (also called medium base), the availability of lamps, shades, and fixtures using this size must be immense. To keep with this trend, the DC Light Bulb should also have a similar form factor of a standard " $\mathrm{A}$ " light bulb using a medium base. Figure 3-1 suggests the dimensions of a standard A19 light bulb with an E26 screw base. 


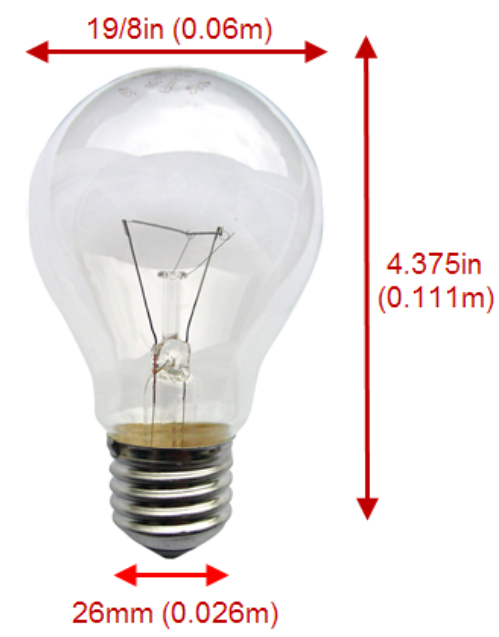

Figure 3-1: Standard A19 Light Bulb and E26 Screw Base Dimensions.

The slide dimmer should fit into a standard outlet/switch box. There should also be a wall plate to hold the custom slide dimmer circuitry. Figure 3-2 illustrates the custom slide dimmer enclosure's outlet box and wall plate dimensions. Construction constraints are addressed in the next section.

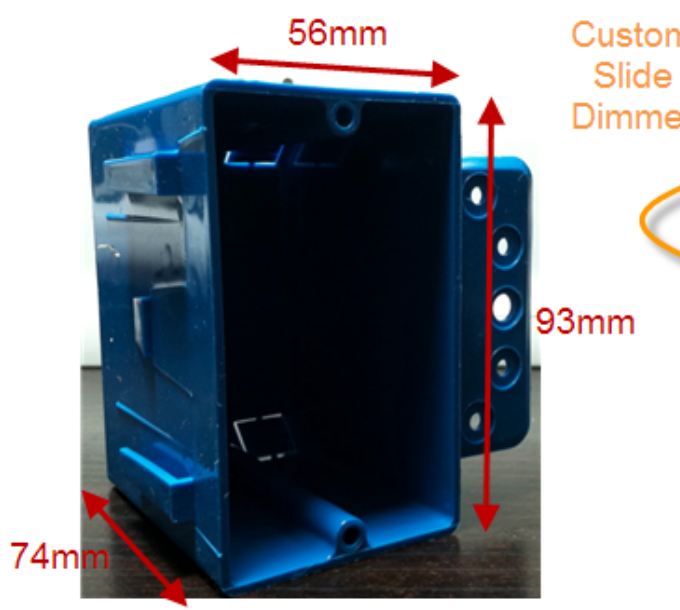

Switch Box

a)

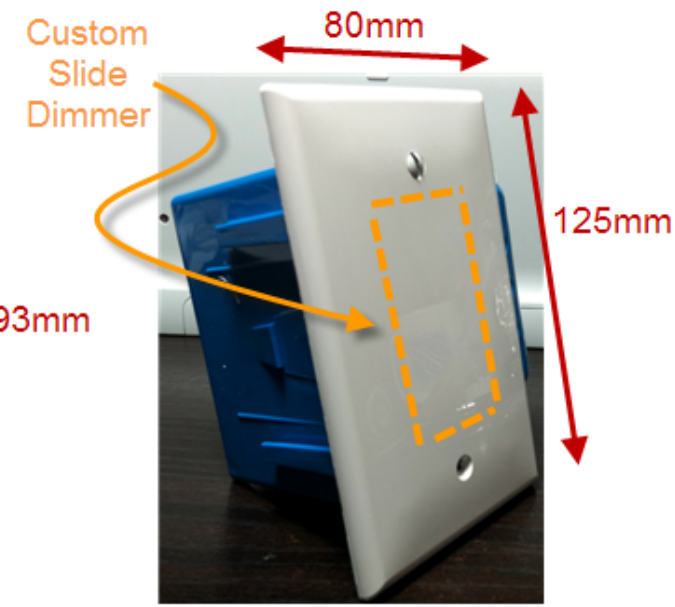

Switch Box w/ Wall Plate

b)

Figure 3-2: Custom Slide Dimmer Enclosure, a) Switch Box, b) Switch Box With Wall Plate. 


\section{4 : Construction Constraints}

The DC Light Bulb should follow the safe installation of electrical wiring and equipment installation standards suggested by the National Fire Protection Association (NFPA 70), in particular the most current National Electrical Code, NEC 2011 [50]. The complete DC Light Bulb system (light bulb and dimmer box) should be easy to install with minimal skill required. Wiring between the main bus voltage, the DC Light Bulb, and to the dimmer box should be color coded and uses simple quick connects, such as the luminaire disconnects shown in Figure 3-3 [51].

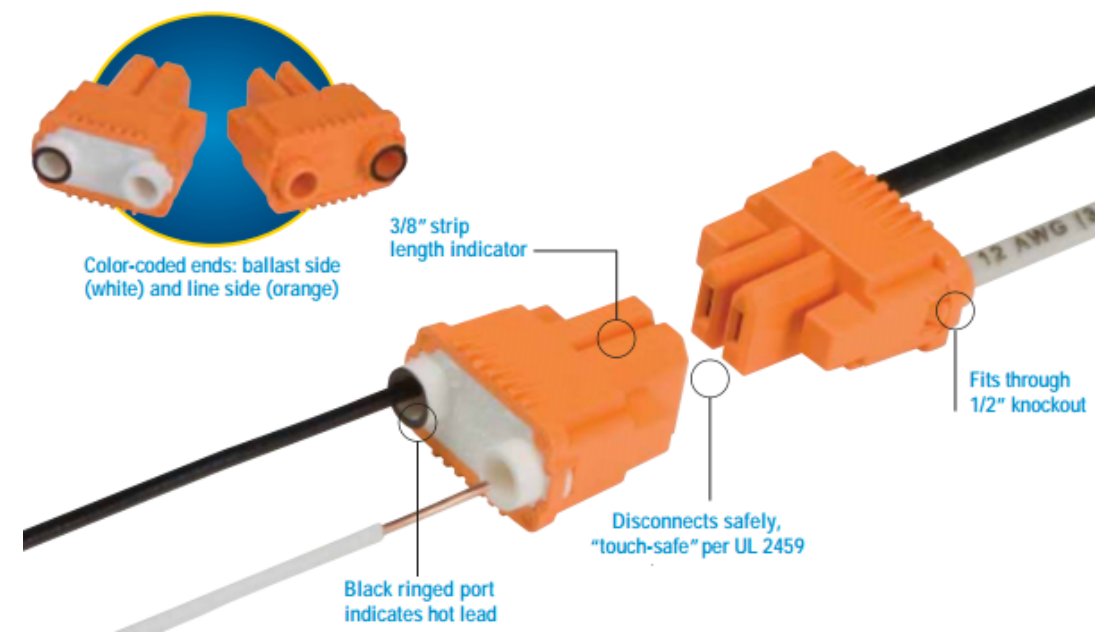

Figure 3-3: PowerPlug Luminaire Disconnect Plugs [51]. 


\section{5 : Prototype Cost Constraints}

Currently there is no DC light bulb available on the market that accepts a wide input DC voltage that range from 12 VDC - 72 VDC. Despite the availability of 12 VDC light bulbs, they do not provide sufficient lumens and are not dimmable [44]. Since the DC Light Bulb presented in this thesis will be the first prototype, a reasonable cost of $\$ 100-\$ 200$ seems appropriate. This cost should cover all electrical components, custom PCB board design and manufacturing, wires, and a custom dimmer required per DC Light Bulb design.

\section{6 : Summary of Design Requirements}

A summary of the DC Light Bulb's electrical, lumination, physical, prototype cost, and construction design constraints presented in Sections 3.1-3.5 is provided in Table 3-1. A brief description supporting each specification is also provided in Table 3-1. 
Table 3-1: DC Light Bulb Design Requirements.

\begin{tabular}{|c|c|c|c|}
\hline & & Design Requirements & Justification \\
\hline \multirow[t]{5}{*}{ Electrical } & 1 & $\begin{array}{l}\text { DC Light Bulb must operate at Vin }=48 \\
\text { VDC }\end{array}$ & $\begin{array}{l}\text { Previous DC load flow study suggests the DC House } \\
\text { operates best at } 48 \text { VDC when supplied with } 500 \text { W } \\
\text { from renewable generation [45] [49]. }\end{array}$ \\
\hline & 2 & $\begin{array}{l}\text { DC Light Bulb should operate between } \\
12 \text { VDC }<\text { Vin }<72 \text { VDC }\end{array}$ & Common renewable generation supply voltages. \\
\hline & 3 & Have efficiency $>80 \%$ & $\begin{array}{l}\text { Typical DC - DC converter can achieve efficiencies } \\
\text { of } 78 \%-92 \%[46] .\end{array}$ \\
\hline & 4 & $\begin{array}{l}\text { Have line regulation }<5 \% @ \pm 15 \% \\
\text { Input DC Voltage fluctuation }\end{array}$ & $\begin{array}{l}\text { A DC - DC converter with poor line regulation } \\
\text { driving a LED array will be damaged. Small change } \\
\text { in forward-voltage generates an exponential } \\
\text { change in current across a LED [Figure 2-9]. }\end{array}$ \\
\hline & 5 & DC Light Bulb should not exceed $20 \mathrm{~W}$ & $\begin{array}{l}\text { Previous DC load flow study suggest maximum } \\
\text { indoor luminaire }=21 \mathrm{~W} \text { and outdoor luminaire }= \\
30 \mathrm{~W}[45] \text {. }\end{array}$ \\
\hline \multirow[t]{4}{*}{ Lumination } & 6 & $\begin{array}{l}\text { Have luminous efficacy }>75 \\
\text { lumens/watt }\end{array}$ & $\begin{array}{l}\text { Projected luminous efficacy of solid-state lighting in } \\
2010 \text { is about } 75 \text { lumens/watt [Figure 2-15]. }\end{array}$ \\
\hline & 7 & Have brightness $>800$ lumens & $\begin{array}{l}\text { A } 60 \mathrm{~W} \text { incandescent light bulb produces about } 800 \\
\text { lumens [Figure 2-14]. }\end{array}$ \\
\hline & & $\begin{array}{l}\text { Brightness must be adjustable from } 0 \text { - } \\
800+\text { lumens via dimmer circuit }\end{array}$ & $\begin{array}{l}\text { A dimmer can alleviate some guesswork from } \\
\text { determining the desired brightness level required } \\
\text { during cooking, reading, or watching a movie. }\end{array}$ \\
\hline & 8 & $\begin{array}{l}\text { Have a cool white color temperature of } \\
5000 \mathrm{~K}-5900 \mathrm{~K}\end{array}$ & $\begin{array}{l}\text { Independent study indicates a color temperature of } \\
5000 \mathrm{~K}-5900 \mathrm{~K} \text { is ideal for optimum clarity, } \\
\text { productivity, and comfort throughout a normal } \\
\text { work day [46]. }\end{array}$ \\
\hline \multirow[t]{2}{*}{ Physical } & 9 & $\begin{array}{l}\text { DC Light Bulb design must retain } \\
\text { standard A19 light bulb and E26 screw } \\
\text { base dimensions }\end{array}$ & $\begin{array}{l}\text { Technology progressed from incandescent, to CFL, } \\
\text { and to LED light bulbs, but the trend was to } \\
\text { maintain the standard A19 and E26 dimensions. } \\
\text { Over } 100 \text { years of lamps, shades, and fixtures fitted } \\
\text { for the A19 light bulb [14]. }\end{array}$ \\
\hline & 10 & $\begin{array}{l}\text { Dimmer Enclosure must fitted into a } \\
\text { standard switch box with a typical wall } \\
\text { plate }\end{array}$ & $\begin{array}{l}\text { Standard switch box dimensions: } 93 \mathrm{~mm}(\mathrm{~L}) \times 56 \mathrm{~mm} \\
(\mathrm{~W}) \times 74 \mathrm{~mm}(\mathrm{H}) . \text { Standard wall plate dimensions: } \\
125 \mathrm{~mm}(\mathrm{~L}) \times 80 \mathrm{~mm}(\mathrm{~W}) \text {. Refer to [Figure 3-2]. }\end{array}$ \\
\hline \multirow[t]{2}{*}{ Construction } & 11 & $\begin{array}{l}\text { Meet all installation and wiring } \\
\text { standards dictated by NEC } 2011\end{array}$ & $\begin{array}{l}\text { NEC } 2011 \text { is a recognized safe installation of } \\
\text { electrical wiring and equipment practices in USA } \\
\text { [50]. }\end{array}$ \\
\hline & 12 & $\begin{array}{l}\text { DC Light Bulb and dimmer box must be } \\
\text { easy to install using minimal training }\end{array}$ & $\begin{array}{l}\text { Luminaire disconnects can aid quick connection of } \\
\text { DC Light Bulb wires [Figure 3-3]. }\end{array}$ \\
\hline $\begin{array}{l}\text { Prototype } \\
\text { Cost }\end{array}$ & 13 & Cost $<\$ 100-\$ 200$ & $\begin{array}{l}\text { Total prototype cost includes all electrical } \\
\text { components and chips, custom PCB board design } \\
\text { and manufacturing, wires, and custom dimmer } \\
\text { circuitry per bulb. }\end{array}$ \\
\hline
\end{tabular}




\section{Chapter 4: Design Simulations and Components Selection}

In this chapter, a proposed DC Light Bulb design that satisfies the design constraints and performance targets presented in Chapter 3 will be explained in greater detail. First, a high level overview of the DC Light Bulb design will be presented. Then, each subsystem of the DC Light Bulb design will be analyzed using schematic diagrams, component calculations and selections, and simulations showing its performance characteristics. Lastly, the complete DC Light Bulb design with all subsystems will be summarized.

\section{1 : High Level Design}

The DC Light Bulb for the DC House project provides variable lumination via slidedimmer box and 48 VDC input source. Figure 4-1 illustrates the DC Light Bulb's fundamental (Level 0) block diagram.

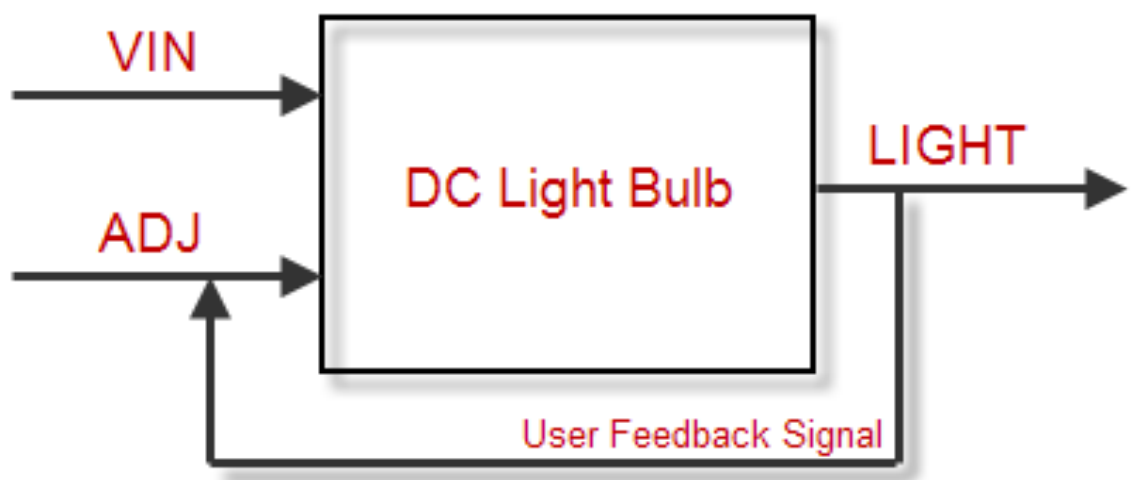

Figure 4-1: Level 0 - DC Light Bulb Block Diagram. 
The VIN input is supplied from the DC House's main 48 VDC bus voltage. The ADJ input is the variable brightness signal supplied to the dimmer circuitry. The LIGHT output represents the lumination generated from the DC Light Bulb. The user is the feedback signal (between LIGHT and ADJ signals) that determines the desire brightness intensity by setting the dimmer's ADJ slider position. Table 4-1 summarizes the fundamental block diagram's input and output signal names and their functionalities.

Table 4-1: Level 0 - DC Light Bulb Functionality.

\begin{tabular}{|c|c|l|}
\hline \multirow{2}{*}{ Inputs } & Signal Name & \multicolumn{1}{c|}{ Functionality } \\
\hline & VIN & 48 VDC from DC house's main voltage bus. \\
\cline { 2 - 3 } & ADJ & $\begin{array}{l}\text { Brightness level signal to the dimmer circuit. The user is the } \\
\text { feedback signal that determines the desire brightness and sets the } \\
\text { dimmer's ADJ slider position. }\end{array}$ \\
\hline Outputs & LIGHT & Lumination generated from DC Light Bulb. \\
\hline
\end{tabular}

The DC Light Bulb's Level 0 block diagram can be further decomposed to Level 1, as shown in Figure 4-2. The DC Light Bulb consists of three main subsystems, LED driver, dimmer circuit, and the LED lighting array. The LED driver consist of all the electronics required to transfer a source of 48 VDC to drive the output LED lighting array, while offering the user the ability to adjust the brightness via the dimmer circuit. Similar to Level 0, VIN signal is supplied by the DC House's main 48 VDC bus voltage. GND signal is the return path from the main 48 VDC bus and used as a common ground for the DC Light Bulb's electronic circuitries. The user sets the ADJ signal by varying the slide potentiometer into the dimmer circuit. PWM5V is the 
resulting pulse width modulation (PWM) signal outputted from the dimmer circuit. Signals LED_P and LED_N represents the differential output voltage powering the LED lighting array subsystem. Lastly, LIGHT represents the lumination supplied from the DC Light Bulb. A summary of the input and output signals illustrated in the level 1 block diagram is provided in Table 4-1.

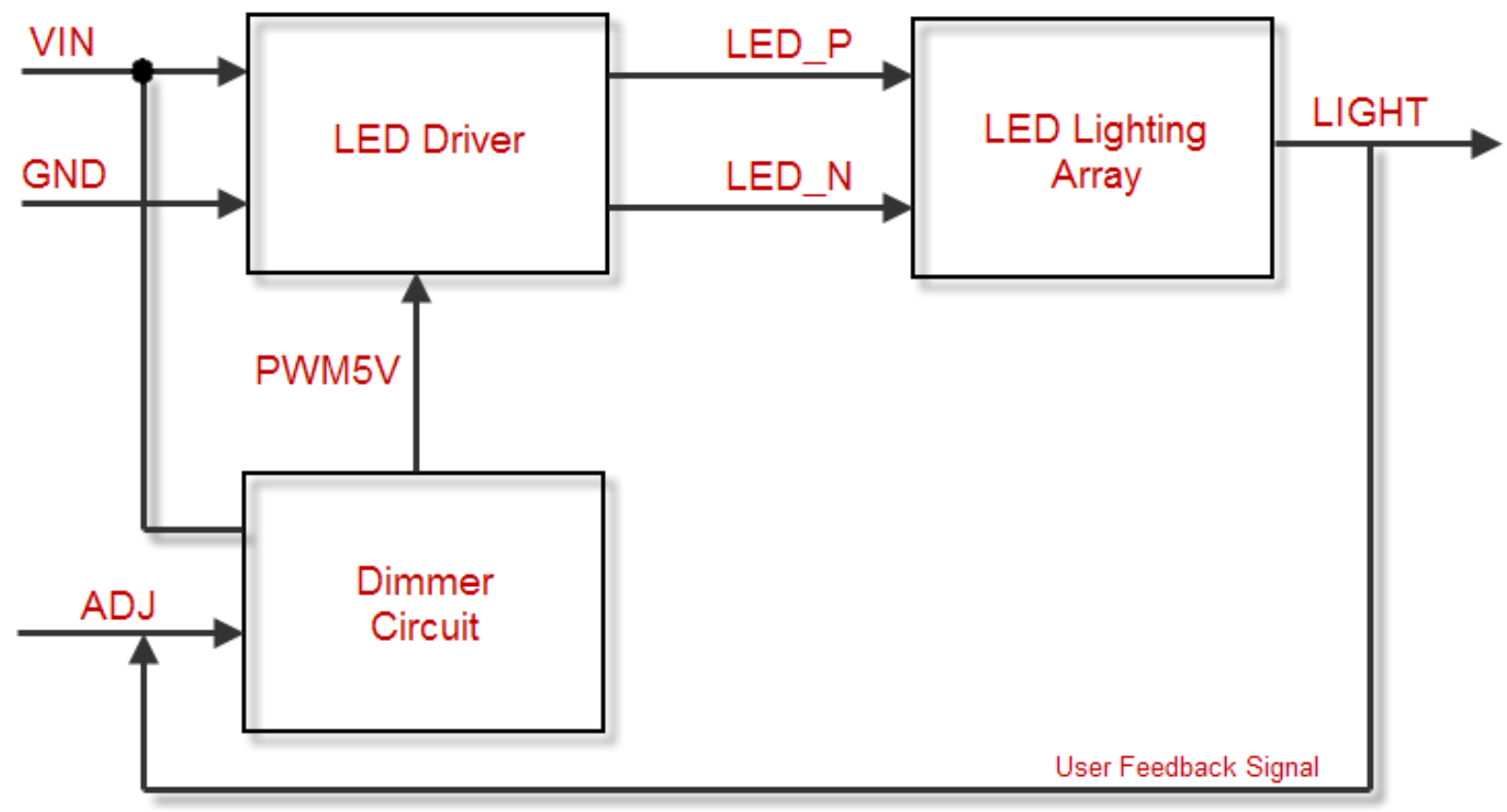

Figure 4-2: Level 1 - DC Light Bulb Block Diagram.

Table 4-2: Level 1 - DC Light Bulb Functionality.

\begin{tabular}{|c|c|c|l|}
\hline $\begin{array}{c}\text { Subsystem } \\
\text { Name }\end{array}$ & I/O & Signal Name & \multicolumn{1}{c|}{ Functionality } \\
\hline \multirow{2}{*}{ LED Driver } & Inputs & VIN, GND & $\begin{array}{l}48 \text { VDC from DC House's main voltage bus. GND is the } \\
\text { common return and reference signal. }\end{array}$ \\
\cline { 2 - 4 } & Outputs & $\begin{array}{l}\text { LED_P, } \\
\text { LED_N }\end{array}$ & Differential output voltage powering the LED lighting array. \\
\hline $\begin{array}{c}\text { Dimmer } \\
\text { Circuit }\end{array}$ & Inputs & ADJ, VIN & $\begin{array}{l}\text { The user is the feedback signal that varies the ADJ signal via } \\
\text { variable slide potentiometer to adjust the brightness level. } \\
\text { VIN signal powers the dimmer's electronics. }\end{array}$ \\
\cline { 2 - 4 } & Outputs & PWM5V & $\begin{array}{l}\text { The resulting pulse width modulation signal supplied to the } \\
\text { LED driver. }\end{array}$ \\
\hline LED Lighting & Inputs & LED_P, & Differential input voltage supplied by the LED driver. \\
\hline
\end{tabular}




\begin{tabular}{|l|c|c|l|}
\multirow{3}{*}{ Array } & & LED_N & Change in this voltage varies the output brightness. \\
\cline { 2 - 4 } & Outputs & Light & Output LED lumination. \\
\hline
\end{tabular}

\section{2: Low Level Design}

In the following section, a detailed analysis of each subsystem of DC Light Bulb will be presented. The subsystem's design will be shown in a level 2 schematic and its component selection, sizing, and performance will be evaluated through LTspice simulations and manufacturer's datasheets. The dimmer circuit will be reviewed first. Follow by the LED driver and the LED array design.

\subsection{1: Dimmer Circuit}

The dimmer circuit essentially allows the user to adjust the output brightness of the DC Light Bulb. Since it was determined in Chapter 2 that LEDs are the desired choice when it comes to highest luminous efficacy (lumens/watt) and the lowest power consumption. Referring to the I-V curve of a LED (or diode) shown in Figure 2-9, varying a small change in voltage would create an exponential change in current. With this in mind, the two most common ways of dimming a LED is the analog method and the PWM method. The analog method consists of a variable potentiometer in series with a LED. With a constant voltage source, as the resistance is increased via the potentiometer the amount of current allowed to flow through the LED is decreased, thus a dimmer light output. As Figure 2-9 suggests the analog method is a poor choice, since it offers very little current limiting control and the LED 
will fail due to over current if the resistance is reduced to a very small value, such as when the slide potentiometer is fully off (roughly $0 \Omega$ ). The second approach is the PWM method that pulsates a constant voltage source over a given time ( $\left.t_{\mathrm{ON}}\right)$ per fixed period $(T)$, also called duty cycle (Equation 4-1).

$$
\text { Duty cylce }=D=\frac{t_{O N}}{t_{O N}+t_{O F F}}=\frac{t_{O N}}{T}
$$

The amount of voltage that the output $\left(V_{0}\right)$ receives is then a function of its average voltage over the time it is on, assuming the input voltage $\left(\mathrm{V}_{\mathrm{i}}\right)$ is supplying the voltage directly to the output (Equation 4-2).

$$
\overline{V_{O}}=\frac{1}{T} * \int_{0}^{T} V_{O}(t) * d t=\frac{1}{T} * \int_{0}^{D T} V_{i} * d t=V_{i} * D
$$




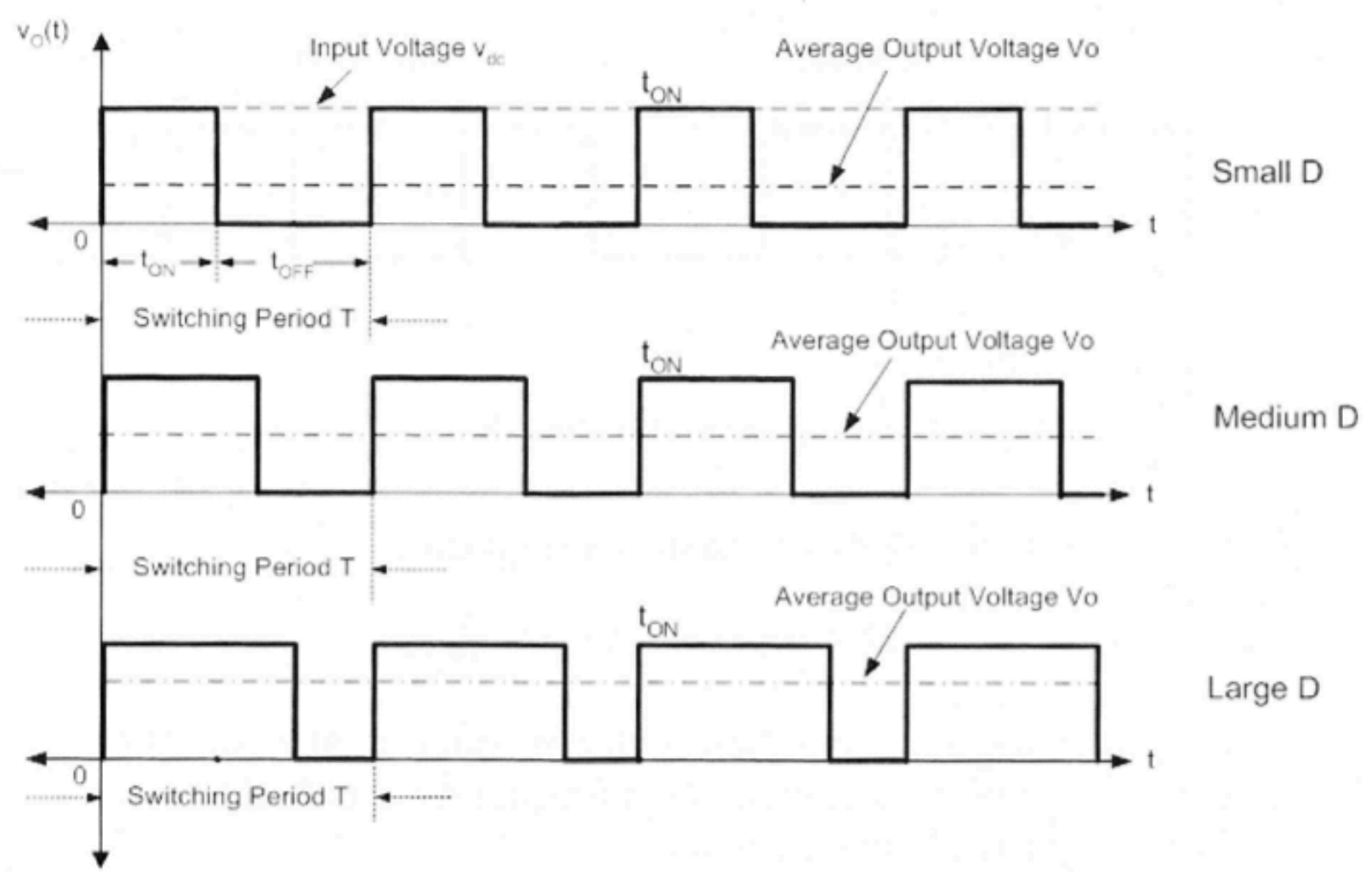

Figure 4-3: Pulse Width Modulation Explained [52].

Figure 4-3 illustrates that the available output voltage is a function of how long the pulse ( $t_{0 N}$ ) remains on or a function of the size the duty cycle (D). The greater the $D$ means the greater the average output voltage. For a LED application, the larger the D means the more constant voltage per period it sees, thus a brighter lumination generated from the LED. If the D is small, it means that the amount of constant voltage per period the LED sees is less, thus a dimmer lumination. The PWM method is good for a LED application because it does not change the amount of current applied across the LED, thus reducing its chance of burning out due to over-current damage. 
Linear Technology's voltage-controlled pulse width modulator TimerBlox, LTC6992-1, was selected as one of the components in the DC Light Bulb's dimmer circuit, shown in Figure 44 [53]. LTC6992-1 comes in a simple 6-pin SOT-23 package and its PWM duty cycle ranges from $0 \%-100 \%$ (fully off to fully on). It can operate from a supply voltage $(\mathrm{V}+$ ) between $2.25 \mathrm{~V}-5.5$ V. Voltage applied at the MOD pin controls the output duty cycle. Where V(MOD) ranges from $0.064 * \mathrm{~V}(\mathrm{SET})-0.936 * \mathrm{~V}(\mathrm{SET})$. The oscillator output (OUT) swings from GND to $\mathrm{V}+$ at a duty cycle determined by the MOD pin. The SET pin defines the switching frequency of the PWM chip. Reference voltage of V(SET) equals $1 \mathrm{~V}$. Lastly, resistor configurations (R23 and R24) between the V+ and DIV pin defines the range of the output PWM duty cycle seen at OUT.

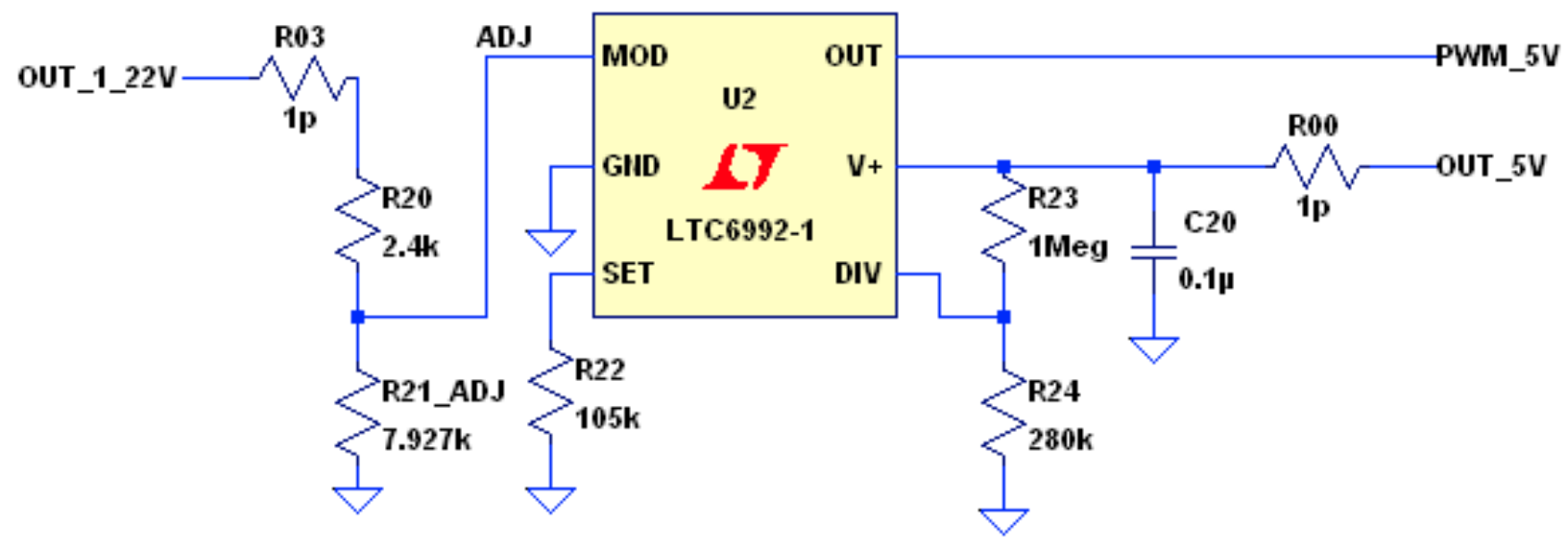

Figure 4-4: LTC6992-1 TimerBlox: Voltage-Controlled Pulse Width Modulator.

Note in Figure 4-4, R03 should represents a $0 \Omega$ resistor, but LTspice requires that a resistor cannot equal zero. 
Per Linear Technology's LTC6992-1 datasheet, high power LED direct voltage controlled PWM dimming $\left(0-15000 \mathrm{Cd} / \mathrm{m}^{2}\right)$, a PWM switching frequency should be between $976.6 \mathrm{~Hz}-$ $15.63 \mathrm{kHz}$ [53]. Where candela per square meter $\left(\mathrm{Cd} / \mathrm{m}^{2}\right)$ is a measure of light emitted per unit area. Following Linear Technology's recommendation, the LTC6992-1 switching frequency was determined to be $7.5 \mathrm{kHz}$, when R22 = $105 \mathrm{k} \Omega, \mathrm{R} 23=1 \mathrm{M}, \mathrm{R} 24=280 \mathrm{k} \Omega$ (referring to Figure 44). Equation 4-3 and Figure 4-5 were used in determining the optimum switching frequency of the PWM controller.

$$
f_{S W}=\frac{1 M H z 50 \mathrm{k} \Omega}{N_{D I V^{*}} R_{S E T}}=\frac{1 \mathrm{MHz} * 50 \mathrm{k} \Omega}{64 * 105 \mathrm{k} \Omega}=7.441 \mathrm{kHz} \approx 7.5 \mathrm{kHz}
$$

Table 1. DIVCODE Programming

\begin{tabular}{|c|c|c|c|c|c|}
\hline DIVCODE & POL & $\mathrm{N}_{\mathrm{DIV}}$ & RECOMMENDED $\mathrm{f}_{\text {OUT }}$ & R1 $(\mathrm{k} \Omega)$ & $\mathrm{R} 2(\mathrm{k} \Omega)$ \\
\hline 0 & 0 & 1 & $62.5 \mathrm{kHz}$ to $1 \mathrm{MHz}$ & Open & Short \\
\hline 1 & 0 & 4 & $15.63 \mathrm{kHz}$ to $250 \mathrm{kHz}$ & 976 & 102 \\
\hline 2 & 0 & 16 & $3.906 \mathrm{kHz}$ to $62.5 \mathrm{kHz}$ & 976 & 182 \\
\hline 3 & 0 & 64 & $976.6 \mathrm{~Hz}$ to $15.63 \mathrm{kHz}$ & 1000 & 280 \\
\hline 4 & 0 & 256 & $244.1 \mathrm{~Hz}$ to $3.906 \mathrm{kHz}$ & 1000 & 392 \\
\hline 5 & 0 & 1024 & $61.04 \mathrm{~Hz}$ to $976.6 \mathrm{~Hz}$ & 1000 & 523 \\
\hline 6 & 0 & 4096 & $15.26 \mathrm{~Hz}$ to $244.1 \mathrm{~Hz}$ & 1000 & 681 \\
\hline 7 & 0 & 16384 & $3.815 \mathrm{~Hz}$ to $61.04 \mathrm{~Hz}$ & 1000 & 887 \\
\hline 8 & 1 & 16384 & $3.815 \mathrm{~Hz}$ to $61.04 \mathrm{~Hz}$ & 887 & 1000 \\
\hline 9 & 1 & 4096 & $15.26 \mathrm{~Hz}$ to $244.1 \mathrm{~Hz}$ & 681 & 1000 \\
\hline 10 & 1 & 1024 & $61.04 \mathrm{~Hz}$ to $976.6 \mathrm{~Hz}$ & 523 & 1000 \\
\hline 11 & 1 & 256 & $244.1 \mathrm{~Hz}$ to $3.906 \mathrm{kHz}$ & 392 & 1000 \\
\hline 12 & 1 & 64 & $976.6 \mathrm{~Hz}$ to $15.63 \mathrm{kHz}$ & 280 & 1000 \\
\hline 13 & 1 & 16 & $3.906 \mathrm{kHz}$ to $62.5 \mathrm{kHz}$ & 182 & 976 \\
\hline 14 & 1 & 4 & $15.63 \mathrm{kHz}$ to $250 \mathrm{kHz}$ & 102 & 976 \\
\hline 15 & 1 & 1 & $62.5 \mathrm{kHz}$ to $1 \mathrm{MHz}$ & Short & Open \\
\hline
\end{tabular}

Figure 4-5: LTC6992-1 Switching Frequency Programming [53]. 
The 1.22 VDC constant voltage source and a resistor divider network were used to vary the voltage across the MOD pin. Resistor R21_ADJ represents a $10 \mathrm{k} \Omega$ variable slide potentiometer used to vary the output brightness of the LED lighting array. The constant 1.22 VDC reference voltage is supplied by a LT3014, linear regulator chip (which will be described in greater detail shortly). Referring to Figure 4-4 and applying Equation 4-4, the voltage $\mathrm{V}_{\mathrm{ADJ}}$ seen at the MOD pin is then calculated. $V_{A D J}$ at different R21_ADJ resistance values are summarized in Table 4-3.

$$
V(M O D)=V_{A D J}=V_{O U T 12 \mathrm{~V}} * \frac{R 21 \mathrm{ADJ}}{R 21 \mathrm{ADJ}+R 20}=1.22 \mathrm{~V} * \frac{1.668 \mathrm{k} \Omega}{1.668 \mathrm{k} \Omega+2.4 \mathrm{k} \Omega}=0.501 \mathrm{~V}
$$

Table 4-3: Dimmer Slide Potentiometer V(MOD) Voltage Divider Network.

\begin{tabular}{|c|c|c|c|c|}
\hline $\begin{array}{c}\text { *Duty Cycle } \\
\text { \% }\end{array}$ & $\begin{array}{c}\text { R21_ADJ } \\
\mathbf{( k \boldsymbol { \Omega } )}\end{array}$ & ADJ (V) & R20 (k $\mathbf{\Omega})$ & $\begin{array}{c}\text { OUT_1_22V } \\
\mathbf{( V )}\end{array}$ \\
\hline $0.00 \%$ & 0.133 & 0.064 & 2.4 & 1.222 \\
\hline $6.61 \%$ & 0.341 & 0.152 & 2.4 & 1.222 \\
\hline $17.41 \%$ & 0.584 & 0.239 & 2.4 & 1.222 \\
\hline $28.09 \%$ & 0.873 & 0.326 & 2.4 & 1.222 \\
\hline $39.62 \%$ & 1.23 & 0.414 & 2.4 & 1.222 \\
\hline $50.07 \%$ & 1.668 & 0.501 & 2.4 & 1.222 \\
\hline $58.83 \%$ & 2.226 & 0.588 & 2.4 & 1.222 \\
\hline $67.94 \%$ & 2.971 & 0.676 & 2.4 & 1.222 \\
\hline $82.74 \%$ & 3.99 & 0.763 & 2.4 & 1.222 \\
\hline $93.18 \%$ & 5.484 & 0.85 & 2.4 & 1.222 \\
\hline $100.00 \%$ & 7.927 & 0.938 & 2.4 & 1.222 \\
\hline
\end{tabular}

*Note: Duty cycle was measured in LTspice simulation for each change in R21_ADJ.

Figure 4-6 illustrates LTC6992-1's duty cycle responses at varying $\mathrm{V}_{\mathrm{ADJ}}$ voltages. V(ADJ) represents the voltage applied at the MOD pin and V(PWM_5V) represents the pulsing output voltage signal at the OUT pin of the PWM controller. 


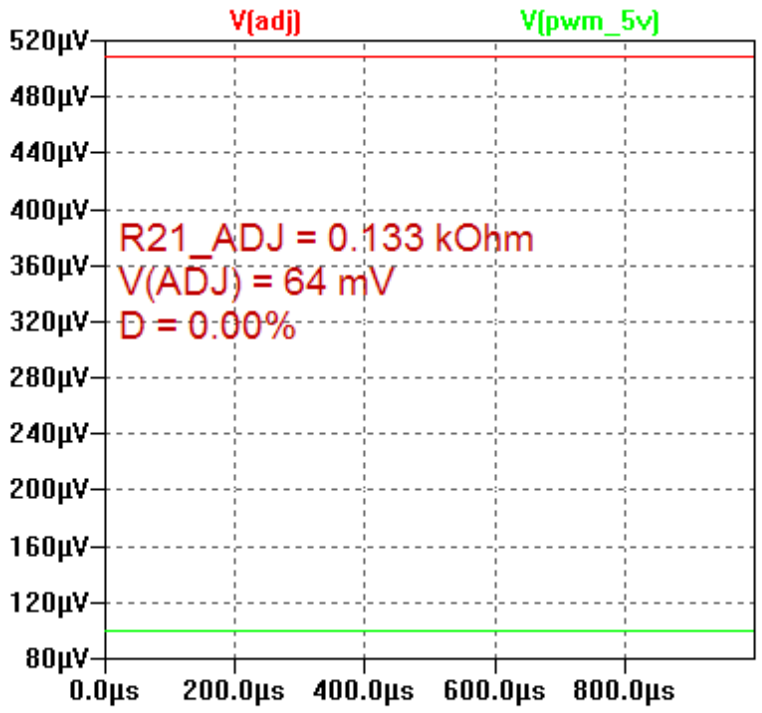

(a)

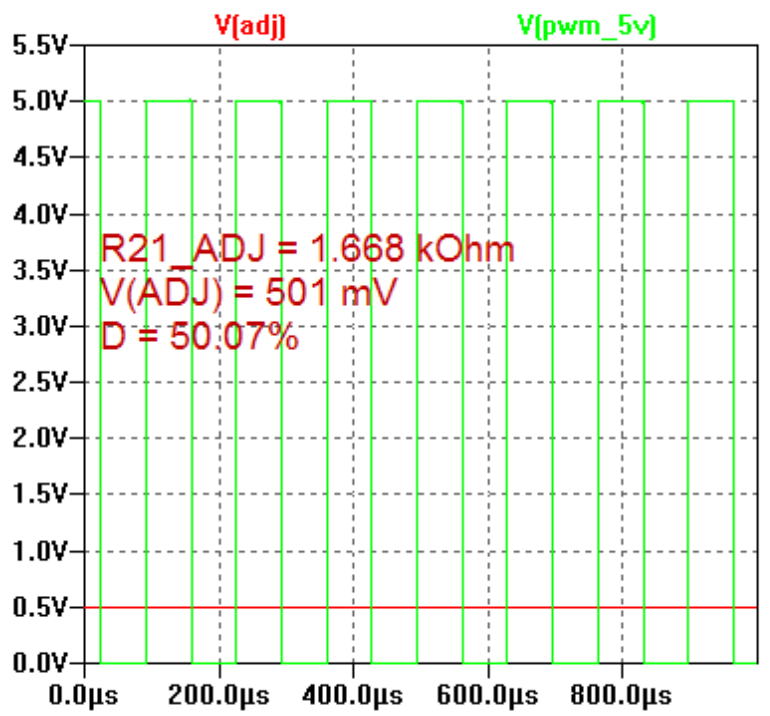

(c)

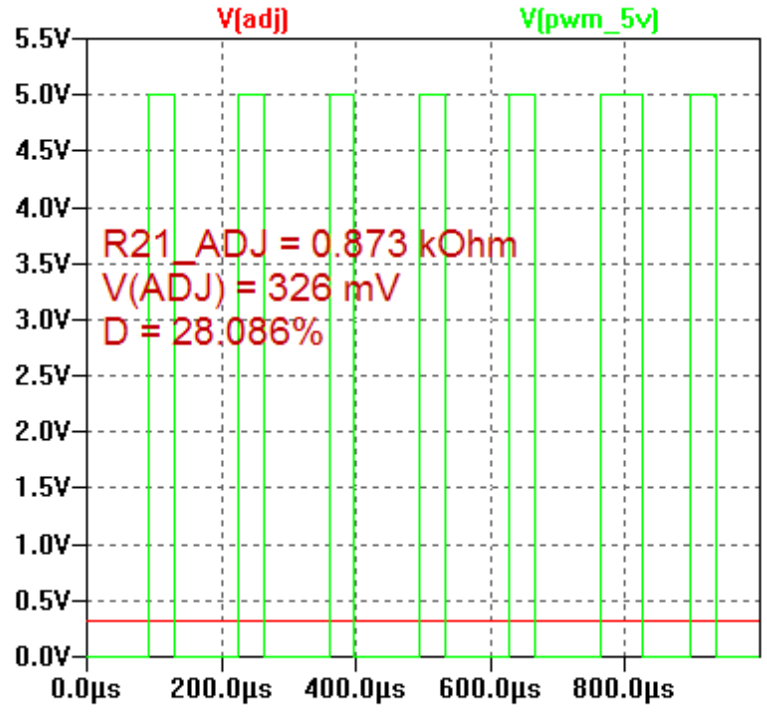

(b)

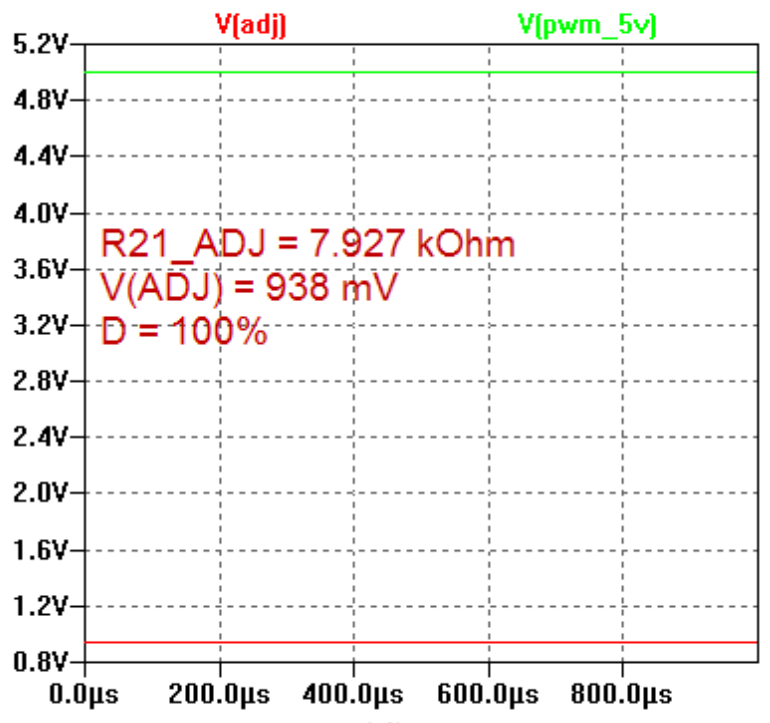

(d)

Figure 4-6: LTC6992-1 PWM at (a) $D=0 \%$, (b) $D=28 \%$, (c) $D=50 \%$, and (d) $D=100 \%$.

As briefly mentioned earlier, the LTC6992-1 PWM controller requires a source voltage between $2.25 \mathrm{~V}-5.5 \mathrm{~V}$ at the $\mathrm{V}+$ pin and requires a constant $1.22 \mathrm{~V}$ reference voltage at the voltage divider circuit (R20 and R21_ADJ) suggested in Figure 4-4. The MOD pin only requires a 
voltage of $0.064 * V_{S E T}$ to produce $D=0 \%$ and $0.936 * V_{S E T}$ to produce a $D=100 \%$, so a $1.22 \mathrm{~V}$ source is more then sufficient to meet these requirements.

Since the DC House supplies 48 VDC, the voltage must be stepped down to at least $5.5 \mathrm{~V}$ to power the PWM controller. LTC6992-1's datasheet suggests the maximum (or worst case) required source current $\left(I_{S}\right)$ into the chip is $420 \mu \mathrm{A}$ [53]. With such a low current draw, linear regulators (sometimes refer to as low dropout linear regulator, LDO) were chosen to step down the $48 \mathrm{~V}$ to $5 \mathrm{~V}$ and to step down $5 \mathrm{~V}$ to $1.22 \mathrm{~V}$

Linear Technology's LT3014, low dropout micropower linear regulator was selected to meet the required $5 \mathrm{~V}$ and $1.22 \mathrm{~V}$ constant voltages needed to operate the LTC6992-1 PWM controller. LT3014 is a great choice because it accepts a wide input voltage of $3 \mathrm{~V}-80 \mathrm{~V}$, can supply an output current up to $20 \mathrm{~mA}$, offer an adjustable output voltage between $1.22 \mathrm{~V}-60$ V, and comes in a simple 5-pin SOT23 package, and offers a dropout voltage of 350mV [54]. Traditionally, a LDO is great due to its simplicity and low cost, often requiring only two capacitors for storage and stability. It offers quiet operation since it generates little to no noise at its output, due to no switching elements or a transformer. LDO also offers great load handling compensation due to very short dynamic load response times [55]. However, an LDO is not recommended for high power voltage step downs since an LDO's efficiency $(\eta)$ is roughly $\mathrm{V}_{\mathrm{OUT}} / \mathrm{V}_{\mathrm{IN}}$, thus its efficiency can be extremely low. For example, stepping down $48 \mathrm{~V}$ to $5 \mathrm{~V}$ creates an efficiency about $10.42 \%$ (Equation 4-5). For high power applications this would be a huge problem because the remaining $89.58 \%$ is wasted through the form of heat, thus a huge heatsink is required and overall cost goes up. For the case of the LTC6992-1 PWM controller, 
low efficiency is not a major concern. Since the PWM controller produces $2.1 \mathrm{~mW}$ (Equation 46) in worst case scenario and the voltage is stepped down from $48 \mathrm{~V}$ to $5 \mathrm{~V}$ produces an efficiency of 10.417\% (Equation 4-5), it only sees a power loss of $20.939 \mathrm{~mW}$ (Equation 4-9). A power loss this low can be negligible. Figure 4-7 suggests an average power consumption across the LTC6992-1 chip to be $0.908 \mathrm{~mW}$, when $\mathrm{D}=100 \%$.

$$
\begin{aligned}
& L D O \eta=\frac{P_{\text {OUT }}}{P_{I N}} \approx \frac{V_{\text {OUT }}}{V_{I N}}=\frac{5 \mathrm{~V}}{48 \mathrm{~V}} * 100=10.417 \% \\
& P_{\text {OUT }}=V_{\text {OUT }} * I_{\text {OUT }}=5 \mathrm{~V} * 420 \mu \mathrm{A}=2.1 \mathrm{~mW} \\
& P_{I N}=\frac{P_{\text {OUT }}}{\eta}=\frac{2.1 \mathrm{~mW}}{0.10417}=23.039 \mathrm{~mW} \\
& P_{I N}=P_{\text {LOSS }}+P_{\text {OUT }} \\
& P_{\text {LOSS }}=P_{I N}-P_{\text {OUT }}=23.039 \mathrm{~mW}-2.1 \mathrm{~mW}=20.939 \mathrm{~mW}
\end{aligned}
$$

Figure 4-7: LTC6992-1 Power Consumption at Full Load, $D=100 \%$ 

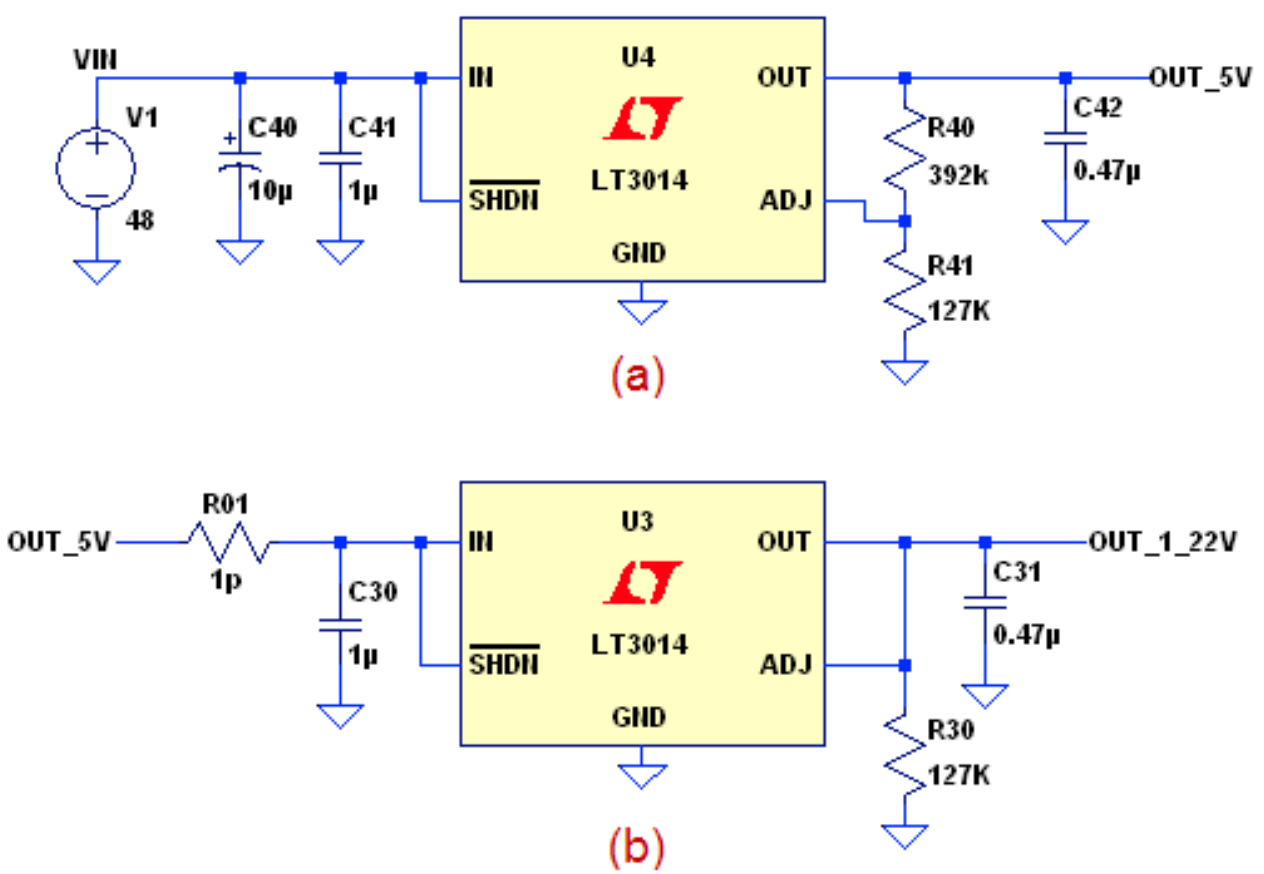

Figure 4-8: LT3014: Low Dropout Micropower Linear Regulator, (a) 48 V - 5 V LDO and (b) 5 V - 1.22 V LDO.

Figure 4-8 illustrates the LT3014 linear regulators used to step down $48 \mathrm{~V}-5 \mathrm{~V}$ and $5 \mathrm{~V}-$ 1.22 V required to drive the LTC6992-1 PWM controller. The IN pin is tied to the source voltage. Per LT3014's datasheet, a bypass capacitor in the range of $0.1 \mu \mathrm{F}$ to $10 \mu \mathrm{F}$ is sufficient [54]. Since C40 is tied directly to the DC House main 48 VDC bus voltage, a higher quality capacitor with low ESR is desired. Possible options are ceramic X7R capacitor, aluminum electrolytic, or tantalum electrolytic capacitor. For C40 a $10 \mu \mathrm{F} 75 \mathrm{~V}$ tantalum electrolytic capacitor was selected since it offers the best noise limiting and stability filtering at a higher frequency and temperature range, while maintaining the lowest ESR [55]. The LDO's IN to GND and OUT to GND pins acts as a diode in the event the source voltage is connected backwards, thus protecting the chip an the load. The $\overline{S H D N}$ pin goes into low shutdown mode if it is tied to a low logic. The voltage divider resistors R40 and R41 tied to the OUT and ADJ pin sets the 
output voltage. For a $5 \mathrm{~V}$ output, Equation 4-10 and 4-11 are used to size resistor R40, assuming $\mathrm{R} 41$ is fixed at $127 \mathrm{k} \Omega$. ADJ pin is referenced internally to $\mathrm{V}_{\mathrm{ADJ}}=1.22 \mathrm{~V}$ and to bias current $\mathrm{I}_{\mathrm{ADJ}}=4 \mathrm{nA}$ at $25^{\circ} \mathrm{C}$. LT3014's datasheet recommends that a minimum output capacitor of $0.47 \mu \mathrm{F}$ with an ESR of $3 \Omega$ or less should be used to prevent oscillations [54]. A $0.47 \mu \mathrm{F} 25 \mathrm{~V}$ X7R ceramic capacitor was chosen, since the LDO produces a worst case output ripple voltage of $18.974 \mathrm{mV}$ if the input swings from $12 \mathrm{~V}$ to $72 \mathrm{~V}$ (Equation 4-13). LT3014 offers a typical ripple rejection of $70 \mathrm{~dB}$. Equations 4-12 and 4-13 suggest that the output voltage ripple is equal to an input voltage divided by a factor of 3162 .

$$
\begin{aligned}
& V(\text { OUT } 5 V)=1.22 \mathrm{~V} *\left(1+\frac{R 40}{R 41}\right)+I_{A D J} * R 40 \\
& V(\text { OUT } 5 \mathrm{~V})=1.22 \mathrm{~V} *\left(1+\frac{392 \mathrm{k} \Omega}{127 \mathrm{k} \Omega}\right)+4 \mathrm{nA} * 392 \mathrm{k} \Omega=4.987 \mathrm{~V} \\
& \text { Ripple Rejection }=70 \mathrm{~dB}=20 * \log _{10} \frac{\Delta V_{I N}}{\Delta V_{\text {OUT }}} \\
& \Delta V_{\text {OUT }}=\frac{\Delta V_{I N}}{10^{\frac{70 d B}{20 d B}}}=\frac{72 \mathrm{~V}-12 \mathrm{~V}}{3162.278}=18.974 \mathrm{mV}
\end{aligned}
$$

For the $5 \mathrm{~V}-1.22 \mathrm{~V}$ LDO, to effectively produce an output voltage of $1.22 \mathrm{~V}$, a short is placed between OUT and ADJ pin, since ADJ is referenced internally to $1.22 \mathrm{~V}$. Input and output capacitors C30 and C31 are sized using the same method for the $48 \mathrm{~V}-5 \mathrm{~V}$ LDO. In this particular case a X7R $0.1 \mu \mathrm{F}$ ceramic capacitor is sufficient for C30.

Common methods in evaluating a voltage regulator or DC - DC converters ability to maintain output voltage at a changing input voltage or at a changing load are line regulation 
and load regulation, respectfully. The first test is line regulation, which measures a power converter's ability to maintain the desired output voltage even when the input source voltage fluctuates. This relationship is shown in Equation 4-14.

$\%$ Line Regulation $_{\text {at full load }}=\frac{V_{\text {OUT high input }}-V_{\text {OUT low input }}}{V_{\text {OUT nominal }}} * 100 \%$

The second test is load regulation, which measures a power converter's ability to maintain the designed output voltage even when the output power fluctuates. Equation 4-15 expresses load regulation.

$\%$ Load Regulation at nominal input voltage $=\frac{V_{\text {OUT low load }}-V_{\text {OUT high load }}}{V_{\text {OUT high load }}} * 100 \%$

LT3014 48V - 5 V Low Dropout Linear Regulator - Line Regulation Results

In the following section, the LT3014 Low Dropout Linear Regulator line regulation is tested. Figure 4-9 illustrates the schematic for the LT3014 (U4). U4 steps down the 48 VDC voltage bus to a $5 \mathrm{VDC}$ voltage rail required to supply a constant $1.22 \mathrm{~V}$ source (U3) and to power the PWM Dimmer (U2) circuit.

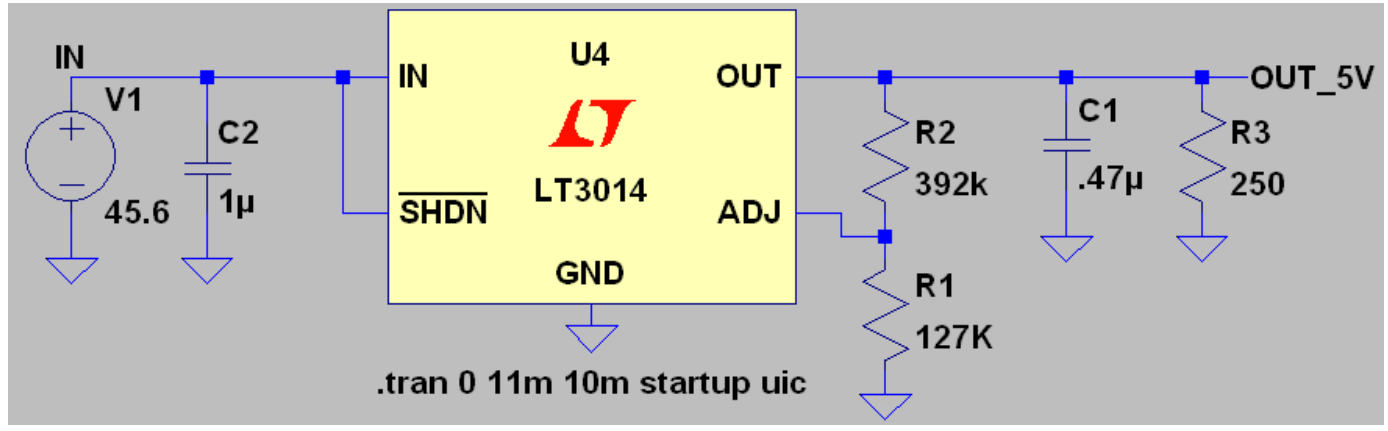

Figure 4-9: LT3014 48 V -5V LDO (U4) at 5\% Vin and rated load $20 \mathrm{~mA}$. 
Figure 4-10 shows a sample $\mathrm{V}_{\mathrm{OUT}}$ waveform at $\mathrm{V}_{\mathrm{IN}}$, low input $=45.6 \mathrm{~V}\left(5 \%\right.$ of $\mathrm{V}_{\mathrm{IN}}$, Nominal $)$. The output voltage is determined by taking the average of $\mathrm{V}_{\mathrm{OUT}}$, low input and $\mathrm{V}_{\text {OUT, high input }}$ as suggested in Equation 4-16.

$$
\overline{V_{\text {OUT }}}=\frac{V_{\text {OUT low input }}+V_{\text {OUT high input }}}{2}
$$

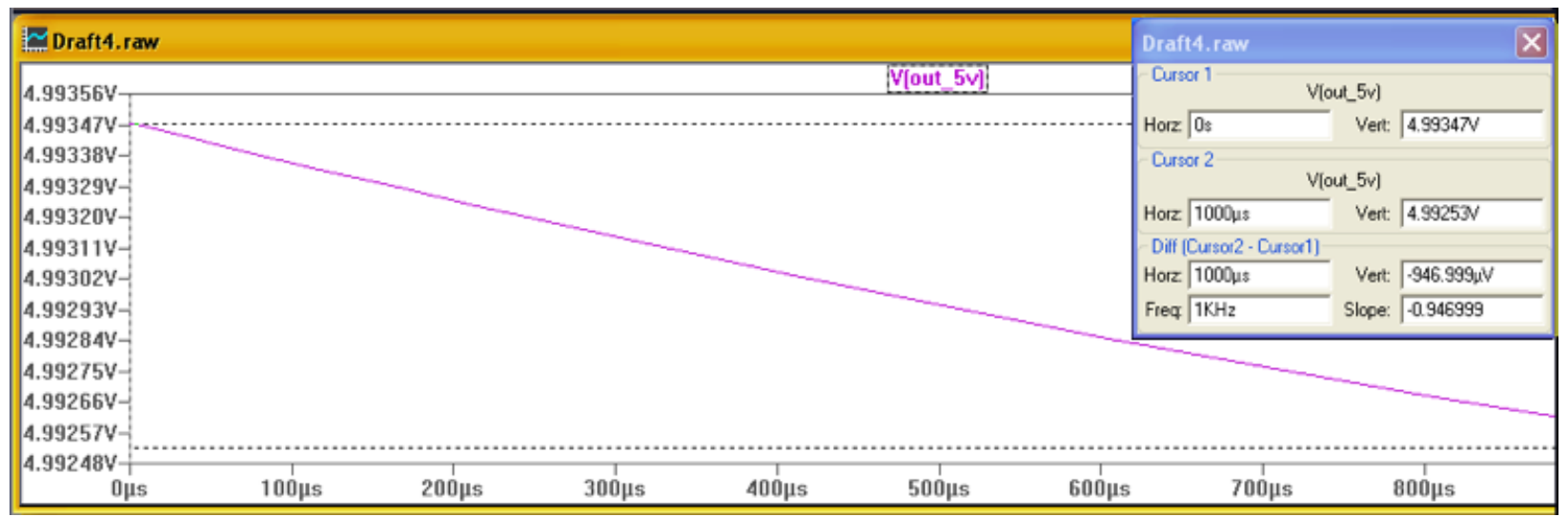

Figure 4-10: LT3014 $48 \mathrm{~V}-5 \mathrm{~V}$ LDO at $\mathrm{V}_{\mathrm{IN}}$, low input $=45.6 \mathrm{~V}\left(5 \% \mathrm{~V}_{\mathrm{IN} \text {, Nominal }}\right)$ and rated load $20 \mathrm{~mA}$.

Table 4-4: LT3014 48 V - 5 V LDO Line Regulation Simulation Results.

\begin{tabular}{|c|c|c|c|c|c|c|c|c|}
\hline $\begin{array}{c}\text { \% of } \mathrm{V}_{\text {IN, }} \\
\text { Nominal }\end{array}$ & $\begin{array}{c}\mathrm{V}_{\text {IN, }} \\
\text { Nominal } \\
(\mathrm{V})\end{array}$ & $\begin{array}{c}\mathrm{V}_{\text {OUT, }} \\
\text { Nominal } \\
(\mathrm{V})\end{array}$ & $\begin{array}{c}\mathrm{V}_{\text {IN, }} \\
\mathrm{Min} \\
(\mathrm{V})\end{array}$ & $\begin{array}{c}\mathrm{V}_{\text {IN, }} \\
\mathrm{Max} \\
(\mathrm{V})\end{array}$ & $\begin{array}{c}\mathrm{V}_{\text {OUT, low }} \\
\text { input }\end{array}$ & $\begin{array}{c}\mathrm{V}_{\text {OUT, high }} \\
\text { input }\end{array}$ & $\begin{array}{c}\text { I } \mathrm{V}) \\
\text { Rat, } \\
(\mathrm{mA})\end{array}$ & $\begin{array}{c}\text { \% Line } \\
\text { Regulation } \\
(\%)\end{array}$ \\
\hline $5 \%$ & 48 & 4.993 & 45.6 & 50.4 & 4.993 & 4.9932 & 19.814 & 0.004 \\
\hline $10 \%$ & 48 & 4.993 & 43.2 & 52.8 & 4.9929 & 4.9933 & 19.814 & 0.008 \\
\hline $15 \%$ & 48 & 4.993 & 40.8 & 55.2 & 4.9928 & 4.9934 & 19.814 & 0.012 \\
\hline
\end{tabular}

Table 4-4 summarizes the LT3014 $48 \mathrm{~V}-5 \mathrm{~V}$ LDO's line regulation at $\pm 5 \%, \pm 10 \%$, and $\pm 15 \% V_{I N}$, Nominal voltage variations. The resulting line regulations indicate that the LT3014 can easily maintain an output voltage of $4.993 \mathrm{~V}$ with fluctuations less than $0.012 \%$. LT3014's 
datasheet electrical characteristic suggests it produces a maximum line regulation of $10 \mathrm{mV}$. With a $5 \mathrm{~V}$ output and a $10 \mathrm{mV}$ ripple means that its output voltage can decrease down to 4.95 $V$ at its worst case. Applying Equation $4-14$ suggests a $1 \%$ maximum line regulation using the datasheet specifications. LTspice simulation suggests that with a $15 \%$ swing in input voltage it produces a $0.012 \%$ line regulation, which is way within datasheet specifications.

\section{LT3014 48V - 5 V Low Dropout Linear Regulator - Load Regulation Results}

Next load regulation test is performed to evaluate the performance of the LT3014 $48 \mathrm{~V}$ 5 V LDO (U4), shown in Figure 4-11. A .step SPICE directive at RLOAD was used to increment the output in $10 \%$ load changes.

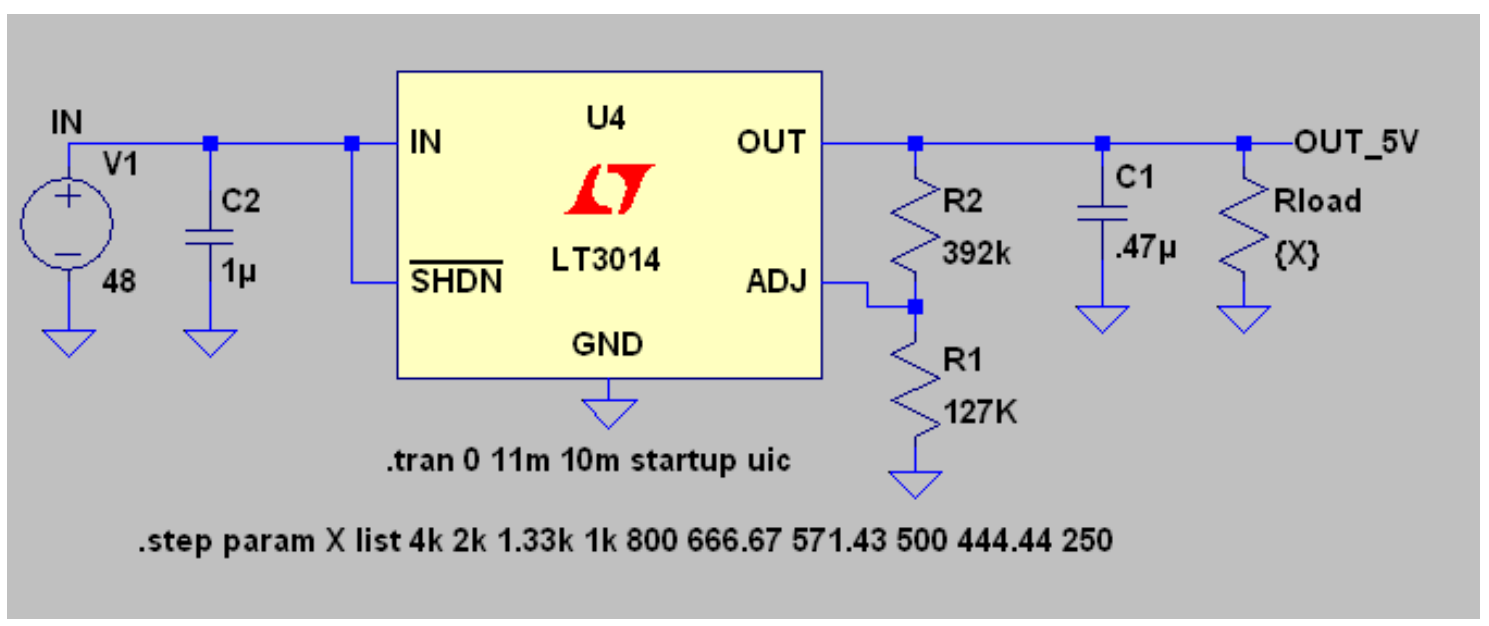

Figure 4-11: $L T 301448 \mathrm{~V}-5 \mathrm{~V} L D O, \mathrm{R}_{\mathrm{Load}}=4 \mathrm{~K} \Omega, 2 \mathrm{~K} \Omega, 1.33 \mathrm{~K} \Omega, 1 \mathrm{~K} \Omega, 800 \Omega, 666.67 \Omega, 571.43 \Omega, 500 \Omega, 444.44 \Omega$, and $250 \Omega$. 
The resulting change in output voltage V(OUT_5V) versus change in output load resistances is shown in Figure 4-12. As the load resistance decreases, the required output current increases, thus the voltage slowly sags more and more.

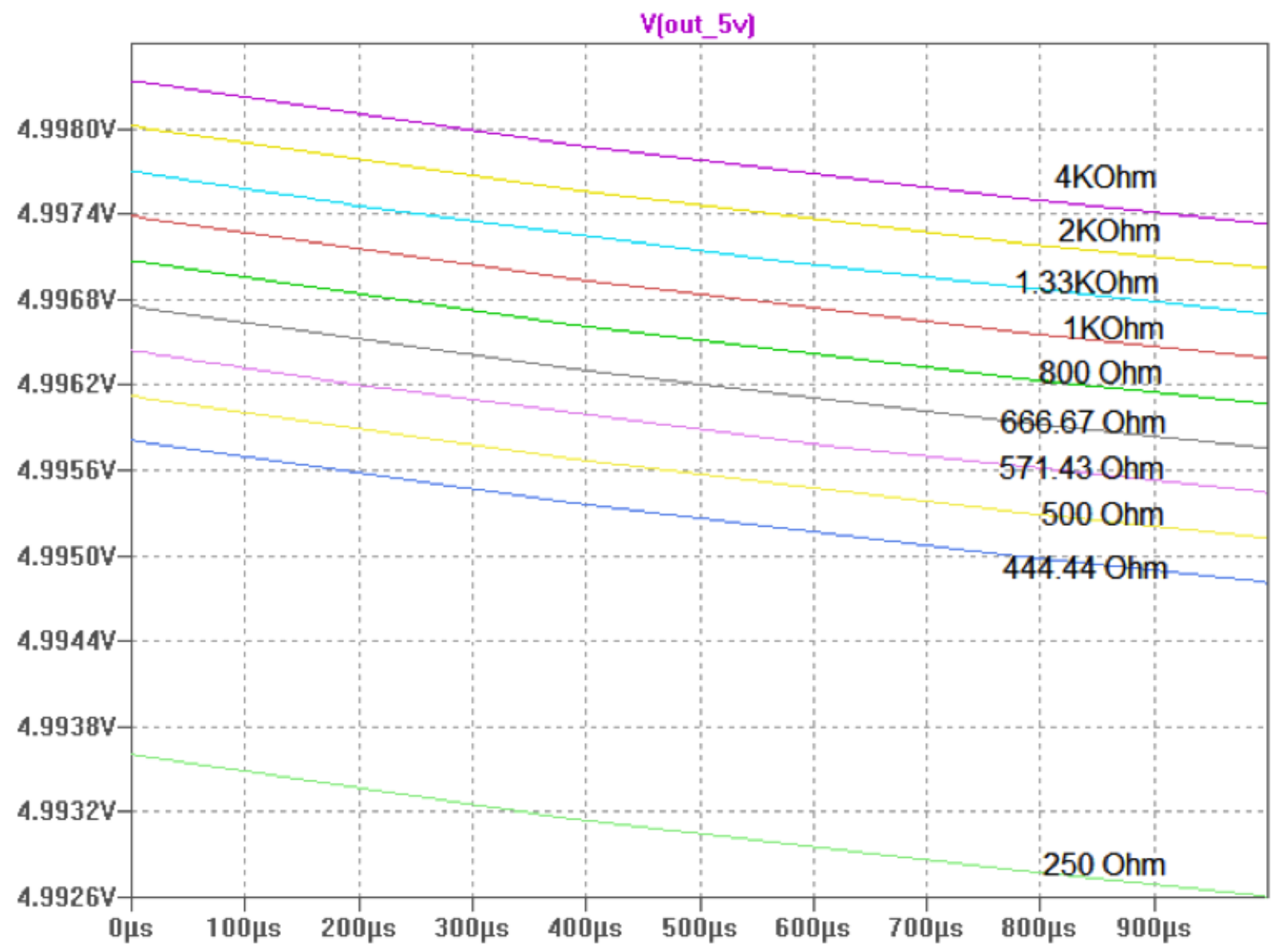

Figure 4-12: LT3014 48Vdc-5Vdc LDO Simulation Waveform at $V_{\mathrm{IN}, \text { Nominal }}=48 \mathrm{~V}$, $\mathrm{I}_{\mathrm{LOAD}}$ varying from $10 \%$ to $100 \%$ of $I_{\text {Rated }}=20 \mathrm{~mA}$.

Table 4-5 summaries the load step changes versus output voltage V(OUT_5V). Applying the load regulation Equation 4-15 to Table 4-5, a 0.05\% load regulation was obtained (Equation 4-17). 
$\%$ Load Regulation $=\frac{4.9978 \mathrm{~V}-4.9953 \mathrm{~V}}{4.9953 \mathrm{~V}} * 100=0.05 \%$

Table 4-5: LT3014 48Vdc-5Vdc LDO Load Regulation Simulation Results; $\mathrm{V}_{\mathrm{IN}, \text { Nominal }}=48 \mathrm{~V}$.

\begin{tabular}{|c|c|c|c|}
\hline \% Load (\%) & $\begin{array}{c}\text { IOUT_5V } \\
(\mathrm{mA})\end{array}$ & ROUT_5V $(\Omega)$ & $\mathrm{V}_{\text {OUT_5V }}(\mathrm{V})$ \\
\hline 10 & 2 & 4000 & 4.9978 \\
\hline 20 & 4 & 2000 & 4.9977 \\
\hline 30 & 6 & 1333.33 & 4.9972 \\
\hline 40 & 8 & 1000 & 4.9969 \\
\hline 50 & 10 & 800 & 4.9966 \\
\hline 60 & 12 & 666.67 & 4.9963 \\
\hline 70 & 14 & 571.43 & 4.9959 \\
\hline 80 & 16 & 500 & 4.9956 \\
\hline 90 & 18 & 444.44 & 4.9953 \\
\hline 100 & 20 & 250 & 4.9931 \\
\hline
\end{tabular}

LT3014's datasheet electrical characteristics suggest a worst case load regulation ripple of $40 \mathrm{mV}$ can occur. LTspice simulated load regulation of $0.05 \%$ is within the specifications defined by LT3014's datasheet [54].

$\underline{\text { LT3014 } 5 \text { V - 1.22 V Low Dropout Linear Regulator - Line Regulation Results }}$

Next, the LT3014 $5 \mathrm{~V}-1.22 \mathrm{~V}$ LDO (U3) is tested for line regulation and load regulation using equations 4-14, 4-15, and 4-16. Figure 4-13 illustrates the LT3014 (U3) linear regulator at $\mathrm{V}_{\mathrm{IN}}$, low input $=4.7434 \mathrm{~V}\left(5 \%\right.$ of $\left.\mathrm{V}_{\mathrm{IN} \text {, Nominal }}=4.993 \mathrm{~V}\right)$. This LDO is used to provide a fixed $1.22 \mathrm{~V}$ 
voltage source needed for the analog voltage-controlled pulse width modulation (PWM) circuitry (U2).

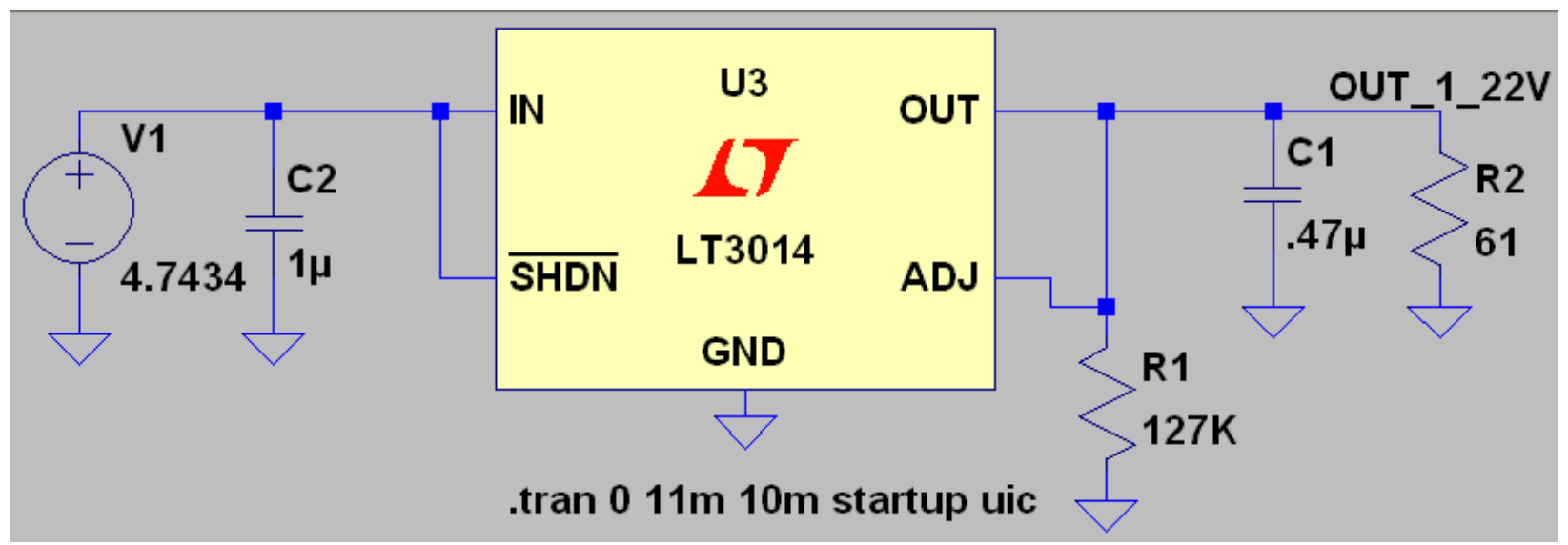

Figure 4-13: LT3014 5Vdc-1.22Vdc LDO (U3) at 5\% Vin and rated load 20mA.

Figure 4-14 illustrates LDO U3's $V_{\text {OUT, low input }}=1.221 \mathrm{~V}$ at an input voltage $\mathrm{V}_{\mathrm{IN} \text {, Min }}=4.7434$ $\mathrm{V}\left(5 \%\right.$ of $\mathrm{V}_{\mathrm{IN}}$, Nominal). Table 4-6 summarizes LT3014 $5 \mathrm{~V}-1.22 \mathrm{~V}$ LDO's line regulation at $\pm 5 \%$,

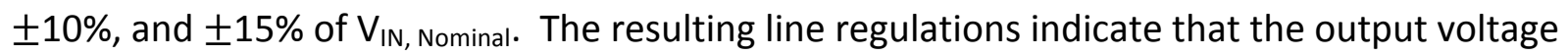
can be considered constant with no fluctuation. 


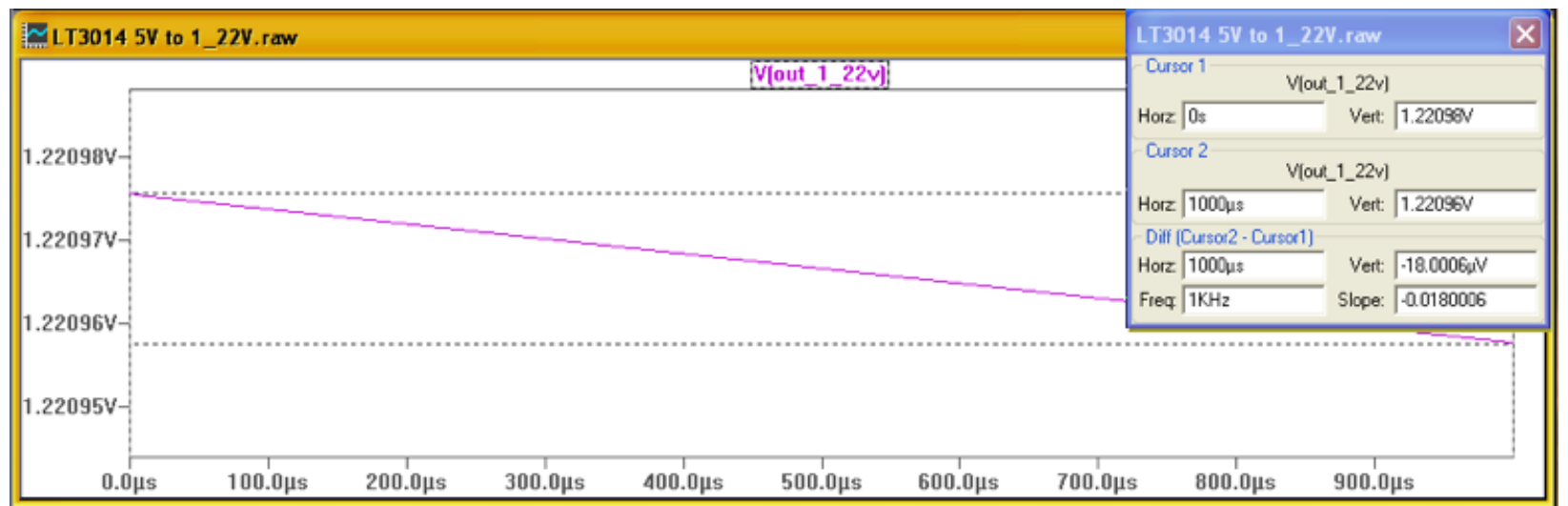

Figure 4-14: LT3014 5 V - 1.22 V LDO at $\mathrm{V}_{\mathrm{IN} \text {, low input }}=4.993 \mathrm{~V}\left(5 \% \mathrm{~V}_{\mathrm{IN} \text {, Nominal }}\right)$ and rated load $20 \mathrm{~mA}$.

Table 4-6: LT3014 48 V - 5 V LDO Line Regulation Results.

\begin{tabular}{|c|c|c|c|c|c|c|c|c|}
\hline $\begin{array}{c}\% \text { of } \mathrm{V}_{\text {IN, }} \\
\text { Nominal }\end{array}$ & $\begin{array}{c}\mathrm{V}_{\text {IN, }} \\
\text { Nominal } \\
(\mathrm{V})\end{array}$ & $\begin{array}{c}\mathrm{V}_{\text {OUT, }} \\
\text { Nominal } \\
(\mathrm{V})\end{array}$ & $\begin{array}{c}\mathrm{V}_{\text {IN, Min }} \\
(\mathrm{V})\end{array}$ & $\begin{array}{c}\mathrm{V}_{\text {IN, Max }} \\
(\mathrm{V})\end{array}$ & $\begin{array}{c}\mathrm{V}_{\text {OUT, low }} \\
\text { input }\end{array}$ & $\begin{array}{c}\mathrm{V}_{\text {OUT, high }} \\
\text { input }\end{array}$ & $\begin{array}{c}\text { lOUT, }_{\text {OUT }} \\
\text { Rated } \\
(\mathrm{mA})\end{array}$ & $\begin{array}{c}\% \text { Line } \\
\text { Regulation } \\
(\%)\end{array}$ \\
\hline $5 \%$ & 4.993 & 1.221 & 4.7434 & 5.2427 & 1.221 & 1.221 & 20.016 & 0 \\
\hline $10 \%$ & 4.993 & 1.221 & 4.4937 & 5.4923 & 1.221 & 1.221 & 20.016 & 0 \\
\hline $15 \%$ & 4.993 & 1.221 & 4.2441 & 5.742 & 1.221 & 1.221 & 20.016 & 0 \\
\hline
\end{tabular}

$\underline{\text { LT3014 } 5 \text { V - } 1.22 \text { V Low Dropout Linear Regulator - Load Regulation Results }}$

Similarly, load regulation is found using the same approach (Equation 4-15) used for the LT3014 $48 \mathrm{~V}-5 \mathrm{~V}$ LDO. A schematic diagram of the LT3014 $5 \mathrm{~V}-1.22 \mathrm{~V}$ LDO (U3) is shown in Figure 4-15. A .step SPICE directive was applied at RLOAD to increment $10 \%$ output load steps. 


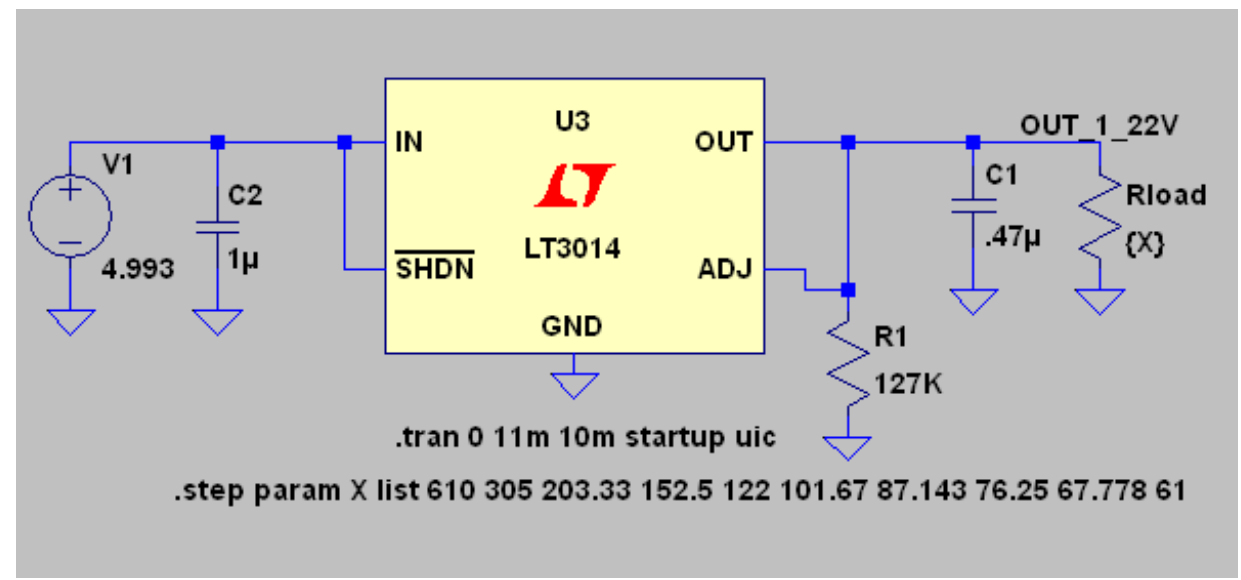

Figure 4-15: LT3014 5 V - 1.22 V LDO Schematic Diagram, $R_{\text {Load }}=610 \Omega, 305 \Omega, 203.33 \Omega, 152.5 \Omega, 101.67 \Omega$, $87.143 \Omega, 76.25 \Omega, 67.778 \Omega$, and $61 \Omega$.

Figure 4-16 illustrates the output voltage, Vout_1_22V, for the LT3014 5 V - 1.22 V LDO.

Figure 4-16 suggests that the output voltage decreases slightly with an increase in output load.

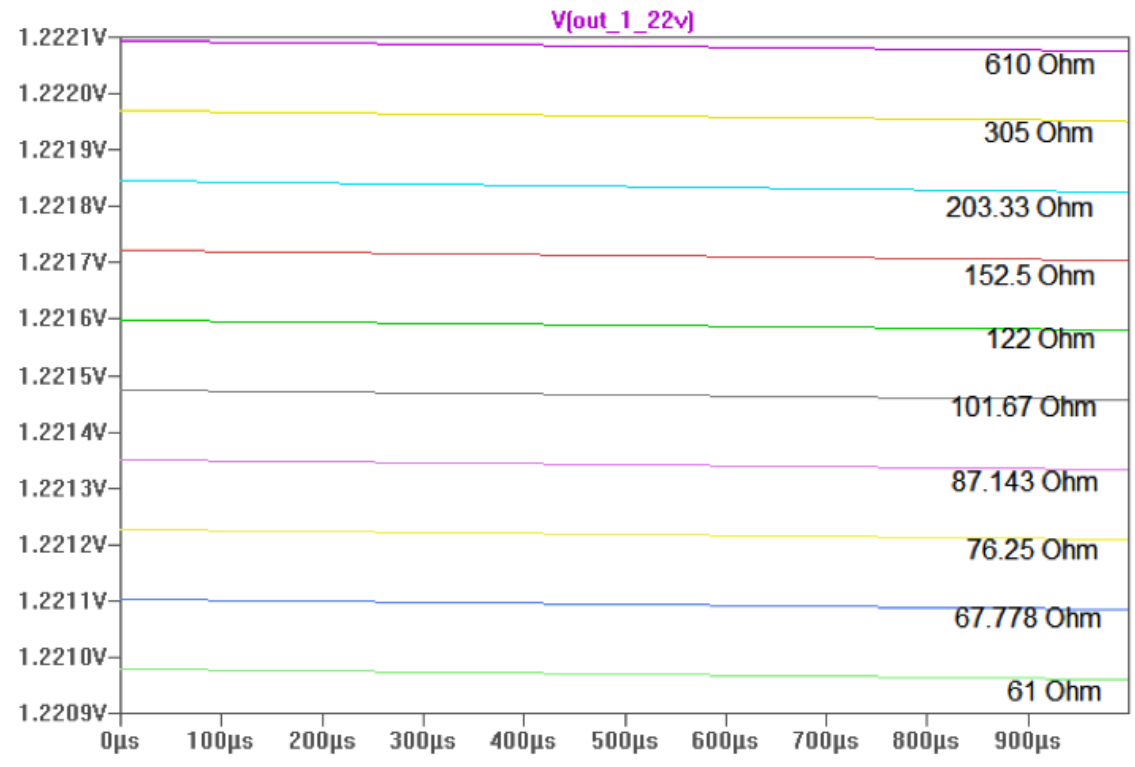

Figure 4-16: LT3014 5 V - 1.22 V LDO Simulation Waveform at $V_{\mathrm{IN} \text {, Nominal }}=4.993 \mathrm{~V}, \mathrm{I}_{\text {LOAD }}$ varying from $10 \%$ to $100 \%$ of $I_{\text {Rated }}=20 \mathrm{~mA}$. 
Table 4-7 summarizes the output voltage, VOUT_1_22v, versus the output current, IOUT_5V, as the load is varied from $10 \%$ to $100 \%$. Applying Equation $4-15$ and Table $4-7$, determines the $5 \mathrm{~V}-1.22 \mathrm{~V}$ LDO's load regulation to be $0.08 \%$ (Equation 4-18).

$\%$ Load Regulation $=\frac{1.2221 \mathrm{~V}-1.2211 \mathrm{~V}}{1.2211 \mathrm{~V}} * 100=0.08 \%$

Table 4-7: LT3014 5 V - 1.22 V LDO Load Regulation Simulation Results; $V_{\text {IN, Nominal }}=4.993 \mathrm{~V}$.

\begin{tabular}{|c|c|c|c|}
\hline \% Load (\%) & I OUT_5V $(\mathrm{mA})$ & RoUT_1_22V $(\Omega)$ & $V_{\text {OUT_1_22V }}(\mathrm{V})$ \\
\hline 10 & 2 & 610 & 1.2221 \\
\hline 20 & 4 & 305 & 1.222 \\
\hline 30 & 6 & 203.33 & 1.2218 \\
\hline 40 & 8 & 152.5 & 1.2217 \\
\hline 50 & 10 & 122 & 1.2216 \\
\hline 60 & 12 & 101.67 & 1.2215 \\
\hline 70 & 14 & 87.143 & 1.2213 \\
\hline 80 & 16 & 76.25 & 1.2212 \\
\hline 90 & 18 & 67.778 & 1.2211 \\
\hline 100 & 20 & 61 & 1.221 \\
\hline
\end{tabular}

The complete DC Light Bulb's dimmer design is shown in Figure 4-17. The dimmer's worst case line and load regulations are summarized in Table 4-8. 

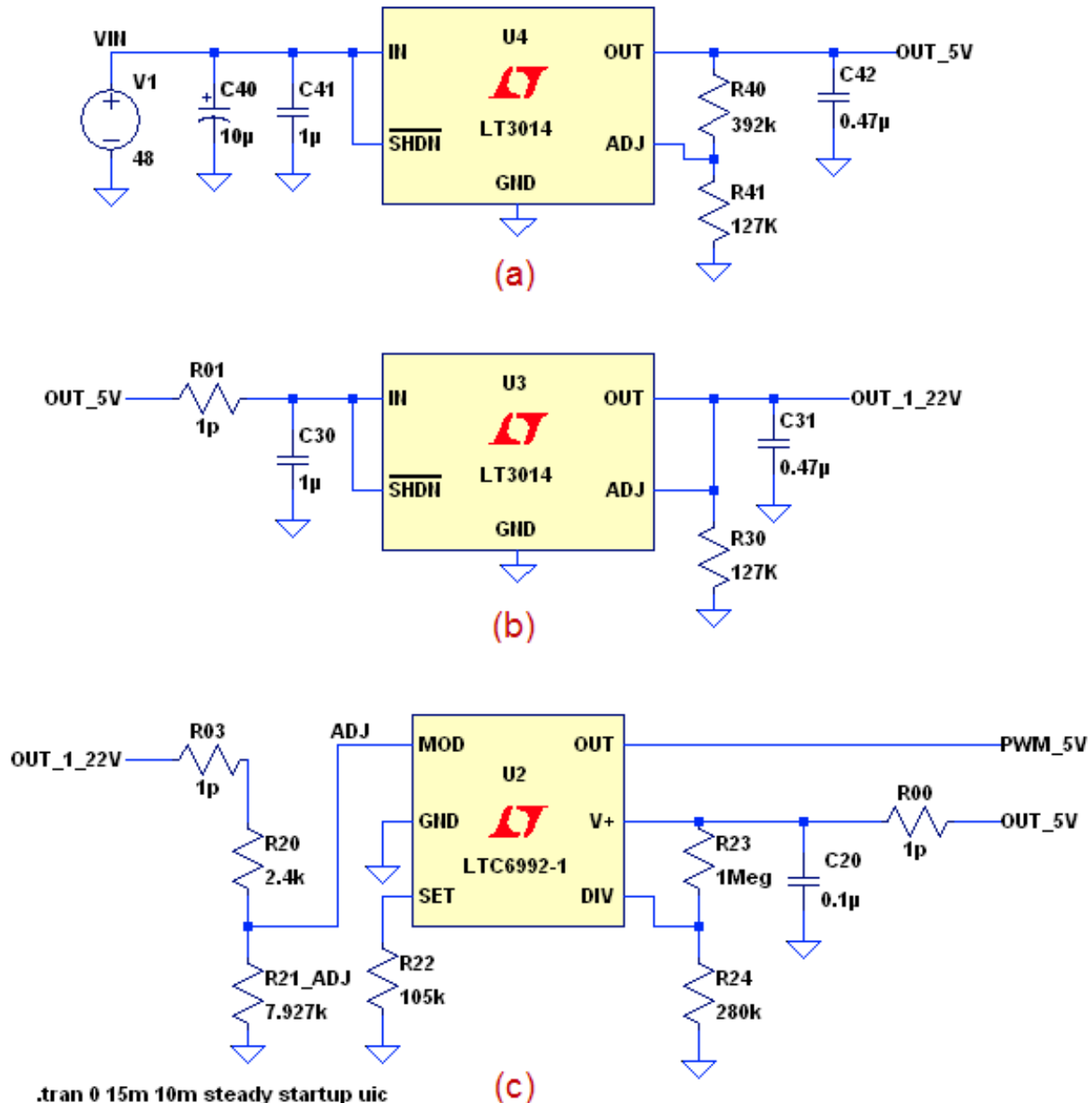

Figure 4-17: Complete Dimmer Circuit Design, (a) 48 V - 5 V LDO, (b) 5 V - 1.22 V LDO, (c) PWM Controller.

Table 4-8: Dimmer Circuit's LDO Worst Case Line and Load Regulations.

\begin{tabular}{|l|l|}
\hline \multicolumn{2}{|l|}{48 V - 5 V LDO } \\
\hline Line Regulation @ 15\% change in Vin & $0.01 \%$ \\
\hline Load Regulation from 10\% to 90\% load & $0.05 \%$ \\
\hline $\mathbf{5}$ V - 1.22 V LDO \\
\hline Line Regulation @ 15\% change in Vin & $0.00 \%$ \\
\hline Load Regulation from 10\% to 90\% load & $0.08 \%$ \\
\hline
\end{tabular}




\subsection{2: LED Array}

Next, the LED array is designed and LED type is selected. As Chapter 3 suggests, one of the design requirements was to maintain the A19 dimension (Figure 3-1), which means the LED array and LED driver circuitry must fit within those parameters. After countless hours of research, it was determined to not be cost effective to design a custom light bulb housing from scratch. Custom computer aided design (CAD) and manufacturing can cost more than $\$ 1000$ and should only be considered for mass production. Therefore, mechanical design of the Light Bulb is out of the scope of this thesis. As an alternative, a relatively inexpensive (\$9.97) 120VAC LED light bulb made by EcoSmart (Figure 2-10) was used to house the new DC Light Bulb design. Figure 4-18 illustrates the disassembled EcoSmart light bulb housing. Figure 4-18 (b) suggests that the placement of the LEDs must fit within a circular area with a diameter less than $31 \mathrm{~mm}$. 


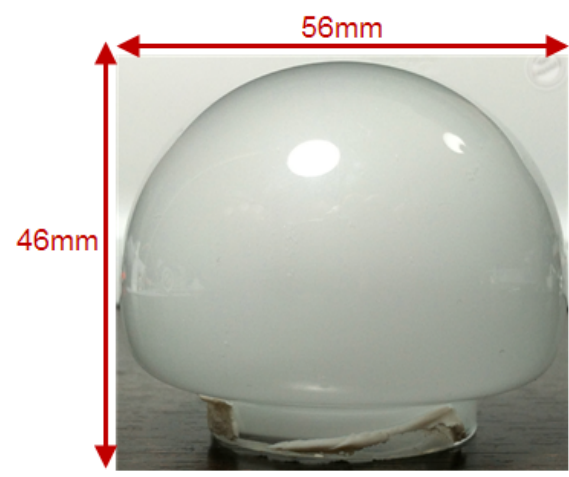

(a)

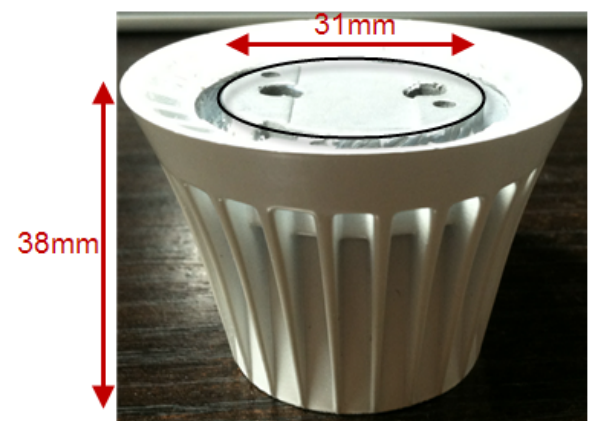

(b)

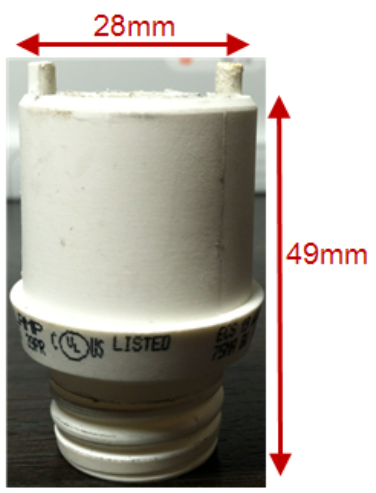

(c)

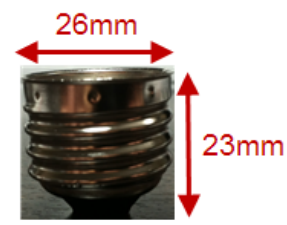

(d)

Figure 4-18: DC Light Bulb Enclosure Dimensions, (a) Light Diffuser, (b) Aluminum Heatsink, (c) Inner Sleeve for Electronics, (d) E26 Screw Base.

Metal core printed circuit boards (MCPCB) are often used for high power LED applications, because it dissipates heat better. A $25 \mathrm{~mm}$ custom MCPCB designed for CREE XPE/XPC/XPG series LEDs was chosen to meet the space requirement indicated in Figure 4-18 (b) [56]. Figure 4-19 illustrates the (a) physical 25 mm MCPCB design and (b) 4 CREE XPG LEDs in series configuration. 


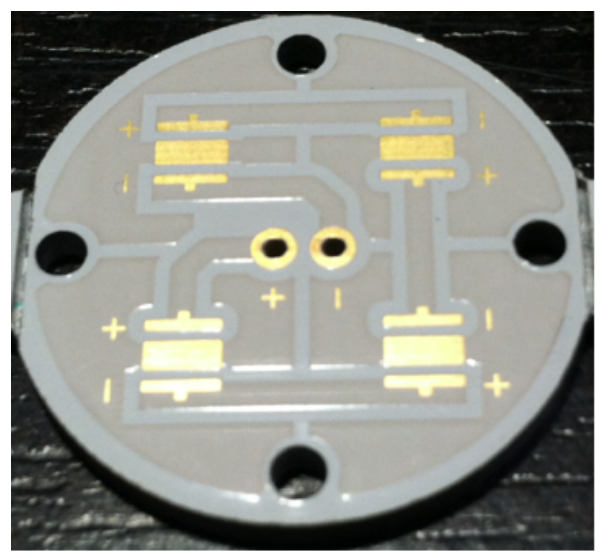

(a)

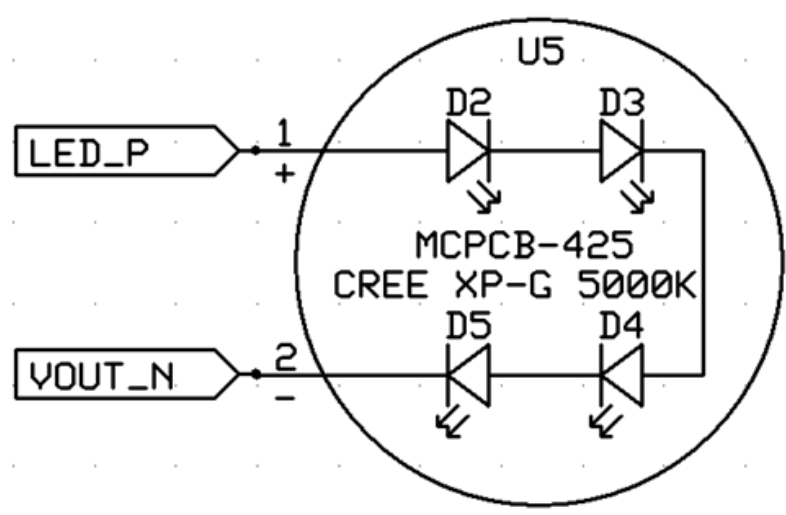

(b)

Figure 4-19: 25 mm MCPCB for 4 CREE XPG LEDs in Series, (a) Physical Design, (b) Schematic Design.

CREE's high power XPG (XPGWHT-01-R250-00GC1) LED with a cool white (5000K) color temperature was selected. This LED was chosen because it offers great luminous efficacy of 110 lumens/watt. Note this closely follows the projected Lm/W for the year 2010 , as suggested in Figure 2-15. This particular CREE LED was also chosen because it is rated up to $1.5 \mathrm{~A}$ at a forward voltage of $3.25 \mathrm{~V}$. With this in mined, the DC Light Bulb was selected to operate at $1 \mathrm{~A}$ with a forward voltage of $3.15 \mathrm{~V}$ so that it can produce 110 lumens/watt. Figure 4-20 illustrates CREE XPG LED's forward current versus forward voltage characteristic at a junction temperature of 25 ㅇ․ The estimated total output power for 4 LEDs in series is then calculated to be $12.6 \mathrm{~W}$ (Equation 4-19).

$$
P_{\text {OUT }}=4 * V_{F} * I_{F}=4 * 3.15 \mathrm{~V} * 1 \mathrm{~A}=12.6 \mathrm{~W}
$$




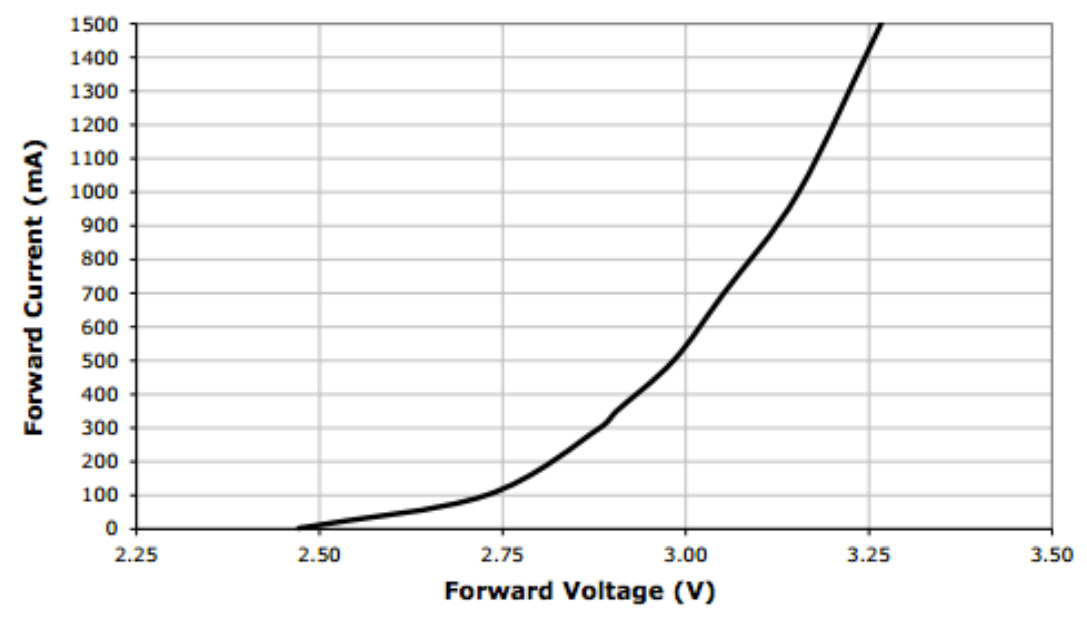

Figure 4-20: CREE XPG LED's Forward Current Vs. Voltage Characteristics [58].

Figure 4-21 suggests that driving the LED array at $1 \mathrm{~A}$, maximum ambient temperature of about $110 \stackrel{\circ}{ } \mathrm{C}$ should not be exceeded. Chapter 5 will cover the physical thermal response of the DC Light Bulb operating from 0 hour to 12 hour at 30 minute increments.

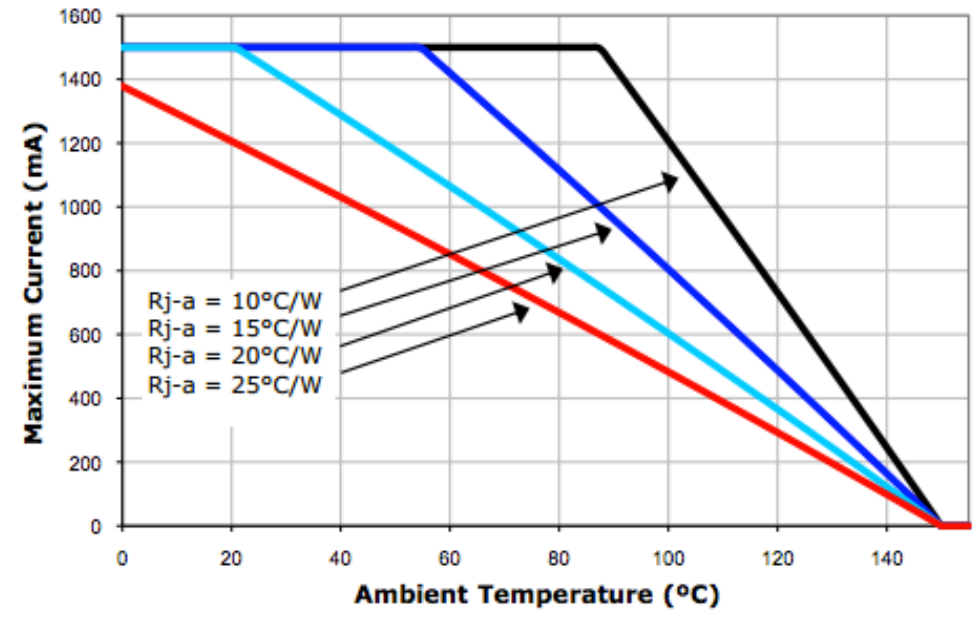

Figure 4-21:CREE XPG Cool White (5000K) Forward Current vs. Ambient Temperature [58]. 


\subsection{3: LED Driver}

In the following section, the DC Light Bulb's LED driver circuit will be designed and simulated. Linear Technology's LT3756-2, LED controller was selected to meet the 1 A output with PWM dimming capabilities. LT3756-2 offers a wide input voltage range of $6 \mathrm{~V}-100 \mathrm{~V}$, 3000:1 PWM dimming ratio, and can drive LEDs in a Buck, Boost, Buck-Boost, SEPIC, or Flyback topology [57]. This LED driver offers great versatility and flexibility to meet the wide power requirements in different lumination applications. As suggested in section 4.2.1, four CREE XPG LEDs in series would require $12.6 \mathrm{~V}$ at full load of $1 \mathrm{~A}$. Therefore a Buck mode configuration was chosen for the LED driver's output stage. Figure 4-22 suggests the final LED driver design for the DC Light Bulb.

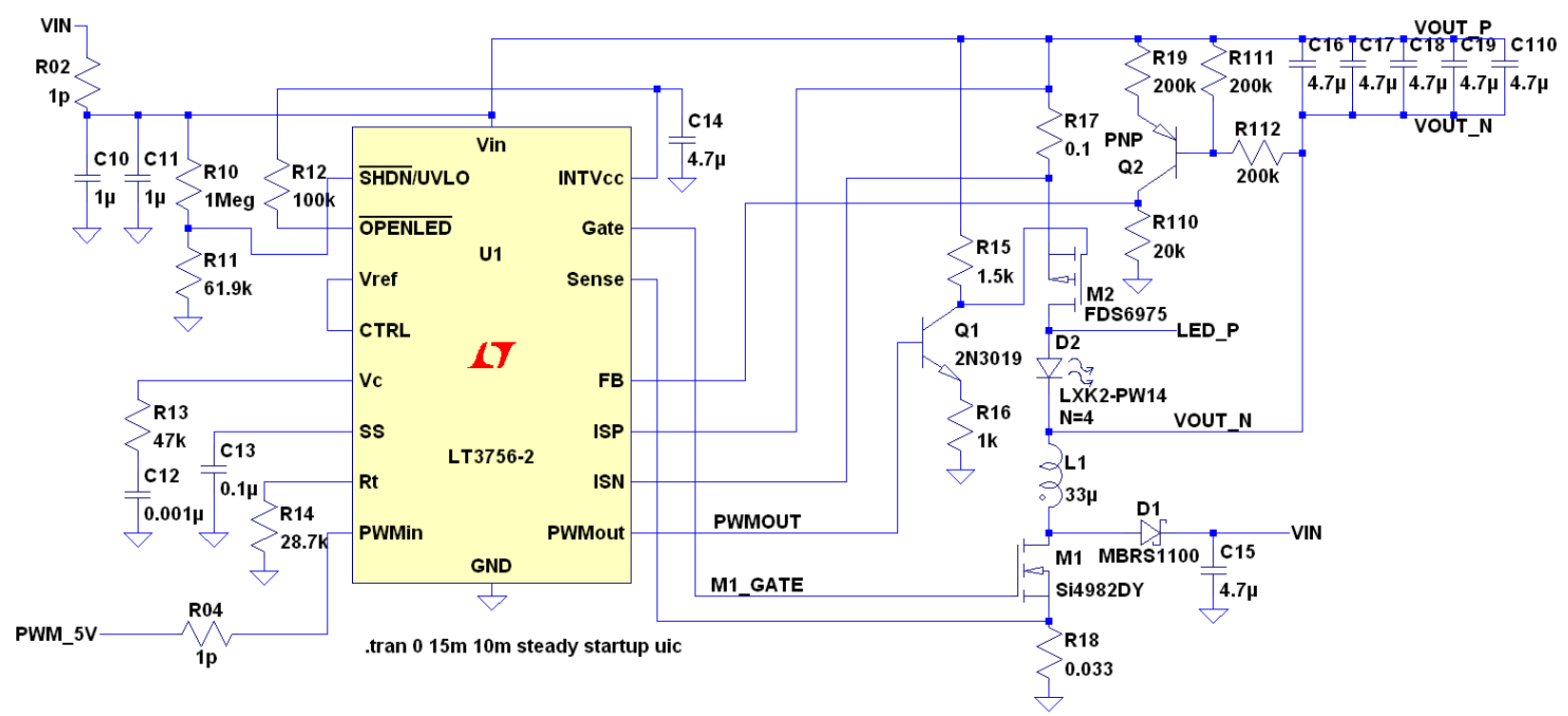

Figure 4-22: LED Driver Schematic in Buck Mode operating at 1 A Full Load. 
The VIN pin is tied directly to DC House's main 48 VDC bus voltage. PWMin pin is connected to the PWM controller, LTC6992-1, suggested in Figure 4-17 (c). PWMout produces a high logic of 7.15 V when PWMin sees more than $1.5 \mathrm{~V}$ and PWMout produces a low logic of 0 V when PWMin sees less than $0.4 \mathrm{~V}$ at the PWMin pin. Figure 4-23 illustrates the input (PWMin) and output (PWMout) effects when a PWM signal is applied to the LED driver at duty cycles of $0 \%, 28.086 \%, 50.07 \%$, and $93.176 \%$. As the duty cycle increases, the time, ton stays on for a longer duration, while the switching frequency remains fixed at $7.5 \mathrm{kHz}$ (defined by PWM controller settings and calculated in Equation 4-3).

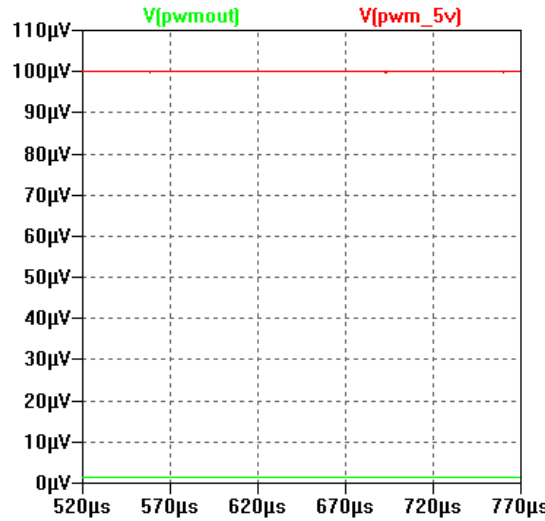

(a)

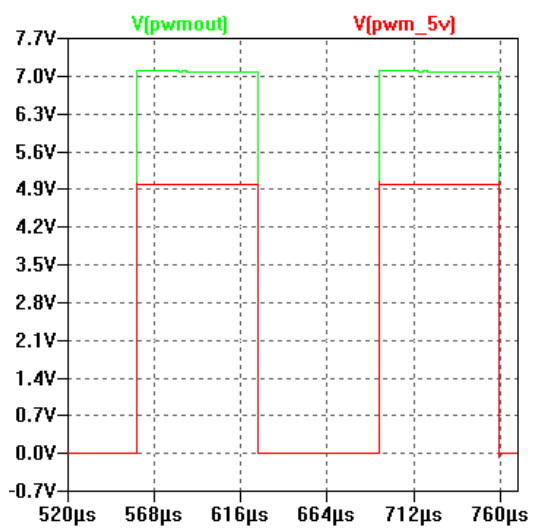

(c)

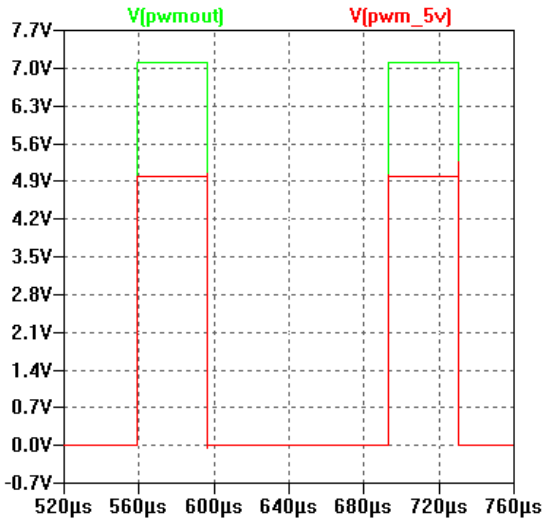

(b)

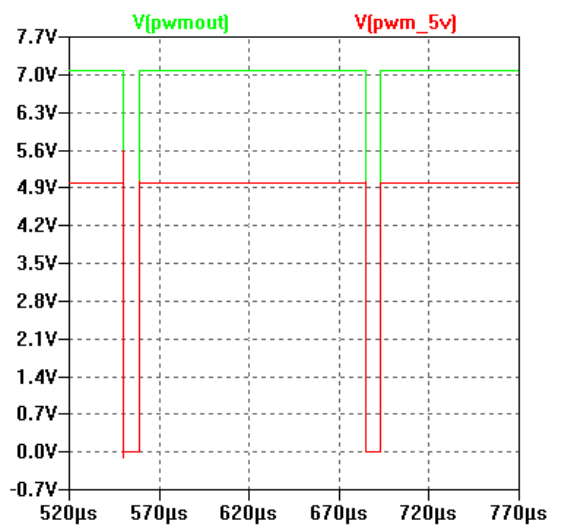

(d)

Figure 4-23: $V\left(P W M \_5 V\right)$ vs. $V(P W M O U T)$ For $(a) D=0 \%$, (b) $D=28.086 \%,(c) D=50.07 \%,(d) D=93.176 \%$. 
Next, the Buck mode output stage of the LED driver will be analyzed and validated through LTspice simulations for V(PWMOUT) versus V(M1 gate), V(M2 gate), I(LED), and I(L1) relationship at various duty cycles. Figure 4-24 illustrates V(PWMOUT) versus V(M1 gate) for duty cycles of $0 \%, 28.086 \%, 50.07 \%$, and $93.176 \%$.

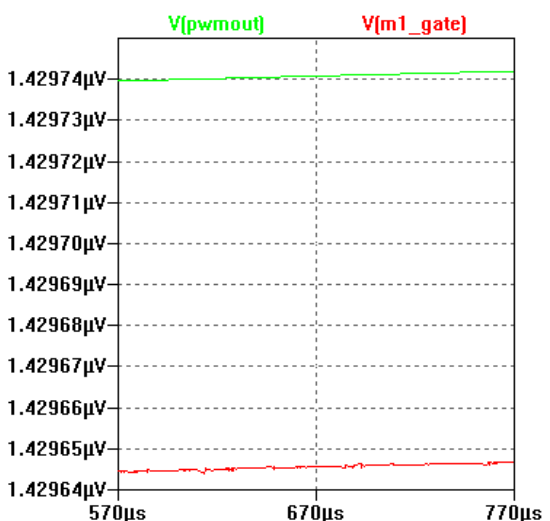

(a)

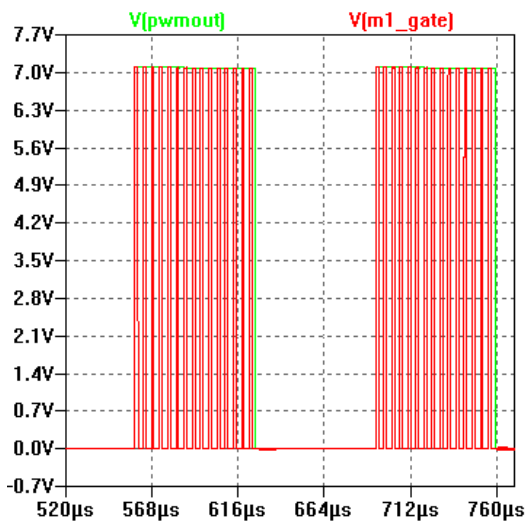

(c)

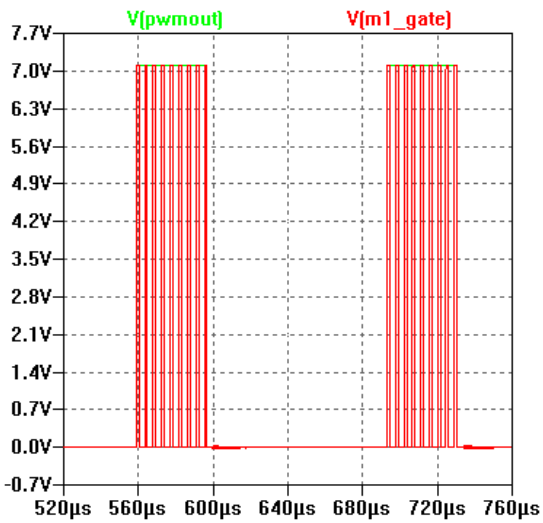

(b)

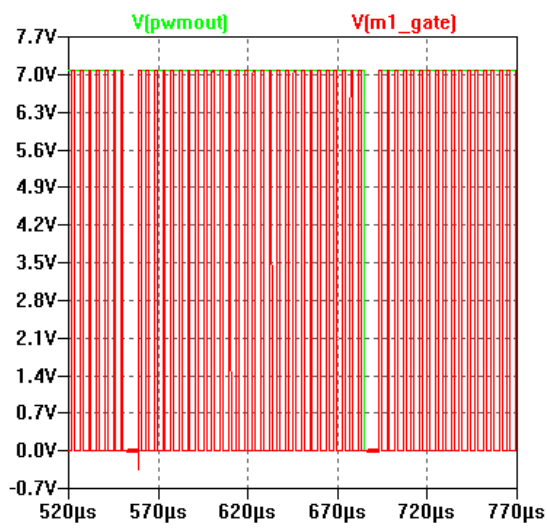

(d)

Figure 4-24: $V(P W M O U T)$ vs. $V(M 1$ Gate) For (a) $D=0 \%$, (b) $D=28.086 \%$, (c) $D=50.07 \%$, (d) $D=93.176 \%$.

M1 gate represents the LT3756-2's GATE pin. The GATE pin pulses the (M1) N-channel MOSFET on and off according to the current sense control loop seen by the SENSE pin. This current sense control loop also interacts with the voltage feedback loop seen at the FB pin and the differential voltage between ISP and ISN to ensure it does not exceed the internal $2 \mathrm{~V}$ 
threshold voltage set by the CTRL pin [57]. Through both the current and voltage control loops, constant current of roughly $1 \mathrm{~A}$ is maintained across the LED array. Figure 4-24 also suggests that the GATE only pulsates within the duty cycle duration set by the PWM signal supplied by LTC6992-1 PWM controller. Next, V(PWMOUT) versus V(M2 Gate) relationship is compared and analyzed through Figure 4-25.

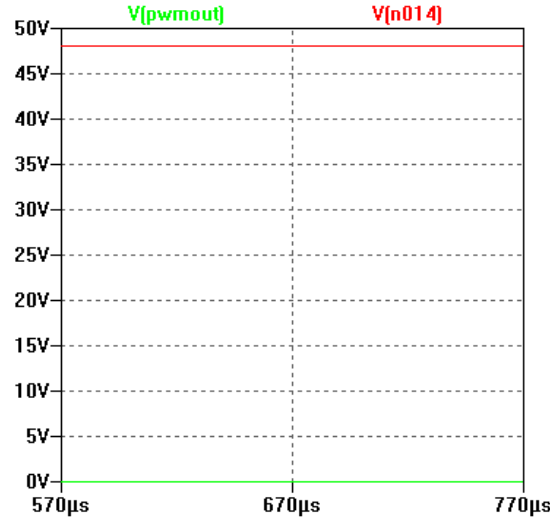

(a)

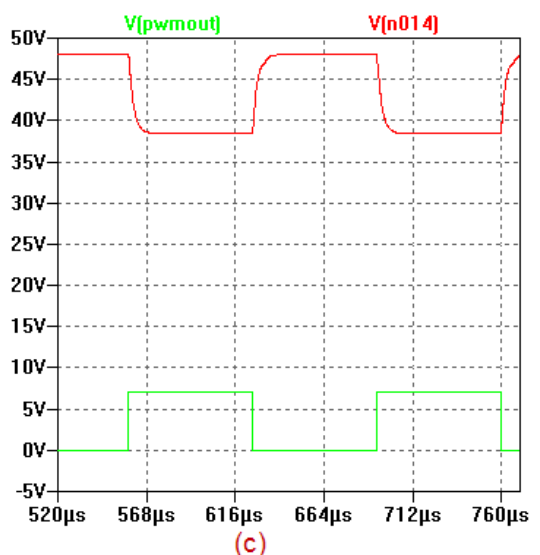

(c)

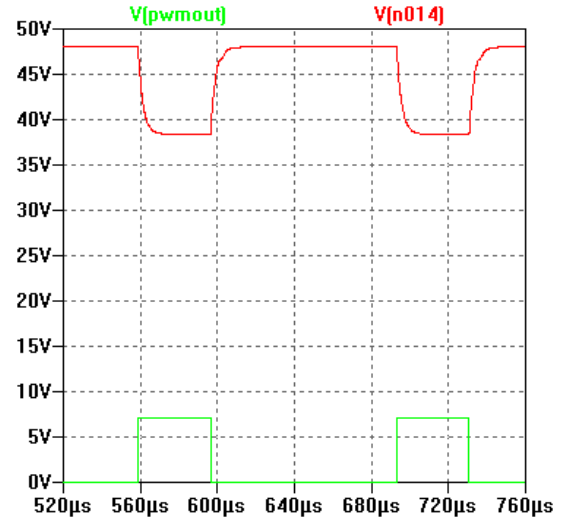

(b)

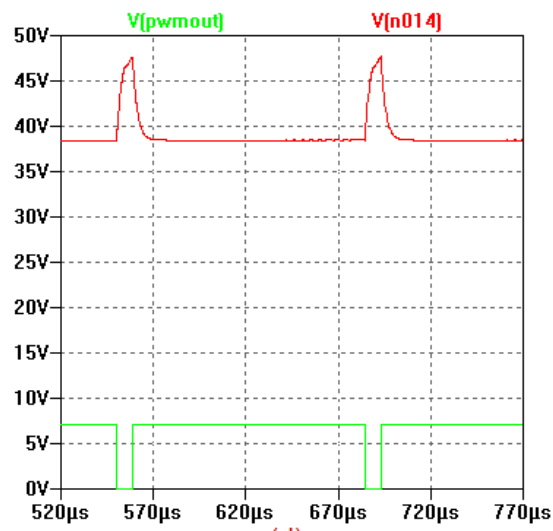

(d)

Figure 4-25: V(PWMOUT) vs. $V(M 2$ Gate) For $(a) D=0 \%$, (b) $D=28.086 \%$, (c) $D=50.07 \%$, (d) $D=93.176 \%$.

$M 2(n 014)$ is a P-channel MOSFET that turns on when it sees a logic low signal (in this case 38V). When the (Q1) NPN BJT sees a logic low (OV) from the PWMOUT pin, it does not turn on and $\mathrm{M} 2$ gate is maintained at $48 \mathrm{~V}$. When $\mathrm{Q} 1$ receives a logic high $(7 \mathrm{~V})$ across its base 
terminal, it turns on and connects roughly $38 \mathrm{~V}$ to ground. Now $\mathrm{M} 2$ 's gate terminal sees a voltage decrease of $10 \mathrm{~V}$ when referenced to $48 \mathrm{~V}$, thus a logic low occurs and $\mathrm{M} 2$ turns on. When $\mathrm{M} 2$ turns on it completes the path of current flow through the LED array. The use of a Pchannel MOSFET is smart, because it eliminates the need of a high power MOSFET to handle its high current switching.

Next, V(PWMOUT) versus I(L1) and V(PWMOUT) versus I(LED) are reviewed and its simulation waveforms at various duty cycles are shown in Figure 4-26 and Figure 4-27, respectfully. LT3756-2 internal error amplifier sets the correct peak switch current seen by the inductor (L1) to maintain the LED current in regulation [57]. When the error amplifiers output increases, it means that the switch requires more current. If the error amplifier output signal decreases, it means the switch demands less current. The current control loop through the SENSE pin monitors that the current limit threshold voltage of $108 \mathrm{mV}$ is not exceeded [57]. 


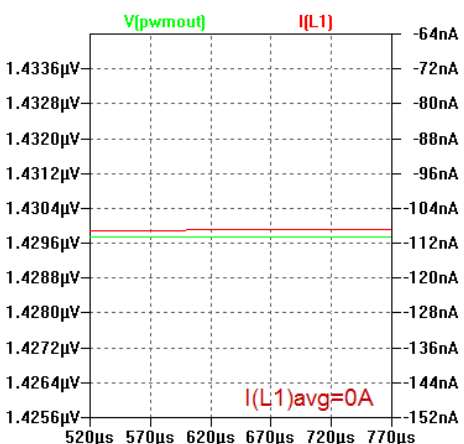

(a)

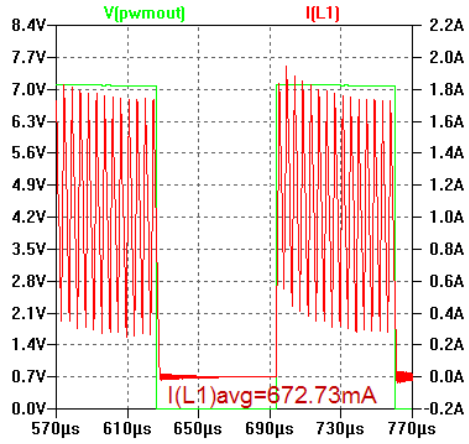

(c)

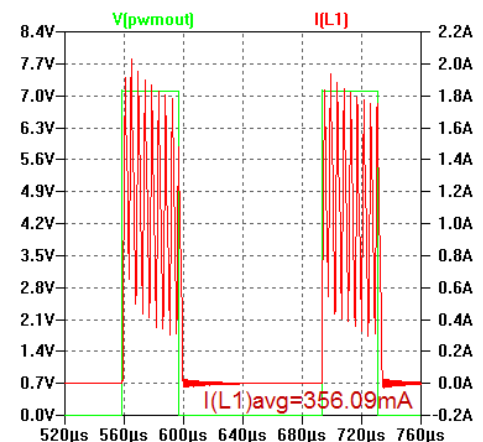

(b)

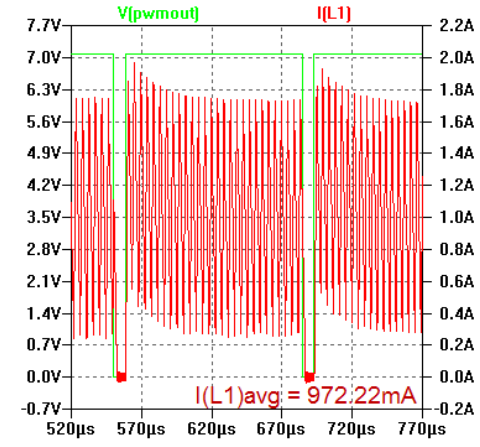

(d)

Figure 4-26: V(PWMOUT) vs. I(L1) For (a) $D=0 \%$, (b) $D=28.086 \%$, (c) $D=50.07 \%$, (d) $D=93.176 \%$.

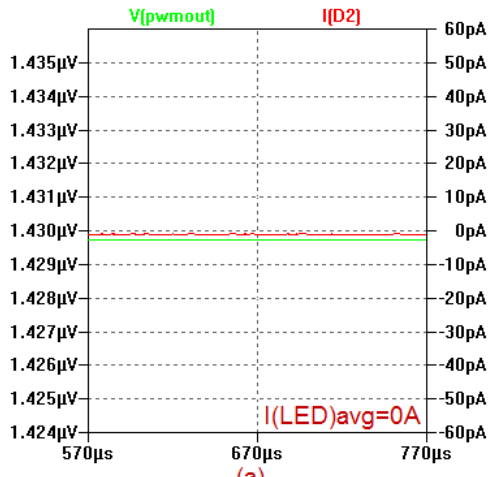

(a)

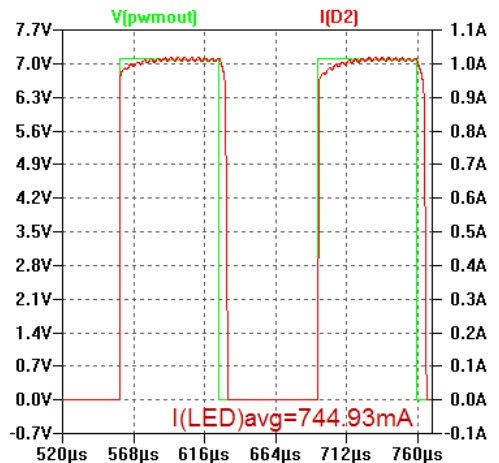

(c)

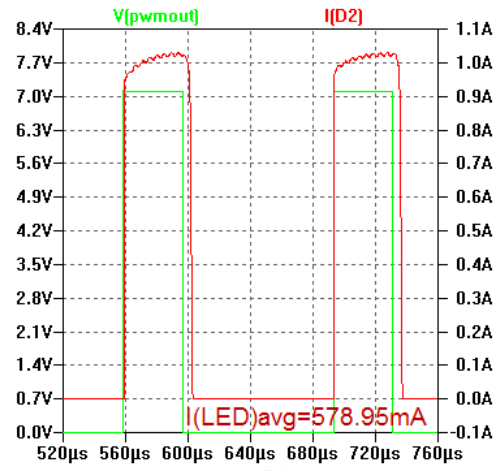

(b)

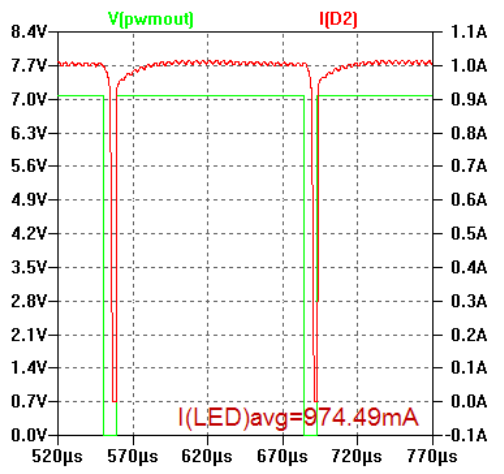

(d)

Figure 4-27: V(PWMOUT) vs. I(LED) For (a) $D=0 \%$, (b) $D=\mathbf{2 8 . 0 8 6 \% , ~ ( c ) ~} D=50.07 \%$, (d) $D=93.176 \%$. 


\section{3 : Summary of DC Light Bulb Design}

The complete DC Light Bulb design and simulation results are summarized in Table 4-9.

The DC Light Bulb was simulated to operate at input voltages from $24 \mathrm{~V}$ to $72 \mathrm{~V}$. In order for it to work at $12 \mathrm{~V}$, the output Buck Mode components must be recalculated and resized. Despite not meeting the suggested design goal of being a truly universal light bulb, it satisfies the required target constraints for the DC House project. Figure 4-28 illustrates the complete DC Light Bulb design schematic. Table 4-10 summarizes the simulation data collected. Figure 4-29 illustrates the DC Light Bulb's simulation efficiency versus varying LED load.

Table 4-9: DC Light Bulb Design and Simulation Results.

\begin{tabular}{|c|c|}
\hline Parameters & Specifications \\
\hline Wide Input Voltage Range (Simulated): VIN & $24 \mathrm{~V}$ to $72 \mathrm{~V}$ \\
\hline Output Voltage in Buck Mode: V(LED) & $0 \mathrm{~V}$ to $25 \mathrm{~V}$ \\
\hline PWM Dimming via $10 \mathrm{k} \Omega$ Potentiometer: Duty Cycle & $0 \%$ to $100 \%$ \\
\hline Efficiency at Full Load & $* 91.34 \%$ \\
\hline Total Power Consumption & $* 14.85 \mathrm{~W}$ \\
\hline LED Type & $\begin{array}{c}\text { CREE XLAMP XP-G } \\
\text { XPGWHT-01-R250-00GC1 }\end{array}$ \\
\hline Number of LEDs in Series & 4 \\
\hline Color Temperature & Cool White (5000K) \\
\hline Luminous Efficacy & 110.48 Lumens/Watt \\
\hline Luminous Flux at $1 \mathrm{~A}$ & 348 Lumens \\
\hline Max Forward Voltage & $3.25 \mathrm{~V}$ \\
\hline Max Forward Current & $1.5 \mathrm{~A}$ \\
\hline Max Temperature Recommended at Forward Current of $1 \mathrm{~A}$ & $110 \stackrel{\circ}{C}$ \\
\hline Max LED Junction Temperature & $150 \cong \mathrm{C}$ \\
\hline Line Regulation at $15 \%$ Input Voltage Swing & $0.01 \%$ \\
\hline LDO Load Regulation from $10 \%$ to $90 \%$ Load & $0.08 \%$ \\
\hline Constant Current Regulation & Yes \\
\hline Constant Voltage Regulation & Yes \\
\hline Open LED Protection & Yes \\
\hline
\end{tabular}




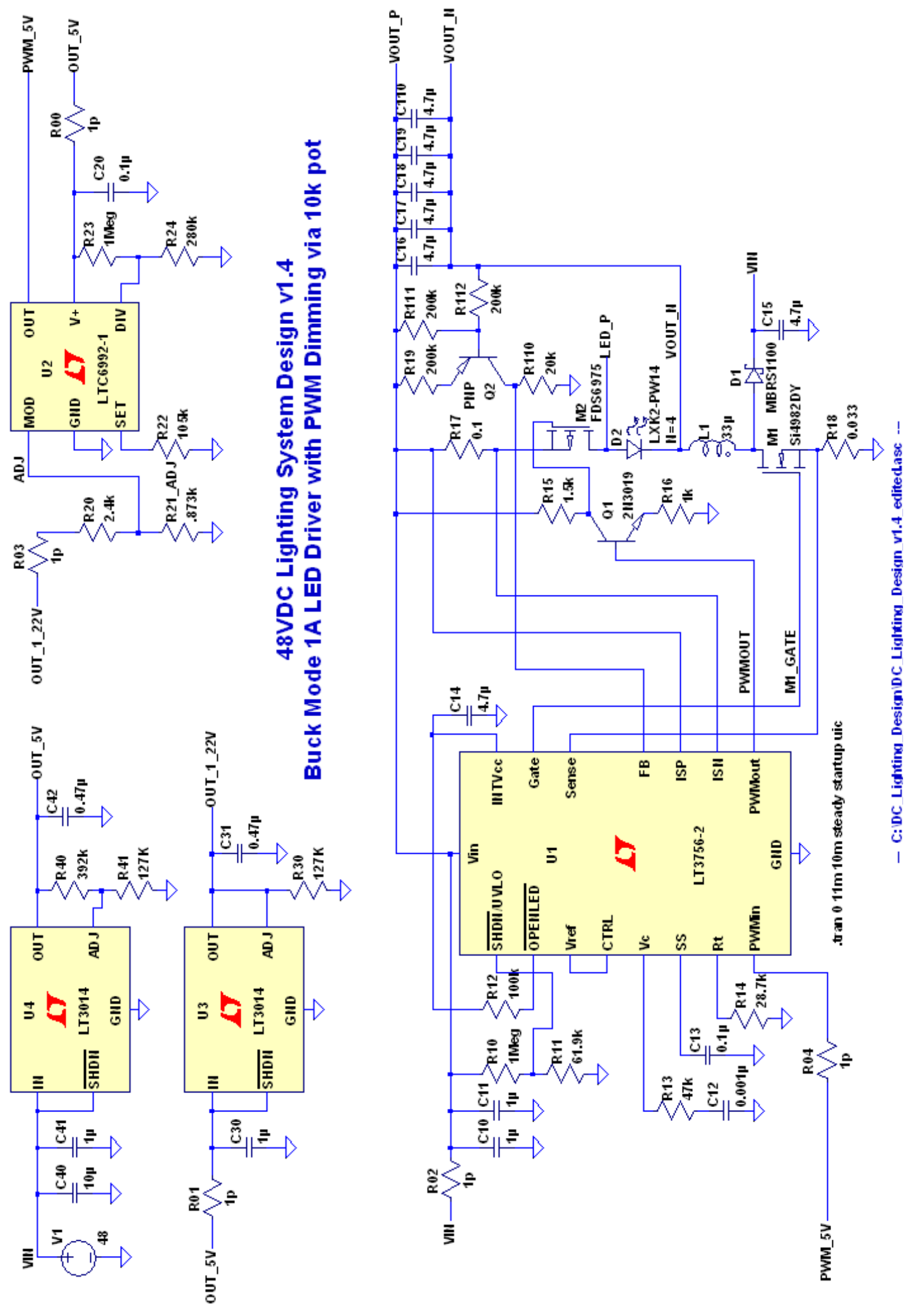

Figure 4-28: Complete DC Light Bulb Design Schematic. 
Table 4-10: DC Light Bulb Simulation Data.

\begin{tabular}{|c|c|c|c|c|c|c|c|c|}
\hline $\begin{array}{c}\text { Duty Cycle } \\
\%\end{array}$ & $\begin{array}{c}\text { PWMOUT } \\
f_{\text {SW }}(\mathrm{kHz})\end{array}$ & $\begin{array}{c}\text { R21_ADJ } \\
(\mathrm{k} \Omega)\end{array}$ & $\begin{array}{c}\text { ADJ } \\
(\mathrm{V})\end{array}$ & $\begin{array}{c}\text { Steady } \\
\text { State } \\
\text { Pin }(\mathrm{W})\end{array}$ & $\begin{array}{c}\text { Steady } \\
\text { State } \\
\text { (D2)avg } \\
(\mathrm{mA})\end{array}$ & $\begin{array}{c}\text { LED Vout } \\
(\mathrm{V})\end{array}$ & $\begin{array}{c}\text { Steady } \\
\text { State } \\
\text { LED } \\
\text { Pout } \\
(\mathrm{W})\end{array}$ & $\begin{array}{c}\text { Efficiency } \\
(\%)\end{array}$ \\
\hline $0.000 \%$ & 7.500 & 0.000 & 0.000 & 0.054 & 0.000 & 0.000 & 0.000 & $0.000 \%$ \\
\hline $0.000 \%$ & 7.500 & 0.133 & 0.064 & 0.081 & 0.000 & 0.000 & 0.000 & $0.000 \%$ \\
\hline $6.606 \%$ & 7.434 & 0.341 & 0.152 & 2.777 & 195.340 & 12.797 & 2.420 & $87.144 \%$ \\
\hline $17.409 \%$ & 7.443 & 0.584 & 0.239 & 7.134 & 468.260 & 13.863 & 6.355 & $89.072 \%$ \\
\hline $28.086 \%$ & 7.442 & 0.873 & 0.326 & 9.066 & 578.950 & 14.206 & 8.105 & $89.394 \%$ \\
\hline $39.616 \%$ & 7.384 & 1.230 & 0.414 & 10.776 & 678.330 & 14.498 & 9.711 & $90.113 \%$ \\
\hline $50.070 \%$ & 7.440 & 1.668 & 0.501 & 11.965 & 744.930 & 14.668 & 10.808 & $90.330 \%$ \\
\hline $58.827 \%$ & 7.193 & 2.226 & 0.588 & 12.862 & 796.630 & 14.785 & 11.666 & $90.701 \%$ \\
\hline $67.938 \%$ & 7.384 & 2.971 & 0.676 & 14.314 & 876.800 & 15.003 & 12.998 & $90.806 \%$ \\
\hline $82.743 \%$ & 7.439 & 3.990 & 0.763 & 15.256 & 933.340 & 15.133 & 13.962 & $91.518 \%$ \\
\hline $93.176 \%$ & 7.420 & 5.484 & 0.850 & 16.051 & 974.490 & 15.204 & 14.679 & $91.452 \%$ \\
\hline $100.000 \%$ & 7.500 & 7.927 & 0.938 & 16.258 & 984.250 & 15.215 & 14.850 & $91.340 \%$ \\
\hline $100.000 \%$ & 7.500 & 12.047 & 1.019 & 16.339 & 984.160 & 15.216 & 14.849 & $90.881 \%$ \\
\hline
\end{tabular}

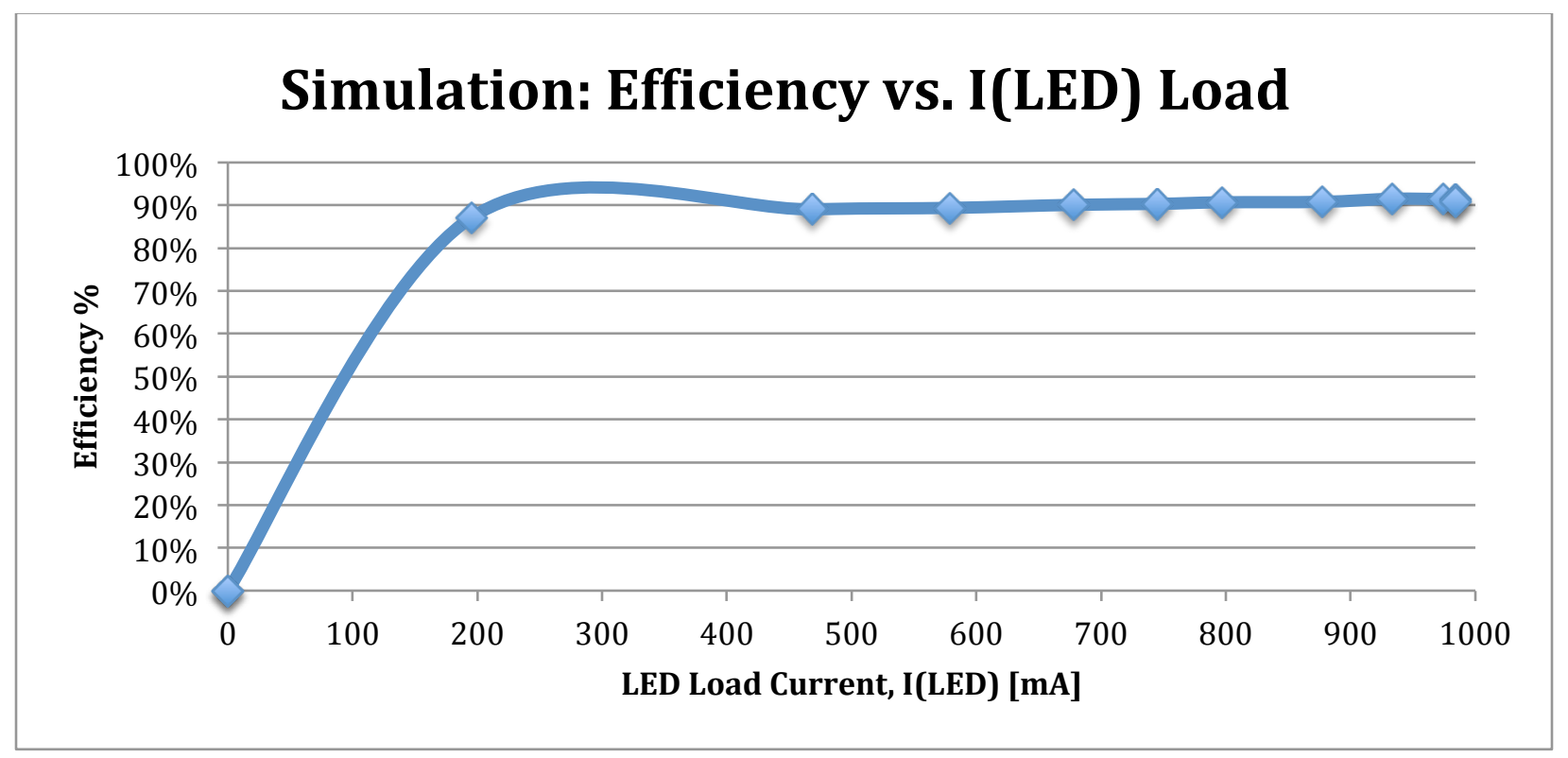

Figure 4-29: DC Light Bulb Simulation: Efficiency vs. I(LED). 


\section{Chapter 5: Hardware Design and Results}

In this chapter, the DC Light Bulb's hardware design, implementation, and testing are reviewed. First, the design of a custom 4-layer PCB layout will be described. Next, the LED array and heatsink implementation will be covered. Then, laboratory test setups for efficiency, line regulation, lumination, and thermal measurements are evaluated. Lastly, the DC Light Bulb's hardware characteristics and electrical specifications are summarized and compared with the simulation data presented in Chapter 4.

\section{1 : Custom 4-Layer PCB Layout Design}

The design of the DC Light Bulb's custom 4-layer PCB involves a two-step process. First, a new schematic was created (based on the design generated in LTspice, Figure 4-28) using ExpressSCH (Figure 5-1). Then, this new schematic was used in aiding the component pad sizing and routing of the signal traces using ExpressPCB [60]. Linking the ExpressSCH schematic to the Express $\mathrm{PCB}$ layout file helps the designer by highlighting the pins that should be connected together, thus reducing the chance of incorrect routing of the signal traces. The DC Light Bulb's custom 4-layer layout design is shown in Figure 5-2. 


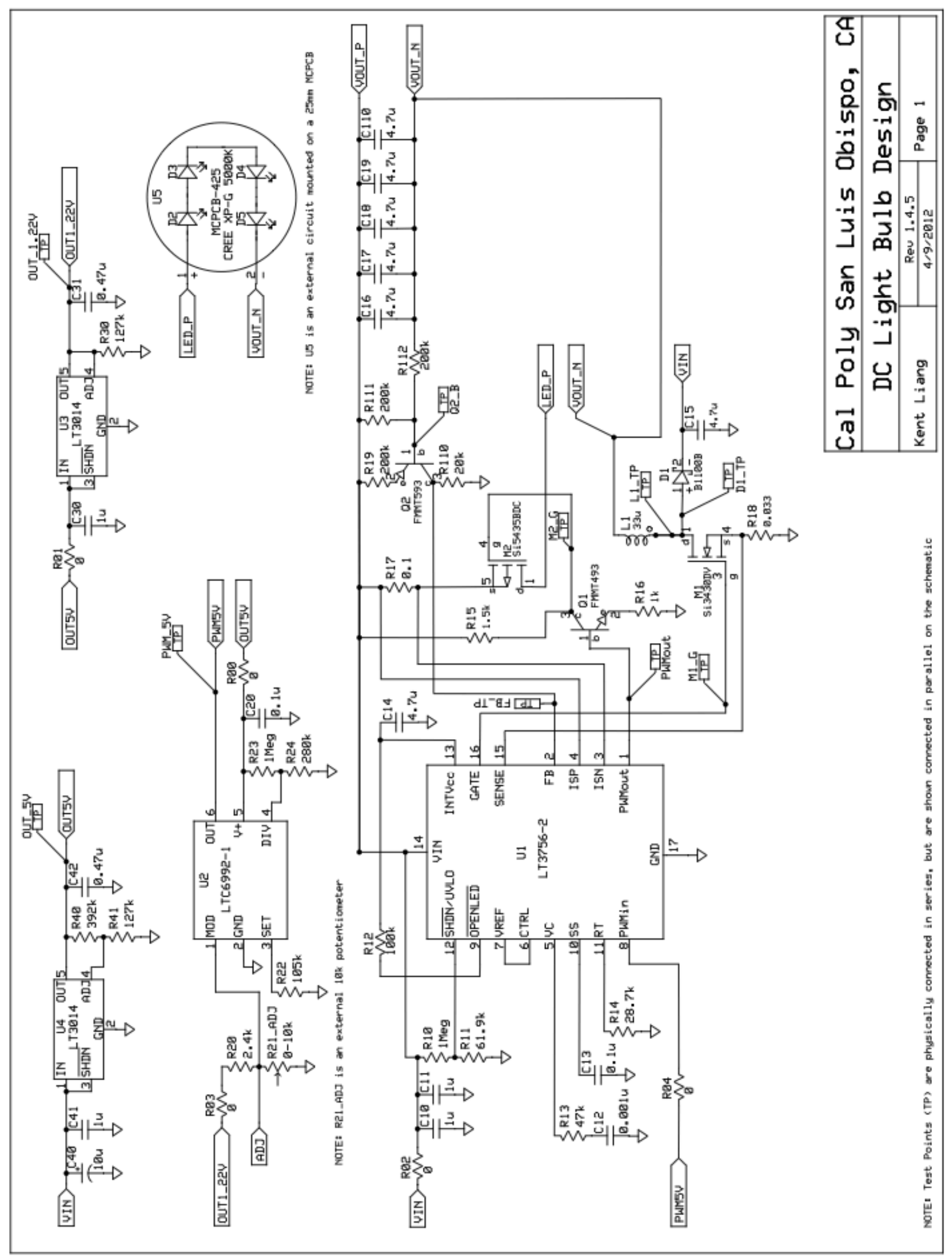

Figure 5-1: ExpressSCH - DC Light Bulb Schematic Design. 


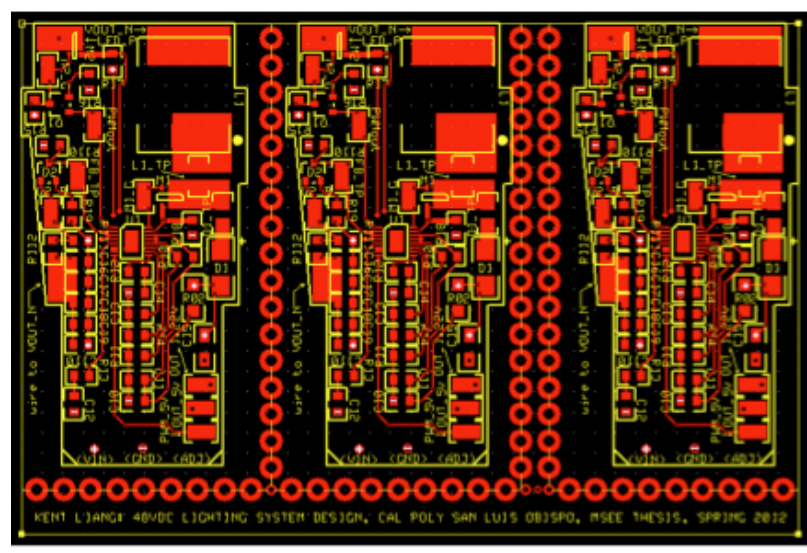

(a) $1^{\text {st }}$ Layer: Top Signal Plane

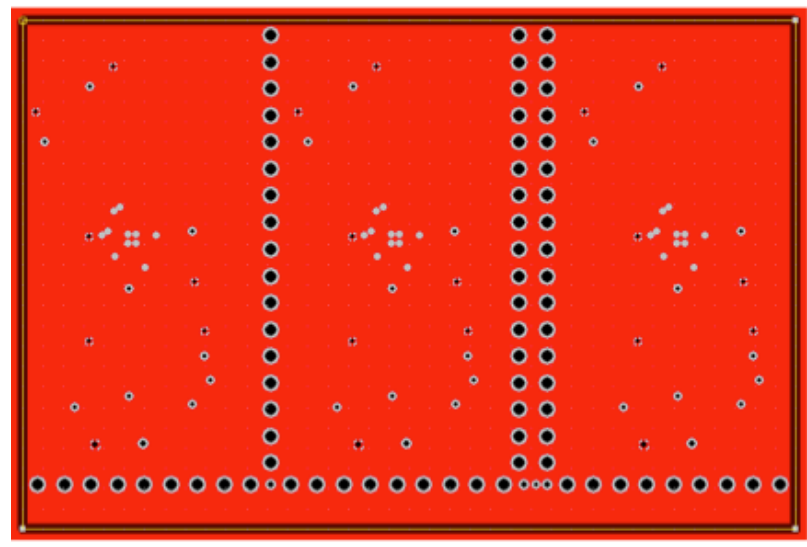

(c) $3^{\text {rd }}$ Layer: Inner Power Plane

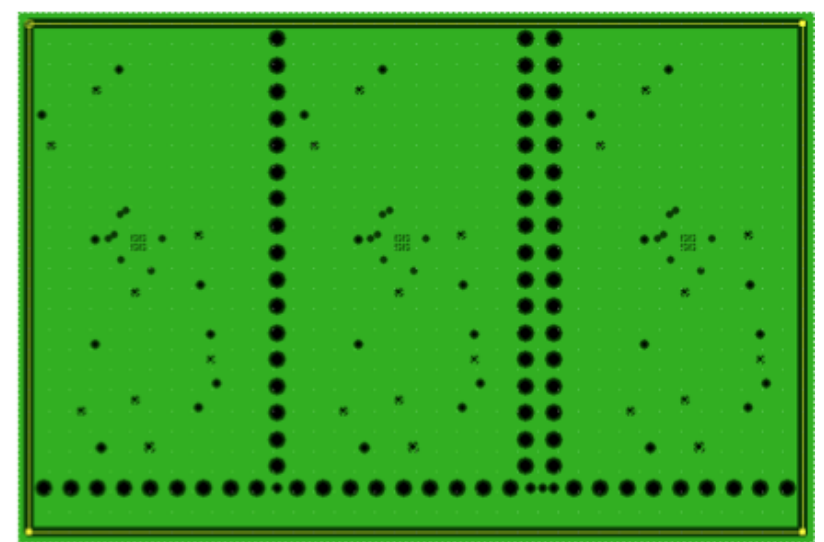

(b) $2^{\text {nd }}$ Layer: Inner Ground Plane

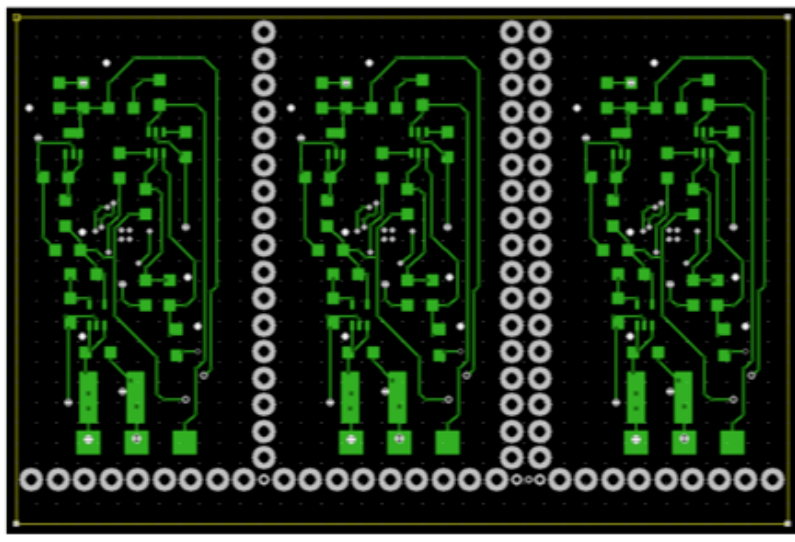

(d) $4^{\text {th }}$ Layer: Bottom Signal Plane

Figure 5-2: ExpressPCB - 4-Layer PCB Layout Design, (a) Top Signal Plane, (b) Inner Ground Plane, (c) Inner Power Plane, (d) Bottom Signal Plane.

Figure 5-2 (a) illustrates the top signal plane. Referring to Figure 5-1, the high power Buck Mode output stage is specifically grouped together and placed on the top half of the $1^{\text {st }}$ layer. Since the Buck Mode output stage supplies constant 1 A into the LED array, it would generate more heat and more noise due to the switching elements (in particular the MOSFETs M1, M2, and inductor L1). The LED driver chip (LT3756-2) and associated circuit resistors and capacitors are placed on the bottom half of the $1^{\text {st }}$ layer. Figure 5-2 (b) and (c) illustrates the 
inner ground and inner power planes, respectfully. Having a solid ground plane instead of individual ground islands offer greater immunity to noise and electromagnetic coupling caused by high frequency switching and unbalanced ground loops. Due to the complexity of the DC Light Bulb's circuitry, having a dedicated power and ground plane reduces the routing required for 48 VDC (power plane) and ground traces. Lastly, Figure 5-2 (d) illustrates the bottom signal layer, where the dimmer circuitry (in particular the two LT3014 LDOs and LT6992-1 PWM controller and their associated resistors and capacitors) is placed. Figure 5-3 illustrates the finished $3.8 \times 2.5$ inch custom 4-layer PCB layout (also called MiniBoardPro by ExpressPCB) after manufacturing.

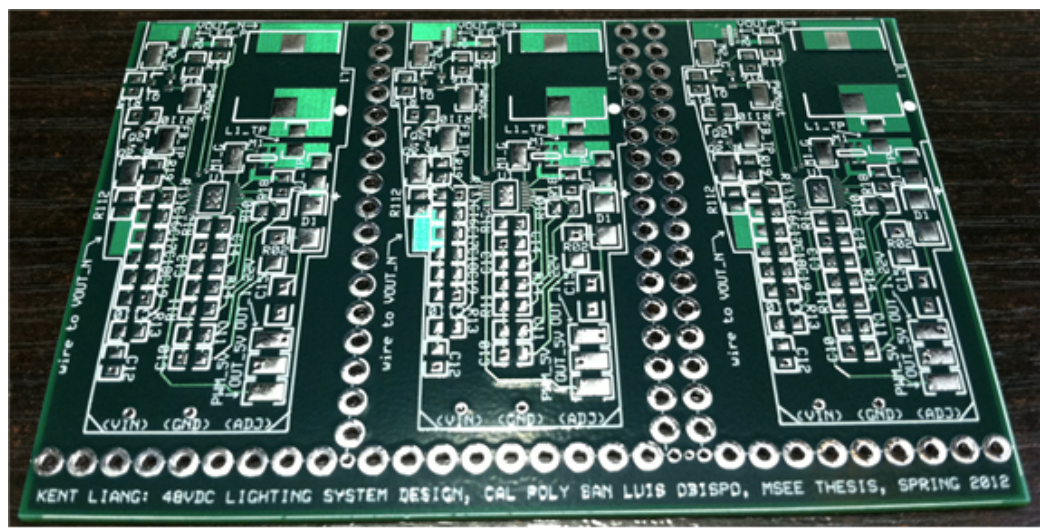

(a)

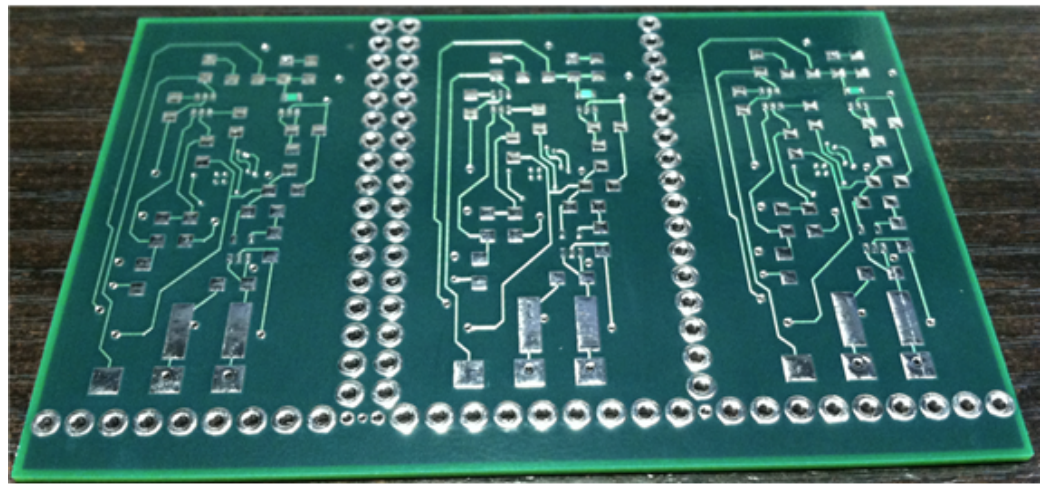

(b)

Figure 5-3: DC Light Bulb Custom 4-Layer PCB Layout After Manufacturing, (a) Top Layer, (b) Bottom Layer. 


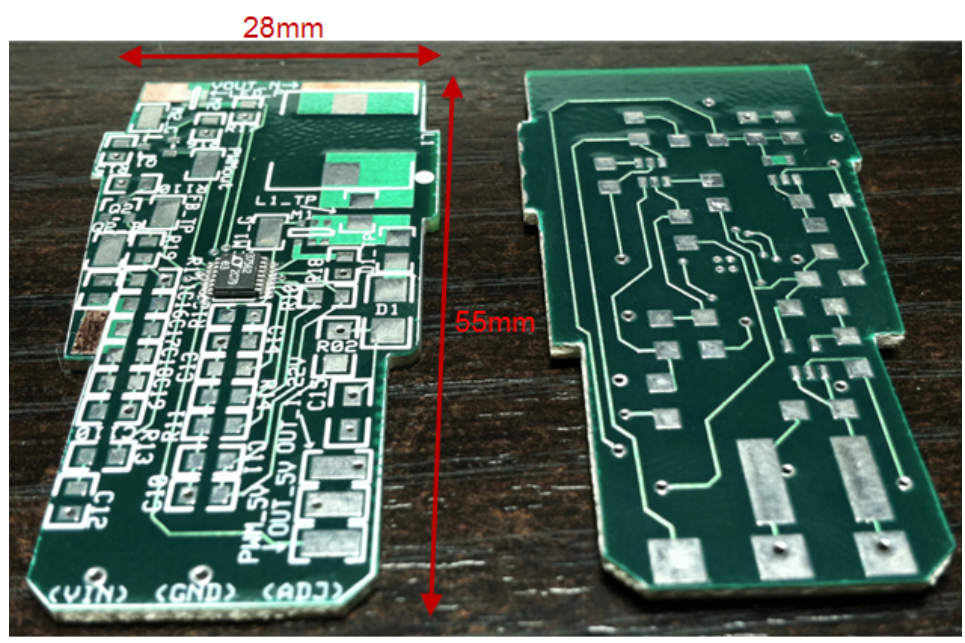

(a)

(b)

Figure 5-4: DC Light Bulb Custom 4-Layer PCV After Being Cut to Size, (a) Top Layer, (b) Bottom Layer.

Figure 5-4 illustrates the DC Light Bulb's custom PCB after being cut to size. This PCB is roughly $56 \mathrm{~mm} \times 28 \mathrm{~mm}$ in size. It was specifically sized this particular way because it is like a key that is required to fit into the inner light bulb sleeve. Figure 5-5 illustrates the custom PCB fitted into the light bulb's enclosure.

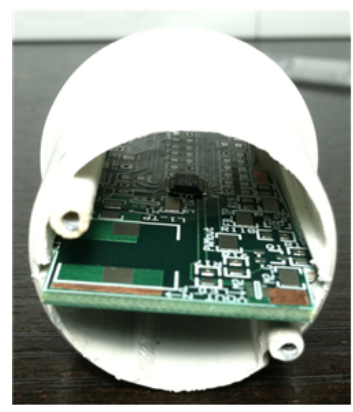

(a)

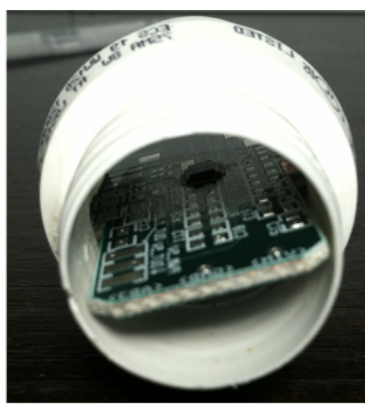

(b)

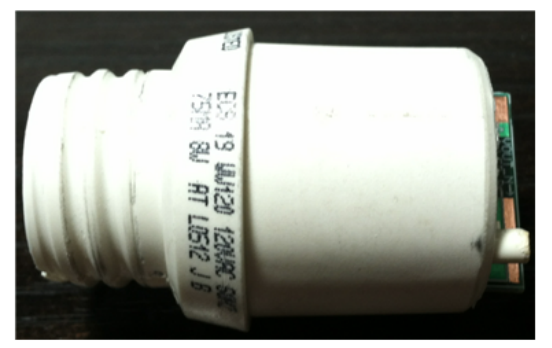

(c)

Figure 5-5: Custom PCB Fitted into Inner Sleeve, (a) Top View, (b) Bottom View, (c) Side View. 
Figure 5-6 illustrates the first DC Light Bulb prototype that has been populated with components and ready for testing. Note a current clamp probe was placed between the black loop wire to measure the current flowing through the inductor, L1. The red and white wires on the left side of Figure 5-6 supplies a differential voltage to power the LED array.

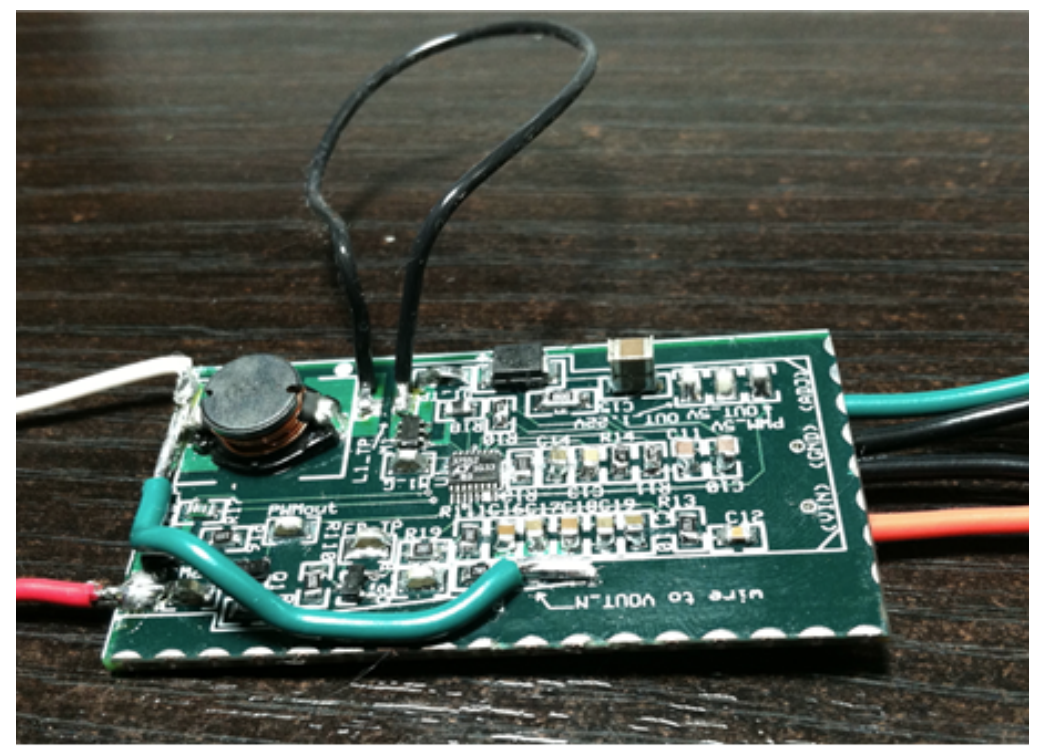

(a)

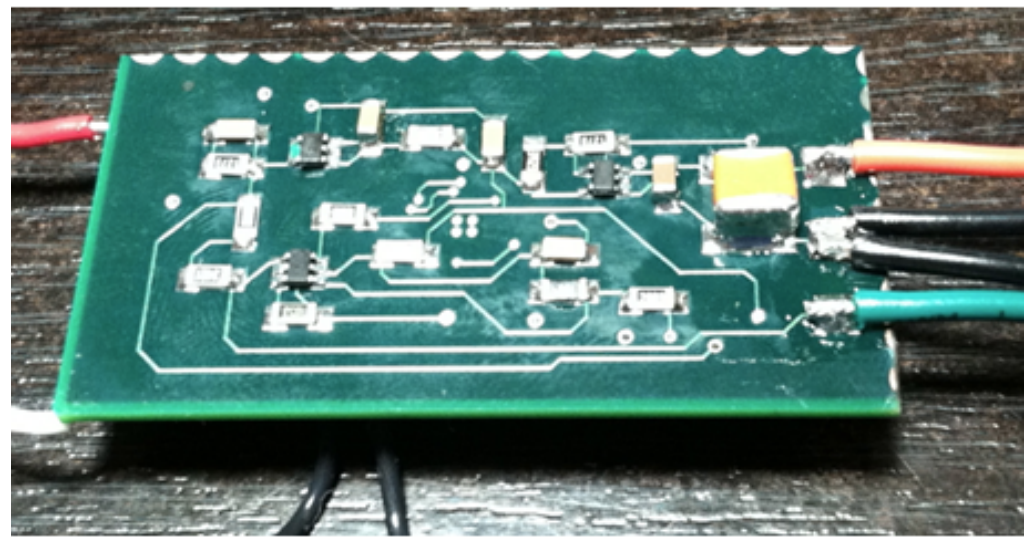

(b)

Figure 5-6: Custom PCB Populated With Components and Ready For Testing, (a) Top Signal Plane, (b) Bottom Signal Plan. 


\section{2: LED Array and Heatsink Design}

As suggested in Figure 4-29 and 4-19, the size of the LED array must fit into a circular area with a diameter less than $31 \mathrm{~mm}$. A custom $25 \mathrm{~mm}$ MCPCB made by Cutter Electronics was used to mount four CREE XPG high power LEDs in a series configuration. A two part white color paste called Arctic Alumina was used between the MCPCB and the aluminum heatsink to provide a permanent thermal conductive bond. Figure 5-7 illustrates the physical mounting of the CREE XPG LEDs to the custom MCPCB and to the aluminum heatsink.

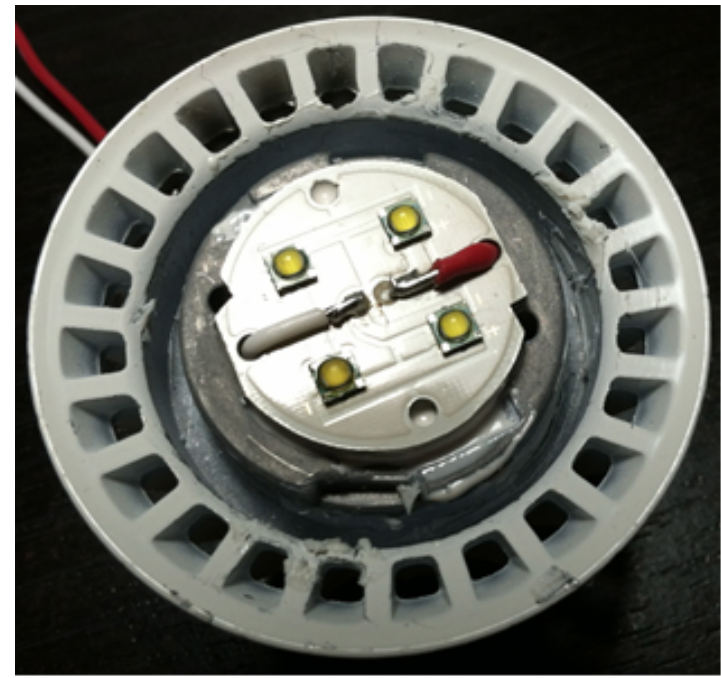

(a)

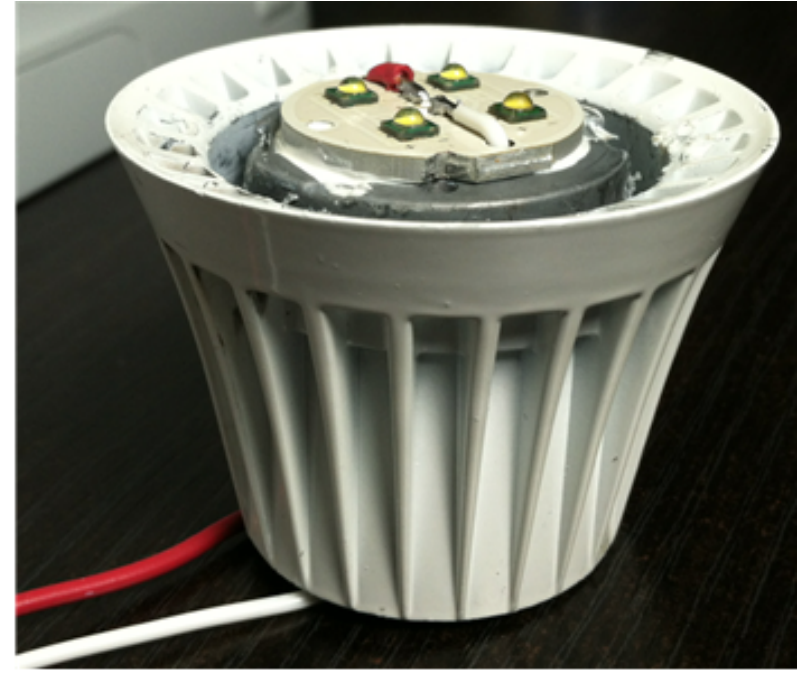

(b)

Figure 5-7: CREE XPG LEDs Mounted on Aluminum Heatsink, (a) Top View, (b) Side View. 


\section{3 : Efficiency and Line Regulation Testing}

\subsection{1: Hardware Setup}

Figure 5-8 illustrates the laboratory setup used during the DC Light Bulb's efficiency and line regulation testing. Table 5-1 lists the equipment used for data measurements.

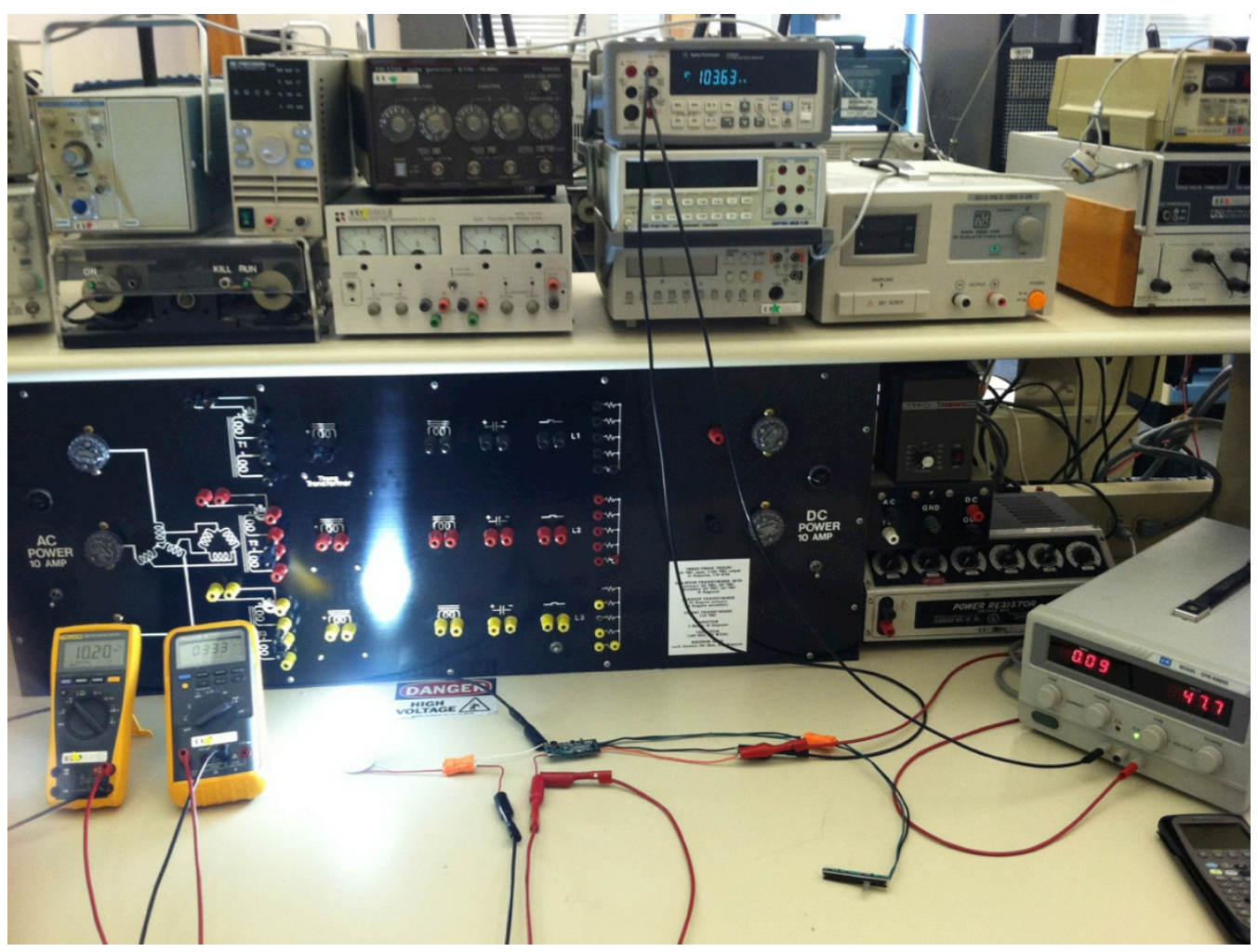

Figure 5-8: Setup for Efficiency and Line Regulation Testing.

Table 5-1: Equipment Used for Efficiency and Line Regulation.

\begin{tabular}{|l|l|l|l|}
\hline Purpose & Equipment & Manufacture & Model \\
\hline $\mathrm{V}_{\text {IN }}$ & DC Power Supply & GW & GPR-6060D \\
\hline $\mathrm{I}_{\text {IN }}$ & Multimeter & Agilent Technologies & U341A \\
\hline V $_{\text {OUT }}$ & Multimeter & Fluke & 179 \\
\hline I & Multimeter & Fluke & 87 \\
\hline Duty Cycle & Oscilloscope & GW & Instek GDS-2204 \\
\hline
\end{tabular}




\subsection{2: Test Results}

The DC Light Bulb was tested to evaluate its efficiency at incrementing load steps. The LED's brightness (load) levels were varied at $10 \mathrm{~mA}$ steps changes in input current (l $\left.\mathrm{I}_{\mathrm{N}}\right)$. A $10 \mathrm{k} \Omega$ slide potentiometer in the dimmer circuit was used to vary the PWM signal into the LED driver, thus changing the output load (brightness intensity) of the LED array. Table 5-2 summarizes the data collected and Figure 5-9 illustrates that efficiency increases at higher load currents. Note, duty cycle was measured using oscilloscope connected to the PWMOUT pin of LT3756-2. At full load (duty cycle $=100 \%$ or when the slide potentiometer is position all the way up) an efficiency of $85.631 \%$ was achieved. The hardware efficiency at full load produces a $6.25 \%$ difference compared to the simulated efficiency of $91.34 \%$ at full load, as suggested in Figure 4-10, and Equation 5-1 and 5-2. 
Table 5-2: Efficiency Data Measurements.

\begin{tabular}{|c|c|c|c|c|c|c|c|}
\hline $\begin{array}{l}\text { Duty } \\
\text { Cycle \% }\end{array}$ & $V_{\text {IN }}(V)$ & $\begin{array}{c}I_{I N} \\
(m A)\end{array}$ & $P_{\text {IN }}(W)$ & $\mathrm{V}_{\text {out }}(\mathrm{V})$ & $\begin{array}{c}\text { LED } \\
\text { Iout(mA) }\end{array}$ & $\begin{array}{c}\text { Pout } \\
\text { (W) }\end{array}$ & $\begin{array}{c}\text { Efficiency } \\
(\%)\end{array}$ \\
\hline 0.000 & 48.000 & 2.167 & 0.104 & 0.430 & 0.000 & 0.000 & $0.000 \%$ \\
\hline 2.970 & 48.000 & 10.675 & 0.512 & 9.160 & 27.000 & 0.247 & $48.267 \%$ \\
\hline 5.980 & 48.000 & 19.670 & 0.944 & 9.270 & 56.000 & 0.519 & $54.982 \%$ \\
\hline 8.870 & 48.000 & 29.194 & 1.401 & 9.370 & 85.000 & 0.796 & $56.836 \%$ \\
\hline 11.950 & 48.000 & 39.210 & 1.882 & 9.480 & 119.000 & 1.128 & $59.940 \%$ \\
\hline 14.930 & 48.000 & 50.430 & 2.421 & 9.590 & 156.000 & 1.496 & $61.803 \%$ \\
\hline 19.370 & 48.000 & 60.280 & 2.893 & 9.700 & 189.000 & 1.833 & $63.361 \%$ \\
\hline 22.380 & 48.000 & 69.920 & 3.356 & 9.760 & 222.000 & 2.167 & $64.559 \%$ \\
\hline 25.370 & 48.000 & 79.250 & 3.804 & 9.810 & 255.000 & 2.502 & $65.761 \%$ \\
\hline 28.330 & 48.000 & 90.220 & 4.331 & 9.920 & 293.000 & 2.907 & $67.117 \%$ \\
\hline 32.790 & 48.000 & 99.940 & 4.797 & 10.030 & 327.000 & 3.280 & $68.370 \%$ \\
\hline 35.840 & 48.000 & 110.680 & 5.313 & 10.130 & 364.000 & 3.687 & $69.407 \%$ \\
\hline 40.310 & 48.000 & 120.470 & 5.783 & 10.230 & 399.000 & 4.082 & $70.588 \%$ \\
\hline 43.270 & 48.000 & 130.130 & 6.246 & 10.330 & 432.000 & 4.463 & $71.444 \%$ \\
\hline 46.260 & 48.000 & 139.230 & 6.683 & 10.410 & 465.000 & 4.841 & $72.432 \%$ \\
\hline 50.730 & 48.000 & 149.970 & 7.199 & 10.510 & 503.000 & 5.287 & $73.439 \%$ \\
\hline 55.240 & 48.000 & 160.220 & 7.691 & 10.600 & 540.000 & 5.724 & $74.429 \%$ \\
\hline 57.310 & 48.000 & 170.230 & 8.171 & 10.690 & 577.000 & 6.168 & $75.488 \%$ \\
\hline 60.330 & 48.000 & 180.070 & 8.643 & 10.780 & 612.000 & 6.597 & $76.329 \%$ \\
\hline 64.740 & 48.000 & 190.360 & 9.137 & 10.880 & 650.000 & 7.072 & $77.397 \%$ \\
\hline 67.640 & 48.000 & 200.110 & 9.605 & 10.960 & 686.000 & 7.519 & $78.275 \%$ \\
\hline 72.100 & 48.000 & 210.640 & 10.111 & 11.060 & 724.000 & 8.007 & $79.198 \%$ \\
\hline 76.120 & 48.000 & 220.120 & 10.566 & 11.140 & 759.000 & 8.455 & $80.025 \%$ \\
\hline 80.610 & 48.000 & 230.210 & 11.050 & 11.230 & 792.000 & 8.894 & $80.490 \%$ \\
\hline 83.940 & 48.000 & 240.530 & 11.545 & 11.320 & 831.000 & 9.407 & $81.477 \%$ \\
\hline 88.040 & 48.000 & 250.430 & 12.021 & 11.400 & 867.000 & 9.884 & $82.224 \%$ \\
\hline 91.190 & 48.000 & 259.800 & 12.470 & 11.470 & 902.000 & 10.346 & $82.964 \%$ \\
\hline 95.520 & 48.000 & 269.840 & 12.952 & 11.550 & 940.000 & 10.857 & $83.823 \%$ \\
\hline 100.000 & 48.000 & 280.330 & 13.456 & 11.600 & 993.000 & 11.519 & $85.604 \%$ \\
\hline 100.000 & 48.000 & 280.000 & 13.440 & 11.590 & 993.000 & 11.509 & $85.631 \%$ \\
\hline
\end{tabular}




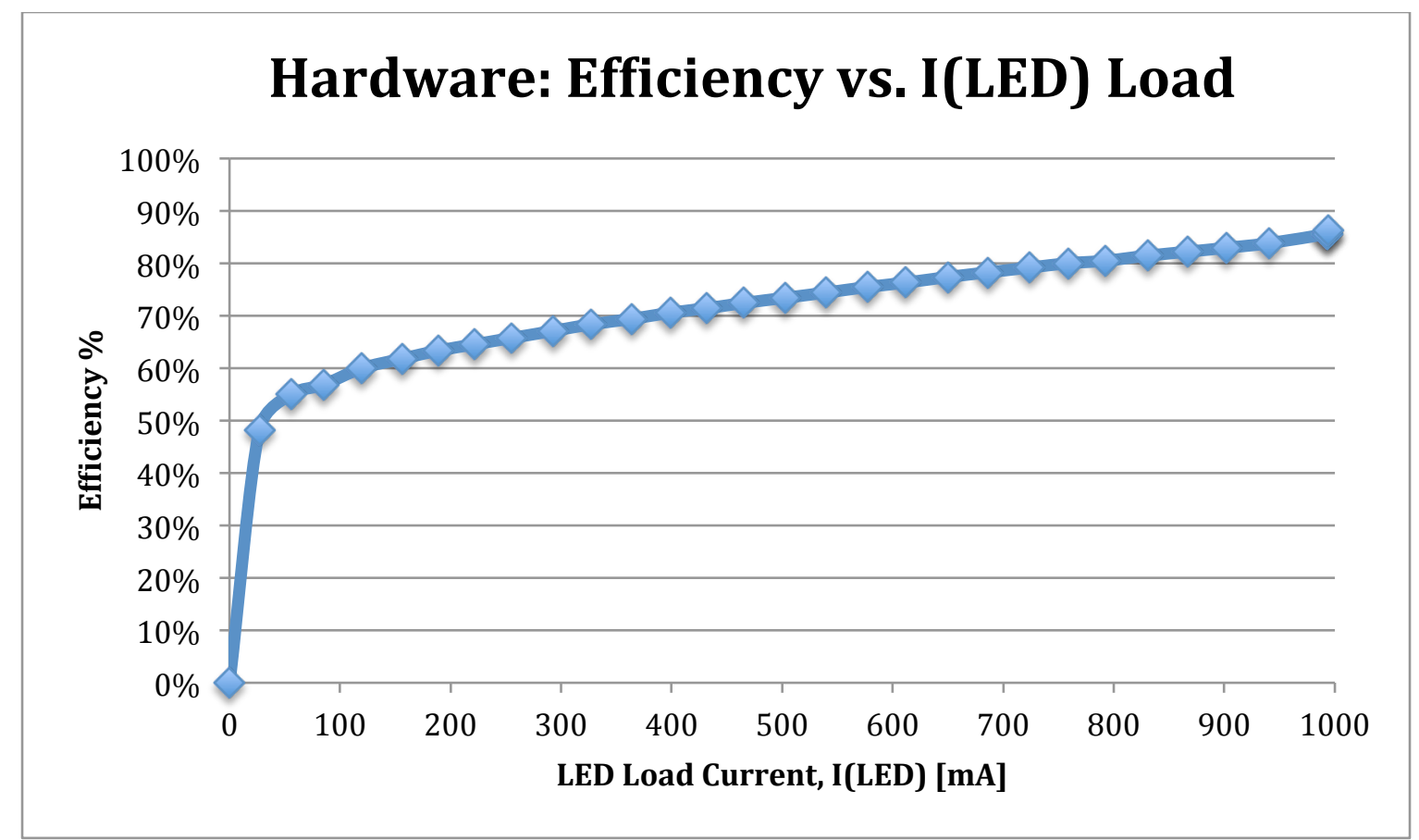

Figure 5-9: Hardware: Efficiency vs. Varying Output LED Load, I(LED).

$$
\begin{aligned}
& \% \text { Difference }=\left|\frac{X_{\text {simulated }}-X_{\text {measured }}}{X_{\text {simulated }}}\right| * 100 \% \\
& \% \text { Difference }=\left|\frac{91.34 \%-85.631 \%}{91.34 \%}\right| * 100 \%=6.25 \%
\end{aligned}
$$

Next, the DC Light Bulb's line regulation was tested at $\pm 5 \%$ to $\pm 31 \%$ (roughly $5 \%$

increments) swing in input voltages to test its ability to maintain constant output voltage across the LED array. Line regulation was calculated using Equation 4-14. A worst-case line regulation of $2.53 \%$ occurred when the input voltage varied $\pm 20 \%$. Possible causes in line regulation deviation may be due to a slow feedback response in the LED driver (LT3756-2) or the DC Light Bulb was not in steady state when the data measurements were recorded. In the next section, the DC Light Bulb's circuit functionality is verified. 
Table 5-3: Hardware: Line Regulation Measurements at Full Load.

\begin{tabular}{|c|c|c|c|c|c|c|c|c|}
\hline $\begin{array}{l}\% \text { of } \\
V_{\text {IN, }} \\
\text { Nominal }\end{array}$ & $\begin{array}{l}\mathrm{V}_{\mathrm{IN}} \\
\text { Nominal } \\
\text { (V) }\end{array}$ & $\begin{array}{l}\text { Vout, } \\
\text { Nominal } \\
\text { (V) }\end{array}$ & $\begin{array}{l}V_{\text {IN, Min }} \\
(\mathrm{V})\end{array}$ & $\begin{array}{c}\mathrm{V}_{\mathrm{IN}} \\
\operatorname{Max}(\mathrm{V})\end{array}$ & $\begin{array}{l}V_{\text {OUt, low }} \\
\text { input }(V)\end{array}$ & $\begin{array}{l}\mathrm{V}_{\text {OUt, high }} \\
\text { input }(\mathrm{V})\end{array}$ & $\begin{array}{l}\text { lout, } \\
\text { RATED } \\
\text { (mA) }\end{array}$ & $\begin{array}{c}\text { \% Line } \\
\text { Regulation } \\
\text { (\%) }\end{array}$ \\
\hline $5 \%$ & 48.00 & 13.44 & 45.60 & 50.40 & 11.71 & 11.68 & 993 & 0.223 \\
\hline $10 \%$ & 48.00 & 13.44 & 43.20 & 52.80 & 11.74 & 11.66 & 993 & 0.595 \\
\hline $15 \%$ & 48.00 & 13.44 & 40.80 & 55.20 & 11.86 & 11.64 & 993 & 1.637 \\
\hline $20 \%$ & 48.00 & 13.44 & 38.40 & 57.60 & 11.97 & 11.63 & 993 & 2.530 \\
\hline $25 \%$ & 48.00 & 13.44 & 36.00 & 60.00 & 11.47 & 11.47 & 993 & 0.000 \\
\hline $31 \%$ & 48.00 & 13.44 & 33.00 & 63.00 & 11.49 & 11.52 & 993 & 0.223 \\
\hline
\end{tabular}

\section{4 : Circuit Functionality Verification}

\subsection{1: Hardware Setup}

Figure 5-10 illustrates the laboratory test setup used to verify the DC Light Bulb's circuit functionalities. A voltage scope probe is used to measure the PWM signal at PWMOUT pin of the LED driver. Another voltage scope probe is used to measure voltage at M1 and M2 MOSFET gate nodes. A current clamp probe is used to measure current through the LED and L1 inductor. The current clamp probe is connected to an AM 503 Current Probe Amplifier that converts the current to a voltage signal read on the oscilloscope. Table 5-4 summarizes the equipment used for the circuit functionality tests. 
Table 5-4: Equipment used for Hardware Circuit Functionality Verification.

\begin{tabular}{|l|l|l|l|}
\hline Purpose & Equipment & Manufacture & Model \\
\hline $\mathrm{V}_{\text {IN }}$ & DC Power Supply & GW & GPR-6060D \\
\hline $\mathrm{I}_{\mathrm{IN}}$ & Multimeter & Agilent Technologies & U341A \\
\hline $\begin{array}{l}\text { Current to } \\
\text { Voltage } \\
\text { Converter. }\end{array}$ & Current Probe Amplifier & Tektronix & \\
\hline $\begin{array}{l}\text { VouT, IouT, } \\
\text { Duty Cycle }\end{array}$ & Oscilloscope & GW & AM 503 \\
\hline
\end{tabular}




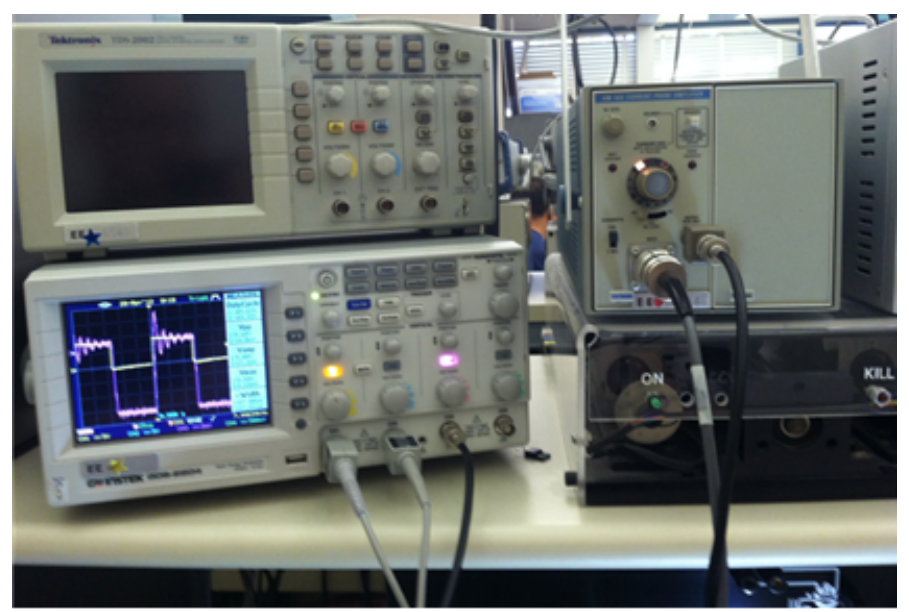

(a)

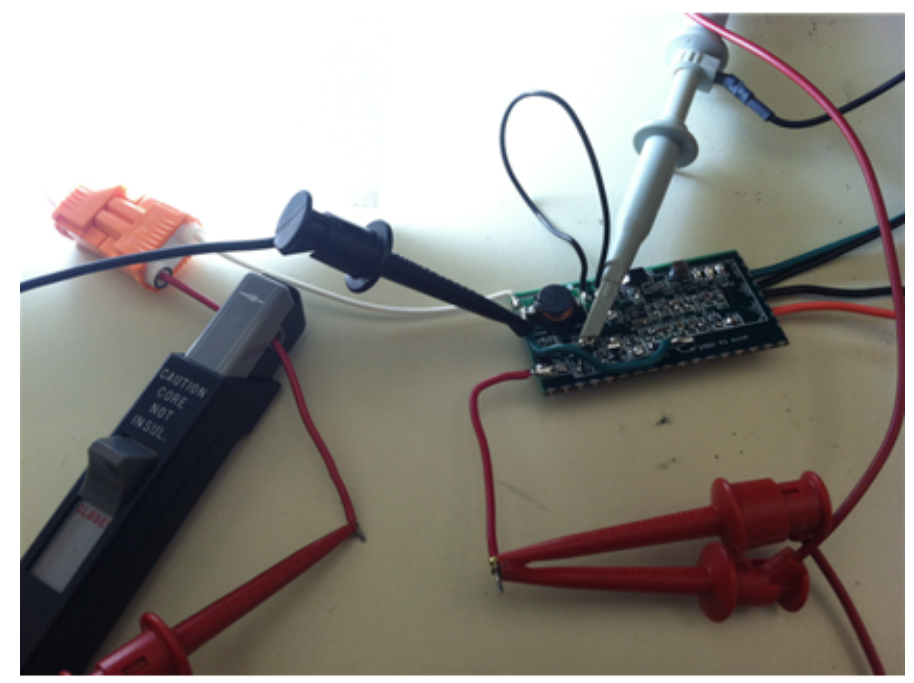

(b)

Figure 5-10: Setup for Circuit Functionality Verification, (a) Oscilloscope and Current Probe Amplifier for Waveform Measurements, (b) Current and Scope Probe Connections.

\subsection{2: Hardware Results}

The first test performed was to make sure the PWM signal generated at the PWM5V (referring to Figure 5-1) pin of the PWM controller was indeed working properly. Figure 5-11 validates that as the $10 \mathrm{k} \Omega$ slide potentiometer is varied a resulting change in PWM signal is 
generated. Figure 5-11 illustrates PWM signals for duty cycles at $2.97 \%, 25.39 \%, 50.71 \%$, and 95.54\%. Note, that when the variable potentiometer is at full $10 \mathrm{k} \Omega$ it indeed produced a duty cycle of $100 \%$.

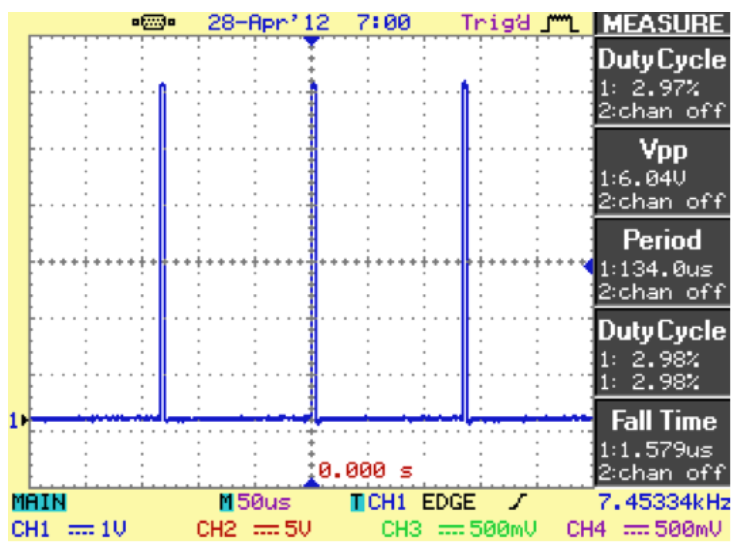

(a)

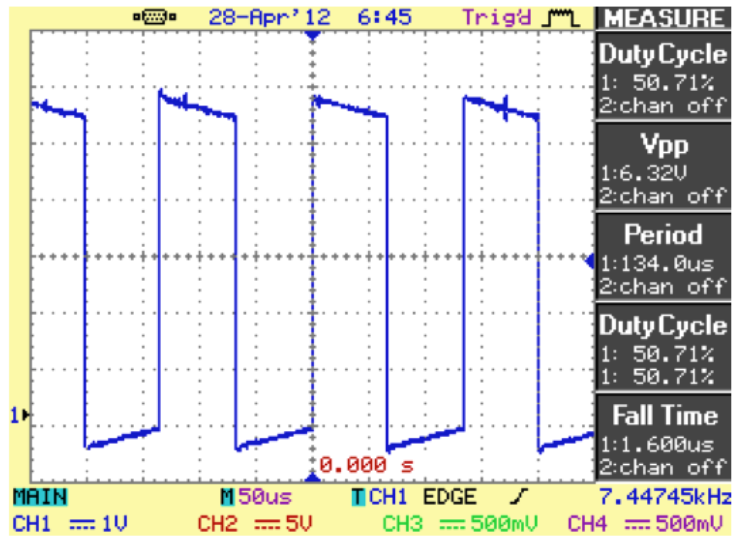

(c)

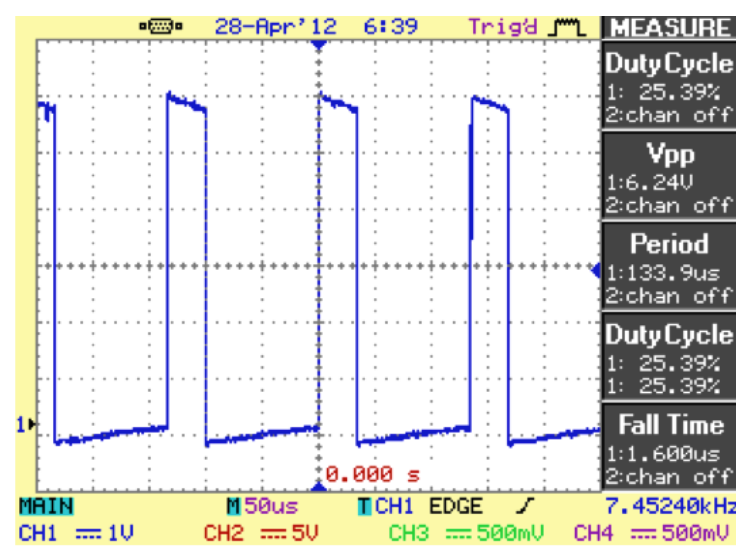

(b)

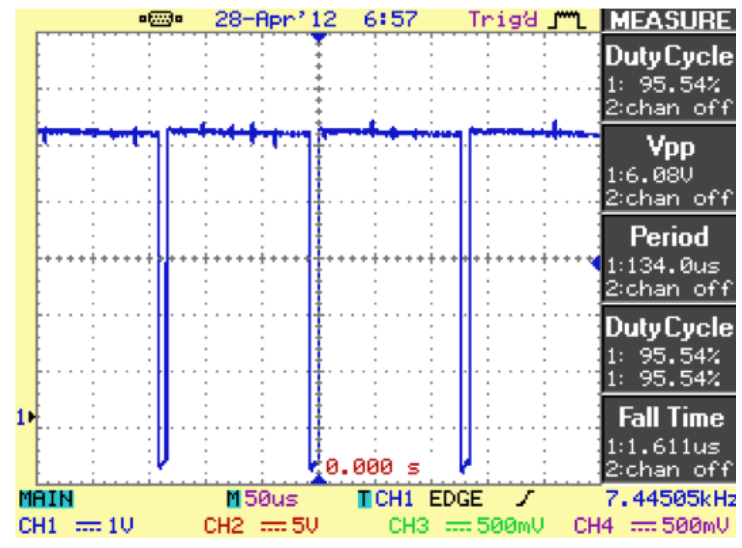

(d)

Figure 5-11: V(PWM_5V) For (a) $D=2.97 \%$, (b) $D=25.39 \%$, (c) $D=50.71 \%$, (d) $D=95.54 \%$.

Next, the voltage into the gate of M1 MOSFET (M1_GATE) was compared to the PWMout pin of the LT3756-2 chip (PWMOUT). Figure 5-12 illustrates that LT3756-2 provides a pulsing voltage only during the on time. Comparing simulation results shown in Figure 4-14 (c) 
and (d) with the hardware waveforms in Figure 5-12 validates that the circuit is functioning correctly.

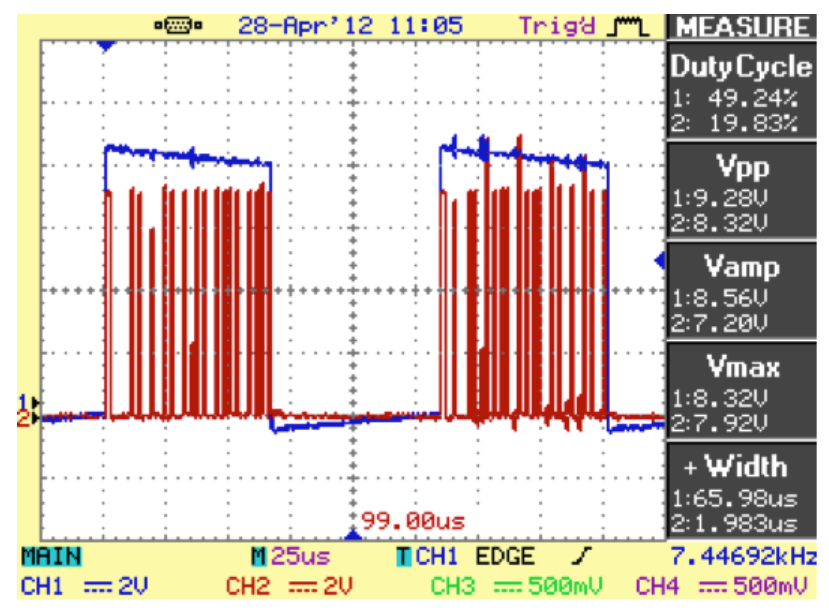

(a)

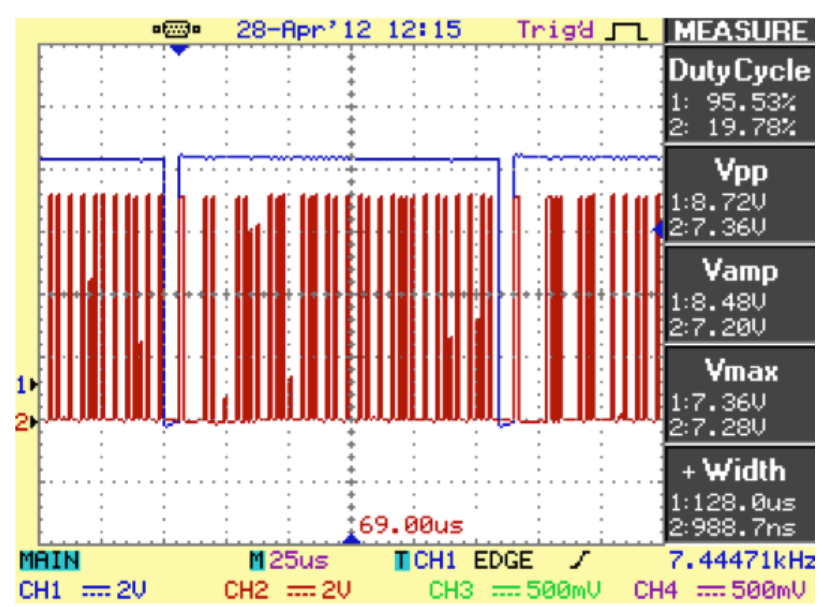

(b)

Figure 5-12: [CH1] V(PWMout) vs. [CH2] V(M1_Gate) For (a) $D=49.24 \%$, (b) $D=95.53 \%$.

A similar circuit functionality test is performed for the M2_GATE pin. Figure 5-13

illustrates PWMOUT versus M2_GATE. Since M2 is a P-channel MOSFET, it turns on when it receives a logic low. Comparing the simulated waveforms shown in Figure 4-25 (c) and (d) with the hardware waveforms shown in Figure 5-13 (a) and (b) validates that when PWMOUT is at 0 V (logic low), M2_GATE remain at 48V (logic high). When PWMOUT outputs $7 \mathrm{~V}$ (logic high), M2_GATE is pulled down to $38 \mathrm{~V}$ (logic low) and turns on. M2 can be seen as a switch such that when closed it allows current to flow to the LED. M1 can be seen as a pulsing switch that trickle charges the inductor. The current feedback loop determines how frequently M1 needs to turn on, in order to maintain an output regulation of $1 \mathrm{~A}$. 


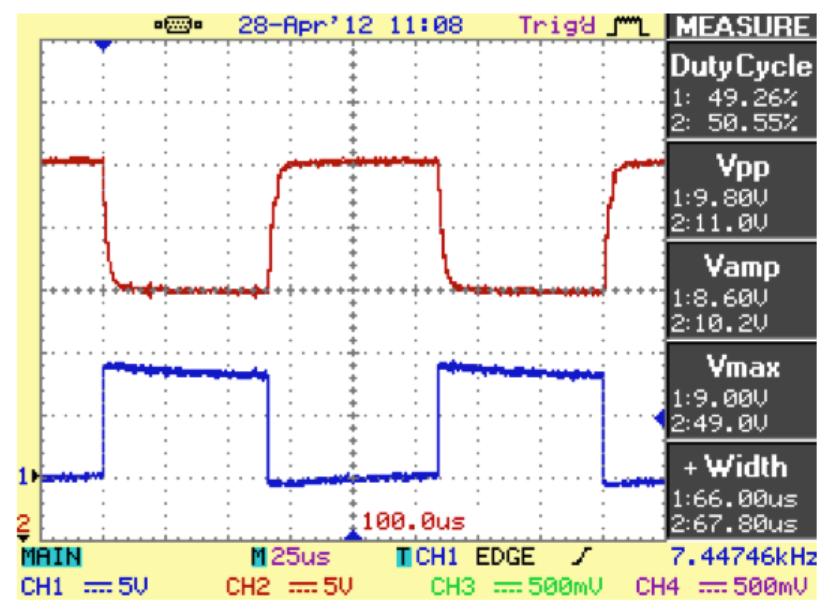

(a)

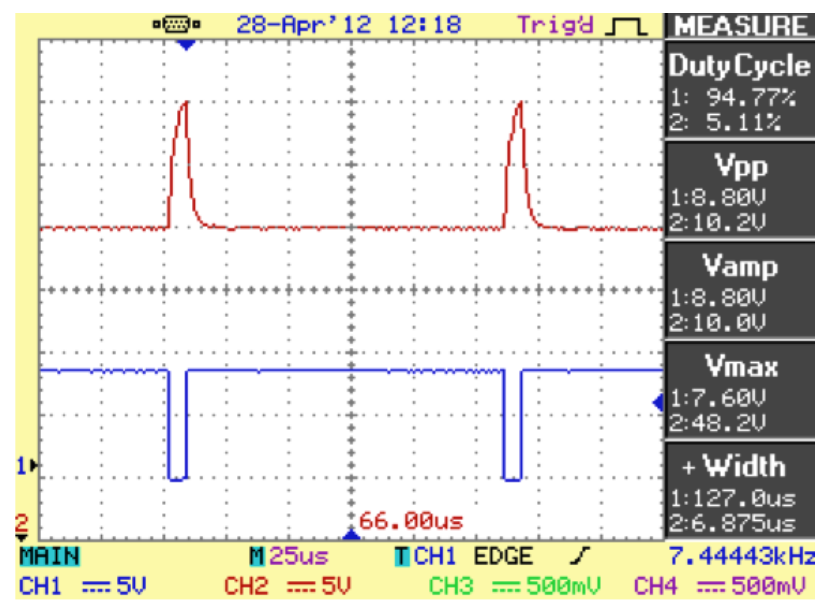

(b)

Figure 5-13: [CH1] V(PWM_OUT) vs. [CH2] V(M2_Gate) For (a) $D=49.26 \%$, (b) $D=94.77 \%$.

Figure 5-14 illustrates PWM signal PWMOUT relationship to the amount of current I(L1) flowing through inductor, L1. Since a current probe amplifier was used to convert the current signal to a voltage signal, the voltage waveform of L1 must be converted back to current to get the correct readings. Since the current amplifier produces $1 \mathrm{~A}$ per division $(1 \mathrm{~A} / \mathrm{div})$ and the oscilloscope is scaled at $5 \mathrm{mV} /$ div. then Equation 5-3 can be used to obtain the correct readings.

$$
I(L E D)=\frac{(\# \text { vertical squares }) x \operatorname{Scope}\left(\frac{5 m V}{\text { div }}\right)}{\frac{2 * S \operatorname{Scope}\left(\frac{5 m V}{\text { div }}\right)}{\text { Current Probe }\left(\frac{1 A}{\text { div }}\right)}} \quad\left[\frac{A}{d i v}\right]
$$

Table 5-5 translates the inductors voltage reading to the correct current reading for duty cycles at $49.99 \%$ and $95.52 \%$. Comparing simulated inductor waveforms in Figure 4-26 (c) and (d) to hardware waveforms in Figure 4-14 (a) and (b), respectfully indicates that the inductor somewhat produces an underdamped response as it reaches the end of its turn on time. This is also a good indicator that LT3756-2's internal current control loop is attempting to regulate the inductor's peak current so that the LED array sees a constant 1 A supply. 


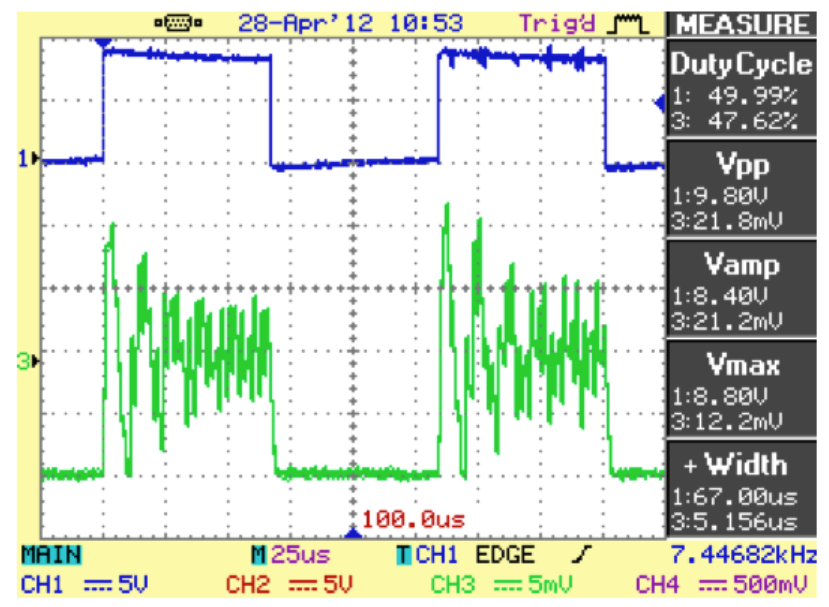

(a)

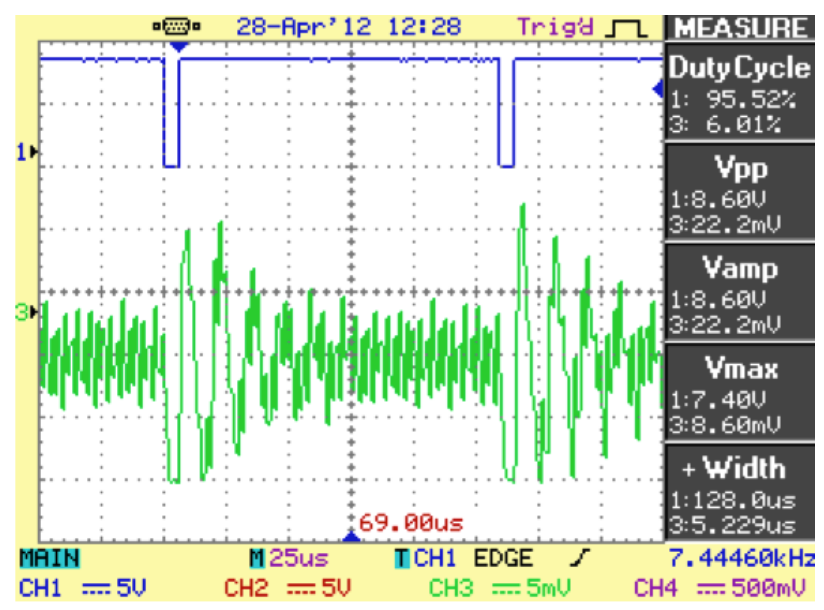

(b)

Figure 5-14: [CH1] V(PWM_OUT) vs. [CH3] I(L1) For (a) $D=49.99 \%$, (b) $D=5.52 \%$.

Table 5-5: Inductor Current, I(L1) Conversion for Figure 5-14 (a) and (b).

\begin{tabular}{|c|c|c|}
\hline Duty Cycle & $49.99 \%$ & $95.52 \%$ \\
\hline I(L1) $)_{\text {peak-peak }}(\mathrm{A})$ & 2.18 & 2.22 \\
\hline I(LED) $)_{\text {amp }}(\mathrm{mA})$ & 2.12 & 2.22 \\
\hline $\mathrm{I}(\mathrm{LED})_{\text {avg }}(\mathrm{mA})$ & 1 & 1 \\
\hline
\end{tabular}

Figure 5-15 illustrates the PWM signal (PWMOUT) versus current through the LED, I(LED) for duty cycles at $50.02 \%$ and $94.71 \%$. Similar to the case for the inductor, a current probe amplifier was used to convert current to voltage. Therefore Equation 5-3 must be used to convert the oscilloscope voltage waveform to the correct current measurements. Table 5-6 summarizes the peak-peak, amplitude, and average current through the LED array shown in Figure 5-15. 


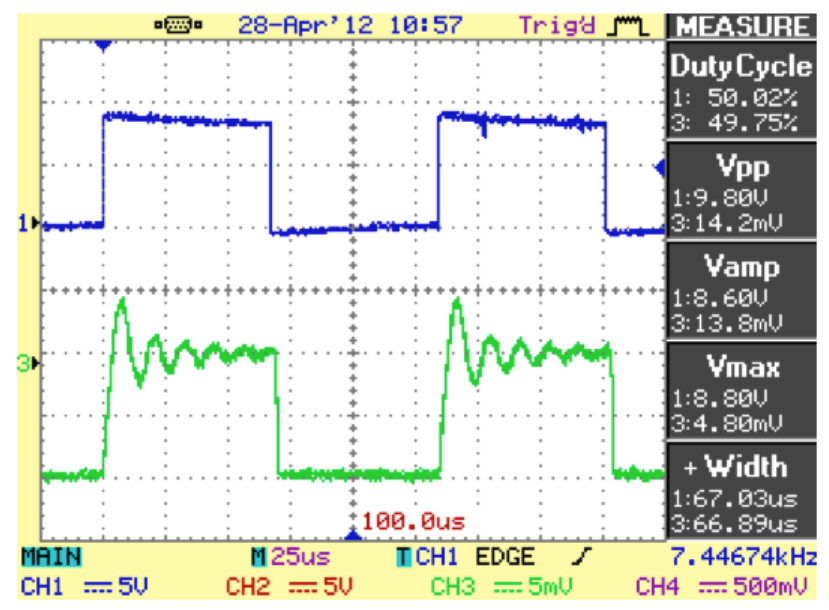

(a)

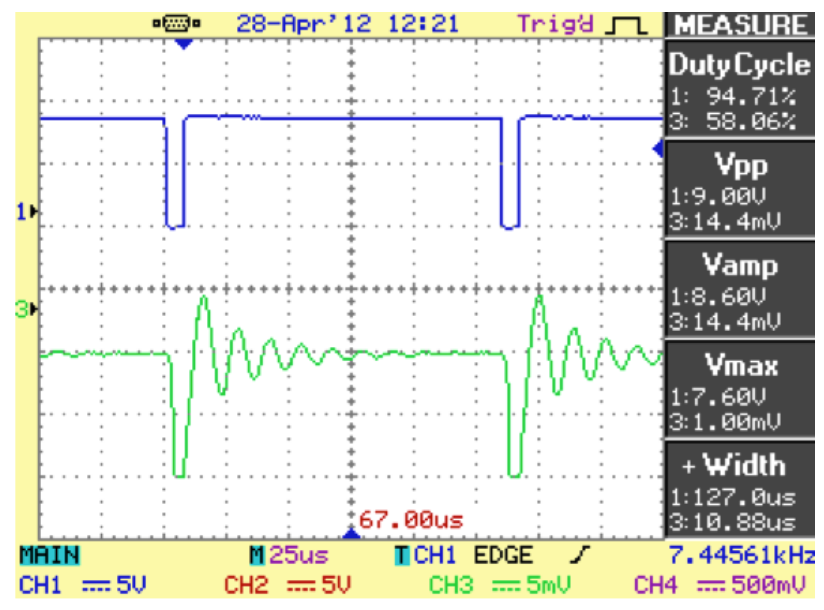

(b)

Figure 5-15: [CH1] V(PWM_OUT) vs. [CH3] I(LED) For (a) $D=50.02 \%$, (b) $D=94.71 \%$.

Table 5-6: LED Current, I(LED) Conversion for Figure 5-15 (a) and (b).

\begin{tabular}{|c|c|c|}
\hline Duty Cycle & $50.02 \%$ & $94.71 \%$ \\
\hline $\begin{array}{c}\text { I(LED) peak-peak } \\
(\mathrm{A})\end{array}$ & 1.42 & 1.44 \\
\hline I(LED) $)_{\mathrm{amp}}(\mathrm{mA})$ & 1.38 & 1.44 \\
\hline I(LED) $)_{\text {avg }}(\mathrm{mA})$ & 1 & 1 \\
\hline
\end{tabular}

\section{5 : Lumination Measurement}

\subsection{1: Hardware Setup}

Figure 5-16 illustrates the laboratory setup for lumination measurement at varying duty cycles. Two clear bookstand holders $(29 \mathrm{~cm}$ tall) were equally placed between the DC Light Bulb. Using the bookstands as support, a Sylvania DS-2000 light meter was then placed directly 
above it. This setup created a fixed distance between the light bulb and the light meter. Similar to before, a DC power supply supplied a constant 48 VDC to the DC Light Bulb and a multimeter was used to read the input current. Table 5-7 summarizes the equipment used during the lumination measurement test.

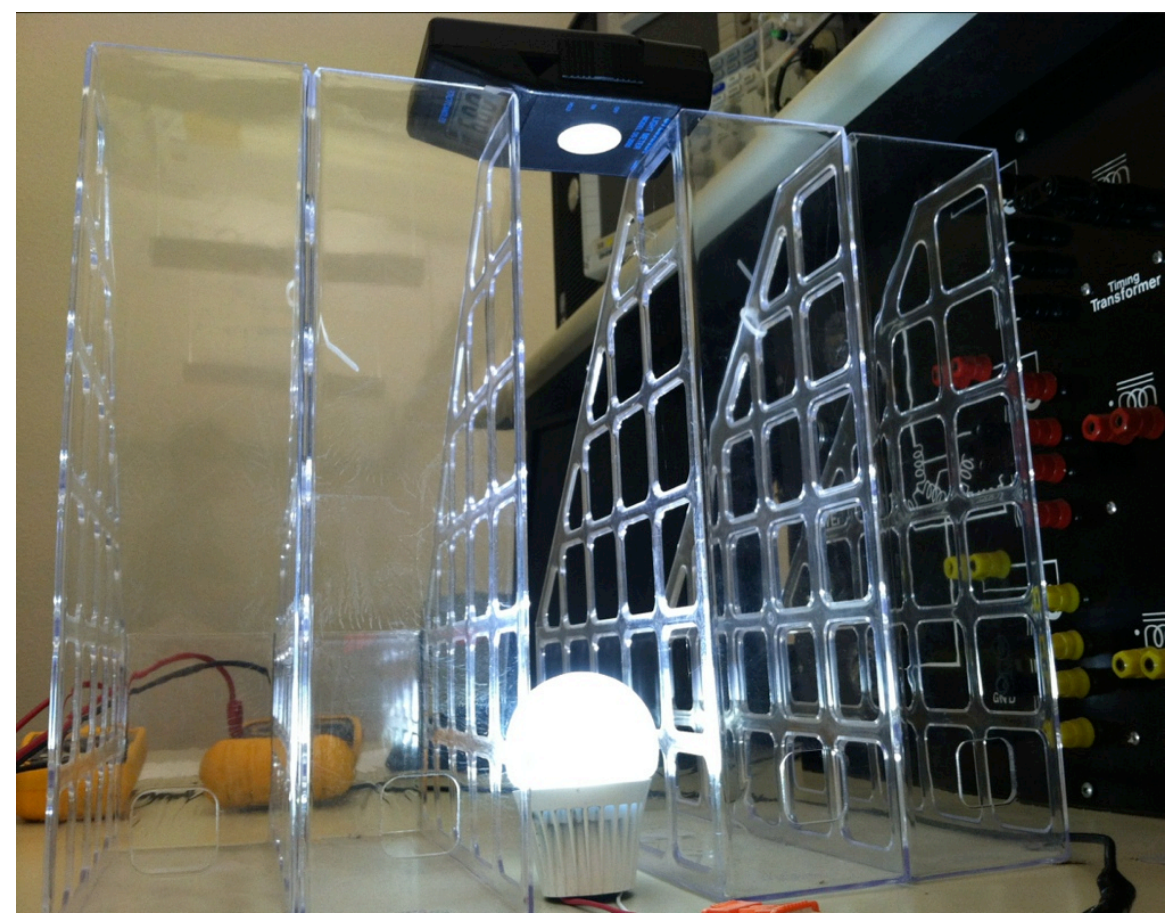

Figure 5-16: Setup for Lumination Measurement.

Table 5-7: Equipment Setup Used for Lumination Measurements.

\begin{tabular}{|l|l|l|l|}
\hline Purpose & Equipment & Manufacture & Model \\
\hline $\mathrm{V}_{\text {IN }}$ & DC Power Supply & GW & GPR-6060D \\
\hline $\mathrm{I}_{\text {IN }}$ & Multimeter & Agilent Technologies & U341A \\
\hline $\begin{array}{l}\text { Light } \\
\text { Reading }\end{array}$ & Light Meter & Sylvania & DS-2000 \\
\hline $\begin{array}{l}\text { Measure } \\
\text { Distance }\end{array}$ & Ruler & Generic & \\
\hline
\end{tabular}




\subsection{2: Test Results}

Referring to the lumination test fixture setup shown in Figure 5-16, the slide dimmer via the $10 \mathrm{k} \Omega$ potentiometer was slowly incremented (at $10 \mathrm{~mA}$ input current steps, not shown) from $D=0 \%$ to $D=100 \%$ and the light meter was used to record the amount of light it produced at each step. Note the light meter records the amount of light in the units of footcandles. However, lighting manufacturers usually advertise their products using units of lumens. Therefore, to convert foot-candles to lumens, the surface area where the light shines into must be calculated. As mentioned earlier the light meter is fixed $29 \mathrm{~cm}$ away from the DC Light Bulb. The light bulb's aluminum base is $0.04 \mathrm{~m}$ tall and its diffuser have a diameter of 5.6 $\mathrm{cm}$ (or a radius of $0.028 \mathrm{~m}$ ). The light bulb can be considered to be spherical shape and its directional light output fills only half of a sphere, applying Equations 5-4 to 5-9 is then applied to calculate the amount of lumens. Figure 5-17 illustrates how to calculate the surface area that the light fills. When $D=100 \%$ and the light meter reads 426 foot-candles, the DC Light Bulb produces 1420.1 lumens, which is almost the equivalent to a $100 \mathrm{~W}$ incandescent light bulb that produces about 1600 lumens. The DC Light Bulb is almost able to produce the same amount of light that a $100 \mathrm{~W}$ incandescent light bulb does, but remarkably requiring only 13.44 W. Appling Equations 5-10 and 5-11 suggests that with an input power of $13.44 \mathrm{~W}$ at full load the DC Light Bulb produces a luminous efficacy of 105.54 lumens/watt. Comparing this to the rated datasheet (CREE XPG LED) value of 110.48 lumens/watt suggests that the measured values were only $4.47 \%$ different from rated specifications. 


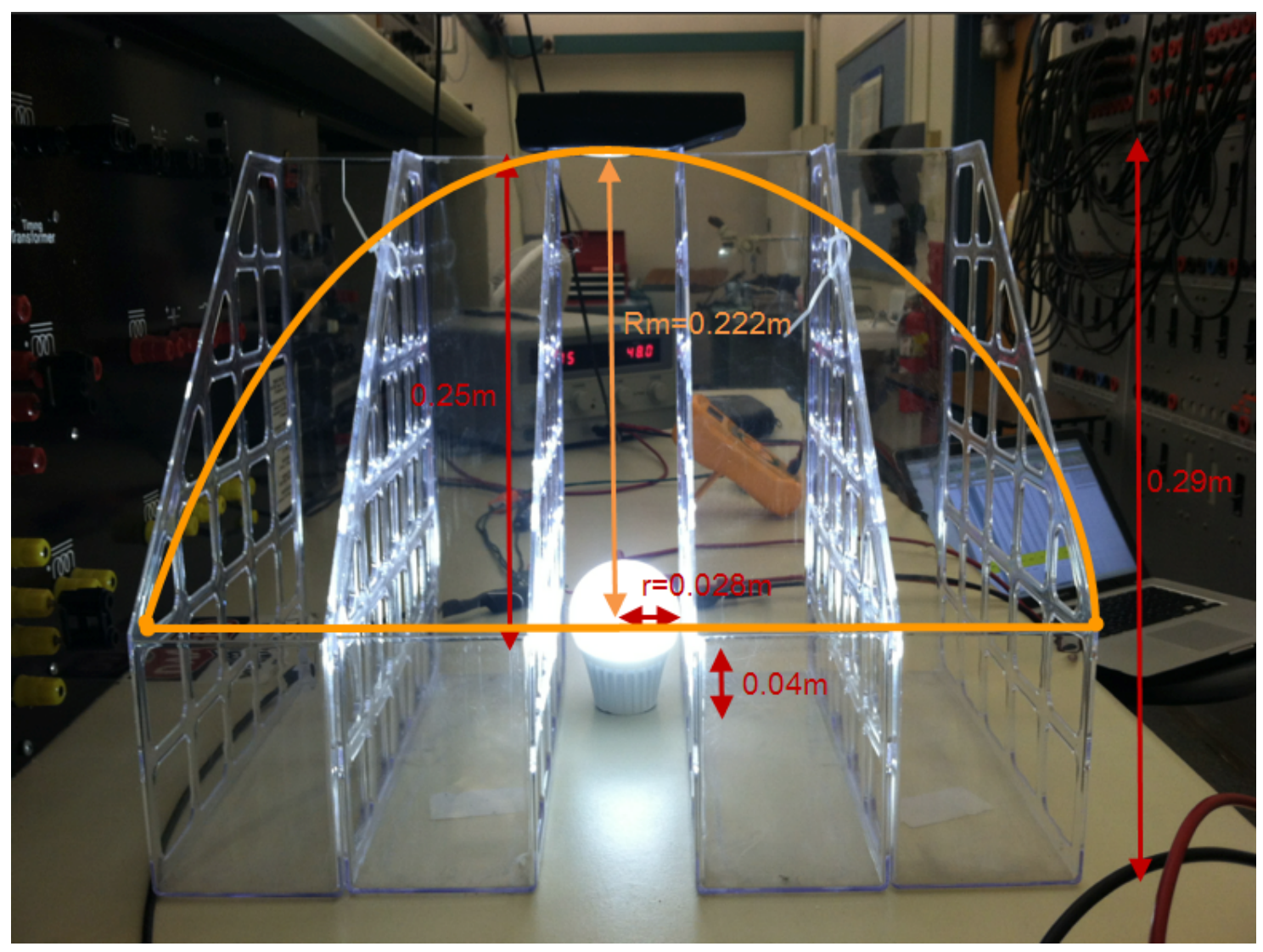

Figure 5-17: Conversion From Foot-Candles to Lumens.

$$
\begin{gathered}
A_{\text {SPHERE }}=4 * \pi * r^{2} \\
\quad \frac{1}{2} A_{\text {SPHERE }}=2 * \pi * r^{2} \\
A_{\text {MEASURED }}=2 * \pi * r_{m}^{2}=2 * \pi * 0.222 \mathrm{~m}=0.3097 \mathrm{~m}^{2} \\
1 \text { foot }- \text { candle }=10.76391 \frac{\text { lumens }}{\mathrm{m}^{2}} \\
426 \text { foot }- \text { candle } * \frac{10.76391 \frac{\text { lumens }}{\mathrm{m}^{2}}}{1 \text { foot }- \text { candle }}=4585.4 \frac{\text { lumens }}{\mathrm{m}^{2}} \\
\\
4585.4 \frac{\text { lumens }}{\mathrm{m}^{2}} * 0.3097 \mathrm{~m}^{2}=1420.1 \text { lumens } \\
\text { luminous efficacy }=\frac{\text { lumens }}{P_{I N}} \\
\text { luminous efficacy } \\
\text { MEASURED }=\frac{1420.1 \text { lumens }}{13.456 \mathrm{~W}}=105.54 \frac{\text { lumens }}{\mathrm{W}}
\end{gathered}
$$


Table 5-8 summarizes the DC Light Bulb's lumination at various duty cycles. Note the initial values (denoted with an *) are not consistence since the room's light was on during the testing.

Table 5-9 summarizes the DC Light Bulb's lumination measurements when its diffuser was removed. Overall, the DC Light Bulb's efficacy remained within $12 \%$ of the CREE XPG LED's datasheet projected luminous efficacy of 110.48 lumens/watt. 
Table 5-8: Lumination Measurement Using Light Bulb Diffuser.

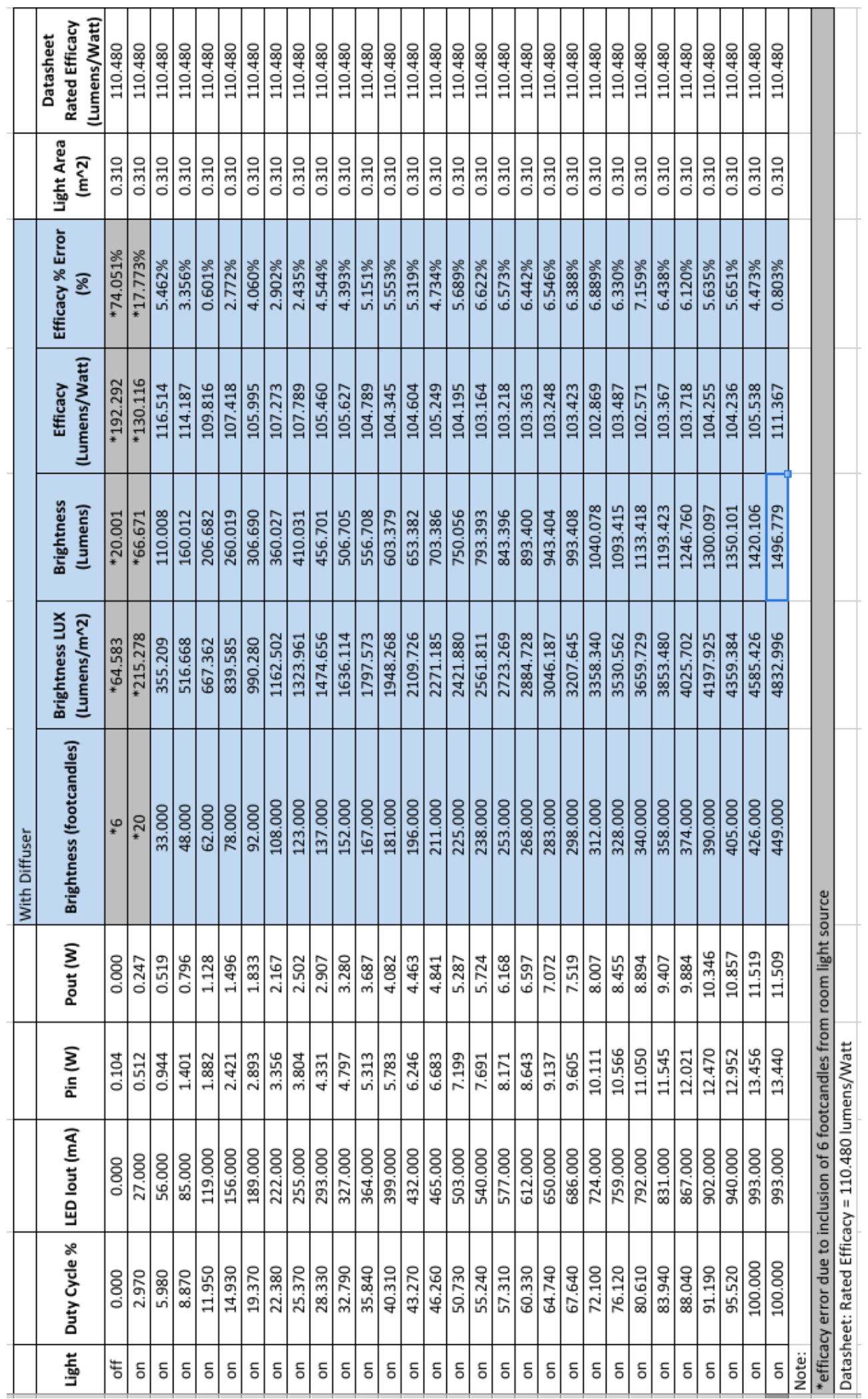


Table 5-9: Lumination Measurement Not Using Light Bulb Diffuser.

\begin{tabular}{|c|c|c|c|c|c|c|c|c|c|c|c|c|c|c|c|c|c|c|c|c|c|c|}
\hline & 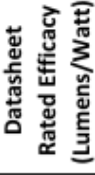 & & & 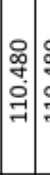 & & & 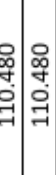 & & & 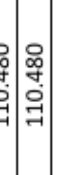 & & & & & & 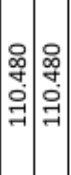 & & 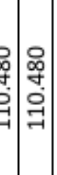 & & & | & \\
\hline & 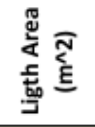 & 일 & 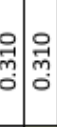 & 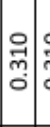 & & & 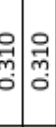 & & : & ְ̦ & & & & 商 & & 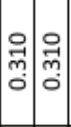 & 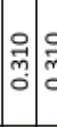 & & & 일 & $\begin{array}{l}0 \\
\vec{m} \\
0\end{array}$ & \\
\hline & 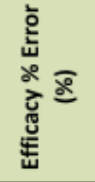 & 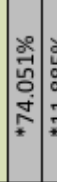 & 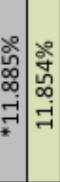 & & & 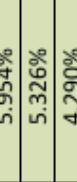 & : & & & 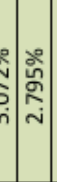 & & & & & & 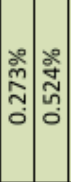 & 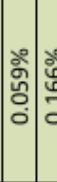 & & & & & \\
\hline & 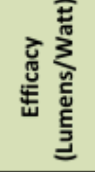 & 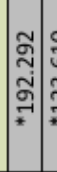 & 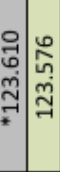 & & & & & & 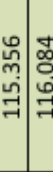 & 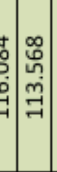 & & & & 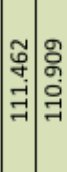 & & & & & & $\mid$ & & \\
\hline & 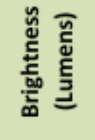 & 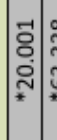 & 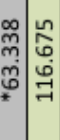 & & & 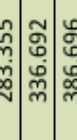 & 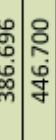 & & 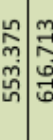 & $\begin{array}{l}n \\
0 \\
0\end{array}$ & & & 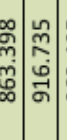 & & 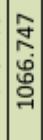 & 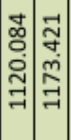 & 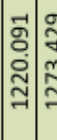 & 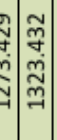 & & & & \\
\hline & 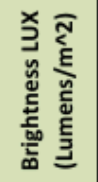 & 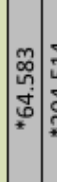 & 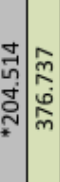 & 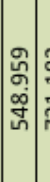 & & 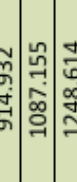 & 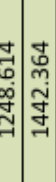 & 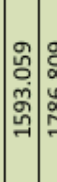 & 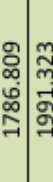 & & & & & & $\begin{array}{l}\vec{y} \\
y \\
\dot{y} \\
\end{array}$ & 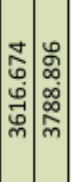 & & & & & & \\
\hline & 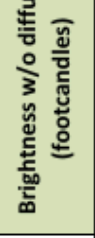 & $\neq$ & ‡) & ठ̊. & & క్రి & 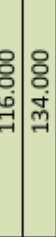 & 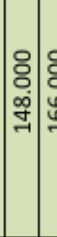 & 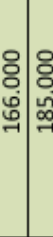 & 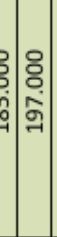 & & & 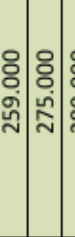 & & $\begin{array}{l}0 \\
0 \\
0 \\
0\end{array}$ & 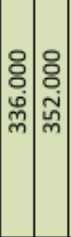 & 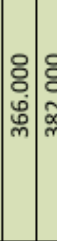 & & & & 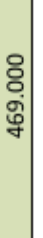 & $\stackrel{\square}{\xi}$ \\
\hline & $\begin{array}{l}3 \\
3 \\
\vdots \\
0\end{array}$ & ¿ & ث્ઠ & 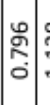 & & 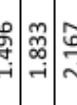 & స్తి & 晾於 & 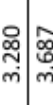 & 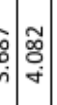 & 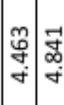 & & & 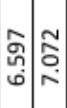 & ?. & 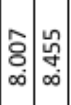 & 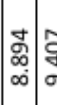 & 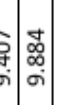 & & & 总 & 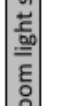 \\
\hline & $\sum_{\frac{c}{a}}^{\bar{z}}$ & : & ヘิ: & 亲 & 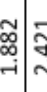 & 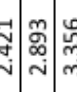 & 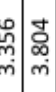 & $\left|\begin{array}{l}\vec{m} \\
\tilde{m} \\
\vec{f}\end{array}\right|$ & 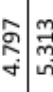 & $n$ & $\mid$ & & & 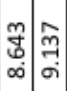 & 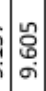 & 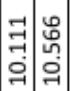 & \begin{tabular}{l|l}
0 \\
\end{tabular} & 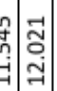 & \begin{tabular}{ll}
\multirow{2}{*}{} \\
\multirow{2}{*}{}
\end{tabular} & 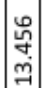 & $\begin{array}{l}\stackrel{q}{+} \\
\stackrel{m}{m}\end{array}$ & 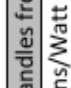 \\
\hline & $\begin{array}{l}\bar{\Phi} \\
\underline{\underline{E}} \\
\underline{\underline{z}} \\
\text { 읍 }\end{array}$ & : & : & 它 & : & : & 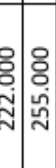 & | & 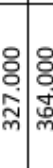 & 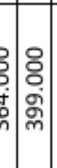 & 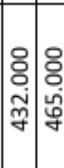 & : & $\left.\begin{array}{l|l}8 \\
0 \\
⿱ 亠 乂 \\
\hdashline\end{array}\right)$ & 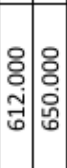 & $\begin{array}{l}0 \\
0 \\
0 \\
0 \\
0 \\
0\end{array}$ & 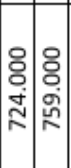 & 各: & 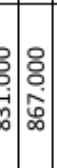 & 离 & & & 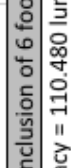 \\
\hline & 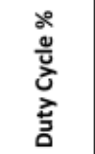 & : & 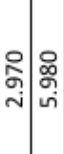 & {$\left[\begin{array}{c}\infty \\
\infty \\
\infty\end{array}\right]$} & تֶ. & 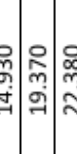 & 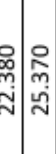 & 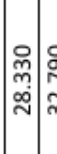 & 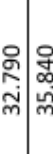 & 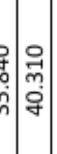 & 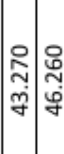 & 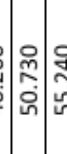 & 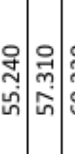 & 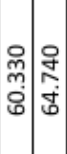 & 亭 & 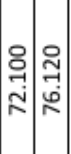 & 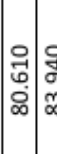 & 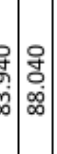 & 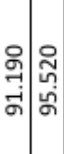 & & & 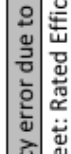 \\
\hline & 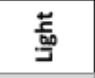 & : & ¿ & & 1 & ᄃ Б & ᄃ & 히영 & 디 & क 5 & \begin{tabular}{|l|l} 
¿ & б \\
\end{tabular} & б & ¿ & 햐 б & 다 & 히 & бᄒ & ᄒᄒ & ᄃ & 하 & . & 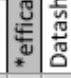 \\
\hline
\end{tabular}




\section{6: Thermal Temperature Measurement}

\subsection{1: Hardware Setup}

The final test performed on the DC Light Bulb was a 12-hour thermal stress test.

Equipment used is summarized in Table 5-10. The DC Light Bulb was run at full load ( $D=100 \%)$ and its temperature was recorded every 30 minutes, for a total of 12 hours.

Table 5-10: Equipment Used For Thermal Measurement.

\begin{tabular}{|l|l|l|l|}
\hline Purpose & Equipment & Manufacture & Model \\
\hline $\mathrm{V}_{\mathrm{IN}}$ & DC Power Supply & GW & GPR-6060D \\
\hline $\mathrm{I}_{\mathrm{IN}}$ & Multimeter & Agilent Technologies & U341A \\
\hline $\begin{array}{l}\text { Temperature } \\
\text { Measurement }\end{array}$ & $\begin{array}{l}\text { Multimeter with } \\
\text { Temperature Capability }\end{array}$ & EXTECH Instruments & MiniTec 26 \\
\hline $\begin{array}{l}\text { Thermal } \\
\text { Image }\end{array}$ & Thermal Image Camera & Fluke & Ti Series \\
\hline
\end{tabular}

Figure 5-18 illustrates the thermal image camera used to capture a couple of readings during the first few hours of the DC Light Bulb's 12-hour thermal stress test.

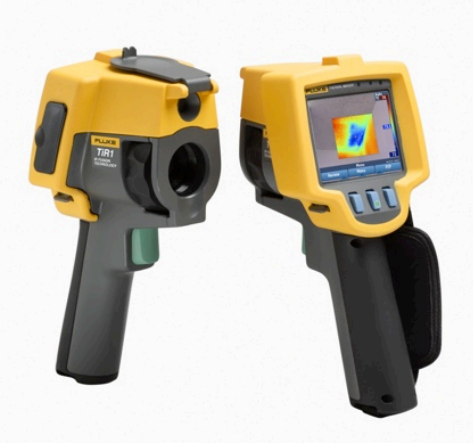

Figure 5-18: Fluke Thermal Imaging Camera [59]. 


\subsection{2: Test Results}

The DC Light Bulb was run at full load $(D=100 \%)$ for 12 -hours and temperature measurements were recorded every 30 minutes. Table 5-11 summarizes the DC Light Bulb's thermal performance. An EXTECH MiniTec 26 with a thermocouple was used to take readings midway along the side of the aluminum heatsink. Comparing the thermal images of the DC Light Bulb's aluminum heatsink shown in Figures 5-22 and 5-24 to the data collected in Table 511 is off by about $10 \stackrel{\circ}{ }$. The difference in measurements may be due to poor heat transfer between the heatsink and the thermocouple. Thermally conductive paste could potentially result in more accurate temperature readings shown in Table 5-11. Equations 5-12 and 5-13 were used to convert between Celsius and Fahrenheit temperature measurements. Figures 519 to 5-25 illustrate thermal temperature of the DC Light Bulb and custom PCB board for various time durations.

$$
\begin{aligned}
& { }^{\circ} C=(\underline{o} F-32) * \frac{5}{9} \\
& \stackrel{\mathrm{o}}{F}={ }^{\mathrm{o}} C * \frac{9}{5}+32
\end{aligned}
$$


Table 5-11: Thermal Temperature Measurements.

\begin{tabular}{|c|c|c|c|c|c|c|}
\hline Time & $\begin{array}{c}\text { Hour } \\
\text { Mark }\end{array}$ & Minutes & $\begin{array}{c}\text { DC } \\
\text { Light } \\
\text { Bulb }\end{array}$ & $\begin{array}{c}\text { Temperature } \\
\text { (oC) }\end{array}$ & $\begin{array}{c}\text { Temperature } \\
\text { (oF) }\end{array}$ & \\
\hline 10:40 AM & 0 & 0 & OFF & 24 & 75.2 & $*$ \\
\hline 11:10 AM & & 30 & ON & 76 & 168.8 & $*$ \\
\hline 11:40 AM & 1 & 60 & ON & 80 & 176.0 & $*$ \\
\hline 12:10 PM & & 90 & ON & 82 & 179.6 & $*$ \\
\hline 12:40 PM & 2 & 120 & ON & 84 & 183.2 & $*$ \\
\hline 1:10 PM & & 150 & ON & 84 & 183.2 & $*$ \\
\hline 1:40 PM & 3 & 180 & ON & 86 & 186.8 & $*$ \\
\hline 2:10 PM & & 210 & ON & 85 & 185.0 & $*$ \\
\hline 2:40 PM & 4 & 240 & ON & 86 & 186.8 & $*$ \\
\hline 3:10 PM & & 270 & ON & 86 & 186.8 & $*$ \\
\hline 3:40 PM & 5 & 300 & ON & 79 & 174.2 & \\
\hline 4:10 PM & & 330 & ON & 78 & 172.4 & \\
\hline 4:40 PM & 6 & 360 & ON & 82 & 179.6 & \\
\hline 5:10 PM & & 390 & ON & 81 & 177.8 & \\
\hline 5:40 PM & 7 & 420 & ON & 80 & 176.0 & \\
\hline 6:10 PM & & 450 & ON & 81 & 177.8 & \\
\hline 6:40 PM & 8 & 480 & ON & 81 & 177.8 & \\
\hline 7:10 PM & & 510 & ON & 79 & 174.2 & \\
\hline 7:40 PM & 9 & 540 & ON & 80 & 176.0 & \\
\hline 8:10 PM & & 570 & ON & 81 & 177.8 & \\
\hline 8:40 PM & 10 & 600 & ON & 80 & 176.0 & \\
\hline 9:10 PM & & 630 & ON & 82 & 179.6 & $* *$ \\
\hline 9:40 PM & 11 & 660 & ON & 84 & 183.2 & $* *$ \\
\hline 10:10 PM & & 690 & ON & 85 & 185.0 & $* *$ \\
\hline 10:40 PM & 12 & 720 & ON & 83 & 181.4 & $* *$ \\
\hline A shet & & 5 & ON & & \\
\hline
\end{tabular}

${ }^{*}$ A sheet of paper was covering the DC Light Bulb, thus trapping extra heat

**The doors were closed, thus possible less air circulation 


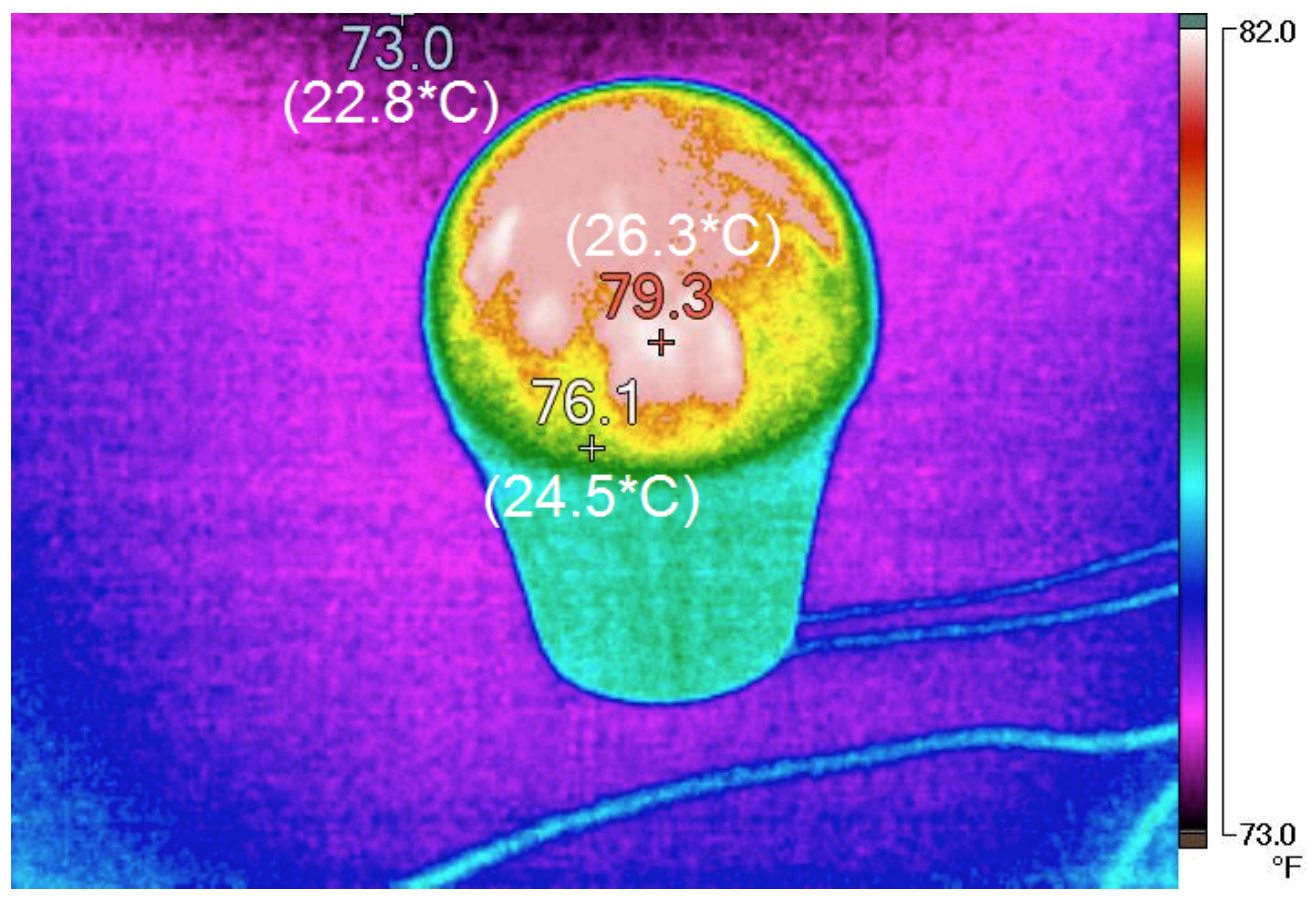

Figure 5-19: DC Light Bulb Off (0 Hours).

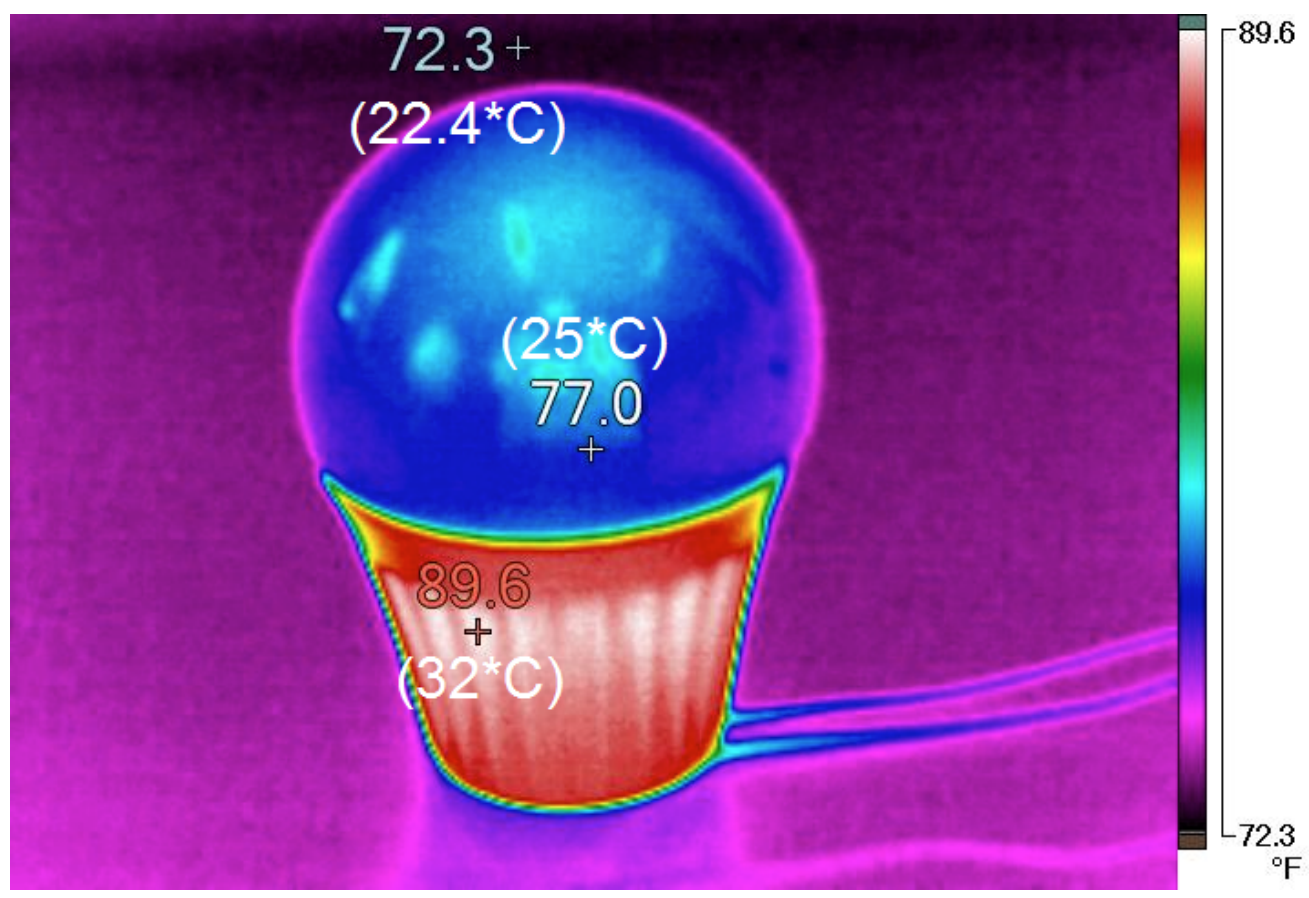

Figure 5-20: DC Light Bulb On ( 15 minutes). 


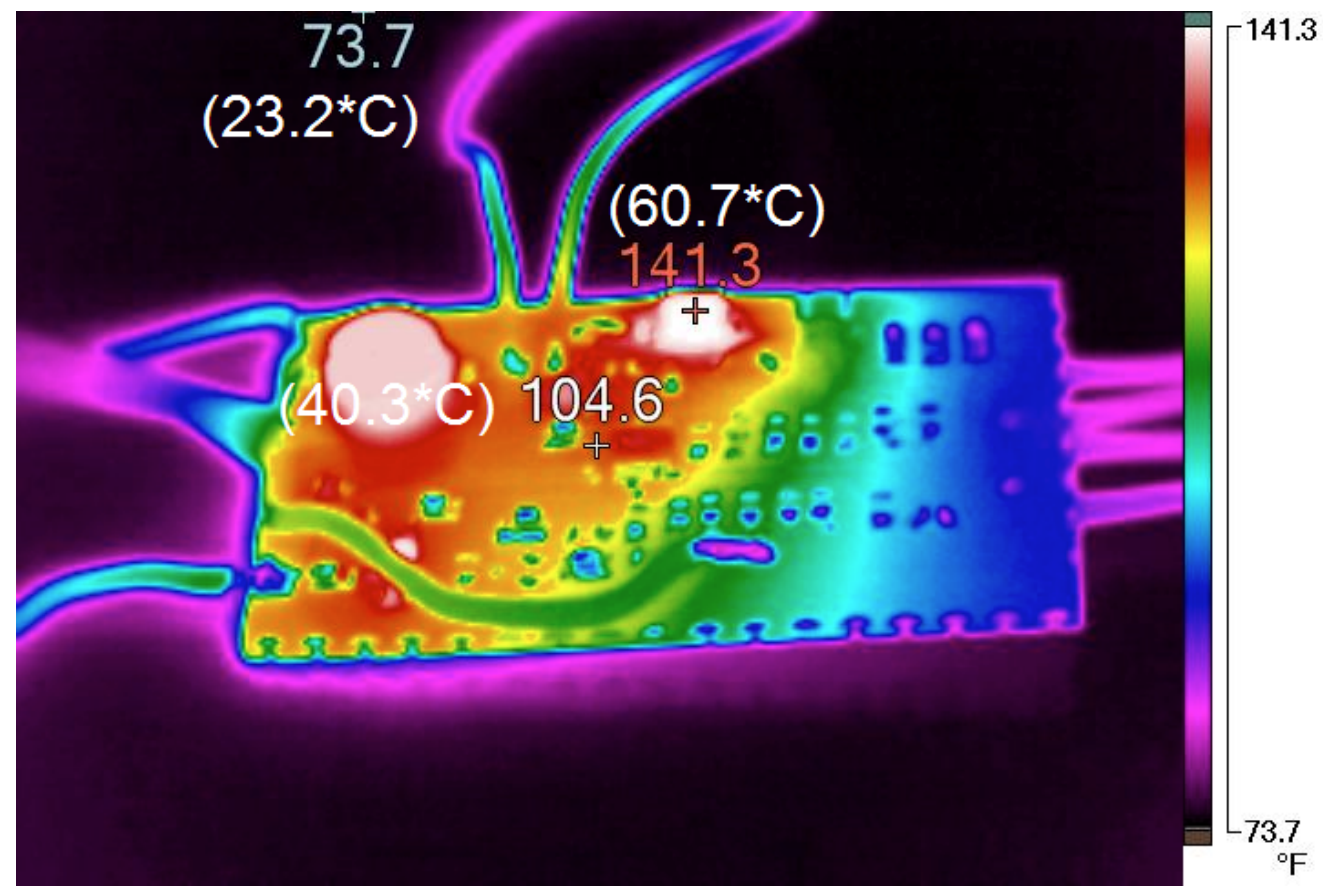

Figure 5-21: DC Light Bulb Circuit On ( 15 minutes).

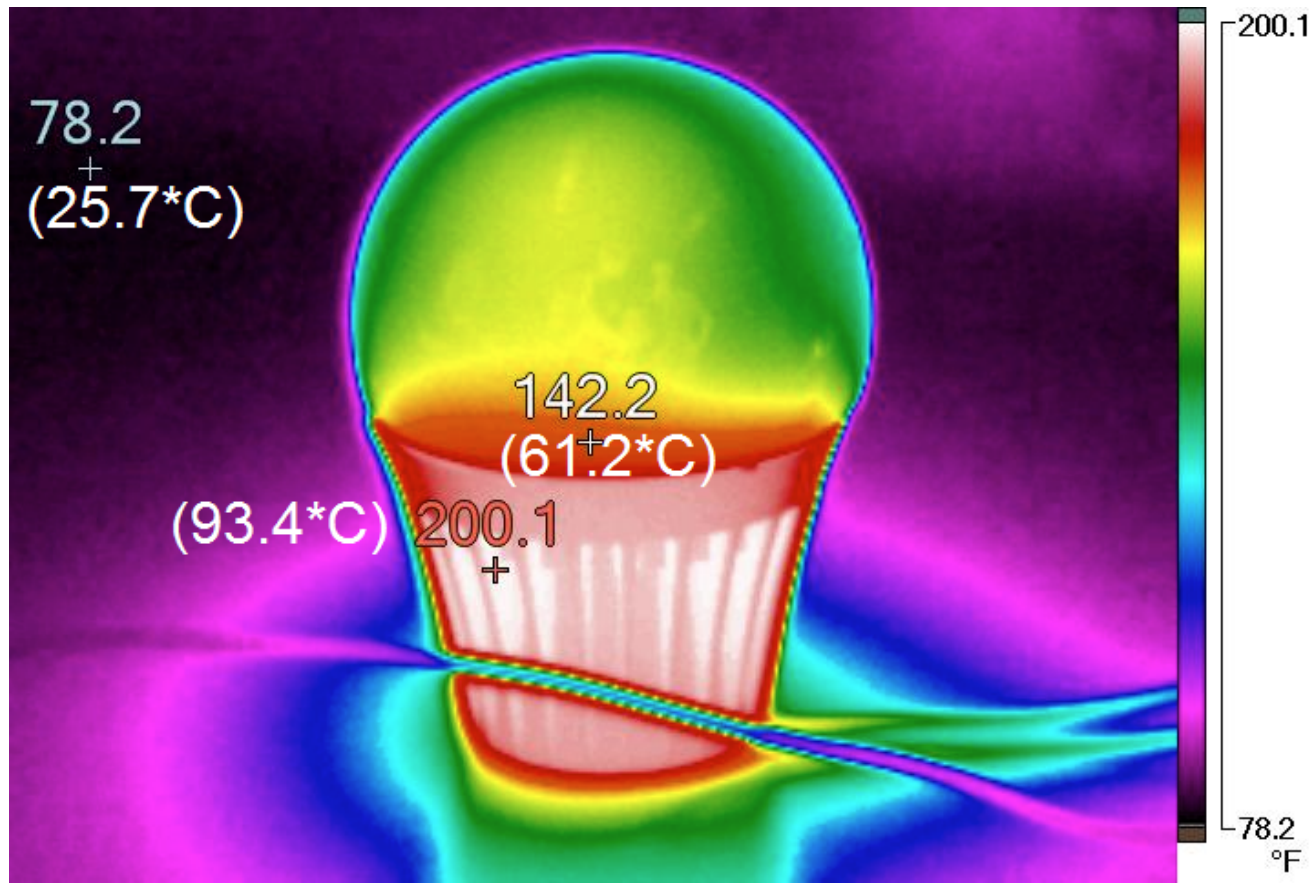

Figure 5-22: DC Light Bulb On ( 4 Hours). 


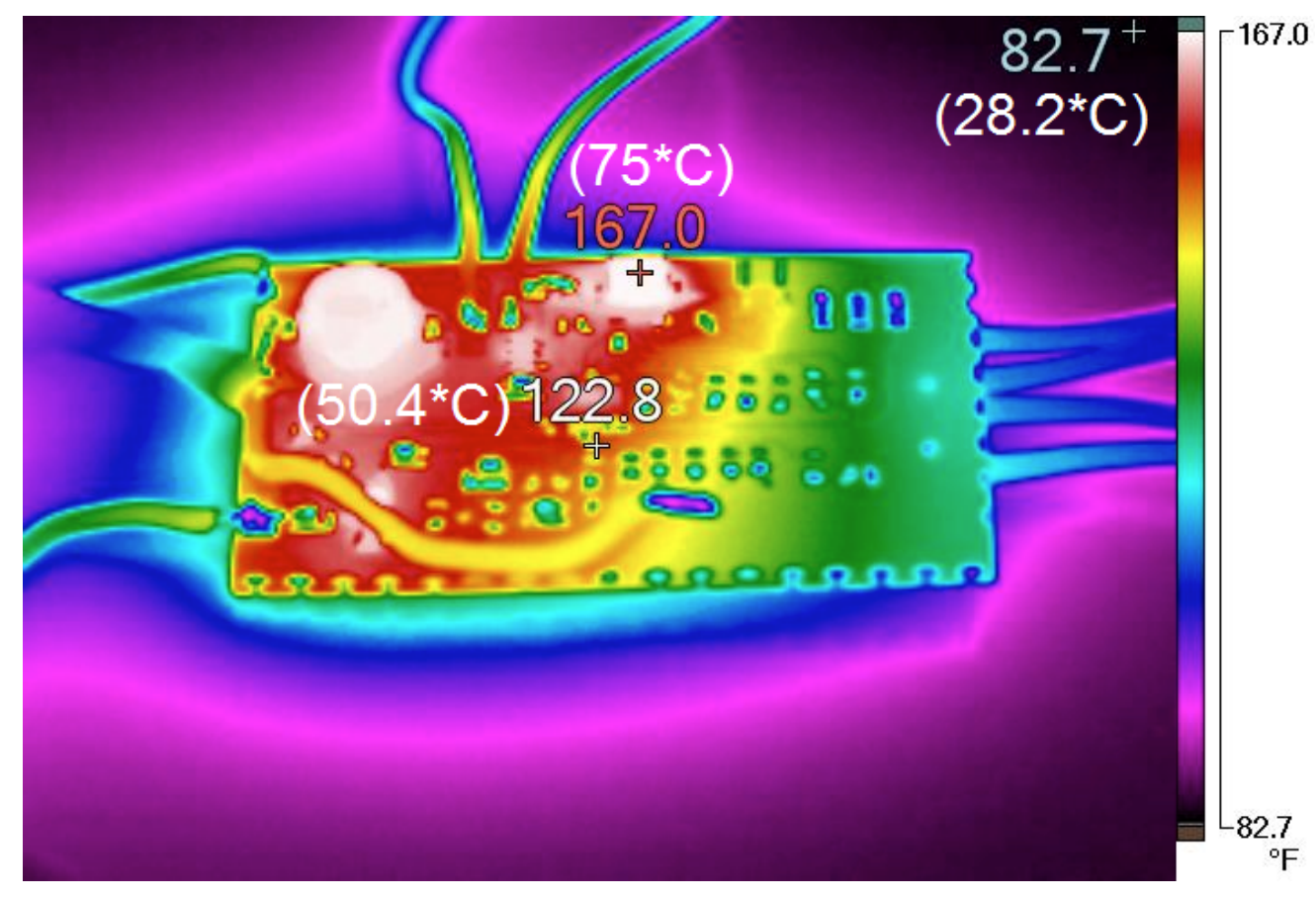

Figure 5-23: DC Light Bulb Circuit On ( 4 Hours).

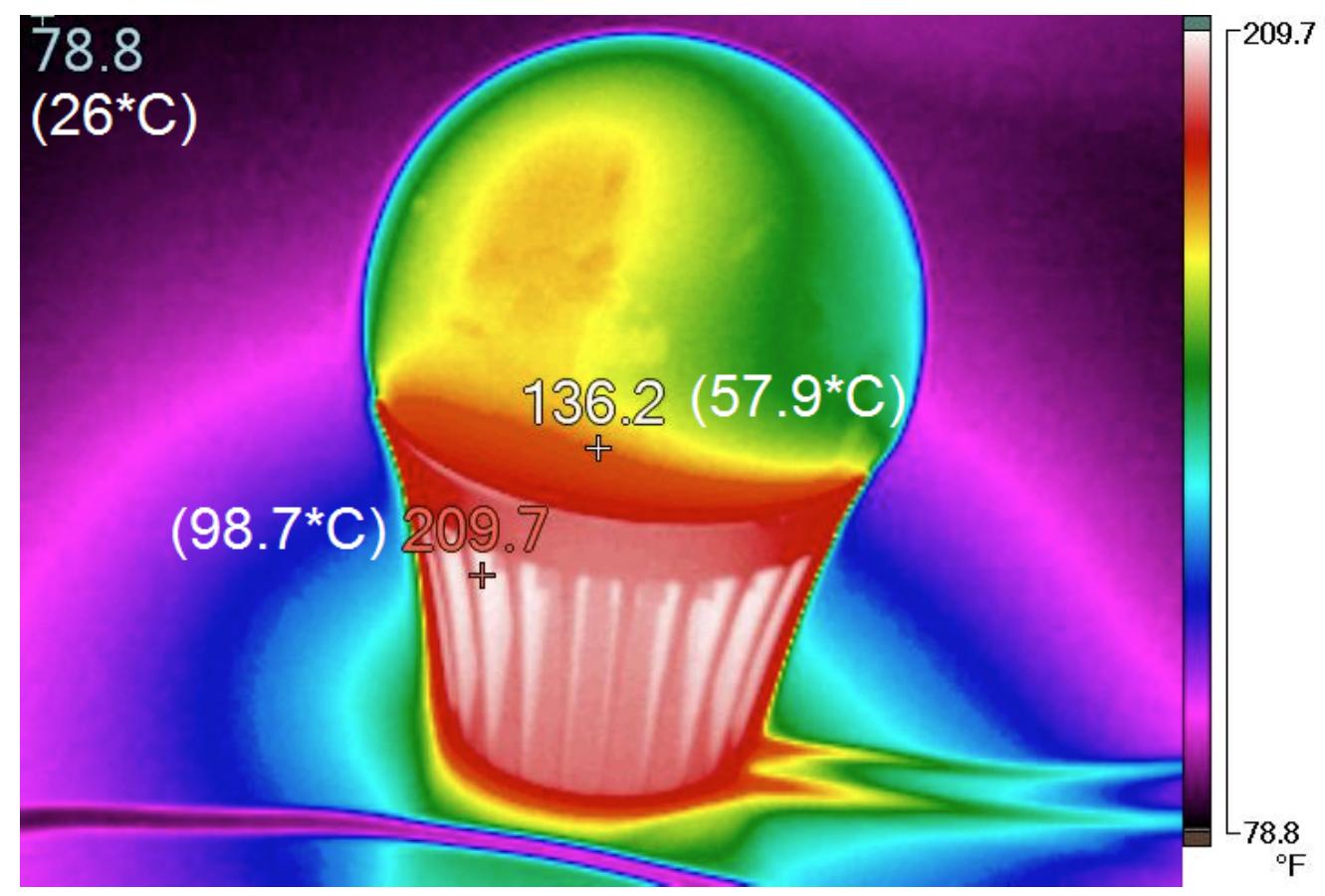

Figure 5-24: DC Light Bulb On ( 6 Hours). 


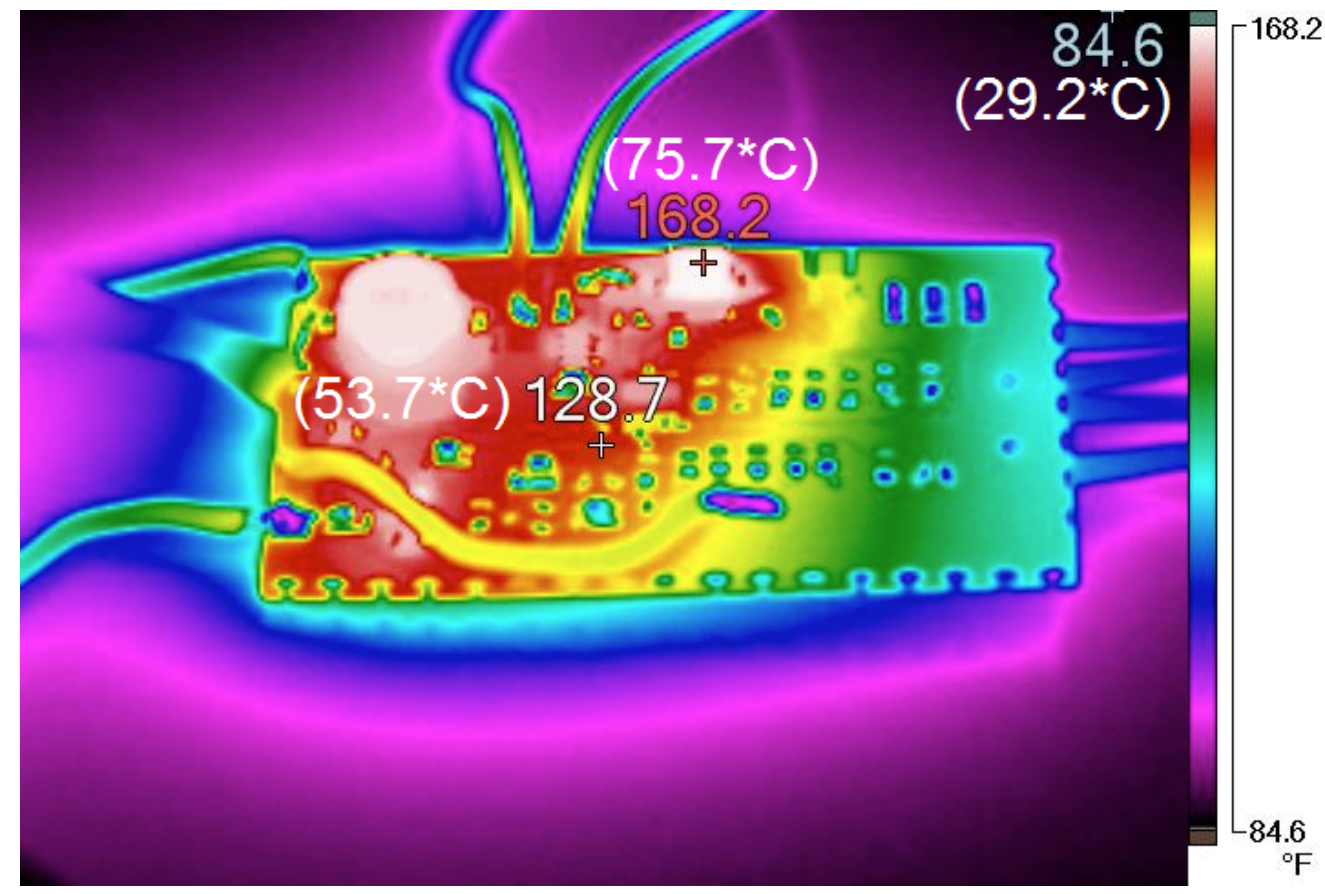

Figure 5-25: DC Light Bulb Circuit On ( 6 Hours).

\section{7 : Summary of Hardware Results}

Overall, the DC Light Bulb was a success. It produced an efficiency of $85.63 \%$ at full brightness with a duty cycle of $100 \%$. At maximum load it produced 1496.78 lumens (or 1563.45 lumens without the diffuser) at an output power of $13.44 \mathrm{~W}$. It produced a luminous efficacy of 111.37 lumens/watt, which is within $0.803 \%$ of rated CREE XPG datasheet values [58]. The DC Light Bulb maintained excellent line regulation. At $\pm 15 \%$ swing from $V_{\text {IN }}$ of 48 VDC, it maintained a line regulation of $1.64 \%$. At $\pm 31 \%$ swing from $V_{\text {IN }}$ of 48 VDC, it maintained a line regulation of $0.23 \%$. Thermal tests suggest that the LED array's worst-case temperature of $98.7 \stackrel{\circ}{\circ}$ (shown in Figure $5-24$ ) operates at only $65.8 \%$ of rated temperature $(150 \stackrel{\circ}{\circ})$. The DC 
Light Bulb was tested to be fully dimmable from 0\% to $100 \%$. The DC Light Bulb's circuit functionality was verified to operate per simulation predictions and follow datasheet specifications. A summary of the DC Light Bulb's simulation and hardware results is provided in Table 5-12.

Table 5-12: DC Light Bulb Simulation vs. Hardware Summary.

\begin{tabular}{|c|c|c|}
\hline & Simulation Results & Hardware Results \\
\hline Parameters & Specifications & Specifications \\
\hline $\begin{array}{l}\text { Wide Input Voltage Range } \\
\text { (Simulated): VIN }\end{array}$ & $24 \mathrm{~V}$ to $72 \mathrm{~V}$ & $* 33 \mathrm{~V}$ to $63 \mathrm{~V}$ \\
\hline Output Voltage in Buck Mode: V(LED) & $0 \mathrm{~V}$ to $25 \mathrm{~V}$ & $0.104 \mathrm{~V}$ to $13.456 \mathrm{~V}$ \\
\hline $\begin{array}{l}\text { PWM Dimming via } 10 \mathrm{k} \Omega \\
\text { Potentiometer: Duty Cycle }\end{array}$ & $0 \%$ to $100 \%$ & $0 \%$ to $100 \%$ \\
\hline Efficiency at Full Load & $* 91.34 \%$ & $85.631 \%$ \\
\hline Total Power Consumption & $14.85 \mathrm{~W}$ & $13.44 \mathrm{~W}$ \\
\hline LED Manufacturer & LUXEON & CREE \\
\hline LED Type & LXK2-PW14 & $\begin{array}{l}\text { CREE XLAMP XP-G } \\
\text { XPGWHT-01-R250- } \\
\text { 00GC1 }\end{array}$ \\
\hline Number of LEDs in Series & 4 & 4 \\
\hline Color Temperature & Cool White (6500K) & Cool White (5000K) \\
\hline Luminous Efficacy & 85 Lumens/Watt & 111.367 Lumens/Watt \\
\hline Luminous Flux at $1 \mathrm{~A}$ & 400 Lumens & 1563.450 Lumens \\
\hline Max Forward Voltage & $4.95 \mathrm{~V}$ & $3.25 \mathrm{~V}$ \\
\hline Max Forward Current & $1.5 \mathrm{~A}$ & $1.5 \mathrm{~A}$ \\
\hline $\begin{array}{l}\text { Max Temperature Recommended at } \\
\text { Forward Current of } 1 \mathrm{~A}\end{array}$ & $75 \stackrel{\circ}{C}$ & 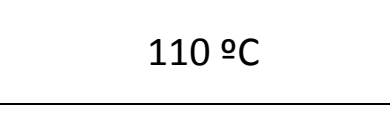 \\
\hline Max LED Junction Temperature & $150 \div \mathrm{C}$ & $150 \div \mathrm{C}$ \\
\hline $\begin{array}{l}\text { Line Regulation at } 15 \% \text { Input Voltage } \\
\text { Swing }\end{array}$ & $0.01 \%$ & $1.64 \%$ \\
\hline $\begin{array}{l}\text { LDO Load Regulation from } 10 \% \text { to } 90 \% \\
\text { Load }\end{array}$ & $0.08 \%$ & - \\
\hline Constant Current Regulation & Yes & Yes \\
\hline Constant Voltage Regulation & Yes & Yes \\
\hline Open LED Protection & Yes & Yes \\
\hline
\end{tabular}


Figure 5-26 illustrates the DC Light Bulb's PCB with fully populated components. Figure 5-27 shows the custom PCB fitted into the inner light bulb housing. Figure 5-28 illustrates the fully assembled DC Light Bulb using an E26 base (lamp holder - white color) mounted on a standard ceiling junction box (blue color). Figure 5-28 also shows the custom slide dimmer in a standard switch box (blue color) with a white faceplate. Lastly, Figure 5-29 illustrates the DC Light Bulb operating at full load ( $D=100 \%)$ from a 48 VDC voltage source.

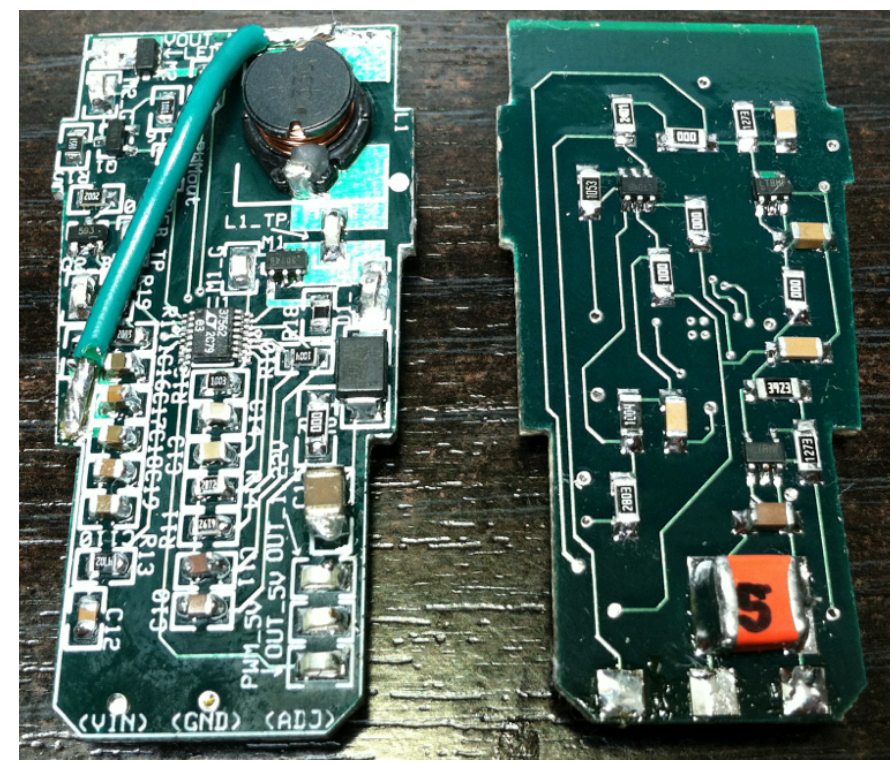

Figure 5-26: Custom DC Light Bulb 4-Layer PCB - Fully Populated, Top (left) and Bottom (right) Layer.

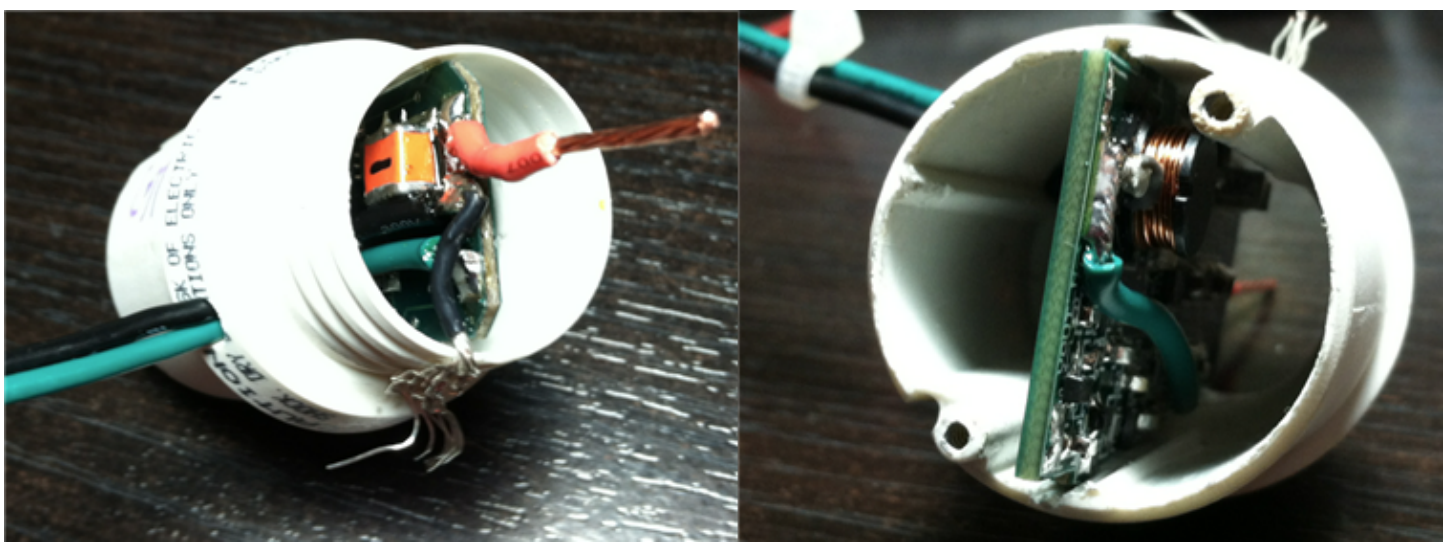

Figure 5-27: Fully Populated PCB Fitted Into Light Bulb’s Inner Sleeve, Bottom (left) and Top (right) View. 


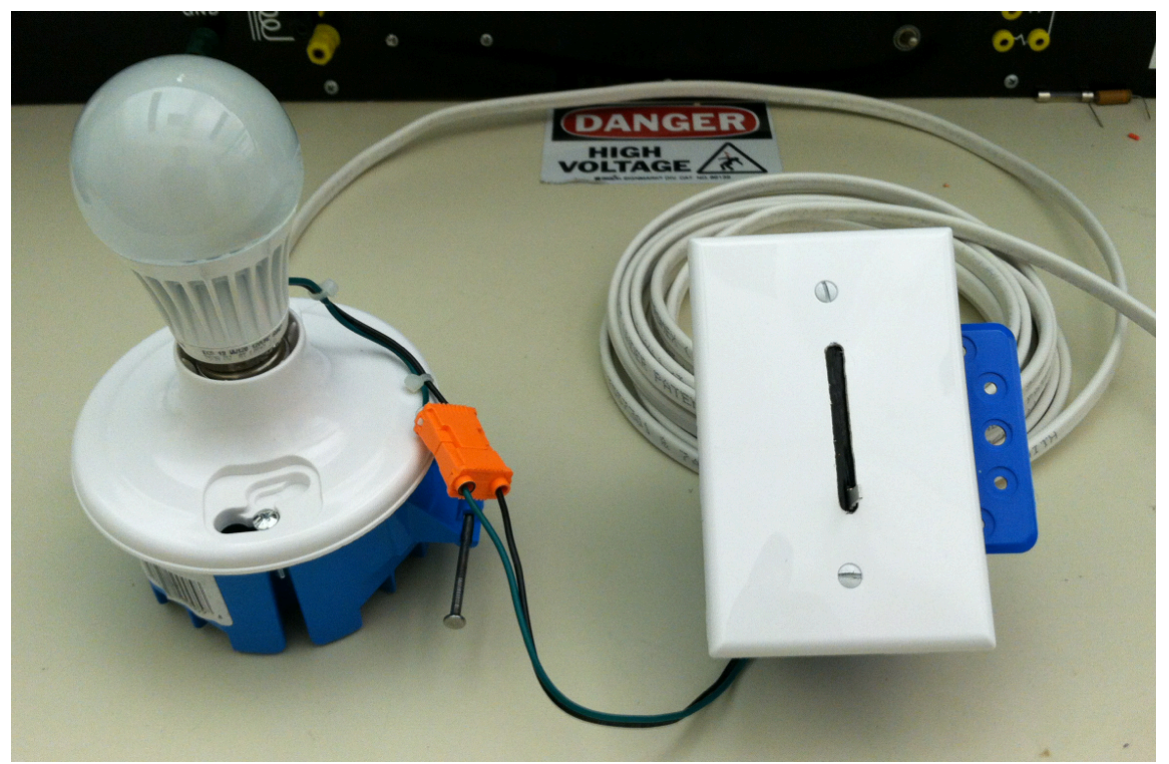

Figure 5-28: A19 DC Light Bulb (left) With Dimmer Box (right) - Fully Assembled.

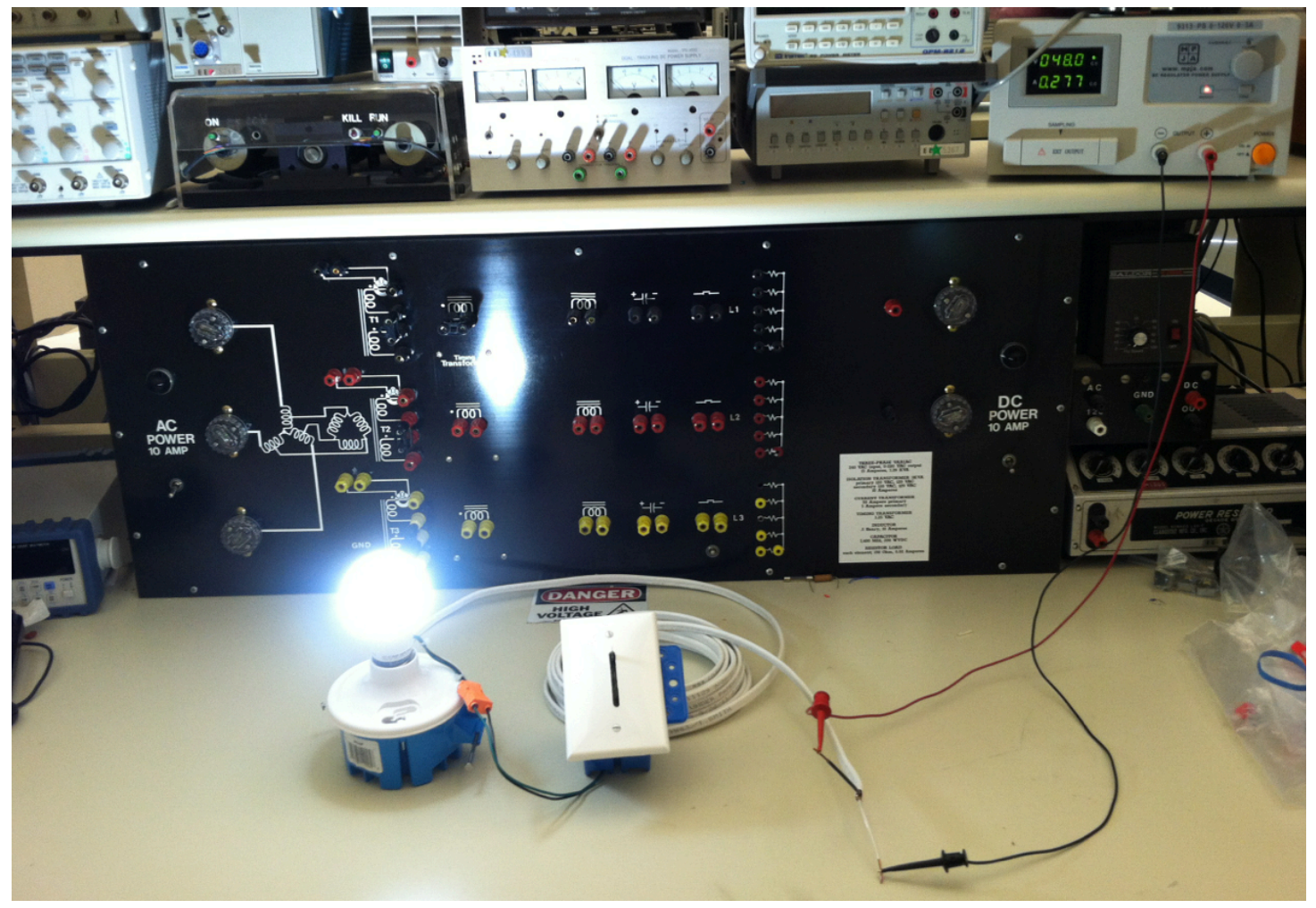

Figure 5-29: Fully Assembled DC Light Bulb Running at Full Load ( $D=100 \%)$ From 48 VDC Input. 


\section{Chapter 6: Conclusion and Future Work}

\section{1 : Summary and Conclusion}

For this thesis, a strong focus is in the design and implementation of an economical and energy efficient DC Light Bulb for Cal Poly San Luis Obispo's DC House Project. For the DC lighting system, emphasis is on the DC-DC LED driver, dimmer circuit, LED lighting array, and physical packing design. It is designed with specific electrical, lumination, physical, construction, and cost constraints, as suggested in Table 3-1.

The DC Light Bulb meets target electrical constraints. It is able to operate from the DC House's main 48 VDC bus voltage. It is also simulated to operate with a wide input voltage ranging from 24 VDC to 72 VDC and hardware tested to operate from input voltage ranging from $33 \mathrm{~V}$ to $63 \mathrm{~V}$ at full load ( $\pm 31 \%$ swing from nominal input voltage of $48 \mathrm{VDC}$ ). The DC Light Bulb maintained excellent line regulation of $0.23 \%$ at $\pm 31 \%$ swing from nominal input voltage of 48 VDC. It produced an efficiency of $85.63 \%$ with a total power consumption of $13.44 \mathrm{~W}$ at full load.

The DC Light Bulb also outperformed initially targeted lumination constraints. It produced 1496.78 lumens (or 1563.45 lumens without the diffuser) with a luminous efficacy of 111.37 lumens/watt at maximum brightness (with a duty cycle of 100\%). A standard $75 \mathrm{~W}$ incandescent light bulb produces about 1100 lumens and a $100 \mathrm{~W}$ incandescent light bulb produces about 1600 lumens (Figure 2-14). The DC Light Bulb produced 1120.08 lumens with a 
total power consumption of 10.11 W The DC Light Bulb only consumed $13.24 \%$ of the total 75 W required by a standard ( $75 \mathrm{~W}$ ) incandescent light bulb that produces 1100 lumens. The DC Light Bulb is also tested to be fully dimmable with duty cycle ranging from $0 \%$ to $100 \%$. It was also designed using a cool white color temperature of 5000K.

The DC Light Bulb's physical design meets the same dimensions of a standard A19 incandescent light bulb with an E26 screw base (Figure 3-1). The DC Light Bulb's custom 4-layer PCB was also able to fit into the inner light bulb sleeve (Figure 5-5). The dimmer circuit also easily fit into a standard switch box as suggested in Figure 3-2 (b).

The DC Light Bulb follows common installation and wiring standards dictated by NEC 2011. The complete lighting system can be easily installed with minimal training. Color coded wires using plug-and-play luminaire connectors (Figure 3-3) make installation straightforward.

Lastly, the DC Light Bulb’s total prototype cost under \$99.68. Target prototype cost constraint suggests it would cost between $\$ 100$ to $\$ 200$ (Table 3-1). The Bill of Material is provided in Appendix A.

\section{2 : Future Considerations and Recommendation}

Overall the DC Light Bulb prototype was a complete success. However there is always room for improvements, such as a wider input voltage range, reduction in production cost, and use of bigger heatsink. 
To make the DC Light Bulb truly universal, it should be designed to work from 12 VDC to 72 VDC. The DC Light Bulb was simulated to work between 24 VDC to 72 VDC. It was hardware tested to operate between 33 VDC to 63 VDC. It should work per simulated suggested results, however a $\pm 31 \%$ swing from the nominal 48 VDC bus voltage provided by the DC House would most likely rarely occur. To create a wider input range, LT3756-2 component selection and sizing would have to be redesigned and re-simulated.

As suggested from Appendix A, the total prototype cost of the DC Light Bulb is $\$ 99.68$. Potential cost savings would be choosing slightly lower performing components. For example, the higher cost of the $10 \mu \mathrm{F} 75 \mathrm{~V}$ tantalum capacitor could be changed to an aluminum electrolytic capacitor or even a X7R ceramic capacitor. A tantalum capacitor was initially chosen because C40 is the main input capacitor into the entire DC Light Bulb's internal circuitry, thus best available filtering was desirable. Depending on how much ripple the main DC House's 48 VDC bus voltage produces, lower rated capacitors can be used. Another cost saving would be choosing a different LED at a lower cost. As Figure 2-18 suggests the cost per lumens have a linear decaying rate with time. Perhaps the time-to-market that the DC Light Bulb takes to be fully commercialized, the cost of high power LEDs would be significantly less. Another potential cost savings is to work with a manufacturer to produce a custom A19 enclosure rather than the EcoSmart A19 temporary solution. It should be kept in mind that a custom A19 enclosure only saves cost when produced in very high volume.

Another recommendation is to use a larger heatsink. Even though the DC Light Bulb 12hour thermal test suggests a maximum temperature of 98.7 으 (measured at its aluminum 
enclosure), which is below the suggested heatsink temperature of $110 \stackrel{\circ}{C}$ and way below the LED maximum junction temperature of $150 \stackrel{\circ}{ }$, a larger heatsink can in the long run extend the operating lifetime of the DC Light Bulb.

In conclusion, the DC Light Bulb was an overall success. It was able to meet all design requirements. The DC Light Bulb was able to operate at 48 VDC, is fully dimmable from $0 \%$ to $100 \%$, and has the same physical dimension of a traditional A19 incandescent light bulb. The DC Light Bulb produces 1496.78 lumens at a color temperature of 5000K and uses only $13.44 \mathrm{~W}$. 


\section{References}

[1] WEO-2011. (2011, October 30). "Access to Electricity." [Online]. Available: http://www.iea.org/weo/electricity.asp.

[2] J. Glover, M. Sarma, and T. Overbye Power System Analysis and Design, $4^{\text {th }}$ Edition. Stamford, CT: Cengage Learning, 2008, p. 4.

[3] A. Vaccaro, (2011, October 30). "Reliable Electric Power for Developing Countries." [Online]. Available: http://www.ieeehtc.org/files/Reliable_Electricity_Challenge_Description.pdf

[4] J. Holden, C. Kelty. (2011, October 30). "The Environmental Impact of the Manufacturing of Semiconductors." [Internet]. Available: http://cnx.org/content/m14503/latest/

[5] EPA. (2011, June 24). "On the Road." [Internet]. Available: http://www.epa.gov/epahome/trans.htm

[6] S. Lim, D. Kang, O. Ogunseitan, J. Schoenung. (2010, December 7). “Potential Environmental Impacts of Light-Emitting Diodes (LEDs): Metallic Resources, Toxicity, and Hazardous Waste Classification." [Internet] Available:

http://pubs.acs.org/doi/abs/10.1021/es101052q

[7] Unknown. (2011, October 30). “Electronic Waste.” [Internet] Available: http://en.wikipedia.org/wiki/Electronic_waste

[8] S. Guynup. (2012, October 30). "Light Pollution Taking Toll on Wildlife, Eco-Groups Say." [Internet] Available: http://news.nationalgeographic.com/news/2003/04/0417_030417_tvlightpollution.htm I

[9] Wikipedia. (2012, February 25). “Diwali." [Internet]. Available: http://en.wikipedia.org/wiki/Diwali

[10] Amazon. (2012, March 5). "Coleman 1-Matle Kerosene Lantern." [Internet]. Available: http://www.amazon.com/Coleman-639C700-1-Mantle-KeroseneLantern/dp/B00168PIQ6

[11] Wikipedia. (2012, March 5). “Oil Lamp.” [Internet]. Available: http://en.wikipedia.org/wiki/Oil_lamp

[12] Wikipedia. (2012, March 5). "Luminous Efficacy." [Internet]. Available: http://en.wikipedia.org/wiki/Luminous_efficacy\#cite_note-12 
[13] Wikipedia. (2012, March 10). “Candle." [Internet]. Available: http://en.wikipedia.org/wiki/Candle\#cite_note-Hamins-4

[14] T. Edison, "Improvement in Electric Lights," U.S. Patent 214,636, April 22, 1879.

[15] Wikimedia Commons. (2012, March 15). “Incandescent Light Bulb." [Internet]. Available: http://en.wikipedia.org/wiki/Incandescent_light_bulb

[16] U.S. Department of Energy. (2012, March 15). "Types of Lighting" [Internet]. Available: http://www.energysavers.gov/your_home/lighting_daylighting/index.cfm/mytopic=120 $\underline{30}$

[17] Xcel Energy. (2012, March 15). “Light Bulb Cost Comparison.” [Internet]. Available: http://www.energyclassroom.com/pdfs/EC_CO_AC_LightBulbCost.pdf

[18] U.S. Department of Energy. (2012, March 18). "Fluorescent Lighting." [Internet]. Available: http://www.eere.energy.gov/basics/buildings/fluorescent.html

[19] Wikipedia. (2012, March 18). “Fluorescent Lamp.” [Internet]. Available: http://en.wikipedia.org/wiki/Fluorescent_lamp

[20] Howstuffworks Inc. (2012, March 18). “How Dimmer Switches Work." [Internet]. Available: http://home.howstuffworks.com/dimmer-switch1.htm

[21] Lutron Electronics Co. Inc. (2012, March 19). "Dimming CFLs and LEDs." [Internet]. Available: http://www.lutron.com/EducationTraining/LCE/Pages/DimmingCFLsandLEDs.aspx

[22] Energy Star. (2012, March 19). "Frequently Asked Questions Information on CFL and Mercury." [Internet] Available:

http://www.energystar.gov/ia/partners/promotions/change_light/downloads/Fact_She et_Mercury.pdf

[23] U.S. Environmental Protection Agency. (2012, March 19). “2005 National Emissions Inventory Data and Documentation," [Internet]. Available: http://www.epa.gov/ttnchie1/net/2005inventory.html

[24] U.S. Department of Energy. (2012, March 19). "Lighting Comparison Chart." [Internet]. Available: http://www.eere.energy.gov/basics/buildings/lighting.html

[25] U.S. Department of Energy. (2012, March 19). "LED Frequently Asked Questions." [Internet]. Available:

http://apps1.eere.energy.gov/buildings/publications/pdfs/ssl/led_basics.pdf 
[26] Wikipedia. (2012, March 20). “Light-Emitting Diode." [Internet]. Available: http://en.wikipedia.org/wiki/Light-emitting_diode

[27] U.S. Department of Energy. (2012, March 20). “Solid-State Lighting: LED Basics." [Internet]. Available:

http://www1.eere.energy.gov/buildings/ssl/sslbasics_ledbasics.html

[28] U.S. Department of Energy. (2012, March 25). "Lifetime of White LEDs." [Internet]. Available:

http://apps1.eere.energy.gov/buildings/publications/pdfs/ssl/lifetime_white_leds.pdf

[29] MSPVL Polytechnic College. (2012, March 30). "VI Characteristics of Diode." [Internet]. Available: http://www.ustudy.in/node/4945

[30] Home Depot. (2011, December 15). "EcoSmart A19 8.6-Watt (40W) LED Light Bulb." [Internet]. Available: http://www.homedepot.com/h_d1/N-5yc1v/R202188260/h_d2/ProductDisplay?catalogld=10053\&langld=-1\&keyword=EcoSmart+8.6Watt+\%2840W\%29+A19+LED+Light+Bulb\&storeld=10051

[31] U.S. Department of Energy. (2012, March 30) "Dimming LEDs." [Internet]. Available: http://cool.conservation-us.org/byorg/us-doe/dimming_leds.pdf

[32] EagleLight. (2012, March 31). "Color Rendering Index Explained." [Internet]. Available: http://www.eaglelight.com/category/lighting_tutorials.color_rendering_index/

[33] J. Birn. (2012, April 2). “Color Temperature." [Internet]. Available: http://www.3drender.com/glossary/colortemp.htm

[34] FlashlightReviews.com. (2012, April 2). "LUX Measurements." [Internet]. Available: http://flashlightreviews.com/features/lux.htm

[35] Home Depot. (2012, December 15). "GE 60-Watt Soft White Double Life A19 General Purpose Incandescent Light Bulb (6-Pack)." [Internet]. Available: http://www.homedepot.com/Electrical-Light-Bulbs-Incandescents-Light-Bulbs/h_d1/N5yc1vZbmglZ1z132piZ1z0ykpc/R100493722/h_d2/ProductDisplay?catalogld=10053\&langld=-1\&storeld=10051

[36] U.S. Department of Energy. (2012, April 2). "Why SSL." [Internet]. Available: http://www1.eere.energy.gov/buildings/ssl/sslbasics_whyssl.html

[37] U.S. Department of Energy. (2012, April 2). "Color Rendering Index and LEDs." [Internet]. Available: http://cool.conservation-us.org/byorg/us-doe/color_rendering_index.pdf

[38] ENERGY STAR. (2012, April 2). “Light Quality." [Internet]. Available: http://www.energystar.gov/index.cfm?c=fixture_guide.pr_fixtures_guide_lightquality 
[39] Cree Inc. (2012, April 10). "Cree Sets New R\&D Performance Record with 254 LumenPer-Watt Power LED." [Internet]. Available: http://www.cree.com/news-andevents/cree-news/press-releases/2012/april/120412-254-lumen-per-watt

[40] Navigant Consulting Inc. (2012, April 13). "Energy Savings Estimates of Light Emitting Diodes in Niche Lighting Applications." pp. 60-65. [Internet]. Available: http://apps1.eere.energy.gov/buildings/publications/pdfs/ssl/nichefinalreport_january2 011.pdf

[41] U.S. Department of Energy. (2012, April 15). "Solid-State Lighting R\&D Challenges." [Internet]. Available: http://www1.eere.energy.gov/buildings/ssl/sslbasics_randd.html

[42] IBOG. (2012, April 15). "Solar Panel Efficiency and the Factors that Affect it." [Internet]. Available: http://howsolarworks.1bog.org/solar-panel-efficiency/

[43] U.S. Department of Energy. (2012, April 16). “A Consumer's Guide: Get Your Power From the Sun." pg. 7 [Internet]. Available: http://www.solar-estimate.org/pdfs/consumerguide-to-solar-power.pdf

[44] Unlimited Solar Inc. (2012, April 20). “A19 - E26 Screw Base 12 Volt AC DC 5.6 Watt LED Light Bulb." [Internet]. Available: http://www.unlimited-

solar.com/LED_Screw_In_Bulb_A19_E26_Screw_Base_12_VOLT_p/led-a19-1016-.htm

[45] J. Crowfoot. "Design and Modeling of the Cal Poly DC House Power Distribution System." M.S. Thesis, California Polytechnic State University, San Luis Obispo, California, 2011.

[46] Taufik and D. Dolan, Advanced Power Electronics EE411, San Luis Obispo, CA: Cal Poly State University, 2011, pp. 50-108.

[47] M. Navvab, Ph.D. (2012, May 1). "Visual Performance Analysis of Office Occupants Working Under Realistic Luminous Environment Conditions." [Internet]. Available: http://www.fullspectrumsolutions.com/reading_lamp_study.htm

[48] Dr. Taufik. (2011, September 11)."The DC House Project: List of On-Going and Past Projects." [Internet]. Available: http://www.calpoly.edu/ taufik/dchouse/projects.html

[49] J. Chaidez. "DC House Modeling and System Design." B.S. Senior Project, California Polytechnic State University, San Luis Obispo, California, 2011.

[50] NFPA. (2011, September 19). "NFPA 70: National Electrical Code." [Internet]. Available: http://www.nfpa.org/aboutthecodes/AboutTheCodes.asp?DocNum=70\&cookie_test=1 
[51] Ideal Industries Inc. (2012, May 1). "PowerPlug Luminaire Disconnect." [Internet]. Available: http://www.idealindustries.ca/media/pdfs/products/brochures/p2733_powerplug_brochure.pdf

[52] Taufik and D. Dolan, Advanced Power Electronics EE411, San Luis Obispo, CA: Cal Poly State University, 2011, pp. 215-217.

[53] Linear Technology, "TimerBlox: Voltage-Controlled Pulse Width Modulator (PWM)," LTC6992-1 datasheet, 2011.

[54] Linear Technology, "20mA, 3V to 80V Low Dropout Micropower Linear Regulator," LT3014 datasheet, 2011.

[55] Taufik, Switching Mode Power Supply Components and Design EE527, San Luis Obispo, CA: Cal Poly State University, 2012.

[56] Cutter Electronics. (2011, December 5). " 25 mm Quad Optic Designed for the CREE XPE/XPC/XPG." [Internet]. Available: http://www.cutter.com.au/proddetail.php?prod=cut935

[57] Linear Technology, “100 V V 100 V OUT LED Controller," LT3756-2 datasheet, 2011.

[58] Cree Inc. (2011, December 5). “Cree XLamp XP-G LEDs." Product Family Data Sheet. [Internet]. Available:

http://www.cree.com/ /media/Files/Cree/LED\%20Components\%20and\%20Modules/XL amp/Data\%20and\%20Binning/XLampXPG.pdf

[59] Fluke (2012, May 20). "Fluke Thermal Image Camera Ti Series." [Internet]. Available: http://www.fluke.com/Fluke/usen/products/TI-Mechanical.htm

[60] ExpressPCB. (2011, December 10). "ExpressPCB.” [Internet]. Available: http://expresspcb.com/.

[61] J. Zukowski. "Implementation of High Power LED Load into the SuPER System," B.S. Senior Project, California Polytechnic State University, San Luis Obispo, California 2009.

[62] R. Lu, B. Ng. "White Light LED Load System." B.S. Senior Project, California Polytechnic State University, San Luis Obispo, California, 2012. 


\section{Appendix A: Bill of Materials}

\begin{tabular}{|c|c|c|c|c|c|c|c|c|}
\hline $\begin{array}{l}\text { Qty } \\
\#\end{array}$ & $\begin{array}{c}\text { Cost } \\
\text { Each } \\
(\$)\end{array}$ & $\begin{array}{l}\text { Total } \\
\text { Cost } \\
\text { (\$) }\end{array}$ & Ref. & Mfg. & Part No. & $\begin{array}{l}\text { Detailed } \\
\text { Description }\end{array}$ & Dimensions & $\begin{array}{l}\text { Digikey } \\
\text { Part \# }\end{array}$ \\
\hline 1 & $\$ 0.48$ & $\$ 0.48$ & $\mathrm{C} 10$ & $\begin{array}{c}\text { TDK } \\
\text { Corporatio } \\
n\end{array}$ & $\begin{array}{l}\text { C2012X7 } \\
\text { S2A105K }\end{array}$ & $\begin{array}{l}\text { CAP CER 1UF 100V } \\
10 \% \text { X7S } 0805\end{array}$ & $\begin{array}{c}0.079 " \mathrm{Lx} \\
0.049 " \mathrm{~W} \\
(2.00 \mathrm{~mm} \mathrm{x} \\
1.25 \mathrm{~mm}) \\
\end{array}$ & $\begin{array}{c}445-5205- \\
1-N D\end{array}$ \\
\hline 1 & $\$ 0.48$ & $\$ 0.48$ & C11 & $\begin{array}{c}\text { TDK } \\
\text { Corporatio } \\
n\end{array}$ & $\begin{array}{l}\text { C2012X7 } \\
\text { S2A105K }\end{array}$ & $\begin{array}{l}\text { CAP CER 1UF 100V } \\
10 \% \times 7 S 0805\end{array}$ & $\begin{array}{c}0.079 " \mathrm{Lx} \\
0.049 " \mathrm{~W} \\
(2.00 \mathrm{~mm} \mathrm{x} \\
1.25 \mathrm{~mm}) \\
\end{array}$ & $\begin{array}{c}445-5205- \\
1-N D\end{array}$ \\
\hline 1 & $\$ 0.48$ & $\$ 0.48$ & $\mathrm{C} 12$ & $\begin{array}{c}\text { TDK } \\
\text { Corporatio } \\
n\end{array}$ & $\begin{array}{l}\text { C2012X7 } \\
\text { R1H102K }\end{array}$ & $\begin{array}{c}\text { AP CER 1000PF 50V } \\
10 \% \text { X7R } 0805\end{array}$ & $\begin{array}{c}0.079 " \mathrm{Lx} \\
0.049 " \mathrm{~W} \\
(2.00 \mathrm{~mm} \mathrm{x} \\
1.25 \mathrm{~mm}) \\
\end{array}$ & $\begin{array}{c}445-1347- \\
1-N D\end{array}$ \\
\hline 1 & $\$ 0.12$ & $\$ 0.12$ & $\mathrm{C} 13$ & Yageo & $\begin{array}{c}\text { CC0805K } \\
\text { RX7R8BB } \\
104\end{array}$ & $\begin{array}{c}\text { CAP CER 0.1UF 25V } \\
10 \% \text { X7R } 0805\end{array}$ & $\begin{array}{c}0.079 " \mathrm{Lx} \\
0.049 " \mathrm{~W} \\
(2.00 \mathrm{~mm} \mathrm{x} \\
1.25 \mathrm{~mm})\end{array}$ & $\begin{array}{c}311-1141- \\
1-N D\end{array}$ \\
\hline 1 & $\$ 0.45$ & $\$ 0.45$ & C14 & $\begin{array}{l}\text { Taiyo } \\
\text { Yuden }\end{array}$ & $\begin{array}{c}\text { TMK212 } \\
\text { AB7475K } \\
\text { G-T }\end{array}$ & $\begin{array}{c}\text { CAP CER 4.7UF 25V } \\
10 \% \text { X7R } 0805\end{array}$ & $\begin{array}{c}0.079 " \mathrm{Lx} \\
0.049 " \mathrm{~W} \\
(2.00 \mathrm{~mm} \mathrm{x} \\
1.25 \mathrm{~mm})\end{array}$ & $\begin{array}{l}\text { 587-2990- } \\
1-N D\end{array}$ \\
\hline 1 & $\$ 4.08$ & $\$ 4.08$ & C15 & Kemet & $\begin{array}{c}\text { C1210C4 } \\
\text { 75M1R2 } \\
\text { C7186 }\end{array}$ & $\begin{array}{l}\text { CAP CER 4.7UF 100V } \\
20 \% \text { X7R } 1210\end{array}$ & $\begin{array}{c}0.138 " \mathrm{Lx} \\
0.091^{\prime \prime} \mathrm{W} \\
(3.50 \mathrm{~mm} \mathrm{x} \\
2.30 \mathrm{~mm})\end{array}$ & $\begin{array}{c}399-5787- \\
1-N D\end{array}$ \\
\hline 1 & $\$ 0.45$ & $\$ 0.45$ & $\mathrm{C} 16$ & $\begin{array}{l}\text { Taiyo } \\
\text { Yuden }\end{array}$ & $\begin{array}{c}\text { TMK212 } \\
\text { AB7475K } \\
\text { G-T }\end{array}$ & $\begin{array}{c}\text { CAP CER 4.7UF 25V } \\
10 \% \text { X7R } 0805\end{array}$ & $\begin{array}{c}0.079 " \mathrm{Lx} \\
0.049 " \mathrm{~W} \\
(2.00 \mathrm{~mm} \mathrm{x} \\
1.25 \mathrm{~mm}) \\
\end{array}$ & $\begin{array}{l}\text { 587-2990- } \\
1-N D\end{array}$ \\
\hline 1 & $\$ 0.45$ & $\$ 0.45$ & $\mathrm{C} 17$ & $\begin{array}{l}\text { Taiyo } \\
\text { Yuden }\end{array}$ & $\begin{array}{c}\text { TMK212 } \\
\text { AB7475K } \\
\text { G-T }\end{array}$ & $\begin{array}{c}\text { CAP CER 4.7UF 25V } \\
10 \% \text { X7R } 0805\end{array}$ & $\begin{array}{c}0.079 " \mathrm{Lx} \\
0.049 " \mathrm{~W} \\
(2.00 \mathrm{~mm} \mathrm{x} \\
1.25 \mathrm{~mm}) \\
\end{array}$ & $\begin{array}{l}\text { 587-2990- } \\
\text { 1-ND }\end{array}$ \\
\hline 1 & $\$ 0.45$ & $\$ 0.45$ & $\mathrm{C} 18$ & $\begin{array}{l}\text { Taiyo } \\
\text { Yuden }\end{array}$ & $\begin{array}{c}\text { TMK212 } \\
\text { AB7475K } \\
\text { G-T }\end{array}$ & $\begin{array}{c}\text { CAP CER 4.7UF 25V } \\
10 \% \text { X7R } 0805\end{array}$ & $\begin{array}{c}0.079 " \mathrm{Lx} \\
0.049 " \mathrm{~W} \\
(2.00 \mathrm{~mm} \mathrm{x} \\
1.25 \mathrm{~mm})\end{array}$ & $\begin{array}{l}\text { 587-2990- } \\
\text { 1-ND }\end{array}$ \\
\hline 1 & $\$ 0.45$ & $\$ 0.45$ & C19 & $\begin{array}{l}\text { Taiyo } \\
\text { Yuden }\end{array}$ & $\begin{array}{c}\text { TMK212 } \\
\text { AB7475K } \\
\text { G-T }\end{array}$ & $\begin{array}{c}\text { CAP CER 4.7UF 25V } \\
10 \% \text { X7R } 0805\end{array}$ & $\begin{array}{c}0.079 " \mathrm{Lx} \\
0.049 " \mathrm{~W} \\
(2.00 \mathrm{~mm} \mathrm{x} \\
1.25 \mathrm{~mm}) \\
\end{array}$ & $\begin{array}{l}\text { 587-2990- } \\
1-N D\end{array}$ \\
\hline 1 & $\$ 0.49$ & $\$ 0.49$ & $\mathrm{C} 20$ & Kemet & $\begin{array}{c}\text { C1206F1 } \\
\text { 04K3RAC } \\
\text { TU }\end{array}$ & $\begin{array}{c}\text { CAP CER 0.1UF 25V } \\
10 \% \text { X7R } 1206\end{array}$ & $\begin{array}{c}0.126 " \mathrm{Lx} \\
0.063^{\prime \prime ~ W} \\
(3.20 \mathrm{~mm} x\end{array}$ & $\begin{array}{l}\text { 399-5615- } \\
1-N D\end{array}$ \\
\hline
\end{tabular}




\begin{tabular}{|c|c|c|c|c|c|c|c|c|}
\hline & & & & & & & $1.60 \mathrm{~mm})$ & \\
\hline 1 & $\$ 0.32$ & $\$ 0.32$ & C30 & Kemet & $\begin{array}{c}\text { C1206C1 } \\
\text { 05K3RAC } \\
\text { TU }\end{array}$ & $\begin{array}{l}\text { CAP CER 1UF 25V } \\
10 \% \text { X7R } 1206\end{array}$ & $\begin{array}{c}0.126 " \mathrm{Lx} \\
0.063^{\prime \prime} \mathrm{W} \\
(3.20 \mathrm{~mm} \mathrm{x} \\
1.60 \mathrm{~mm}) \\
\end{array}$ & $\begin{array}{l}\text { 399-1255- } \\
1-N D\end{array}$ \\
\hline 1 & $\$ 0.38$ & $\$ 0.38$ & C31 & $\begin{array}{c}\text { TDK } \\
\text { Corporatio } \\
n\end{array}$ & $\begin{array}{c}\text { C3216X7 } \\
\text { R1E474 } \\
\text { M/0.85 }\end{array}$ & $\begin{array}{c}\text { CAP CER 0.47UF 25V } \\
20 \% \text { X7R } 1206\end{array}$ & $\begin{array}{c}0.126 " \mathrm{Lx} \\
0.063^{\prime \prime ~ W} \\
(3.20 \mathrm{~mm} \mathrm{x} \\
1.60 \mathrm{~mm})\end{array}$ & $\begin{array}{l}\text { 445-4021- } \\
\text { 1-ND }\end{array}$ \\
\hline 1 & $\begin{array}{c}\$ 16.2 \\
3\end{array}$ & $\$ 16.23$ & $\mathrm{C} 40$ & $\begin{array}{l}\text { Vishay/Spr } \\
\text { ague }\end{array}$ & $\begin{array}{l}\text { T97R106 } \\
\text { K075LSA }\end{array}$ & $\begin{array}{c}\text { CAP TANT 10UF 75V } \\
10 \% 2824\end{array}$ & $\begin{array}{c}0.299 " \mathrm{Lx} \\
0.236 \mathrm{~W} \\
(7.60 \mathrm{~mm} \mathrm{x} \\
6.00 \mathrm{~mm}) \\
\end{array}$ & $\begin{array}{c}\text { 718-1737- } \\
\text { 1-ND }\end{array}$ \\
\hline 1 & $\$ 0.56$ & $\$ 0.56$ & C41 & $\begin{array}{c}\mathrm{AVX} \\
\text { Corporatio } \\
\mathrm{n}\end{array}$ & $\begin{array}{l}\text { 12061C1 } \\
\text { 05KAT2A }\end{array}$ & $\begin{array}{l}\text { CAP CER IUF 100V } \\
10 \% \text { X7R } 1206\end{array}$ & $\begin{array}{c}0.126 " \mathrm{Lx} \\
0.063^{\prime \prime ~ W} \\
(3.20 \mathrm{~mm} \mathrm{x} \\
1.60 \mathrm{~mm})\end{array}$ & $\begin{array}{l}\text { 478-6226- } \\
\text { 1-ND }\end{array}$ \\
\hline 1 & $\$ 0.38$ & $\$ 0.38$ & $\mathrm{C} 42$ & $\begin{array}{c}\text { TDK } \\
\text { Corporatio } \\
\mathrm{n}\end{array}$ & $\begin{array}{l}\text { C3216X7 } \\
\text { R1E474 } \\
\text { M/0.85 }\end{array}$ & $\begin{array}{c}\text { CAP CER 0.47UF 25V } \\
20 \% \text { X7R } 1206\end{array}$ & $\begin{array}{c}0.126 " \mathrm{Lx} \\
0.063^{\prime \prime} \mathrm{W} \\
(3.20 \mathrm{~mm} \mathrm{x} \\
1.60 \mathrm{~mm})\end{array}$ & $\begin{array}{l}445-4021- \\
1-N D\end{array}$ \\
\hline 1 & $\$ 0.45$ & $\$ 0.45$ & C110 & $\begin{array}{l}\text { Taiyo } \\
\text { Yuden }\end{array}$ & $\begin{array}{c}\text { TMK212 } \\
\text { AB7475K } \\
\text { G-T }\end{array}$ & $\begin{array}{l}\text { CAP CER 4.7UF 25V } \\
10 \% \text { X7R } 0805\end{array}$ & $\begin{array}{c}0.079 " \mathrm{Lx} \\
0.049 " \mathrm{~W} \\
(2.00 \mathrm{~mm} \mathrm{x} \\
1.25 \mathrm{~mm})\end{array}$ & $\begin{array}{l}\text { 587-2990- } \\
\text { 1-ND }\end{array}$ \\
\hline 1 & $\$ 1.01$ & $\$ 1.01$ & D1 & Diodes Inc. & $\begin{array}{l}\text { B1100B- } \\
13-\mathrm{F}\end{array}$ & $\begin{array}{c}\text { DIODE SCHOTTKY } \\
\text { 100V 1A SMB }\end{array}$ & $\begin{array}{c}3.94 \mathrm{~mm} \mathrm{x} \\
4.57 \mathrm{~mm}\end{array}$ & $\begin{array}{l}\text { B1100B- } \\
\text { FDICT-ND }\end{array}$ \\
\hline 4 & $\$ 4.16$ & $\$ 16.64$ & D2 & Cree Inc. & $\begin{array}{c}\text { XPGWHT } \\
-01- \\
\text { R250- } \\
\text { 00GC1 }\end{array}$ & $\begin{array}{l}\text { LED XLAMP XP-G } \\
\text { WHITE COOL }\end{array}$ & $\begin{array}{c}2.6 \mathrm{~mm} \times 2.6 \mathrm{~m} \\
\mathrm{~m} ?\end{array}$ & $\begin{array}{c}\text { XPGWHT- } \\
\text { 01-R250- } \\
\text { 00GC1CT- } \\
\text { ND }\end{array}$ \\
\hline 1 & $\$ 1.91$ & $\$ 1.91$ & L1 & $\begin{array}{l}\text { Wurth } \\
\text { Elektronik }\end{array}$ & $\begin{array}{c}7445613 \\
3 \text { WE- } \\
\text { PD4 L }\end{array}$ & $\begin{array}{l}\text { INDUCTOR POWER } \\
33 \mathrm{UH} \text { 2.3A SMD }\end{array}$ & $\begin{array}{c}0.500 " \mathrm{Lx} \\
0.393^{\prime \prime} \mathrm{W} x \\
0.197 " \mathrm{H} \\
(12.70 \mathrm{~mm} \mathrm{x} \\
10.00 \mathrm{~mm} \mathrm{x} \\
5.00 \mathrm{~mm})\end{array}$ & 74456133 \\
\hline 1 & $\$ 1.00$ & $\$ 1.00$ & M1 & $\begin{array}{l}\text { Vishay } \\
\text { Siliconix }\end{array}$ & $\begin{array}{l}\text { SI3430D } \\
\text { V-T1-E3 }\end{array}$ & $\begin{array}{c}\text { MOSFET N-CH } 100 \mathrm{~V} \\
1.8 \mathrm{~A} 6-\mathrm{TSOP}\end{array}$ & $\begin{array}{c}6-T S O P \\
\text { (0.065", } \\
1.65 \mathrm{~mm} \\
\text { Width) } \\
\end{array}$ & $\begin{array}{c}\text { SI3430DV- } \\
\text { T1-E3CT- } \\
\text { ND }\end{array}$ \\
\hline 1 & $\$ 1.10$ & $\$ 1.10$ & M2 & $\begin{array}{l}\text { Vishay } \\
\text { Siliconix }\end{array}$ & $\begin{array}{l}\text { SI5435B } \\
\text { DC-T1- } \\
\text { GE3 }\end{array}$ & $\begin{array}{c}\text { MOSFET P-CH 30V } \\
4.3 \mathrm{~A} 1206-8\end{array}$ & $\begin{array}{l}\text { 8-SMD, Flat } \\
\text { Lead }\end{array}$ & $\begin{array}{c}\text { SI5435BDC- } \\
\text { T1-GE3CT- } \\
\text { ND }\end{array}$ \\
\hline 1 & $\$ 0.54$ & $\$ 0.54$ & Q1 & $\begin{array}{c}\text { Diodes/Zet } \\
\text { ex }\end{array}$ & $\begin{array}{l}\text { FMMT49 } \\
\text { 3TA }\end{array}$ & $\begin{array}{l}\text { TRANS HP NPN } \\
\text { 100V 1000MA } \\
\text { SOT23-3 }\end{array}$ & SOT-23-3 & $\begin{array}{c}\text { FMMT493C } \\
\text { T-ND }\end{array}$ \\
\hline 1 & $\$ 0.54$ & $\$ 0.54$ & Q2 & $\begin{array}{c}\text { Diodes/Zet } \\
\text { ex }\end{array}$ & $\begin{array}{c}\text { FMMT59 } \\
\text { 3TA }\end{array}$ & $\begin{array}{c}\text { TRANS PNP 100V 1A } \\
\text { HV SOT23-3 }\end{array}$ & SOT-23-3 & $\begin{array}{c}\text { FMMT593C } \\
\text { T-ND }\end{array}$ \\
\hline 1 & $\$ 0.06$ & $\$ 0.06$ & RoO & $\begin{array}{l}\text { Panasonic - } \\
\text { ECG }\end{array}$ & $\begin{array}{c}\text { ERJ- } \\
\text { 8GEYORO }\end{array}$ & $\begin{array}{c}\text { RES } 0.0 \text { OHM } 1 / 4 \mathrm{~W} \\
1206 \mathrm{SMD}\end{array}$ & $\begin{array}{l}0.126 " \mathrm{Lx} \\
0.063^{\prime \prime} \mathrm{W}\end{array}$ & PO.OECT-ND \\
\hline
\end{tabular}




\begin{tabular}{|c|c|c|c|c|c|c|c|c|}
\hline & & & & & ov & & $\begin{array}{c}(3.20 \mathrm{~mm} x \\
1.60 \mathrm{~mm})\end{array}$ & \\
\hline 1 & $\$ 0.06$ & $\$ 0.06$ & R01 & $\begin{array}{l}\text { Panasonic - } \\
\text { ECG }\end{array}$ & $\begin{array}{c}\text { ERJ- } \\
\text { 8GEYORO } \\
\text { OV }\end{array}$ & $\begin{array}{c}\text { RES } 0.0 \mathrm{OHM} 1 / 4 \mathrm{~W} \\
1206 \mathrm{SMD}\end{array}$ & $\begin{array}{c}0.126 " \mathrm{Lx} \\
0.063 " \mathrm{~W} \\
(3.20 \mathrm{~mm} \mathrm{x} \\
1.60 \mathrm{~mm})\end{array}$ & PO.OECT-ND \\
\hline 1 & $\$ 0.06$ & $\$ 0.06$ & $\mathrm{R} 02$ & $\begin{array}{l}\text { Panasonic - } \\
\text { ECG }\end{array}$ & $\begin{array}{l}\text { ERJ- } \\
\text { 8GEYORO } \\
\text { OV }\end{array}$ & $\begin{array}{c}\text { RES } 0.0 \mathrm{OHM} 1 / 4 \mathrm{~W} \\
1206 \mathrm{SMD}\end{array}$ & $\begin{array}{c}0.126 " \mathrm{Lx} \\
0.063^{\prime \prime} \mathrm{W} \\
(3.20 \mathrm{~mm} \mathrm{x} \\
1.60 \mathrm{~mm})\end{array}$ & PO.OECT-ND \\
\hline 1 & $\$ 0.06$ & $\$ 0.06$ & R03 & $\begin{array}{l}\text { Panasonic - } \\
\text { ECG }\end{array}$ & $\begin{array}{c}\text { ERJ- } \\
\text { 8GEYORO } \\
\text { OV }\end{array}$ & $\begin{array}{c}\text { RES } 0.0 \mathrm{OHM} 1 / 4 \mathrm{~W} \\
1206 \mathrm{SMD}\end{array}$ & $\begin{array}{c}0.126 " \mathrm{Lx} \\
0.063^{\prime \prime} \mathrm{W} \\
(3.20 \mathrm{~mm} \mathrm{x} \\
1.60 \mathrm{~mm})\end{array}$ & PO.OECT-ND \\
\hline 1 & $\$ 0.06$ & $\$ 0.06$ & R04 & $\begin{array}{l}\text { Panasonic - } \\
\text { ECG }\end{array}$ & $\begin{array}{c}\text { ERJ- } \\
\text { 8GEYORO } \\
\text { OV }\end{array}$ & $\begin{array}{c}\text { RES } 0.0 \text { OHM } 1 / 4 \mathrm{~W} \\
1206 \mathrm{SMD}\end{array}$ & $\begin{array}{c}0.126 " \mathrm{Lx} \\
0.063 " \mathrm{~W} \\
(3.20 \mathrm{~mm} \mathrm{x} \\
1.60 \mathrm{~mm})\end{array}$ & PO.OECT-ND \\
\hline 1 & $\$ 0.04$ & $\$ 0.04$ & R10 & $\begin{array}{l}\text { Stackpole } \\
\text { Electronics } \\
\text { Inc. }\end{array}$ & $\begin{array}{c}\text { RMCF08 } \\
\text { 05FT1M0 } \\
0\end{array}$ & $\begin{array}{c}\text { RES } 1 \mathrm{M} \text { OHM } 1 / 8 \mathrm{~W} \\
1 \% 0805 \mathrm{SMD}\end{array}$ & $\begin{array}{c}0.079 " \mathrm{Lx} \\
0.049 " \mathrm{~W} \\
(2.00 \mathrm{~mm} \mathrm{x} \\
1.25 \mathrm{~mm})\end{array}$ & $\begin{array}{l}\text { RMCF0805 } \\
\text { FT1M00CT- } \\
\text { ND }\end{array}$ \\
\hline 1 & $\$ 0.04$ & $\$ 0.04$ & R11 & $\begin{array}{l}\text { Stackpole } \\
\text { Electronics } \\
\text { Inc. }\end{array}$ & $\begin{array}{c}\text { RMCF08 } \\
\text { 05FT61K } \\
9\end{array}$ & $\begin{array}{c}\text { RES } 61.9 \mathrm{~K} \text { OHM } \\
1 / 8 \mathrm{~W} 1 \% 0805 \mathrm{SMD}\end{array}$ & $\begin{array}{c}0.079 " \mathrm{Lx} \\
0.049 " \mathrm{~W} \\
(2.00 \mathrm{~mm} \mathrm{x} \\
1.25 \mathrm{~mm}) \\
\end{array}$ & $\begin{array}{c}\text { RMCF0805 } \\
\text { FT61K9CT- } \\
\text { ND }\end{array}$ \\
\hline 1 & $\$ 0.04$ & $\$ 0.04$ & $\mathrm{R} 12$ & $\begin{array}{c}\text { Stackpole } \\
\text { Electronics } \\
\text { Inc. }\end{array}$ & $\begin{array}{c}\text { RMCF08 } \\
\text { 05FT100 } \\
\text { K }\end{array}$ & $\begin{array}{c}\text { RES 100K OHM } \\
1 / 8 \mathrm{~W} 1 \% 0805 \text { SMD }\end{array}$ & $\begin{array}{c}0.079 " \mathrm{Lx} \\
0.049 " \mathrm{~W} \\
(2.00 \mathrm{~mm} \mathrm{x} \\
1.25 \mathrm{~mm})\end{array}$ & $\begin{array}{c}\text { RMCF0805 } \\
\text { FT100KCT- } \\
\text { ND }\end{array}$ \\
\hline 1 & $\$ 0.04$ & $\$ 0.04$ & R13 & $\begin{array}{l}\text { Stackpole } \\
\text { Electronics } \\
\text { Inc. }\end{array}$ & $\begin{array}{c}\text { RMCF08 } \\
\text { 05FT47K } \\
0\end{array}$ & $\begin{array}{c}\text { RES } 47 \mathrm{~K} \text { OHM } 1 / 8 \mathrm{~W} \\
1 \% 0805 \mathrm{SMD}\end{array}$ & $\begin{array}{c}0.079 " \mathrm{Lx} \\
0.049 " \mathrm{~W} \\
(2.00 \mathrm{~mm} \mathrm{x} \\
1.25 \mathrm{~mm})\end{array}$ & $\begin{array}{c}\text { RMCF0805 } \\
\text { FT47K0CT- } \\
\text { ND }\end{array}$ \\
\hline 1 & $\$ 0.04$ & $\$ 0.04$ & R14 & $\begin{array}{c}\text { Stackpole } \\
\text { Electronics } \\
\text { Inc. }\end{array}$ & $\begin{array}{c}\text { RMCF08 } \\
\text { 05FT28K } \\
7\end{array}$ & $\begin{array}{c}\text { RES TF } 28.7 \mathrm{~K} \mathrm{OHM} \\
1 \% 0.125 \mathrm{~W} 0805\end{array}$ & $\begin{array}{c}0.079 " \mathrm{Lx} \\
0.049 " \mathrm{~W} \\
(2.00 \mathrm{~mm} \mathrm{x} \\
1.25 \mathrm{~mm})\end{array}$ & $\begin{array}{c}\text { RMCF0805 } \\
\text { FT28K7CT- } \\
\text { ND }\end{array}$ \\
\hline 1 & $\$ 0.04$ & $\$ 0.04$ & R15 & $\begin{array}{c}\text { Stackpole } \\
\text { Electronics } \\
\text { Inc. }\end{array}$ & $\begin{array}{c}\text { RMCF08 } \\
\text { 05FT1K5 } \\
0\end{array}$ & $\begin{array}{c}\text { RES 1.5K OHM } \\
\text { 1/8W 1\% } 0805 \text { SMD }\end{array}$ & $\begin{array}{c}0.079 " \mathrm{Lx} \\
0.049 " \mathrm{~W} \\
(2.00 \mathrm{~mm} \mathrm{x} \\
1.25 \mathrm{~mm}) \\
\end{array}$ & $\begin{array}{c}\text { RMCF0805 } \\
\text { FT1K50CT- } \\
\text { ND }\end{array}$ \\
\hline 1 & $\$ 0.04$ & $\$ 0.04$ & R16 & $\begin{array}{l}\text { Stackpole } \\
\text { Electronics } \\
\text { Inc. }\end{array}$ & $\begin{array}{c}\text { RMCF08 } \\
\text { 05FT1K0 } \\
0\end{array}$ & $\begin{array}{c}\text { RES } 1 \mathrm{~K} \text { OHM } 1 / 8 \mathrm{~W} \\
1 \% 0805 \mathrm{SMD}\end{array}$ & $\begin{array}{c}0.079 " \mathrm{Lx} \\
0.049 " \mathrm{~W} \\
(2.00 \mathrm{~mm} \mathrm{x} \\
1.25 \mathrm{~mm})\end{array}$ & $\begin{array}{c}\text { RMCF0805 } \\
\text { FT1K00CT- } \\
\text { ND }\end{array}$ \\
\hline 1 & $\$ 0.35$ & $\$ 0.35$ & R17 & Susumu & $\begin{array}{l}\text { RL1220S- } \\
\text { R10-F }\end{array}$ & $\begin{array}{c}\text { RES } .10 \text { OHM } 1 / 3 \mathrm{~W} \\
1 \% 0805 \mathrm{SMD}\end{array}$ & $\begin{array}{c}0.079 " \mathrm{Lx} \\
0.049 " \mathrm{~W} \\
(2.00 \mathrm{~mm} \mathrm{x} \\
1.25 \mathrm{~mm})\end{array}$ & $\begin{array}{c}\text { RL12S.10FC } \\
\text { T-ND }\end{array}$ \\
\hline 1 & $\$ 0.77$ & $\$ 0.77$ & R18 & Panasonic - & ERJ- & RESISTOR .033 OHM & $0.079 " L x$ & P.033AQCT \\
\hline
\end{tabular}




\begin{tabular}{|c|c|c|c|c|c|c|c|c|}
\hline & & & & ECG & $\begin{array}{c}\text { 6BWFRO } \\
33 \mathrm{~V}\end{array}$ & $1 / 4 \mathrm{~W} 1 \% 0805$ & $\begin{array}{c}0.049 " \mathrm{~W} \\
(2.00 \mathrm{~mm} \mathrm{x} \\
1.25 \mathrm{~mm})\end{array}$ & $-N D$ \\
\hline 1 & $\$ 0.04$ & $\$ 0.04$ & R19 & $\begin{array}{c}\text { Stackpole } \\
\text { Electronics } \\
\text { Inc. }\end{array}$ & $\begin{array}{c}\text { RMCF08 } \\
\text { 05FT200 } \\
\text { K }\end{array}$ & $\begin{array}{c}\text { RES 200K OHM } \\
\text { 1/8W 1\% } 0805 \text { SMD }\end{array}$ & $\begin{array}{c}0.079 " \mathrm{Lx} \\
0.049 " \mathrm{~W} \\
(2.00 \mathrm{~mm} \mathrm{x} \\
1.25 \mathrm{~mm}) \\
\end{array}$ & $\begin{array}{c}\text { RMCF0805 } \\
\text { FT200KCT- } \\
\text { ND }\end{array}$ \\
\hline 1 & $\$ 0.10$ & $\$ 0.10$ & R20 & $\begin{array}{l}\text { Panasonic - } \\
\text { ECG }\end{array}$ & $\begin{array}{c}\text { ERJ- } \\
\text { 8ENF240 } \\
1 \mathrm{~V}\end{array}$ & $\begin{array}{c}\text { RES 2.40K OHM } \\
\text { 1/4W 1\% } 1206 \text { SMD }\end{array}$ & $\begin{array}{c}0.126 " \mathrm{Lx} \\
0.063^{\prime \prime} \mathrm{W} \\
(3.20 \mathrm{~mm} \mathrm{x} \\
1.60 \mathrm{~mm})\end{array}$ & $\begin{array}{l}\text { P2.40KFCT } \\
\text { ND }\end{array}$ \\
\hline 1 & $\$ 1.40$ & $\$ 1.40$ & $\underset{j}{R 21 \_A D}$ & $\begin{array}{c}\mathrm{TT} \\
\text { Electronics } \\
\text { /BI }\end{array}$ & $\begin{array}{c}\text { PS45M- } \\
\text { OMC2BR } \\
10 \mathrm{~K}\end{array}$ & $\begin{array}{c}\text { POT 10K OHM SLIDE } \\
45 \mathrm{MM}\end{array}$ & $\begin{array}{c}\text { Rectangular - } \\
2.362 " \mathrm{Lx} \\
0.354^{\mathrm{N}} \mathrm{W} x \\
0.276 " \mathrm{H} \\
(60.00 \mathrm{~mm} \mathrm{x} \\
9.00 \mathrm{~mm} \mathrm{x} \\
7.00 \mathrm{~mm}) \\
\end{array}$ & $\begin{array}{c}\text { 987-1406- } \\
\text { ND }\end{array}$ \\
\hline 1 & $\$ 0.06$ & $\$ 0.06$ & R22 & $\begin{array}{l}\text { Stackpole } \\
\text { Electronics } \\
\text { Inc. }\end{array}$ & $\begin{array}{c}\text { RMCF12 } \\
\text { 06FT105 } \\
\text { K }\end{array}$ & $\begin{array}{c}\text { RES TF } 105 \mathrm{~K} \text { OHM } \\
1 \% 0.25 \mathrm{~W} 1206\end{array}$ & $\begin{array}{c}0.126 " \mathrm{Lx} \\
0.063^{\prime \prime} \mathrm{W} \\
(3.20 \mathrm{~mm} \mathrm{x} \\
1.60 \mathrm{~mm}) \\
\end{array}$ & $\begin{array}{c}\text { RMCF1206 } \\
\text { FT105KCT- } \\
\text { ND }\end{array}$ \\
\hline 1 & $\$ 0.06$ & $\$ 0.06$ & R23 & $\begin{array}{l}\text { Stackpole } \\
\text { Electronics } \\
\text { Inc. }\end{array}$ & $\begin{array}{c}\text { RMCF12 } \\
\text { 06FT1M0 } \\
0\end{array}$ & $\begin{array}{c}\text { RES } 1 \mathrm{M} \text { OHM } 1 / 4 \mathrm{~W} \\
1 \% 1206 \mathrm{SMD}\end{array}$ & $\begin{array}{c}0.126 " \mathrm{Lx} \\
0.063^{\prime \prime} \mathrm{W} \\
(3.20 \mathrm{~mm} \mathrm{x} \\
1.60 \mathrm{~mm})\end{array}$ & $\begin{array}{c}\text { RMCF1206 } \\
\text { FT1M00CT } \\
\text { ND }\end{array}$ \\
\hline 1 & $\$ 0.06$ & $\$ 0.06$ & R24 & $\begin{array}{l}\text { Stackpole } \\
\text { Electronics } \\
\text { Inc. }\end{array}$ & $\begin{array}{c}\text { RMCF12 } \\
\text { 06FT280 } \\
\text { K }\end{array}$ & $\begin{array}{c}\text { RES TF } 280 \mathrm{~K} \text { OHM } \\
1 \% 0.25 \mathrm{~W} 1206\end{array}$ & $\begin{array}{c}0.126 " \mathrm{Lx} \\
0.063^{\prime \prime} \mathrm{W} \\
(3.20 \mathrm{~mm} \mathrm{x} \\
1.60 \mathrm{~mm})\end{array}$ & $\begin{array}{c}\text { RMCF1206 } \\
\text { FT280KCT- } \\
\text { ND }\end{array}$ \\
\hline 1 & $\$ 0.06$ & $\$ 0.06$ & R30 & $\begin{array}{l}\text { Stackpole } \\
\text { Electronics } \\
\text { Inc. }\end{array}$ & $\begin{array}{c}\text { RMCF12 } \\
06 \mathrm{FT} 127 \\
\mathrm{~K}\end{array}$ & $\begin{array}{c}\text { RES TF } 127 \mathrm{~K} \mathrm{OHM} \\
1 \% 0.25 \mathrm{~W} 1206\end{array}$ & $\begin{array}{c}0.126 " \mathrm{Lx} \\
0.063^{\prime \prime} \mathrm{W} \\
(3.20 \mathrm{~mm} \mathrm{x} \\
1.60 \mathrm{~mm}) \\
\end{array}$ & $\begin{array}{c}\text { RMCF1206 } \\
\text { FT127KCT- } \\
\text { ND }\end{array}$ \\
\hline 1 & $\$ 0.06$ & $\$ 0.06$ & R40 & $\begin{array}{c}\text { Stackpole } \\
\text { Electronics } \\
\text { Inc. }\end{array}$ & $\begin{array}{c}\text { RMCF12 } \\
\text { 06FT392 } \\
\text { K }\end{array}$ & $\begin{array}{c}\text { RES 392K OHM } \\
1 / 4 \mathrm{~W} 1 \% 1206 \mathrm{SMD}\end{array}$ & $\begin{array}{c}0.126 " \mathrm{Lx} \\
0.063^{\prime \prime} \mathrm{W} \\
(3.20 \mathrm{~mm} \mathrm{x} \\
1.60 \mathrm{~mm})\end{array}$ & $\begin{array}{c}\text { RMCF1206 } \\
\text { FT392KCT- } \\
\text { ND }\end{array}$ \\
\hline 1 & $\$ 0.06$ & $\$ 0.06$ & R41 & $\begin{array}{l}\text { Stackpole } \\
\text { Electronics } \\
\text { Inc. }\end{array}$ & $\begin{array}{c}\text { RMCF12 } \\
\text { 06FT127 } \\
\text { K }\end{array}$ & $\begin{array}{c}\text { RES TF } 127 \mathrm{~K} \mathrm{OHM} \\
1 \% 0.25 \mathrm{~W} 1206\end{array}$ & $\begin{array}{c}0.126 " \mathrm{Lx} \\
0.063^{\prime \prime} \mathrm{W} \\
(3.20 \mathrm{~mm} \mathrm{x} \\
1.60 \mathrm{~mm})\end{array}$ & $\begin{array}{c}\text { RMCF1206 } \\
\text { FT127KCT- } \\
\text { ND }\end{array}$ \\
\hline 1 & $\$ 0.04$ & $\$ 0.04$ & R110 & $\begin{array}{c}\text { Stackpole } \\
\text { Electronics } \\
\text { Inc. }\end{array}$ & $\begin{array}{c}\text { RMCF08 } \\
\text { 05FT20K } \\
0\end{array}$ & $\begin{array}{c}\text { RES } 20 \mathrm{~K} \text { OHM } 1 / 8 \mathrm{~W} \\
1 \% 0805 \mathrm{SMD}\end{array}$ & $\begin{array}{c}0.079 " \mathrm{Lx} \\
0.049 " \mathrm{~W} \\
(2.00 \mathrm{~mm} \mathrm{x} \\
1.25 \mathrm{~mm})\end{array}$ & $\begin{array}{c}\text { RMCF0805 } \\
\text { FT2OKOCT- } \\
\text { ND }\end{array}$ \\
\hline 1 & $\$ 0.04$ & $\$ 0.04$ & R111 & $\begin{array}{c}\text { Stackpole } \\
\text { Electronics } \\
\text { Inc. }\end{array}$ & $\begin{array}{c}\text { RMCF08 } \\
\text { 05FT200 } \\
\text { K }\end{array}$ & $\begin{array}{c}\text { RES 200K OHM } \\
1 / 8 \mathrm{~W} 1 \% 0805 \text { SMD }\end{array}$ & $\begin{array}{c}0.079 " \mathrm{Lx} \\
0.049 " \mathrm{~W} \\
(2.00 \mathrm{~mm} \mathrm{x} \\
1.25 \mathrm{~mm})\end{array}$ & $\begin{array}{c}\text { RMCF0805 } \\
\text { FT200KCT- } \\
\text { ND }\end{array}$ \\
\hline 1 & $\$ 0.04$ & $\$ 0.04$ & R112 & Stackpole & RMCF08 & RES $200 \mathrm{~K}$ OHM & $0.079 " L x$ & RMCF0805 \\
\hline
\end{tabular}




\begin{tabular}{|c|c|c|c|c|c|c|c|c|}
\hline & & & & $\begin{array}{l}\text { Electronics } \\
\text { Inc. }\end{array}$ & $\begin{array}{c}05 \mathrm{FT} 200 \\
\mathrm{~K}\end{array}$ & 1/8W 1\% 0805 SMD & $\begin{array}{l}0.049 " \mathrm{~W} \\
(2.00 \mathrm{~mm} \times \\
1.25 \mathrm{~mm})\end{array}$ & $\begin{array}{c}\text { FT200KCT- } \\
\text { ND }\end{array}$ \\
\hline 1 & $\$ 4.29$ & $\$ 4.29$ & U1 & $\begin{array}{c}\text { Linear } \\
\text { Technology }\end{array}$ & LT3756-2 & $\begin{array}{l}\text { 100Vin, 100Vout } \\
\text { LED Controller }\end{array}$ & $\begin{array}{c}4.039 \mathrm{~mm} x \\
4.90 \mathrm{~mm}\end{array}$ & $\begin{array}{c}\text { LT3756EMS } \\
\text { E-2\#PBF }\end{array}$ \\
\hline 1 & $\$ 2.16$ & $\$ 2.16$ & U2 & $\begin{array}{l}\text { Linear } \\
\text { Technology }\end{array}$ & $\begin{array}{l}\text { LTC6992- } \\
\quad 1\end{array}$ & $\begin{array}{c}\text { PWM with } 0 \% \text { to } \\
\text { 100\% Pulse Width } \\
\text { Control }\end{array}$ & $\begin{array}{l}2.90 \mathrm{~mm} x \\
2.80 \mathrm{~mm}\end{array}$ & $\begin{array}{c}\text { LTC6992CS } \\
\text { 6- } \\
\text { 1\#TRMPBF }\end{array}$ \\
\hline 1 & $\$ 2.21$ & $\$ 2.21$ & U3 & $\begin{array}{c}\text { Linear } \\
\text { Technology }\end{array}$ & LT3014 & $\begin{array}{c}\text { 80Vin, } 20 \mathrm{~mA}, \text { LDO in } \\
\text { ThinSOT }\end{array}$ & $\begin{array}{c}2.90 \mathrm{~mm} x \\
2.80 \mathrm{~mm}\end{array}$ & $\begin{array}{c}\text { LT3014ES5 } \\
\text { \#PBF }\end{array}$ \\
\hline 1 & $\$ 2.21$ & $\$ 2.21$ & U4 & $\begin{array}{c}\text { Linear } \\
\text { Technology }\end{array}$ & LT3014 & $\begin{array}{c}\text { 80Vin, } 20 \mathrm{~mA}, \text { LDO in } \\
\text { ThinSOT }\end{array}$ & $\begin{array}{c}2.90 \mathrm{~mm} \mathrm{x} \\
2.80 \mathrm{~mm}\end{array}$ & $\begin{array}{c}\text { LT3014ES5 } \\
\text { \#PBF }\end{array}$ \\
\hline 1 & $\$ 1.88$ & $\$ 1.88$ & МСРCB & $\begin{array}{c}\text { Cutter } \\
\text { Electronics }\end{array}$ & $\begin{array}{l}\text { МCPCB - } \\
425\end{array}$ & $\begin{array}{c}25 \mathrm{~mm} \text { quad optic } \\
\text { designed for the } \\
\text { Cree XPE/XPC/XPG }\end{array}$ & $\begin{array}{c}25 \mathrm{~mm} \\
\text { diameter }\end{array}$ & $\begin{array}{l}\text { МСРCB - } \\
425\end{array}$ \\
\hline 1 & $\$ 9.97$ & $\$ 9.97$ & Housing & EcoSmart & $\begin{array}{l}\text { ECS } 19 \\
\text { WW } 120\end{array}$ & $\begin{array}{l}\text { EcoSmart A19 LED } \\
\text { Light Bulb }\end{array}$ & & $\begin{array}{c}\text { Home } \\
\text { Depot SKU\# } \\
864680\end{array}$ \\
\hline 10 & $\$ 0.44$ & $\$ 4.40$ & TP & $\begin{array}{c}\text { Keystone } \\
\text { Electronics }\end{array}$ & 5015 & $\begin{array}{l}\text { PC TEST POINT } \\
\text { MINIATURE SMT }\end{array}$ & $\begin{array}{c}0.010 " \\
(0.25 \mathrm{~mm})\end{array}$ & $\begin{array}{c}5015 \mathrm{KCT}- \\
\text { ND }\end{array}$ \\
\hline 1 & $\begin{array}{c}\$ 19.4 \\
0\end{array}$ & $\$ 19.40$ & Layout & ExpressPCB & & 4 layer mini-board & & \\
\hline 70 & & $\$ 99.68$ & & & & & & \\
\hline
\end{tabular}


